\title{
The Architecture of Hysteria: Speculative and Analytic Representations Through the Anamorphic Lens,
}

by

Ryan A. McLennan, B.A.S.

A thesis submitted to

The Faculty of Graduate Studies

in partial fulfillment of

the requirements for the degree of

\section{Master of Architecture}

\author{
Carleton University \\ Ottawa, Ontario
}

September 14, 2005

(C) copyright

2005, Ryan A. McLennan 


\section{Acknowledgements}

Thank you to Professor Michael Jemtrud, my advisor, for introducing me to the writings of Slavoj Zizek and for teaching me the speculative value of looking awry

I must also thank my family for their encouragement and love. 


\section{Abstract}

This thesis investigates the use of theory as an innovative process in the making of architecture as a form of artistry that attempts to resolve an issue through the crafting of a lens. One accomplishes this by 'looking awry' at a topic, whereby the weaving of theoretical and architectural threads allows for the discernment of what would normally escape a straightforward academic view.

The first topos of investigation uses this method to discern a divergent conception of public space in the city by speculating upon inter-subjectivity and its relation to the creation and experience of space. The second topos of investigation presents the design component as a multi-use building in the ByWard Market that is manifested through the anamorphic lens of theory, thereby forming new meanings in the architecture itself in that it is inherently 'stained' by an absence. 


\section{Table of Contents}

\section{Part I. Theoretical Topos}

1 The Contradictory Landscape of the Ideal

The Slippage of Public Space

Living With Lefebvre:

The Contradictions of Abstract Space

A Public Through Difference, Not Fear

\section{Process}

The Market as a Layering of Contradiction:

Spatial and Inter-subjective Relations in the City

2 The Interruption of the Other

Fantasy and the Other

Abjection: Experiencing of the Formless

Abjection: 'Suffering' the City

The Excessive Otherness of Hysteria

\section{Process}

A Process of 40 Interruptions: The Hunger Artist

3 The Architecture of Hysteria

A Marked Spectacle in the Symbolic

A Violated Theatre of the Body 
'Why Am I What You are Saying That I Am?' 75

The Return of the Real 78

The Demark:

Enjoy What Cannot Be Integrated Into Symbolic Reality 80

The Demarked Face of Architecture $\quad 88$

The Face of Public Space, and the Demarked Spaces of the City 92

\section{Process}

The Experience of Publicness:

Creating Place in the City Through Interruption 54

Scene 1: Impresario 68

Scene 2: Framing $\quad 77$

Scene 3: Discourse $\quad 81$

Scene 4: Flesh $\quad 88$

Part II. Bridge: Architecture and Looking Awry

$\begin{array}{lll}4 & \text { The Anamorphic Lens of Theory } & 100\end{array}$

Part III. Architectural Topos

5 Addressing the Gut: A Mixed-Use Building in the Market

Site: The ByWard Market, Ottawa 104

Design: Demarked Architecture 113

Referencing the Theoretical Process Through Architecture 130

Representations of the Artifact 133

Conclusion

153

Bibliography

Appendices 


\section{List of Illustrations}

(All images copyright of the author unless otherwise noted)

\section{Chapter 1}

Figure 1 Experiencing the Ideal Landscape, 'Impresario' storyboard drawing. Ink, graphite and conté on Stonehenge paper.

Figure 2 "Ideal," Merriam-Websters Collegiate Dictionary (11th Ed. 2003).

Figure 3 Site 1 - 'Impresario', Digital Collage and Ink Drawings on Mylar.

Figure 4 Site 2 - 'Frame', Digital Collage and Ink Drawing on Mylar.

Figure 5 Richard Serra, Tilted Arc, Federal Plaza New York City from georgetown.edu (2005. <http://www.georgetown.edu/faculty/ irvinem>).

Figure 6 Site 3 - 'Impresario', Digital Collage and Ink Drawing on Mylar.

Figure $7 \quad$ Site 4 - 'Frame', Digital Collage and Ink Drawing on Mylar.

Figure 8 Site 5 - 'Flesh', Digital Collage and Ink Drawing on Mylar.

Figure 9 Site 6 - 'Impresario', Digital Collage and Ink Drawing on Mylar.

Figure 10 The Temple of Vesta in the Roman Forum, Marble Relief from Joseph Rykwert, The Idea of the Town (Cambridge, MA: MIT P, 1988) 109.

Figure 11 Site 7 - 'Impresario', Digital Collage and Ink Drawing on Mylar. 
Figure 12 Site 8 - 'Discourse', Digital Collage and Ink Drawing on Mylar.

Figure 13 Site 9 - 'Impresario', Digital Collage and Ink Drawing on Mylar.

Figure 14 Site 10 - 'Impresario', Digital Collage and Ink Drawing on Mylar.

Figure 15 Site 11 - 'Frame', Digital Collage and Ink Drawing on Mylar.

Figure 16 Le Corbusier, Contemporary City for 3 Million Inhabitants from hanser.ceat.okstate.edu (2005. <http://hanser.ceat.okstate.edu/ 6083/Corbusier/Urban\%20planning.htm>)

Figure 17 Definition of the 'Balzakian Mentality'.

Figure 18 Site 12 - 'Frame', Digital Collage and Ink Drawing on Mylar.

Figure 19 'Balzakian Mentality' from Honoré de Balzak, Eugénie Grandet, Trans. M.A. Crawford. (London: Penguin, 1969).

Figure 20 Site 13 - 'Impresario', Digital Collage and Ink Drawing on Mylar.

Figure 21 Site 14 - 'Flesh', Digital Collage / Ink Drawing on Mylar.

Figure 22 Site 15 - 'Discourse', Digital Collage and Ink Drawing on Mylar.

Figure 23 Site 16 - 'Frame', Digital Collage and Ink Drawing on Mylar.

Figure 24 Site 17 - 'Impresario', Digital Collage and Ink Drawing on Mylar.

Figure 25 Pablo Picasso, Les Demoiselles d'Avignon, 1907, from acsu.buffalo.edu (2005, <http://www.acsu.buffalo.edu/ jconte/ Pablo_Picasso.html $>$ )

Figure 26 Site 18 - 'Discourse', Digital Collage and Ink Drawing on Mylar.

Figure 27 Site 19 - 'Flesh', Digital Collage and Ink Drawing on Mylar.

Figure 28 Site 20 - 'Frame', Digital Collage and Ink Drawing on Mylar.

Figure 29 "The Eyes of the Poor," from Marshall Berman, All That Is Solid Melts Into Air (New York: Simon and Shuster, 1982) 148-9.

Figure $30 \quad$ Site 21 - 'Flesh', Digital Collage and Ink Drawing on Mylar. 
Figure 31 Site 22 - 'Frame', Digital Collage and Ink Drawing on Mylar.

\section{Chapter 2}

Figure 32 Experiencing the Frame: 'Framing' Storyboard Drawing. Ink, 32 graphite and conté on Stonehenge paper.

Figure 33 Site 23 - 'Flesh', Digital Collage and Ink Drawing on Mylar.

Figure 34 Site 24 - 'Frame', Digital Collage and Ink Drawing on Mylar.

Figure 35 Site 25 - 'Discourse', Digital Collage and Ink Drawing on Mylar.

Figure 36 Definition of the Lacanian Orders summarized from Tony

Myers, Slavoj Zizek (New York: Routledge, 2003) 21-29.

Figure 37 Site 26 - 'Impresario', Digital Collage and Ink Drawing on Mylar.

Figure 38 Site 27 - 'Discourse', Digital Collage and Ink Drawing on Mylar.

Figure 39 Site 28 - 'Impresario', Digital Collage and Ink Drawing on Mylar.

Figure 40 Definition of the Superego.

Figure $41 \quad$ Abjection in art. Mike Kelley, Riddle of the Sphinx, 1971 from

Rosalind Krauss, The Formless (New York: Zone Books, 1997) 249.

Figure 42 Site 29 - 'Frame', Digital Collage and Ink Drawing on Mylar.

Figure 43 Site 30 - 'Flesh', Digital Collage and Ink Drawing on Mylar.

Figure 44 Site 31 - 'Discourse', Digital Collage and Ink Drawing on Mylar.

Figure 45 Site 32 - 'Flesh', Digital Collage and Ink Drawing on Mylar.

Figure 46 Site 33 - 'Impresario', Digital Collage and Ink Drawing on Mylar.

Figure 47 Site 34 - 'Frame', Digital Collage and Ink Drawing on Mylar.

Figure 48 Site 35 - 'Impresario', Digital Collage and Ink Drawing on Mylar.

Figure 49 Site 36 - 'Flesh' Digital Collage and Ink Drawing on Mylar. 
Figure $50 \quad$ Site 37 - 'Flesh', Digital Collage and Ink Drawing on Mylar.

Figure 51 Site 38 - 'Impresario', Digital Collage and Ink Drawing on Mylar. 48

Figure 52 Site 39 - 'Flesh', Digital Collage and Ink Drawing on Mylar.

Figure 53 Site 40 - 'Impresario', Digital Collage and Ink Drawing on Mylar.

\section{Chapter 3}

Figure 54 Inhabiting the Frame: 'Discourse' Storyboard Drawing. Ink, graphite and conté on Stonehenge paper.

Figure 55 Impresario - Script Collage, Video Still.

Figure $56 \quad$ Impresario - Model, Video Still.

Figure 57 Bernard Tschumi, Folie L8 (No Program) from Event-Cities 2

(Cambridge, MA: MIT P, 2000) 198-9.

Figure 58 Impresario - Model, Video Still.

Figure 59 Bernard Tschumi, Folie R4, "Folies are like a mirror: you project your own fantasy on them," from Event-Cities 2, 131.

Figure 60 Bernard Tschumi, Folie N8 (No Program), from Event-Cities 2, 197.

Figure 61 Impresario - Model, Video Still.

Figure 62 Régnard, photograph of Augustine, "Attitudes passionneles:

Mockery" from Georges Didi-Huberman, Invention of Hysteria (Cambridge, MA: MIT P, 2003) 168.

Figure 63 Impresario - Model, Video Still.

Figure 64 Impresario - Digital Model, Video Still.

Figure 65 Impresario - Digital Model, Video Still.

Figure 66 Impresario - Digital Model, Video Still.

Figure 67 Impresario - Digital Módel, Video Still. 
Figure 68 Framing - Script Collage, Video Still.

Figure 69 Quote from Antonin Artaud, The Theatre and Its Double (New 64 York: Grove P, 1958) 89-96.

Figure $70 \quad$ Framing - Model, Video Still.

Figure 71 Definition of the Uncanny.

Figure $72 \quad$ Framing - Model, Video Still.

Figure 73 Régnard, photograph of Augustine, "Onset of an Attack: the 66 Cry" from Georges Didi-Huberman, Invention of Hysteria (Cambridge, MA: MIT P, 2003) 260.

Figure $74 \quad$ Framing - Model, Video Still. 66

Figure $75 \quad$ Framing - Model, Video Still.

Figure 76 Framing - Digital Model, Video Still. 68

Figure 77 Framing - Digital Model, Video Still.

Figure 78 Framing - Digital Model, Video Still. 70

Figure 79 Framing - Digital Model, Video Still.

Figure 80 Coop Himmelblau, UFA Cinema Center, view from the SouthWest at night from Frank Werner, Covering + Exposing (Boston: Birkhäuser, 2000) 125.

Figure 81 Discourse - Script Collage, Video Still.

Figure 82 Coop Himmelblau,Vienna, Austria. Hot Flat, city apartment 73 building, 1978, isometric drawing, typical floor plan, full and partial section, partial view, elevation drawing from Werner, 11.

Figure 83 Discourse - Model, Video Still.

Figure 84 Coop Himmelblau, Graz, Austria, Blazing Wing, 1980 from 74 Werner, 78.

Figure 85 Discourse - Model, Video Still. 
Figure 86 Definition of The Lacanian Discourses summarized from Slavoj

Figure 87 Discourse - Model, Video Still.

Figure 88 Discourse - Model, Video Still.

Figure 89 Discourse - Model, Video Still.

Figure 90 Discourse - Model, Video Still. 78

Figure $91 \quad$ Discourse - Model, Video Still. 79

Figure 92 Discourse - Model, Video Still. 80

Figure 93 Flesh - Script Collage, Video Still.

Figure 94 Idyllic Dutch Landscape from Foreign Correspondent, Dir. Alfred 82 Hitchcock (1940, DVD, Warner Brothers, 2004)

Figure $95 \quad$ Flesh - Model, Video Still.

Figure 96 Max Ernst, La Femme 100 têtes (Paris: 1929), Chapter 3, plate 2. 83 'Open our bag my good man,' from David Lomas, The Haunted Self (New Haven and London: Yale UP, 2000) 90.

Figure $97 \quad$ Flesh - Model, Video Still.

Figure 98 Hans Holbein, The Ambassadors, 1533, from artarchive.com 84 (2005, <http://www.artchive.com/artchive/h/holbein/ ambassadors.jpg.html $>$ )

Figure $99 \quad$ Flesh - Model, Video Still.

Figure $100 \quad$ Flesh - Model, Video Still.

Figure 101 Flesh - Model, Video Still.

Figure 102 'Object small a' Diagram from Slavoj Zizek, Looking Awry (Cambridge, MA: MIT P, 1992) 94.

Figure 103 Definition of the 'Object small a'.

Figure 104 Flesh - Digital Model, Video Still. 
Figure 105 The 'anamorphic flip' of the point of view, from Donald Kunze, art3idea.psu.edu $<2005$, http://art3idea.psu.edu/boundaries/ index.html>.

Figure 106 Flesh - Digital Model, Video Still.

Figure 107 John Hejduk, Berlin Masque, drawing detail, 1983 from

Mask of Medusa (New York: Rizzoli, 1985) 195.

Figure 108 John Hejduk, Berlin Masque, Model, 1983 from Mask of Medusa 89 384.

Figure 109 Flesh - Digital Model, Video Still.

Figure 110 John Hejduk, The House of Suicide, Lancaster/Hanover 90 Masque, drawings from Mask of Medusa, 440-4.

Figure 111 Impresario Digital Model.

Figure 112 John Hejduk, The House of Suicide, Lancaster/Hanover Masque, text from Mask of Medusa, 436-7.

Figure 113 Framing Digital Model.

Figure 114 John Hejduk, The House of Suicide, Lancaster/Hanover Masque, drawings from Mask of Medusa, 444-9.

Figure 115 Discourse Digital Model.

Figure 116 Flesh Digital Model.

Figure 117 Projector Booth.

\section{Chapter 5}

Figure 118 Location Map of the ByWard Market in Downtown Ottawa.

Figure 119 Map Showing the Immediate Context of the ByWard Market Precinct.

Figure 120 Area Map of Market Showing Existing Built Context. 
Figure 121 Area Map of Surrounding Context Showing Major Pedestrian

Routes Through the Market Area.

Figure 122 Area Plan of Surrounding Block Showing Existing Programs.

Figure 123 Site Plan Showing Photographic Documentation of Overlapping 108 Spaces and Programs.

Figure 124 Daytime Photo Montage of Existing Clarence Street Elevation.

Figure 125 Daytime and Nighttime Photo Montages of Existing Clarence

Street Facade and Parking Lot.

Figure 126 Daytime and Nighttime Photo Montages of Existing York Street Elevation.

Figure 127 Early Design Sketches.

Figure 128 Grade Plan Development Drawings. Graphite and ink on paper and trace.

Figure 129 Cross Section Development Drawings. Graphite on paper and trace.

Figure $130 \quad$ Sketches of Tattoo Studio's Relationship to Exterior Surface.

Sectional axonometric, section detail, and elevation.

Figure 131 Axonometric Drawing of Tattoo Studios and Lightstacks.

Graphite on Stonehenge paper.

Figure 132 Views of Sketch Model. Cardboard and basswood. 1:200.

Figure 133 Grade Level Plan, Annotated.

Figure 134 Below Grade Plan, Annotated.

Figure 135 Longitudinal Section, Annotated.

Figure 136 Tattoo Flash - Joseph Hartley, Bristol, Great Britain, 1930s; and

L. Stoney, St. Clair, USA (Ohio) from Henk Shiffmacher, 1000 Tattoos (Köln, Germany: Taschen, 2005.) 129, 94.

Figure 137 Japanese-Style Tattoo by Hori-Kiyo from Schiffmacher, 420. 
Figure 138 Bert Grimm's Tattoo Studio, Long Beach, California from

Clinton R. Sanders, "Drill and Frill," Marks of Civilization (Los Angeles: Museum of Cultural History, 1988) 227.

Figure 139 Cross Section, Annotated.

Figure 140 South Elevation, Annotated.

Figure 141 North Elevation, Annotated.

Figure 142 Vignette Showing York Street Daytime and Nighttime Façades.

Figure 143 Vignette of Section at North Façade (looking South) showing the Relationship between the Tattoo Parlour, Gallery and the 'Mundane' Spaces.

Figure 144 Vignette Showing Section of Entry to the Tattoo Parlour 128 (Looking East).

Figure 145 Vignette Showing Elevation of Tattoo Studios From Exterior.

Figure 146 Vignette Showing Detail Plan of North Gallery and its Relationship to the body modification studio and tattoo parlour below.

Figure 147 Vignettes Showing Nighttime Plan Detail of Tattoo Studio and Floor Pattern Detail in Tattoo Studio and Exterior Court.

Figure 148 Vignette Showing Reflected Ceiling Plan in Tattoo Studio. 


\section{List of Plates}

(All images copyright of the author unless otherwise noted)

Plate 1 Photograph of Model from Southeast. Basswood and plaster.

Plate 2 Grade Level Plan. Graphite on Strathmore, 61 x 91.4cm. 1:100.

Plate 3 Detail of Grade Level Plan.

Plate $4 \quad$ Below Grade Plan. Graphite on Strathmore, 61 x 91.4cm. 1:100.

Plate 5 Detail of Below Grade Plan.

Plate $6 \quad$ Longitudinal Section. Graphite on Strathmore, 61 x 91.4cm. 1:100

Plate 7 Detail of Longitudinal Section (South Building Form).

Plate 8 Detail of Longitudinal Section (North Building Form) and 140 Photograph of Model.

Plate 9 Detail of Cross Section. Graphite on Strathmore, $61 \times 45.7 \mathrm{~cm}$.

Plate 10 South Elevation. Graphite on Strathmore, 61 x $45.7 \mathrm{~cm} .1: 100$

Plate 11 Detail of South Elevation and Photograph of Model.

Plate 12 North Elevation. Graphite on Strathmore, 61 x $45.7 \mathrm{~cm} .1: 100$

Plate 13 Detail of North Elevation and Photograph of Model.

Plate 14 Photograph of Model from North. . 
Plate 15 Photograph of Model from Southwest.

Plate 16 Photographs of South Building Form in Model.

Plate 17 Photographs of North Building Form in Model.

Plate 18 Photograph of Section Model.

Plate 19 Detail Photographs of Section Model. 


\section{List of Appendices}

\section{Appendix}

A

B

\section{Description}

40 Sites in the Market and 4 Models

159

A Brief History (on the Understandings) of Hysteria 


\section{Introduction}

The speculative use of theory in the making of architecture suggests a questioning of architecture itself and thereby the social framework in which it exists and is obliged to embody through its representations. This act of questioning within academia, the profession, or existence in general, involves the identification of self as being distinct from the law of the social structure within which we exist, and is where the subject emerges as being unique within it. By disclosing society's structure itself, as well as its gaps and inconsistencies, the subject is accounted for in psychoanalysis as the hysteric. In this theoretical context, the hysteric, as a questioning of the prevailing order, involves the human subject's existence within the contrasting orders of the symbolic (society) and the un-symbolized.

By being distinct from the framework within which we exist does not mean that we are able to act outside of it, but rather that we remain limited by it. As architects we find ourselves in a similar dilemma as we are limited by the abstractions (language and representation) through which we perceive and understand space. These allow for a certain amount of freedom in the processes of creation although they constrain in a very specific manner the way that we make and reveal our intentions. Resistance to this, as an attempt to operate outside of our modern means through a desire to re-frame a certain understanding of an issue, can be found in the hysteric's other quality: that of displacement.

In hysteria, the un-symbolized - or otherwise unknown - traumatic cause is 
unconsciously displaced into re-presented symptoms or phobias, acting as signs that point to the opaque object-cause. In architecture and theory (as philosophy), such displacement occurs by 'looking awry' at an issue, allowing one to discern that which would normally escape a straightforward academic view. As an issue of one's point-of-view, the anamorphic view that is involved in allowing one to see an issue clearly from the side diverges from the approach of instrumental notions of theory as merely applied, a method that limits invention to a specific framework that guides both practice and further understandings. ${ }^{1}$ In doing so it inhibits alternative forms of thinking.

Rather, the act of looking awry is a speculative means of approaching a topic, allowing one to produce new meanings and understandings through the slippage of the existing meanings it holds in both architecture and culture. This is not an innovative method in the use of theory, as it can be found in both the writings of Slavoj Zizek and Donald Kunze, and is also implicit in Georges Bataille's use of language's low or 'excremental' meanings. This is accomplished through a weaving of the architectural threads of thinking and making. It is a form of making architecture through the creation of a language constituted by both the processes of the written text and 'artistic' representation. In these, topical or analogical associations are used to cross categories, allowing for a certain level of incompleteness to exist within the topics themselves. This incompleteness occurs within the development of the theory itself, as well as in a lack of analysis of issues and examples directly associated to the topic, which does not signal a lack in the understanding of them, but that they are 'left to the side' in order to re-frame the topic. In this manner, the understandings achieved through the speculative process of displacement allow for the formation of a lens through which to comprehend an issue, and from which one can make an architecture that is forever stained by the previous process.

It is this very lens that evaporates the concerns that existed before its creation, while drawing them forth into the architecture itself. 
This thesis is divided into two topoi of investigation that both address the way that we make architecture through theory, while also acting as an investigation into the making and meaning of public spaces in the city. The first topos, which is the use of theory as process, enables the creation of a lens through which we understand the making of a particular architectural design. Through this lens, the second speculative topos addresses the issue of concern, realizing previous ideas and understandings within a proposed architecture as both representation and resolution. Although the first topos informs the making of architecture, it is not a generative or linear process that leads to the building itself, but is rather a means through which the making of the building becomes understood, and is therefore something much larger then a process that taints the architecture.

The first part of this thesis, making up three chapters - "The Contradictory Landscape of the Ideal," "The Interruption of the Other," and "The Architecture of Hysteria" - act as the theoretical topos in an attempt to develop a theoretical dialogue regarding public space in the city, first by developing an understanding of the modern processes of abstraction, and its effect on our understandings of the city; then by describing the nature of the inter-subjective 'political' experience that allows for an experience of public space; and finally by developing a relationship between the interruptive intersubjective experience and the experience of space, thereby the creation of architecture. This discursive undertaking manifests itself in two parts that run parallel to each other both in the book and in the theoretical process itself: one being the philosophical text; the other the architectural process as a mode of speculative representation that inhabits the marginalia in the form of both image and text. These do not occur separately, but rather inform each other in both directions, where the theoretical text informs the making, and the making informs the text. Through this process a specific lens is created, which is used as a means through which to see, think and make architecture.

The second part of this thesis, consisting of one chapter - "Addressing the Cut: 
A Mixed-Use Building in the Market - presents the architectural topos of investigation. This presents to the reader the architectural project, which is addressed through the lens, of theory, but remains distinct from the theoretical process in the generative sense. This is literally represented in a shift in the presentation of the work, where the images and descriptive text are laid out horizontally rather than vertically, indicating the difference between the theory and the architecture as two distinct, yet related, investigations of public space and its meanings. In this section architecture is resolved as a public experience of the city and is not sheltered from the real concerns that exist as a result of the city and the site. In doing so it questions the spatial conditions in which we exist, allowing for the formation of new meanings in architecture as the creation of meaningful spaces in society.

\section{Introduction Notes:}

${ }^{1}$ This follows from the Enlightenment belief that thinking is separate from and is what guides making, where one's actions are based upon a specific discovery. 


\section{1 \\ The Contradictory Landscape of the \\ Ideal}

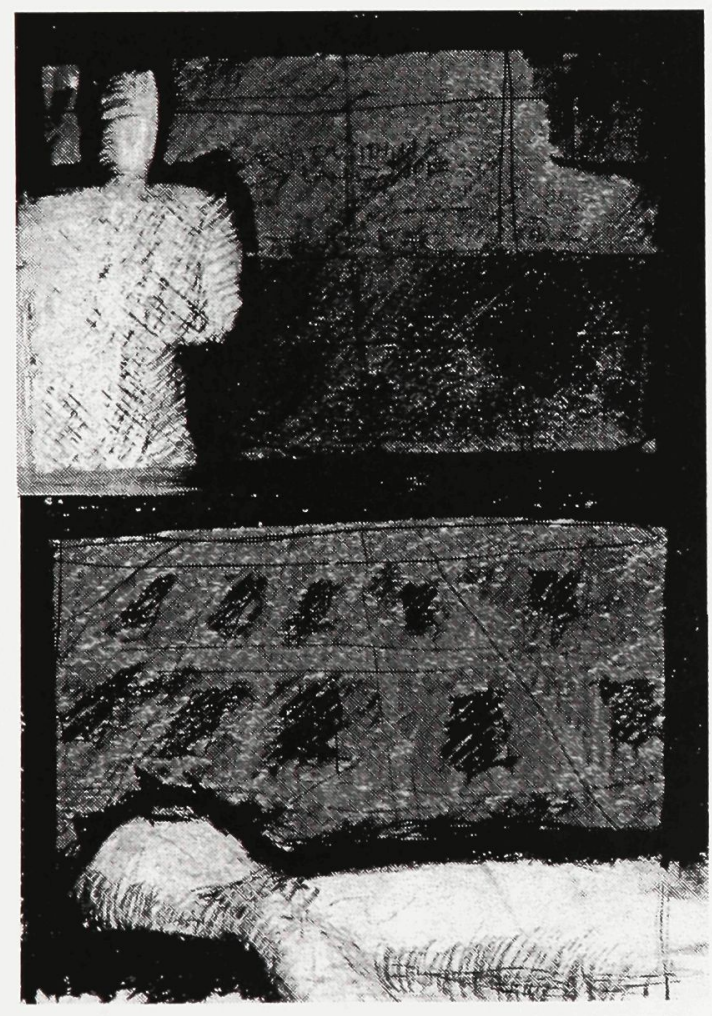

1: Experiencing the Ideal Landscape, 'Impresario' Storyboard Drawing
The Slippage of Public Space

The contradiction implicit in the abstract nature of the modern city is able to be experienced through its public spaces. Functioning politically, ${ }^{1}$ these spaces are essential to the life of the city, allowing for its social existence, while also giving spatial form to its supposedly democratic character, as they relate, and are accessible to the communities and visible groups who constitute the public, thus achieving a space of purported equality. As creators of such social spaces, architects and urbanists find themselves at a loss in attempting to provide a solid definition as to what consists of an authentic form of public space. Even still there is a general recognition of its importance as a part of the formation of the city as a social entity. It is when one attempts to define or give embodiment to this type of space or to understand and represent it through conventional architectural means that the elusiveness of the term is revealed. Thus 'public space' by its very nature is a slippery term, in that its meaning is imprecise and ambiguous. Its definition has not been fully revealed (and can 


\section{ide-al}

1: existing as an archetypal idea $2 \mathrm{a}$ : existing as a mental image or in fancy or imagination only; broadly : lacking practicality $\mathrm{b}$ : relating to or constituting mental images, ideas or conceptions $3 \mathrm{a}$ : of, relating to, or embodying an ideal $<\sim$ beauty $>$ b : conforming exactly to an ideal, law, or standard : PERFECT <an $\sim$ gas $>4$ : of or relating to philosophical idealism

2: "Ideal," Merriam-Websters Collegiate Dictionary (11th Ed. 2003).

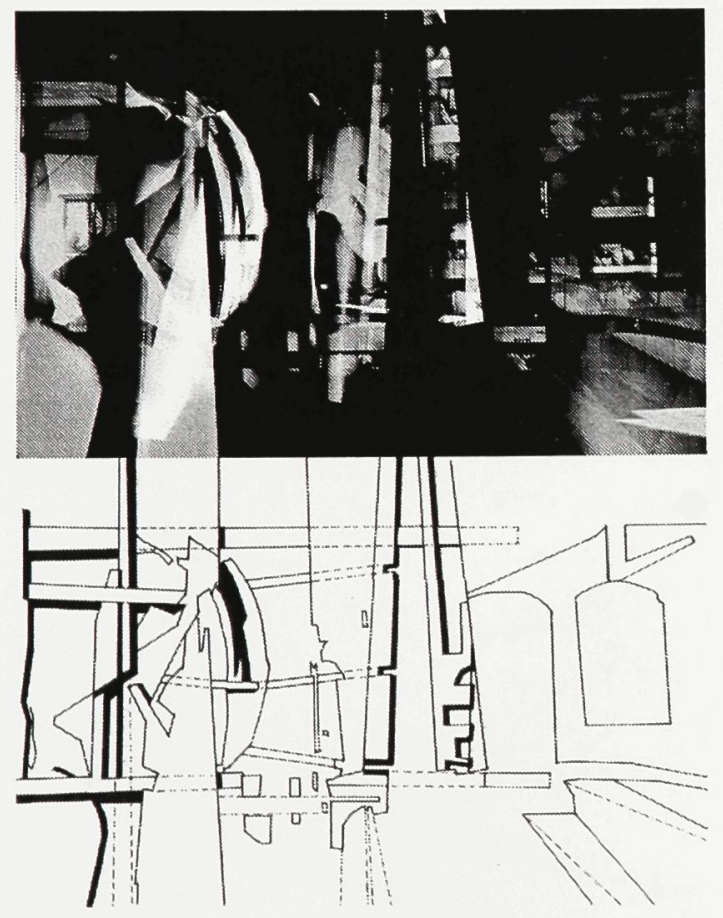

3: Site 1 - 'Impresario', Digital Collage and Ink Drawing on Mylar. never be) within the discourse of architecture, and has remained elusive due to its inherent indeterminate meaning.

Providing a definition is made easier by reverting to examples of existing typological spaces that have been accepted as given forms of public space. These include spaces based upon their participatory or democratic associations, including the street, plaza and public court. In most literature on the subject it is commonplace to refer to examples of famous public spaces that exist in European cities presumably due to the inability to find similar forms of space in most North American cities, as they have not yet achieved the same level of social and political importance. The reference to such forms of public space attempts to invoke the fundamental qualities of historically significant public spaces such as the Agora, which as a religious and political form of marketplace and gathering space within the Greek polis became a definitive form of public space through its inclusion of public discourse, but at the exclusion of the nonclass of the population (including slaves, women, and those without property). ${ }^{2}$ Without the use of such typological associations the definition 
The Market as Layering of Contradiction:

Spatial and Inter-Subjective Relations in the City

The existing space of the modern city presents to its citizens an image of an apparently homogenous whole. As a spatial creation, the city then attempts to remove any social or spatial contradictions that occur within it, created due to its abstract nature. Such abstraction through reductive spatial understandings and representations removes the possibility for these contradictions to function as a part of an understanding

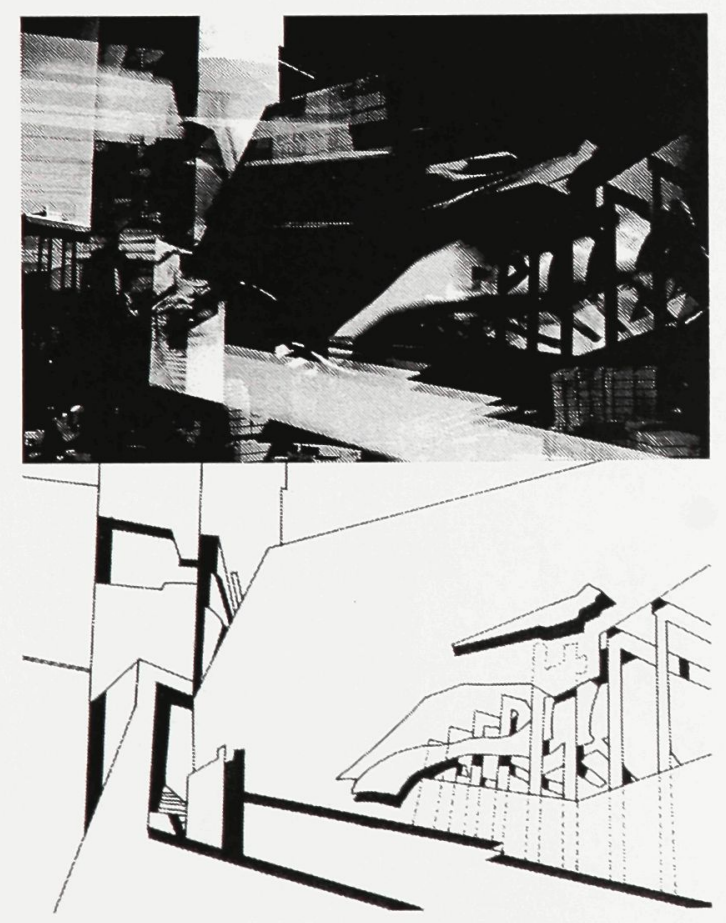

4: Site 2 - 'Frame', Digital Collage and Ink Drawing on Mylar becomes one that is formed in general terms, where the experience of public space is merely the act of leaving private space, which brings us no closer to a means through which we are able to create, and no closer to understanding its forming factors. ${ }^{3}$

Even though the tendency may be to turn to such generalized examples or to ones that exist outside North America, there are examples that exist within North America that clearly embody qualities of successful, or authentic public spaces by existing within, and thus embracing the contradictory nature of the abstract modern city. ${ }^{4}$ These include spaces that have developed over time, and have thus become a representative and defining aspect of the society who inhabits them, such as Montreal's streetscape, whose architectural language and culture has created various forms of accepted and fluid social interactions between 'private', 'semi-public' and 'public spaces' in the city. Ottawa's ByWard Market has a similar nature to it as well, where the layering of programs and social groups creates a diverse and contradictory space in the unusually mundane and apparently homogenous urban whole. The 


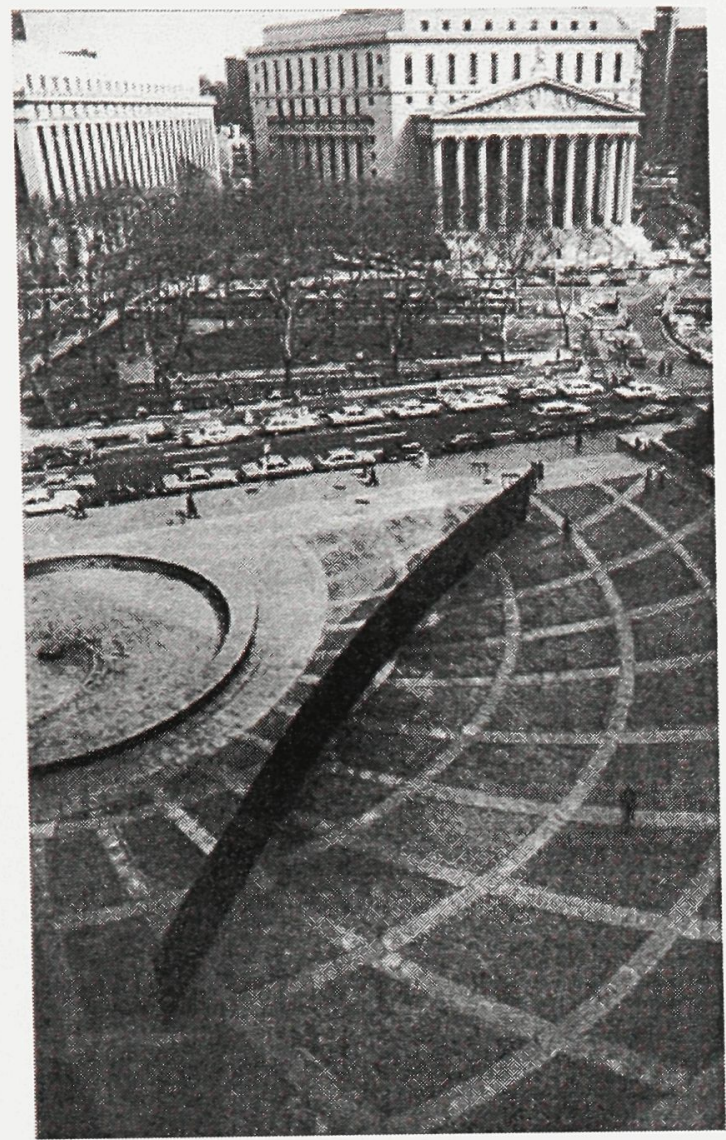

5: Richard Serra, Tilted Arc, Federal Plaza New York City from georgetown.edu (2005. $<$ http://www.georgetown.edu/faculty/irvinem $>$ )
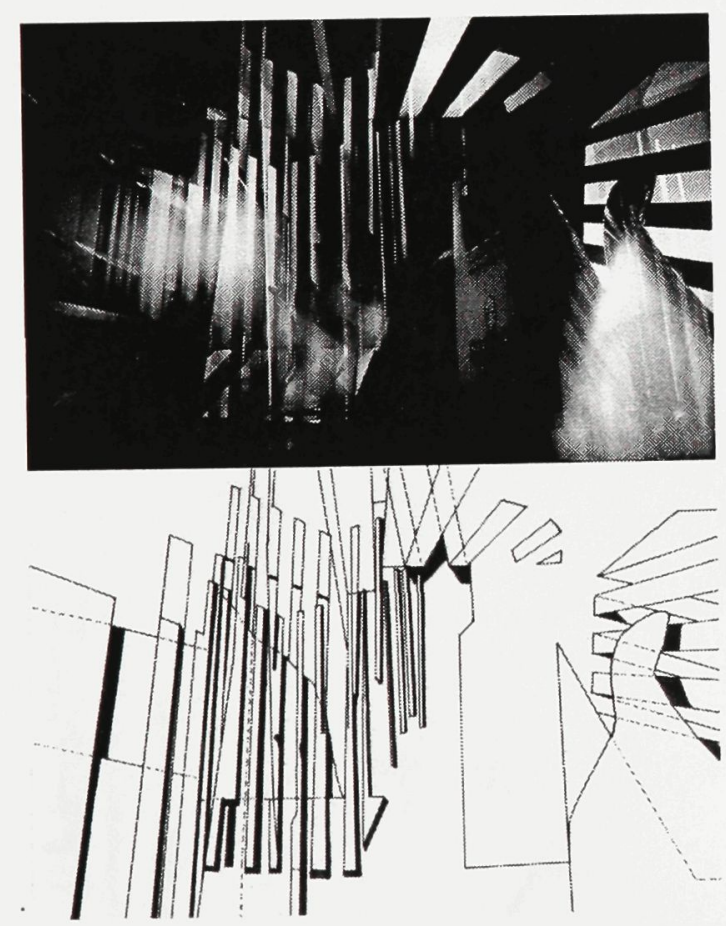

6: Site 3 - 'Impresario', Digital Collage and Ink Drawing on Mylar nature of public space has also been invoked through design, where authentic public space was created through the experience of space as a conflictual event that may only exist for one short moment in time, thus drawing attention to the contradictory and fragile nature of space in the city. One such example is the Richard Serra's Tilted Arc (Fig. 5), a piece of public art in the Federal Plaza in New York City, which created such public controversy regarding the nature of public space and public art through its formal imposition and transformation of space that it was decidedly removed and stored.

In all of these examples the value and (albeit contingent) social function of public space as an inter-subjective space of participation and reconciliation is realized and revealed to those who inhabit them.

There is therefore ability in our means to retrospectively analyze and recognize specific forms of successful or authentic public spaces, but there remains an inability to transform these observations into similar forms of social spaces. What may inhibit this is the perception that the cultural and social aspects that make up the inter-subjectivity of these spaces and 
of the city, although they remain within the fractures of the homogenous whole.

In spaces such as the ByWard Market in Ottawa, these intrinsic contradictions have the ability to rise to the surface more readily due to both programmatic and spatial layering, where they exist as anomalies in the apparently homogenous whole. The citizen or visitors experience of such forms of space occurs as one that is heterogeneous, allowing for the contradictions to become more evident. This can be seen in the

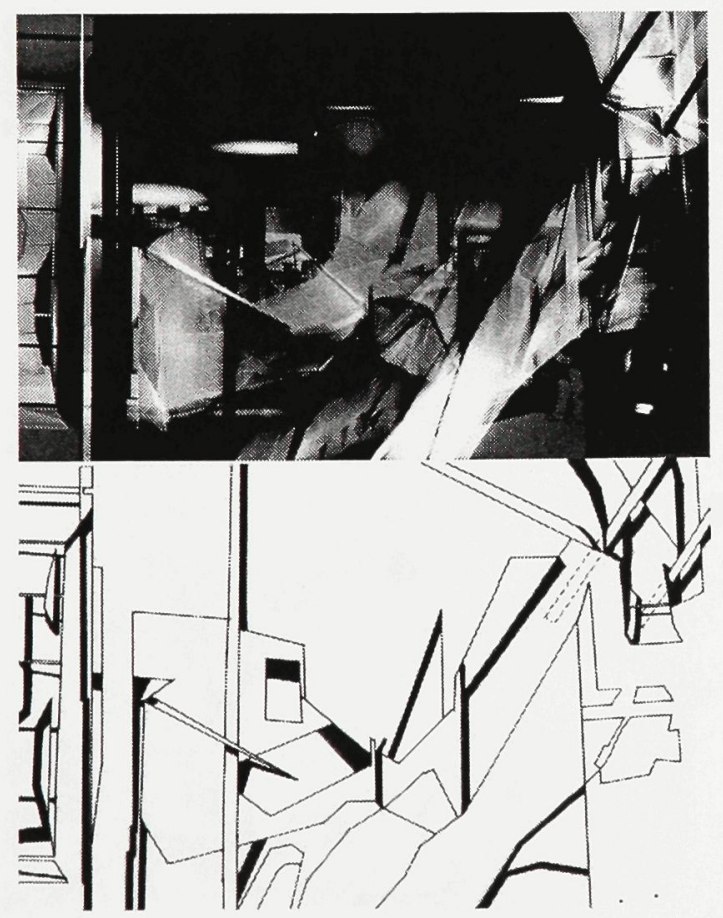

7: Site 4 - 'Frame', Digital Collage and Ink Drawing on Mylar the participation within them as a temporal and spatially mediated event appears as being unpredictable within the realm of architectural design. ${ }^{6}$ The success of these spaces is also not able to be predetermined merely as being caused by the design of the space itself, but it is the historical, social, political, artistic, religious, ritualistic and other meanings that become associated with it over time that give it importance as a social foundation within the urban environment. There is therefore an inability of our modern means to embody, re-present, and transform our lived reality into new forms of public space, reflecting the limitations caused by the social-political-spatial reality of modern abstraction. Instead, it is accepted within the spatial practice developed by the tradition of modern architecture, to accommodate for the development and control of spaces that suit the private financial interests of a client (rather than society at a whole), allowing for consumption of or within space, for transitory space, or for the experience of spectacle within rather predictable and neutral spaces that are "sterile and stupefying, air-conditioned nightmares that desensitize 
close proximity of various types of programs, as well as through the difference between those who use the programmed space, or in those who inhabit the spaces in-between. In the same block, the diverse nature of the programs includes high-end restaurants and shops as well as pubs, bars, gentlemen's clubs and adult 'toy' shops. Between these spaces their users circulate along with the non-class of society, as well as others who come to enjoy the diversity and difference that makes up the Market's heterogeneous

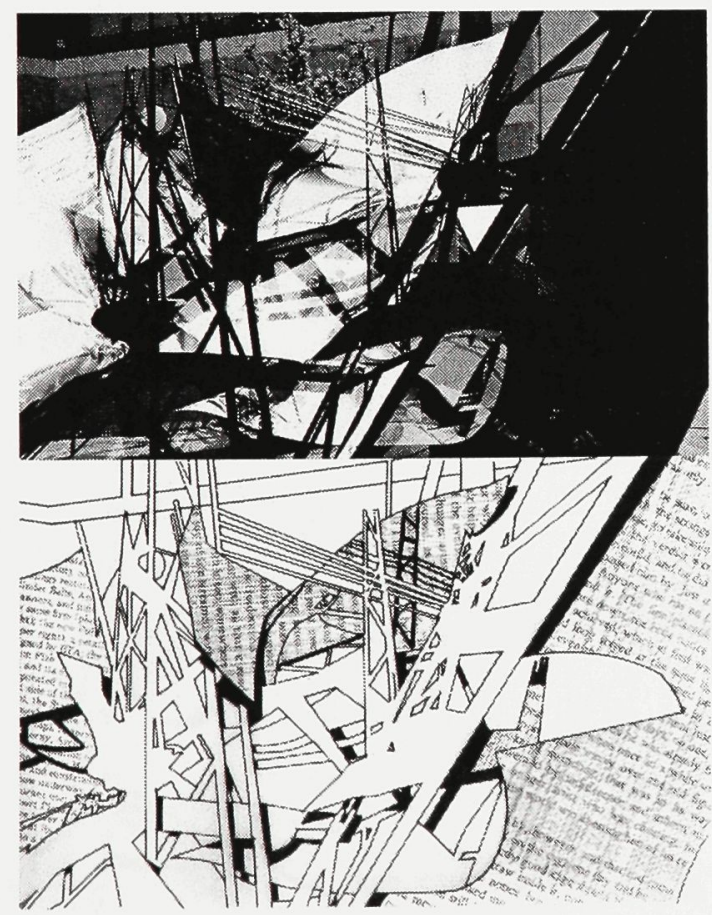

8: Site 5 - 'Flesh', Digital Collage and Ink Drawing on Mylar experience rather than intensify it."

The fact that architects must turn to such things when designing public space points to an inability to give meaning to what public space actually is, or to be able to associate a specific function or program to it. This is due to an existence limited within the space of abstraction, and is a consequence of a lacking cosmological picture. Rather than being able to place oneself within the physical world, the architect exists and is limited by logic and the Euclidean understandings of space that has come through its abstract signification.

Without functional or programmatic interests, which allows for the inherent unpredictability and appropriation of use in public space, it becomes natural to produce a neutral space into which can be introduced disjointed things, people and habits. This leaves the public with a space of absence; a space that is intentionally both physically and symbolically empty. Otherwise the various publics are 'given' a piece of 'public art' or landscape design that does not fulfill the social needs, acting only as representations that cannot be incorporated within the everyday life of the city. The 
nature. In these forms of space, contradiction is experienced both through spatial and inter-subjective relations, where both relations are directly associated to each other.

This experience

of contradiction occurs as one that is disruptive or conflictual in nature. As a form of conflict it is rooted in space, but is experienced as being socially, or inter-subjectively formed. Such an experience of the city is one that is public, where the space of the city becomes public through the experience of the conflictual event.

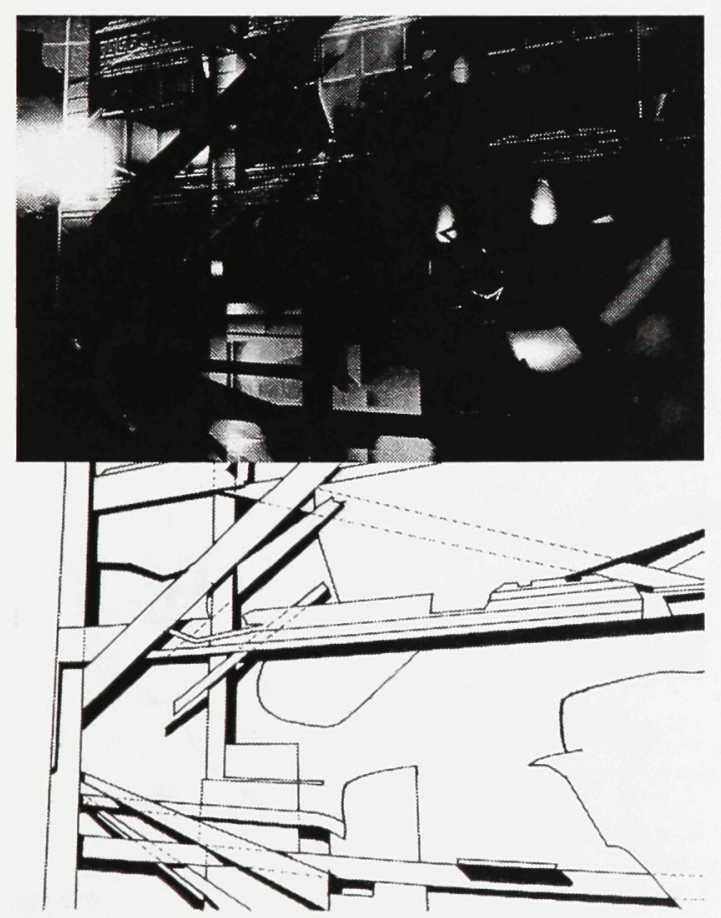

9: Site 6 - 'Impresario', Digital Collage and Ink Drawing on Mylar questions that must be asked then, are how does one (re)define what a successful or authentic form of public space is, while acknowledging its existence as a contradictory space in the abstract city? And how can this realization be translated into successful forms of urban social space in the city that creates a sense of place for the public?

\section{Living With Lefebvre: The Contradictions of Abstract Space}

To be able to operate within, and thus acknowledge the fragmented and contradictory space that is experienced by both architects and citizens, emphasis must be placed upon an understanding and critique of the abstract space of the modern city in order to bring forth a resistance towards its processes of production, analysis and representation. A thorough understanding of this can be found in the writings of the French Marxist Henri Lefebvre, who, in his compendious enquiry The Production of Space, has done more than any other philosopher to make us aware of the nature of space and its production under contemporary capitalism. In doing so he has 


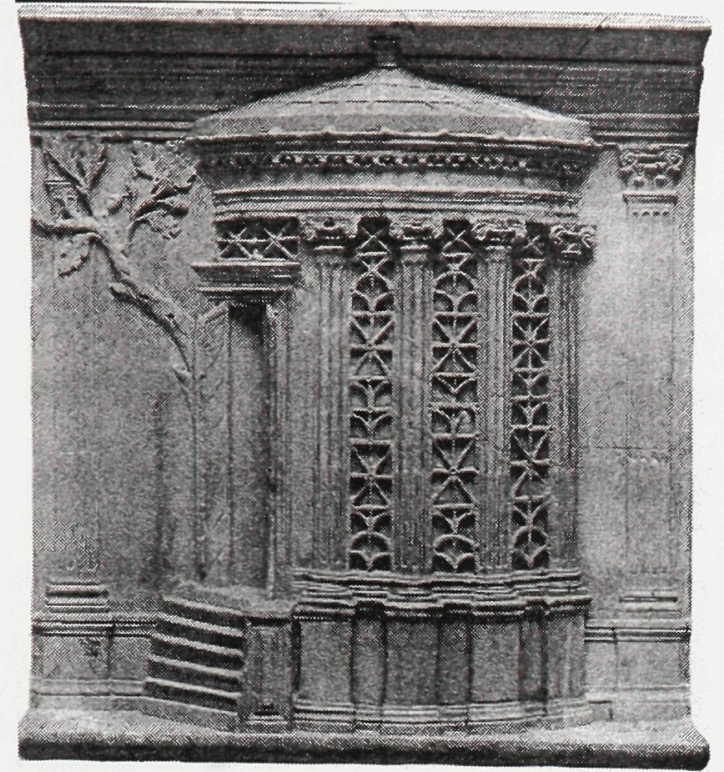

10: The Temple of Vesta in the Roman Forum, Marble Relief from Joseph Rykwert, The Idea of the Town (Cambridge, MA: The MIT P, 1988) 109.

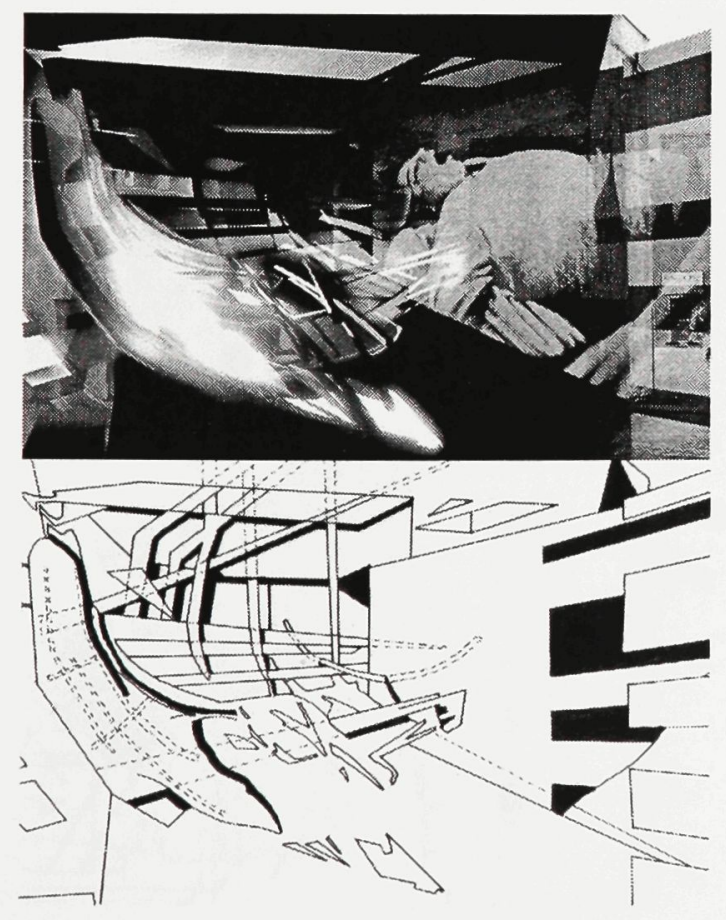

11: Site 7 - 'Impresario', Digital Collage and Ink Drawing on Mylar provided a frame through which to understand and approach the city.

Written in the years following the student movements of May 1968, La production de l'espace culminated his studies into urbanization and the production of space, and thus reinterpreted his previous ideas of revolutionary politics, everyday life, and Marxist theory into how they related to space as a product. ${ }^{8}$ Although the main focus of the work is the nature of space in general and its production under capitalism, he also examines how our understanding, as well as the nature of space in society, has changed throughout history. In doing so, he traces the development of space from the absolute to the abstract, from ancient to modern, associating the transformation to change in both the physical and social structure of humanity. ${ }^{9}$

For Lefebvre, absolute space, which he also refers to in some cases as apparent space, has its origin in 'agro-pastoral' space, where certain spaces obtain symbolic significance by becoming socially connected to a deeper symbolic meaning within a specific culture. In this context, spaces become understood 
Through the event, public space is created through physical, verbal, or visual interaction with the other. In this experience the public is not one that is selective, as through an abstract distinction, but includes all citizens and strangers equally as others. Public space then becomes an experience of space that is rooted in a conflictual nature, interrupting the inhabitants' everyday existence and understanding of the spatial and social nature of the city. This conflict is not negative or violent in nature, but rather one that fulfills the needs

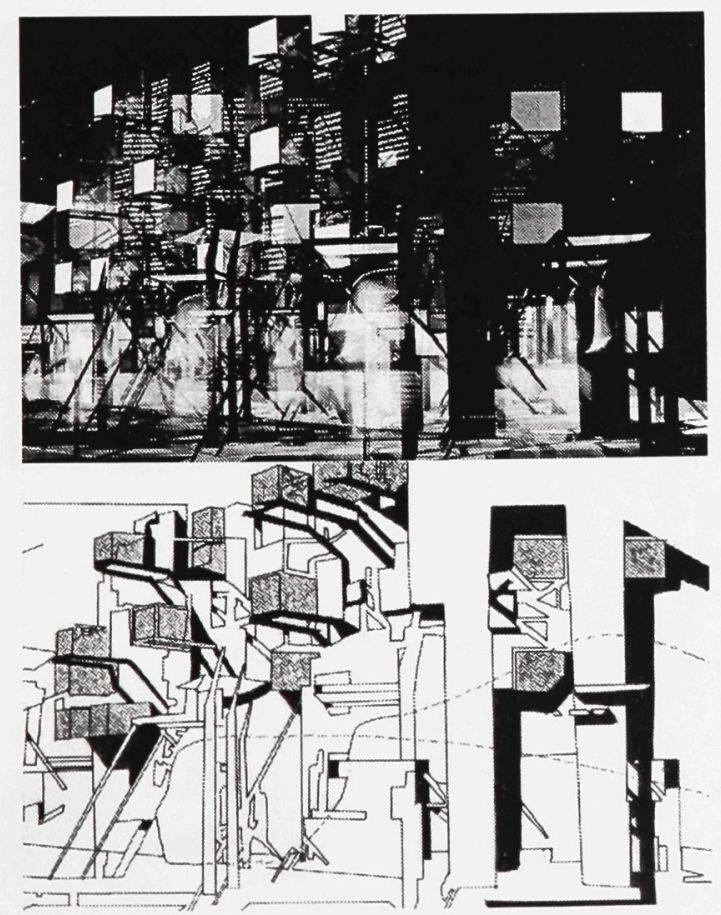

12: Site 8 - 'Discourse', Digital Collage and Ink Drawing on Mylar as being "holy or damned, devoted to the male principle or the female, rich fantasies or phantasmagorias." 10 Thus, everything is comprised of multiple meanings for its citizens, especially in regard to spaces associated with the founding of the city. ${ }^{11}$ The city, and space in general acted not only as a rational solution to 'real' problems, but also as a part of the citizens daily existence, where the "whole universe and its institutions could be spelt out of [their] civic institutions," or in how they created space. ${ }^{12}$

This symbolic nature to absolute space is also a lived space, or what Lefebvre terms a representational space, a space passively experienced through culture and its symbolic meanings. ${ }^{13}$ It is not, and cannot be generated or conceived through Euclidean or geometric space. Instead dimensions and directions have only symbolic force to them, each having their own significance of meaning. Although this appears to leave an ambiguity to the nature of space and its understanding, it does not mean that there was not a rational view of space, but that it had both a mythical or ritual quality to it as well as a real or relative form; both mythological and mathematical narratives of 
of the community by being a space that is accessible to all citizens and strangers, allowing them to experience the city as subjects. This is what allows for space to become both public and political through which conflict can be worked out rather than veiled from its inhabitants. Thus in the experience of the other we find the most essential quality of public space to be apparently one that is social rather than spatial.

How is it then that architecture, as the creation of space relates to the creation of public spaces in the

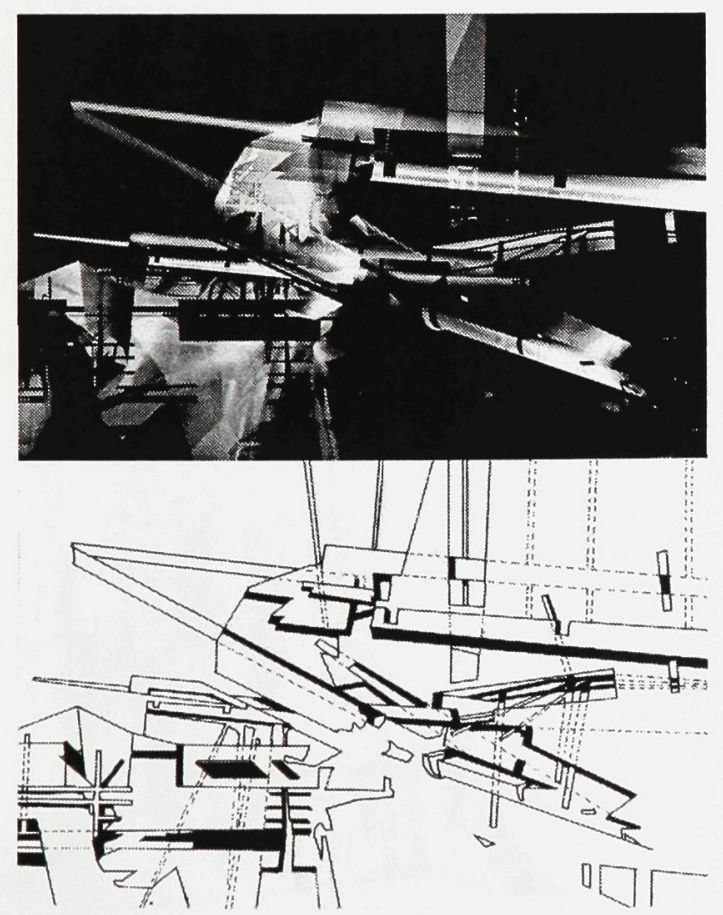

13: Site 9 - 'Impresario', Digital Collage and Ink Drawing on Mylar space existed simultaneously, harmoniously.

Within absolute space both the feminine sphere and the patriarchal sphere co-existed to create an overall symbolic understanding of the world, ${ }^{14}$ yet "abstraction was introduced - and presupposed - by the father's domination over the soil, over possessions, over servants and slaves, and over women" by the imposition of the master. ${ }^{15}$ Through patriarchal power came mental space, and with it the dominance of the conceived or 'representations of space', an ideological space that tends towards a system of visual signs, but is emptied of symbolic meaning. Thus, abstract space became both a representation of space, as a space of practical action and geometric homogeneity, as well as a representational space because of its symbolic association with the phallus, or patriarchal power. Unlike absolute space, the space of abstraction is a complex space dependent upon the formation of a social consensus that exists above law, for its existence and apparent consistency, but in doing so it contains specific contradictions that are a result of its logical nature. ${ }^{16}$ Nonetheless, it maintains and tends toward an illusion of homogeneity that causes 
city, as publicness appears to be constituted as a social experience? Although it may appear to be socially based, the social or inter-subjective aspects of public space occur as relationships between bodies in space, and are therefore a spatial experience. The inter-subjective and conflictual experience of the city is a spatial experience, and therefore an architectural one. In this understanding, architecture does not only frame or give location for the public experience of the city, but also creates it through its

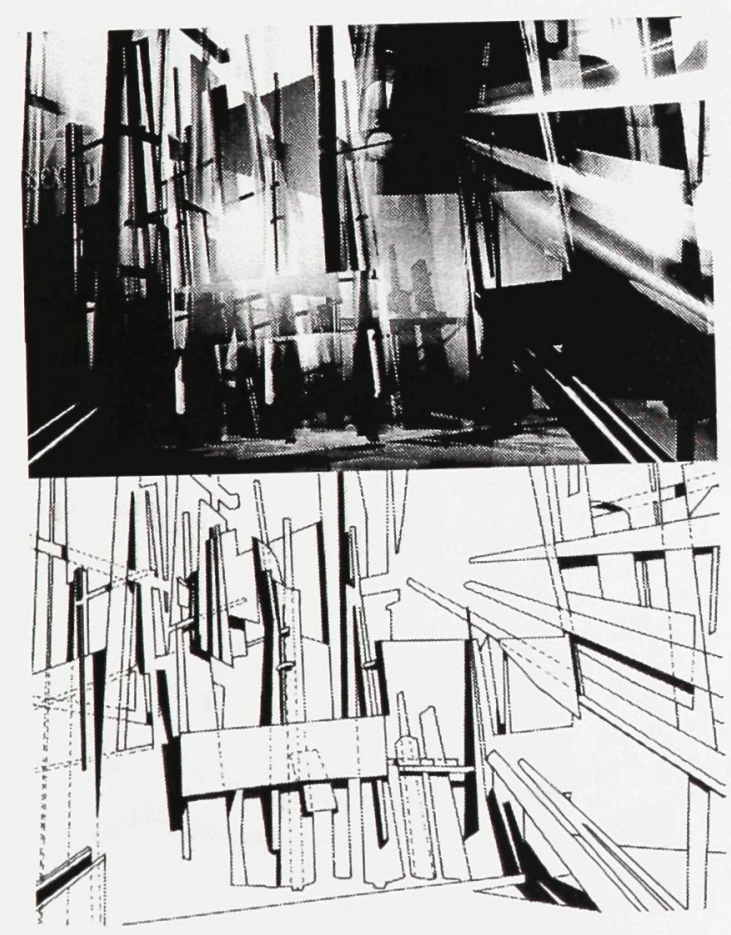

14: Site 10 - 'Impresario', Digital Collage and Ink Drawing on Mylar it to eliminate difference and allows for the erasure, or 'tabula rasa' of what stands in its way, or threatens its consistency of appearance.

Although both forms of space - absolute and abstract - co-existed, Lefebvre notes that the loss of monastic culture, the failure of the dominance of the Roman Church, and the creation of nation-states caused the near disappearance of absolute space. It would only continue to exist in the "heterotopical' 17 places, the strange and damned spaces as well as the divine spaces: contradictory spaces that would maintain themselves as both fascinating and taboo. What would come out of this transformation was "the space of secular life, freed from politico-religious space, from the space of signs of death and of non-body."

This change became apparent in urban space during the $16^{\text {th }}$ century when a gap appeared between town and country. The town-dwellers, who already lived within a space of abstraction, separated from nature, began to view the peasants, or those outside the city walls as "fantasy or as objectors, and accordingly treated them with embarrassment or contempt, as something out of a fairytale or out of a tale 
inhabitation; through the experience of space, material, light, and form. An architecture that is public addresses difference at both the social and spatial levels, while inhabiting and exhibiting the fractures that exist within the apparently homogenous whole. In this manner, architecture operates as an interruption; a conflict in or of space that creates the public experience of the city.

The architectural process undertaken in this thesis acts as a theoretical investigation into the spatial and inter-subjective relations
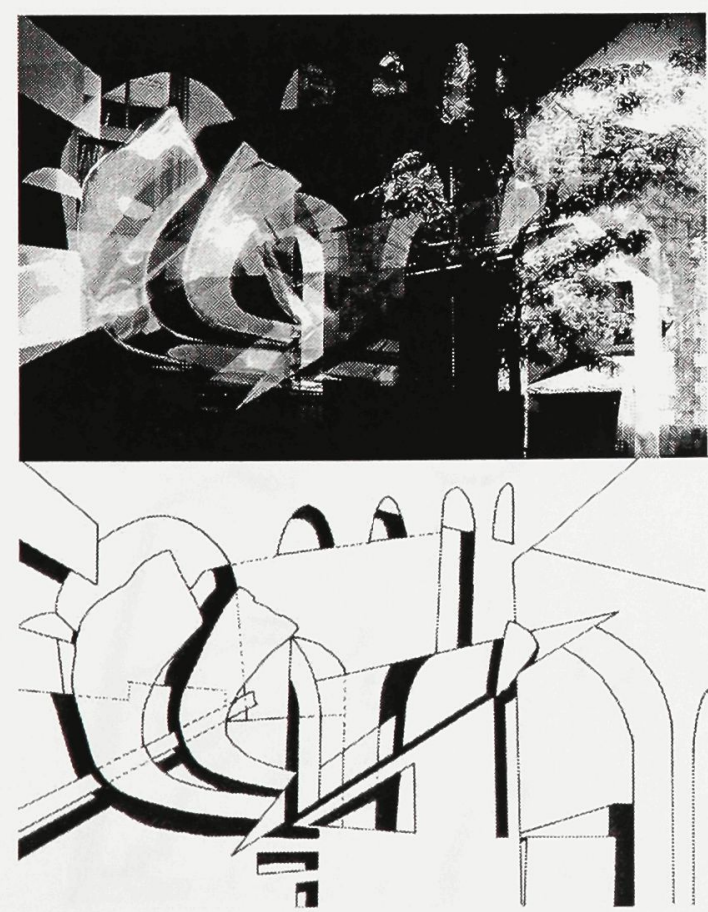

15: Site 11 - 'Frame', Digital Collage and Ink Drawing on Mylar of horror."19 They would view the peasants as something outside of their logical conception of space, and this estrangement created a duality within the unity that had previously existed between town and country, where the town was recognized to be associated to the country through the production and consumption of material. This change in understanding to the country as being opposed to the town came from attempts to eliminate contradiction, thus separating the space within the city from those spaces without, places that were viewed as strange, foreign and hostile to those within the logic of the city walls. The unity of town and country was severed through the abstract processes of inclusion and exclusion, which creates prohibitions of space, limiting its participatory nature to one that is categorized. From this emerged the conceptualization of the town, where it was possible for it to be represented in language, developing what Lefebvre refers to as a code of space. Thus, the town would become understood as a text or work, changing its perception to that of the whole rather than through its distinct parts, as architects had previously viewed it. ${ }^{20}$ 


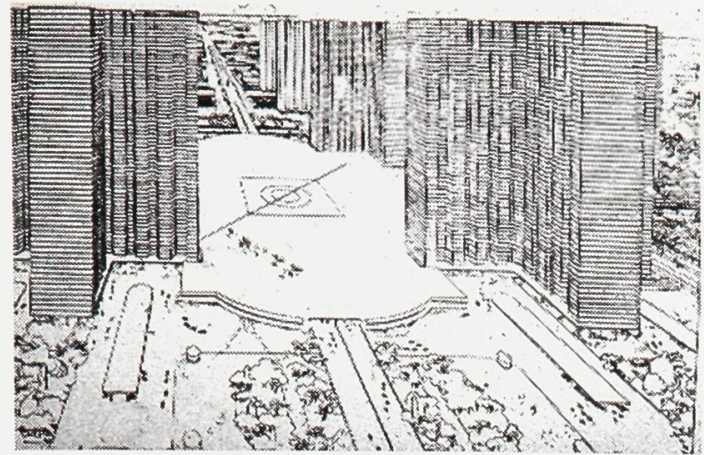

16: Le Corbusier, Contemporary City for 3 Million Inhabitants from hanser.ceat.okstate. edu (2005. <http://hanser.ceat.okstate. edu/6083/Corbusier/Urban\%20planning. htm>)

Balzakian mentality is a reference towards those who focus upon and glorify the dramatic conflicts of life in the city, especially in regards to those spaces of the 'underground' and the pain and suffering that their inhabitants endure.

17: Definition of the 'Balzakian Mentality'

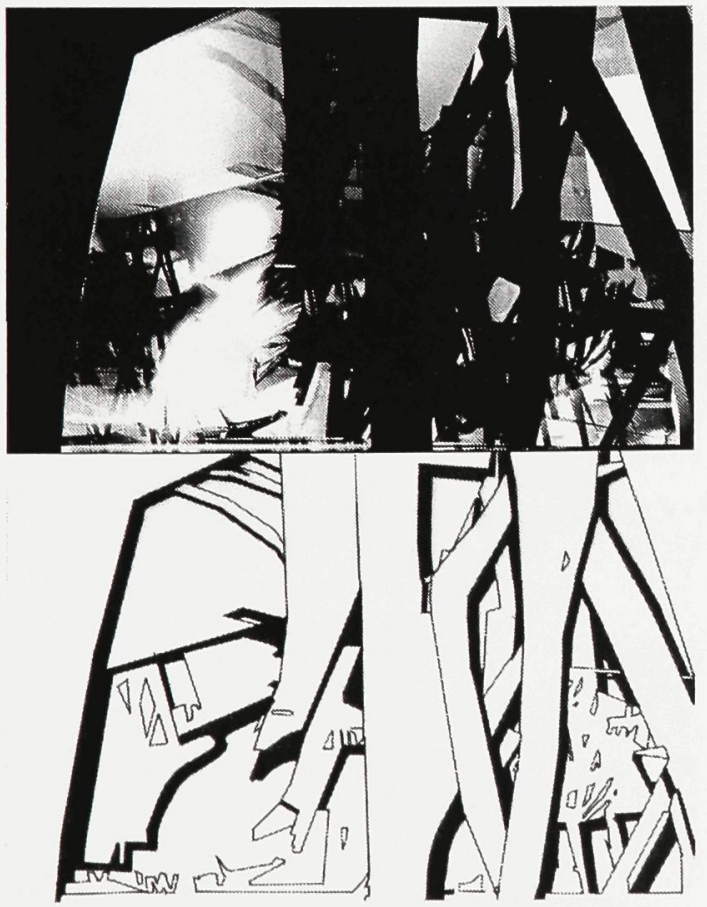

18: Site 12 - 'Frame', Digital Collage and Ink Drawing on Mylar
What Lefebvre is describing in what he refers to as abstract space, is the space of modernism, a space that attempts to achieve homogeneity through the creation of neutral spaces or non-contradictory spaces. But he notes "abstract space is not homogenous, but simply has homogeneity as its goal." Homogeneity is its lens, and thus it renders itself so through reduction, where it depicts and maintains its image through specific representation of space. This abstraction and reduction of space is a violent act, as its repression of contradiction destroys any former meaning that it might have once held.

The modernist movement towards universalization and homogenization can be seen in how Le Corbusier viewed the city; as a place that was in need of being opened up and aired out in order to address its social pathologies. His wish to open the city, "to rid it of all the closed, dirty, dangerous and unhealthy corners," was intended to "rid metropolitan populations of any spatial anxiety they might have felt," due to the dramatic contrasts that existed between spaces. ${ }^{22}$ This spatial difference was what he believed to be the cause of 
"In some country towns there are houses more depressing to the sight than the dimmest cloister, the most melancholy of rains, or the dreariest stretch of sandy waste. Perhaps such houses combine the characteristics of all the three, and to the dumb silence of the monastery they unite the gauntness and grimness of the ruin, and the arid desolation of the waste. So little sign is there of life or of movement about them, that a stranger might take them for uninhabited dwellings; but the sound of an unfamiliar footstep brings some one to the window, a passive face suddenly appears above the sill, and the traveler receives a listless and indifferent gaze - it is almost as if a monk leaned out to look for a moment on the world."

Honoré de Balzak, Eugénie Grandet, Trans. M.A. Crawford. (London: Penguin, 1969)

19: 'Balzakian Mentality'

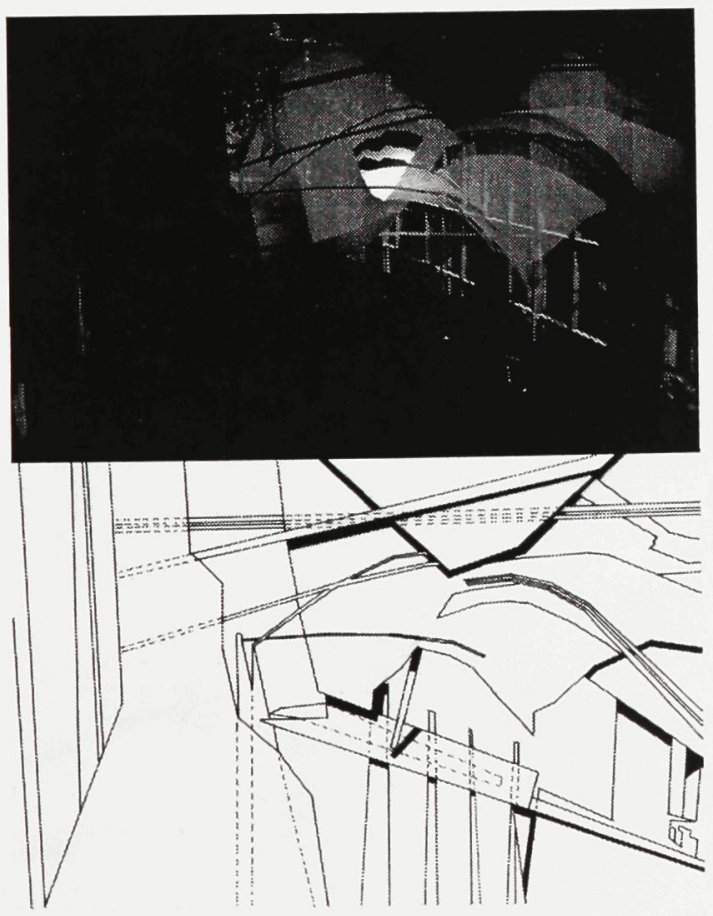

20: Site 13 - 'Impresario', Digital Collage and Ink Drawing on Mylar agoraphobia and claustrophobia in the modern city. It's elimination was a means through which to destroy the totems, taboos and discontents of spaces in the city that were contrary to the efficiency and machine-like quality that it intended to represent. By removing contrast, which Le Corbusier viewed to be embodied in the 'Balzakian mentality' of the street, he allowed for it to be replaced by expanses of verdure and efficient forms of living and moving to go along with the efficiency of work and the machine (Fig. 16).

As a result of this violent destruction, there was a movement toward an understanding of the people as a homogenous mass, eliminating "not only class and social struggles, but also psychological conflicts and contradictions," allowing for a state of total administration, as described by Herbert Marcuse in the OneDimensional Man. ${ }^{23}$ In this view, the goal of modernism was to enable both for the city and people to become totally administered to conform to the spatial construct of the social system, where one can only desire what it can satisfy and nothing more, thus limiting society to the framework of a closed system. Everything 
that occur within the city. Using the hysteric (an extreme form of otherness that is well documented and discussed in both culture and clinical theory) as a basis, this investigation develops a speculative process that allows for an understanding of the conflictual and interruptive experience of the other in the city. Such an analogy towards the public experience of architecture allows for the displacement of the issue into existing theoretical and spatial contexts that directly relate to the inter-subjective experience

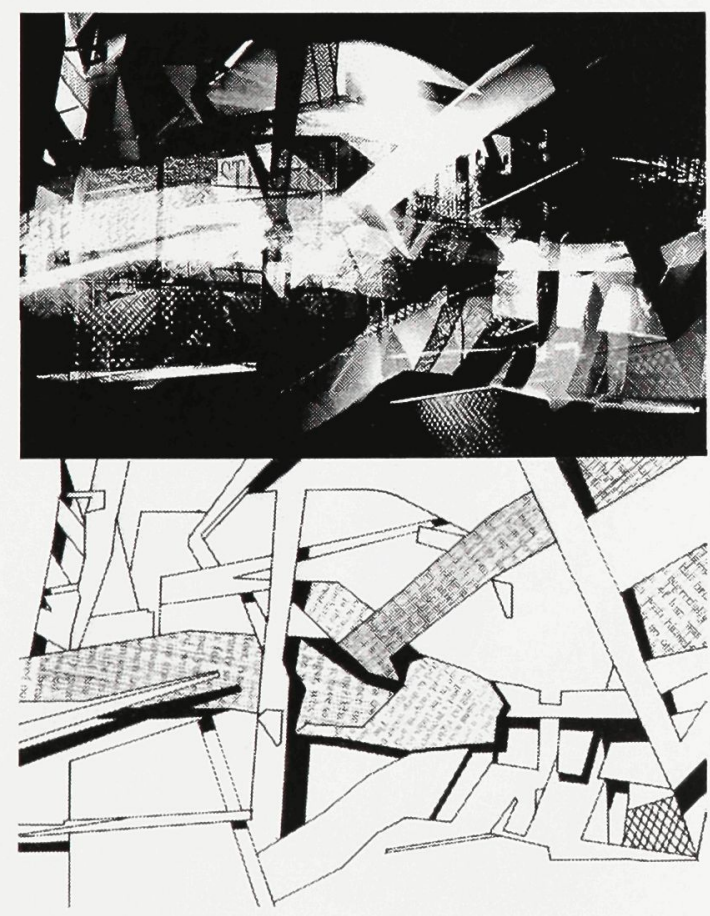

21: Site 14 - 'Flesh', Digital Collage / Ink Drawing on Mylar would become a reproduction of what was possible to be satisfied within the homogenous whole, including the people themselves.

Along with the elimination of contradiction came the elimination of the possibility for multiple meanings where oneto-one correspondence eliminated gaps in logic and representation allowing for the development of a universal theory of truth. The social and spatial transparency of meaning was an attempt to decrypt and make legible what before had multiple functional and symbolic meanings. In architecture, this transparency informed the idea of a visual logic, where all meaning should be revealed in space, and where function would be clarified through form, and thought clarified through language. ${ }^{24}$ This is embodied in our modern means of representation, where the use of orthography and axonometry attempts to systematically remove, or veil through homogeneity and correspondence, the inherent gap between the various architectural representations of an object of three-dimensions.

What emerged from this decryption was that clothing and opacity became a sign 
of the city. By placing a hysterical figure within the city, the architectural process allows for an enquiry into the spatial relationships and conditions that occur due to its experience.

The superimposition of a 'hysterical narrative' situates the hysteric within the city, allowing for the identification of a series of conditions that enable for, or occur within the creation and experience of public space. This occurs as a series of possible installations of the hysteric within the space of the Market, acting as both an unconventional

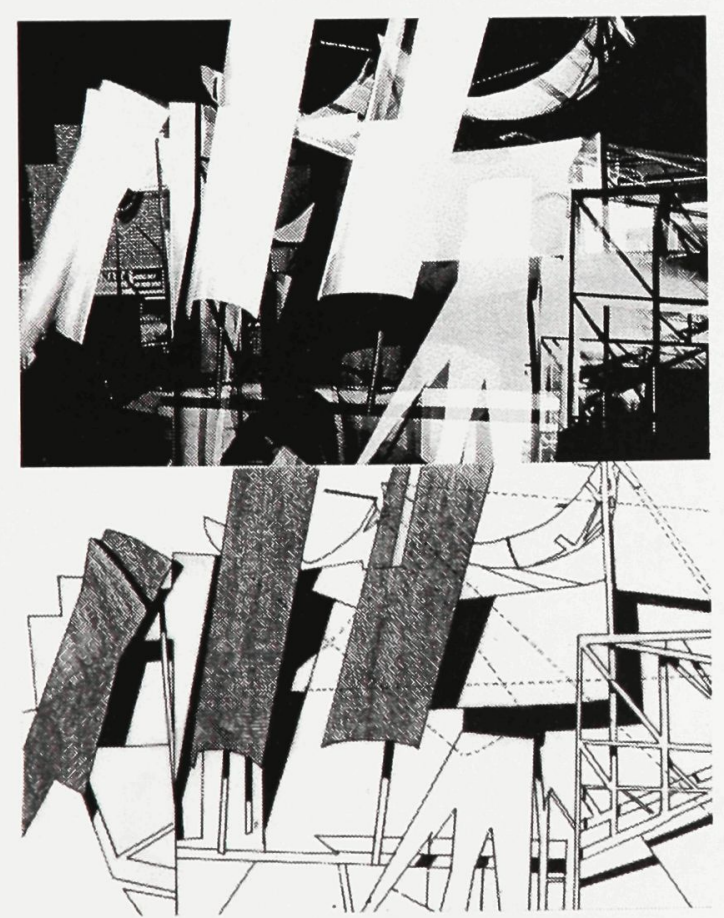

22: Site 15 - 'Discourse', Digital Collage and Ink Drawing on Mylar of the old and illusory mode of life, while nakedness signified the "newly discovered and experienced truth" as well as an "act of spiritual liberation, of becoming real. ${ }^{\prime 25}$ For the creation of space, this meant that form and function were to become visually connected, and thus readable or transparent, where form followed function. Lefebvre also notes that this image of transparency was translated into the utopic image of a glass city, "its buildings invisible and society open." ${ }^{26}$

In its act of rendering itself transparent and homogenous, abstract space is produced as an image by masking, rather than indicating the contradictions it contains. ${ }^{27}$ The space of the city is then reduced to an image, becoming a representation of what is desirable. This production of an image is prevalent in the contemporary space of cities in what has been aptly named 'disnification', ${ }^{28}$ where the production of neutral, and thus unthreatening and sanitized space, attempts to improve a cities place-image through the creation of an idealized political and economic image, allowing for an increase in economic value. ${ }^{29}$ Pursuit of a specific marketable image allows for those in charge of 
site analysis, allowing for an understanding of the existing spatial experience of the city, while also being analogous to the 'authentic' experience of public space.

Through a process of spatial and theoretical displacement, this architectural process questions the existing Symbolic, or Euclidean understanding of space in the city by challenging the abstractions through which architects understand and make space in the city. This allows for a new understanding of the city and how public space and architecture

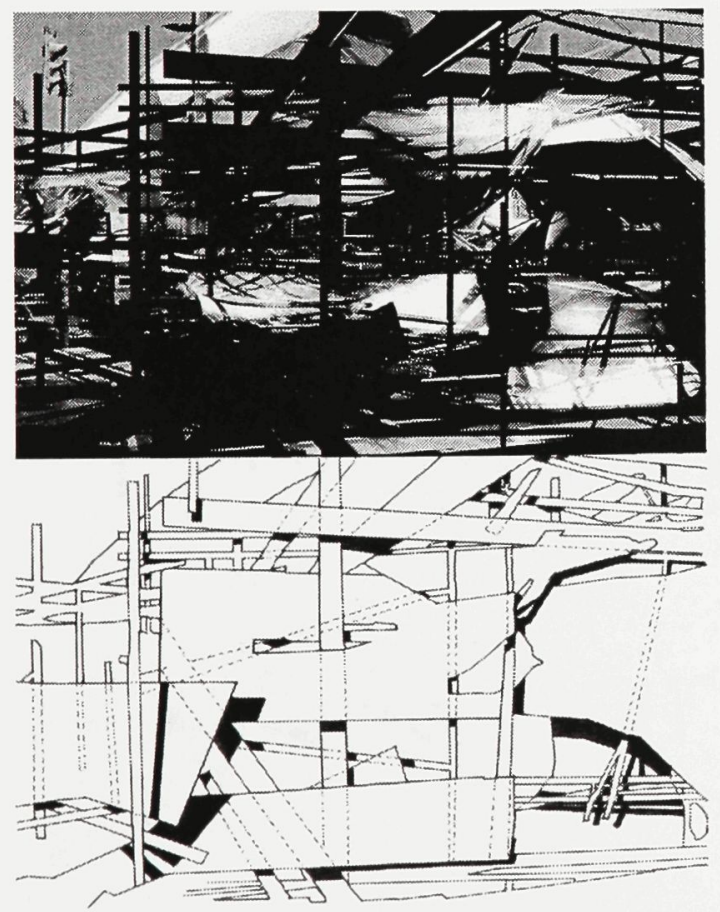

23: Site 16 - 'Frame', Digital Collage and Ink Drawing on Mylar the creation and maintenance of space in the city to continue, in the name of improvement, with the eradication of those spaces seen as unpalatable and problematic, thereby removing the visibility of vagrancy, homelessness, panhandling, and prostitution that occupy such spaces and relocating them elsewhere. ${ }^{30}$ But as Karl Marx reminds us, such contradiction is not something that can be removed, but can only be relocated elsewhere, thus making the capitalist process one of "displacement and re-conquest, a reordering of spaces of luxury and a driving away of the poor into even worse and more crowded hiding places." ${ }^{\prime 31}$

Architecture, as a means to create space, is then forced to exist within the realities made present through abstract space and embodied through the method of modern architecture beginning with Jacques-Nicolas-Louis Durand and the École Polytechnique. ${ }^{32}$ In this method, architecture, which had previously been coherent with intuition as it relates to man's experience and place in the universe, was to be based upon invented orders and categorizations (such as measurements). This allowed for architecture to be seen as an objective and 
exist within it, while challenging the formally generative, linear and thereby rational means of understanding the making of architecture, allowing for one to respond to the contradictory nature of the city. In doing so, this architectural process resists the ideal representations through which we create architecture.

This theoretical process of proposed interventions leads through an investigative and speculative process into a video intentionally created as a projected installation within the market. In doing so it

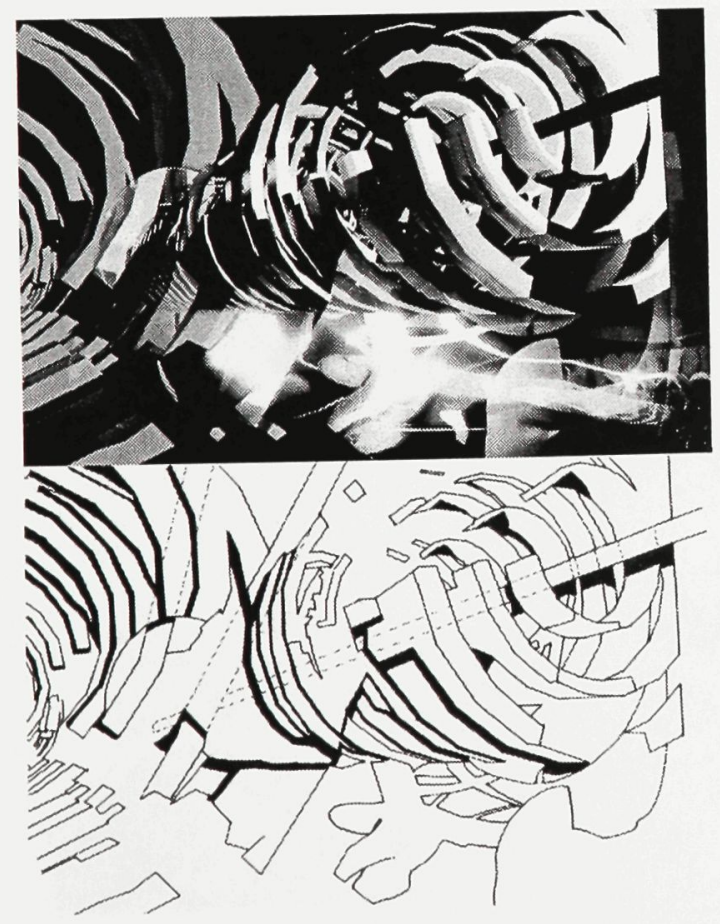

24: Site 17 - 'Impresario', Digital Collage and Ink Drawing on Mylar formal problem of a language of style. Because of this, there is an unconscious or unintentional propensity to create an idealized, and therefore non-contradictory image of space. This is due to the specific representation of space through which architects create, that of architectural space and architectural production, which is inescapable even by intention. As a constructed mental space, representations of space assist in allowing for an interpretation of theoretical and practical social history into the creation of architecture. ${ }^{33}$ The use of graphic signs in orthographic drawings acts as a reduction "of the reality they claim to represent, ${ }^{\prime 34}$ which is also the lived aspect of 'representational space'. It is these approaches that allow architects the freedom of planning, while also limiting them to the modality of an accepted form of social life, and therefore to a particular form of architecture, and a particular form of public space.

If architects are to not eliminate contradiction through a reduction of reality, what must be accepted and operated within is the space of contradiction or difference. This is what Lefebvre refers to as differential space. It is 


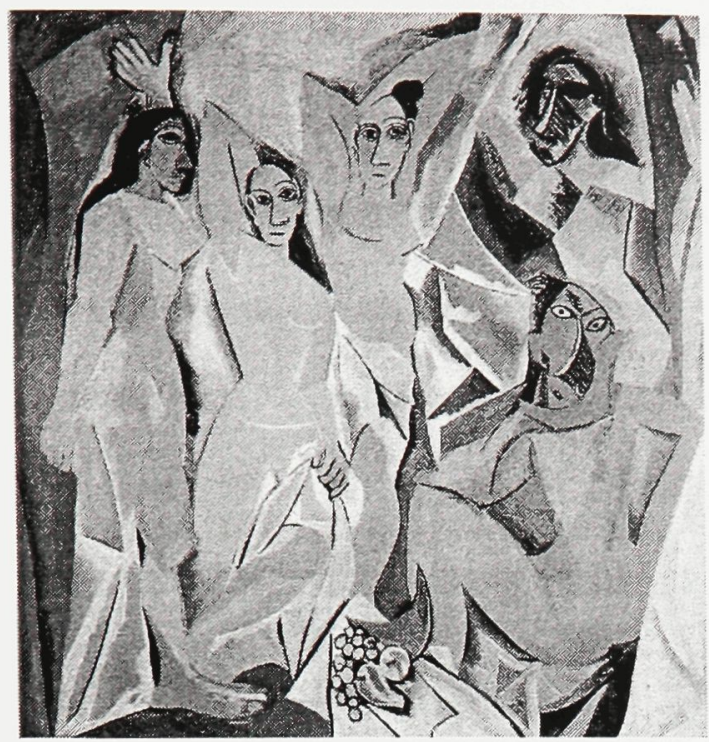

25: Pablo Picasso, Les Demoiselles d'Avignon, 1907, from acsu.buffalo.edu (2005, <http://www.acsu.buffalo.edu/ $\sim$ jconte/Pablo_Picasso.html $>$ )

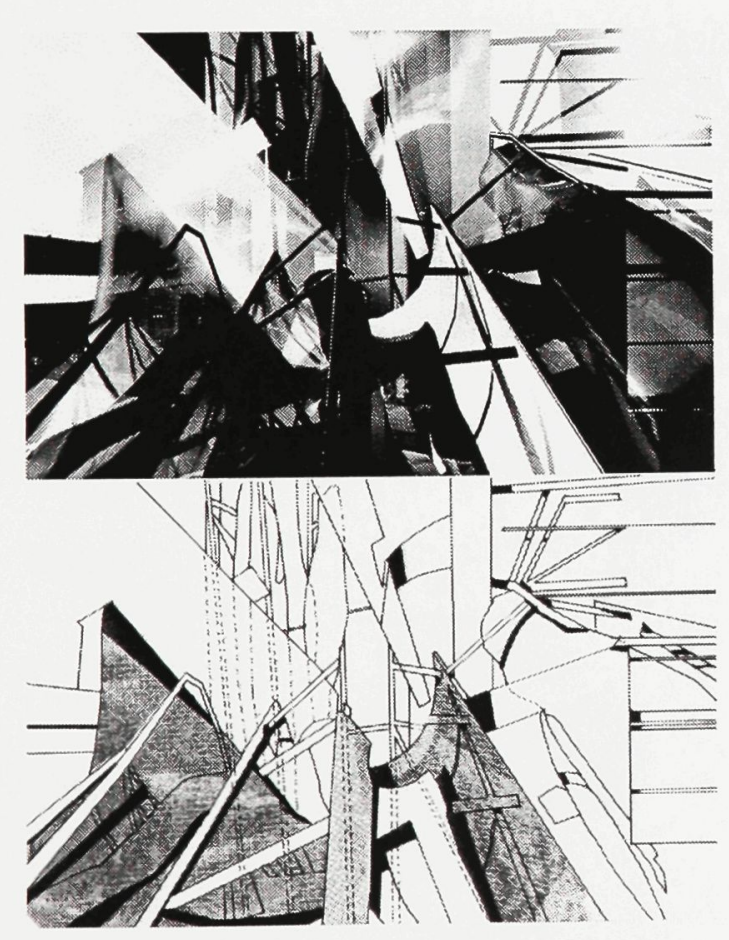

26: Site 18 - 'Discourse', Digital Collage and Ink Drawing on Mylar in this implicit contradiction of abstract space in which $19^{\text {th }}$ century modernist writers, such as Marx, Baudelaire, Dostoevsky and Nietzsche found themselves at home, by accepting and embracing its nature as a part of an existence that was at once experienced as both homogenous and fragmented. But one must also note that in accepting such a realization, it is not intended for it to become merely a representation or image of the fragmented space of modernity, where contradiction is depicted such as was the case in cubist representations of space (Fig. 25). Instead, the architect must exist within and respond to its fragmentation in a manner that preserves and reveals difference. ${ }^{35} \mathrm{~A}$ conception of the space of the city must recognize the existence of the contrasting and underground spaces that have been excluded from abstract space including the strange, the foreign, the hostile, the tabooed, and the 'heterotopic'. Architecture must be able to respond to this as modernist writers have, by understanding that "it is disorder that enables us to feel more, and provide us with enjoyment of the self." ${ }^{36}$ It is in the disorder of the apparently invisible fractures encountered within abstract space that will reveal the "true - invisible yet 
develops an understanding and representation of the relationship of the making of architecture to the public experience of the city.

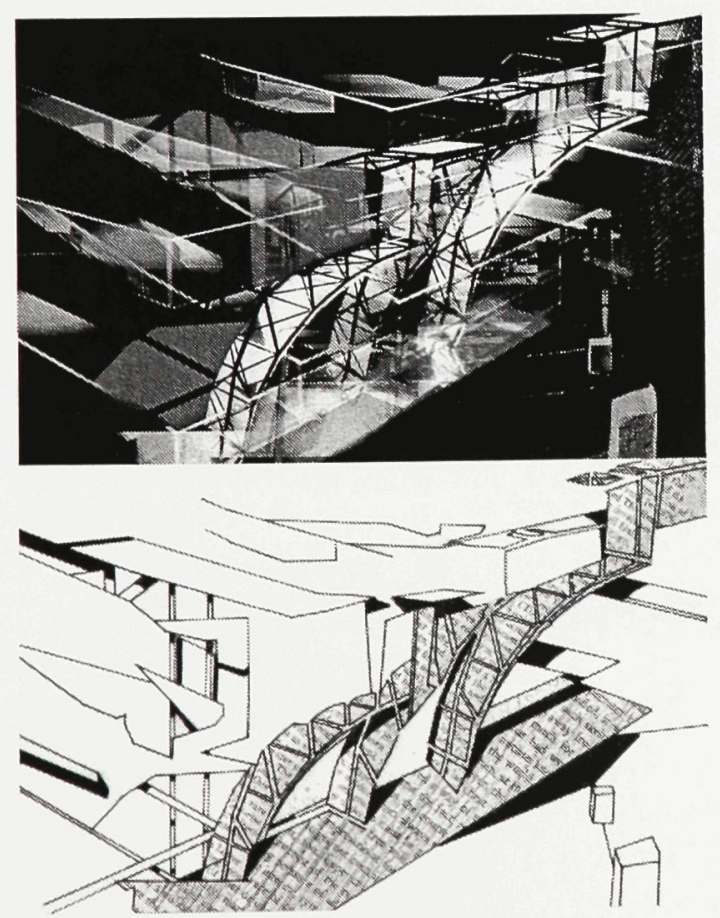

27: Site 19 - 'Flesh', Digital Collage and Ink Drawing on Mylar highly irregular - contours of 'real' social space lying beneath its homogenous surface." ${ }^{37}$

\section{A Public Through Difference, Not Fear}

These fractures in the continuity of space, where contradictions are revealed, are what make the city both threatening and alluring to its citizens, and are what form its public spaces by making us aware of them. The experience of contradiction erupts into an experience of confrontation, where the interruption caused by the fractures in the homogenous whole allows for an experience of the authentic and participatory form of social space. This confrontation occurs as an experience of social and spatial difference, as a conflict of relationships in space. It is in the visual and physical (as bodies in space) experience of the other who also inhabits the space that discourse, as an experience of the richness of spatial-temporal relationships of bodies, words and actions in the city, occurs.

Such discourse as a form of interruption arises through the attempt to assign meaning to the other whom we cannot relate to, thus attempting to situate the experience within language, or within homogenous space. But 
there is a gap that persists in that we are unable to do so. Through this experience there is a form of questioning that takes place; a debate within the self and one's relationship to society ensues, thereby questioning our relation to and objectification of the other. Therefore, for a space to become public, or to be viewed in society as public, there must be the existence of contradiction as an interruption, which occurs by being confronted by the other who is outside of one's spatial or symbolic reality.

Public space must then be something other than the mediated and homogenized space that attempts to veil or eliminate difference altogether, regulating the meaning that both

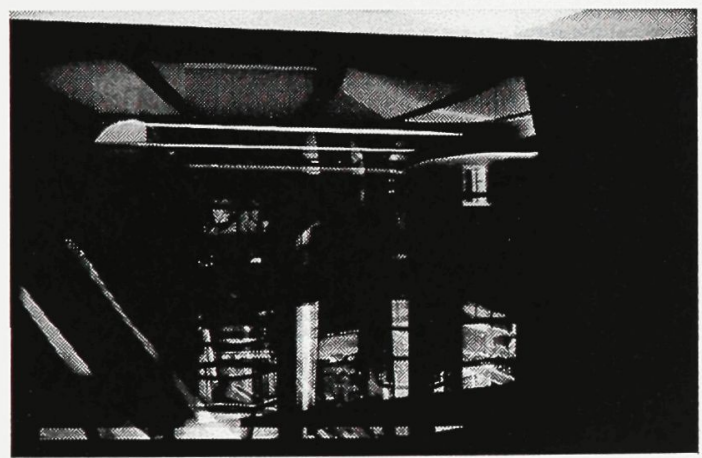
it and what it contains possesses. This occurs when space is set aside or zoned as public so as to not disrupt the consumptive or spectacular experience of the city. Instead public space must be an experience and awareness of difference, plurality, or otherness and the opacity of their

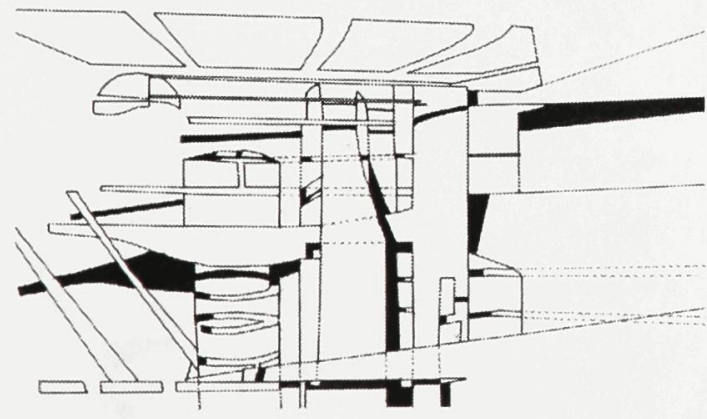
meaning. It is an experience that is suffered as a tragedy, as it reveals to the inhabitant the social and political issues that exist in urban space, and as an inclusive space, allows for a place to work 28: Site 20 - 'Frame', Digital Collage and Ink Drawing on Mylar out personal and social conflicts. ${ }^{38}$ With this in 
This poem takes the form of a lover's complaint: the narrator is explaining to the woman he loves why he feels distant and bitter towards her. He reminds her of an experience they had recently shared. It was an evening of a long and lovely day that they had spent alone together. They sat down on the terrace "in front of a new café that formed the corner of a new boulevard." The boulevard was "still littered with rubble," but the café "already displayed its unfinished splendors." [...]

As the lovers sit gazing happily into each other's eyes, suddenly they are confronted with other people's eyes. A poor family dressed in rags - a graybearded father, a young son, and a baby - come to stop directly in front of them and gaze raptly at the bright new world that is just inside. "The three faces were extraordinarily serious, and those six eyes contemplated the new cafe fixedly with an equal admiration, differing only according to age." [...] Their fascination carries no hostile undertones; their vision of the gulf between the two worlds is sorrowful, not militant, not resentful but resigned. In spite of this, or

29: "The Eyes of the Poor," from Marshall Berman, All That Is Solid Melts Into Air

(New York: Simon and Shuster, 1982) 148-9.

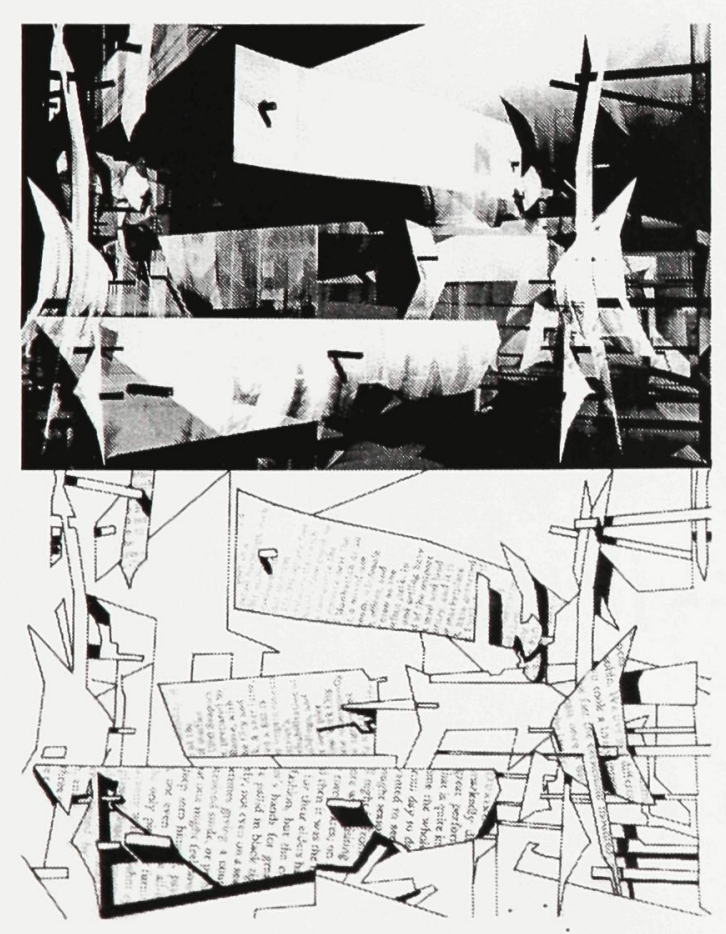

30: Site 21 - 'Flesh', Digital Collage and Ink Drawing on Mylar mind, public space cannot be categorized or zoned public, but becomes public through the experience of the interruption caused by intersubjective relations within the space, forcing inhabitants to question the abstract space of the city and society, and in doing so becoming a public.

An example of this form of confrontation occurs in Charles Baudelaire's poem The Eyes of the Poor, as recounted by Marshall Berman in All That Is Solid Melts Into Air. Set during Haussman's transformation of Paris, it describes a couple's experience and reaction to otherness in the city (Fig. 29). ${ }^{39}$

In this poem, the space of the boulevard forces a political reaction to the encountered confrontation, where contradiction occurs both within space, as well as within the individuals themselves through their reactions to the situation. As Berman notes, it "is not that they are angry or demanding," they just won't go away, as they too want to be able to experience the modern city as well. ${ }^{40}$ By remaining in the light', they force upon the couple an interaction with difference, through which a questioning of self and society ensues. In creating such a 
maybe because of it, the narrator begins to feel uneasy, "a little ashamed of our glasses and decanters, too big for our thirst." $\mathrm{He}$ is "touched by this family of eyes," and feels some sort of kinship with them. But when, moment later, "I turned my eyes to look into yours, dear love, to read my thoughts there," she says, "Those people with their great saucer eyes are unbearable! Can't you go tell the manager to get them away from here?

This is why he hates her today, he says. $\mathrm{He}$ adds that the incident has made him sad as well as angry: he sees now "how hard it is for people to understand each other, how incommunicable thought is" - so the poem ends - "even between people in love."

29 continued: "The Eyes of the Poor," from Marshall Berman, All That Is Solid Melts Into Air (New York: Simon and Shuster, 1982) 148-9.

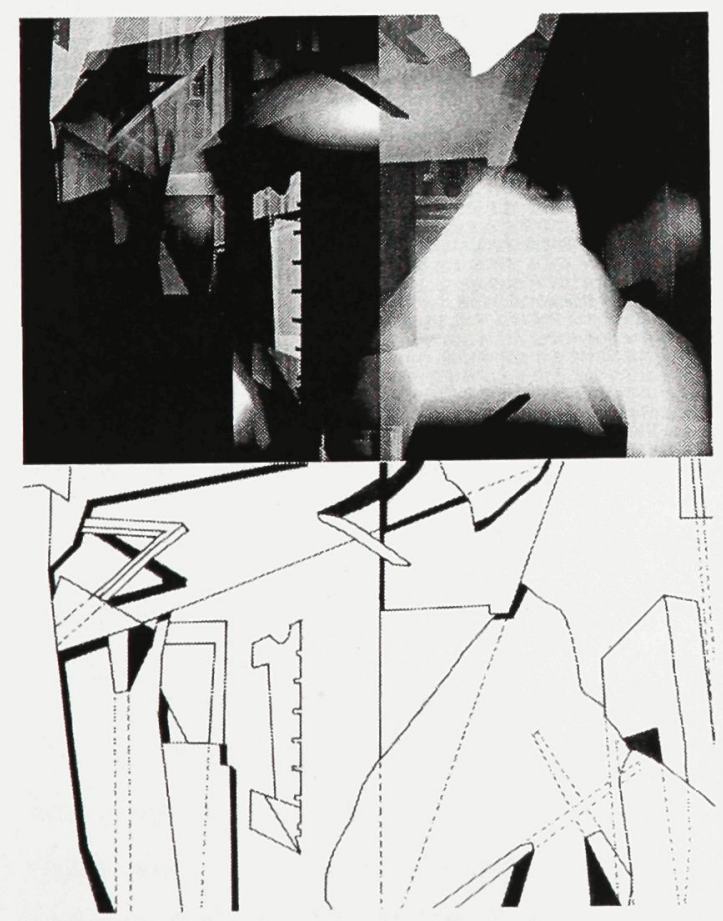

31: Site 22 - 'Frame', Digital Collage and Ink Drawing on Mylar political event in space, it is transformed into one that is inherently public.

The conflictual event as the foundation of both publicness, and of the transformation of space into public space, becomes a means through which we can locate the issue of the creation of space, and thereby the creation of an architecture that becomes public through its experience. By approaching the understanding of public space in such a manner, rather than through a rational or functional approach, an engagement with the social issues of said space becomes possible, revealing what can be understood as the authentic or essential nature of public space. A further understanding of the issues at play in the experience of difference will allow us to address both the spatial and temporal conditions in which these social relations occur, as well as how they might be embodied in our generative and analytic representational means. Through an exploration within this slippage of meaning there will be a progression towards defining the spatial conditions that frame the inter-subjective relationships in space, as well as an exploration of new meanings and understandings of public space. 


\section{The Contradictory Landscape of the Ideal Notes:}

${ }^{1}$ For a public or social space to function politically within the city it must be a part of the complex of dynamic relations between people living in a society, which I refer to throughout this thesis as inter-subjective relations.

${ }^{2}$ Discourse, although a democratic means to resolution, is not and cannot be the only defining factor of public space, for if that were true then it would be possible for this need to be fulfilled through the virtual realm of media and cyberspace. For discussion on the possibility of a democratic nature to cyberspace, and thus its possibility as a new form of public space, see Diana Saco, Cybering Democracy: Public Space and the Internet (Minneapolis, MN: U of Minnesota P, 2002).

${ }^{3}$ Anthony Vidler, Warped Space: Art, Architecture, and Anxiety in Modern Culture (Cambridge, MA: MIT P, 2002) 135. I am referring here to a quote by Vito Acconci where he states "Public space is leaving home," therefore implying that we experience public space whenever we leave private spaces. Acconci's own work follows a subversive path in its commentaries on shelter, but still remains within the realm of public art, as counter-architectural objects removed from the modern condition of the city.

${ }^{4}$ This will be addressed in more detail later in the section on Henri Lefebvre. For the purposes at hand 'abstract' space is taken from Lefebvre's understanding as a space of practical action and of symbolic and geometric homogeneity directly associated through its creation to the mental or conceived space. All citizens exist within this complex space that depends on the creation of a social consensus that exists above the Law for it to appear as consistent. Because of this need for social consensus it contains specific contradictions that are due to its logical basis, and which are removed or veiled.

${ }^{5}$ See Harriet F. Senie, The Tilted ARC Controversy: Dangerous Precedent? (Minneapolis, MN: U of Minnesota P, 2001).

${ }^{6}$ The social aspect of public space is an important issue that also provides a critical stance regarding the existing forms of space that exist in the city as a community. For a strong social activist standpoint towards the right of the public to spaces in the city, their uses, and their re-appropriation see Don Mitchell, The Right to the City: Social Justice and the Fight for Public Space (New York: The Guilford P, 2003), Jeff Ferrell, Tearing Down the Streets: Adventures in Urban Anarchy (New York: Palgrave, 2001), 
and Don Mitchell and Richard Van Deusen, "Downsview Park: Open Space or Public Space?," CASE--Downsview Park Toronto, Ed. Julia Czerniak (New York: Prestel, 2001)
102-15.

\section{${ }^{7}$ Andy Merrifield, Dialectical Urbanism: Social Struggles in the Capitalist City (New York: Monthly Review Press, 2002) 167. \\ ${ }^{8}$ David Harvey, "Afterword," The Production of Space (Cambridge, MA: Blackwell Publishers, 1991) 430.}

${ }^{9}$ Refer to Chapter 4 in The Production of Space for a more in-depth description of this development of space. 1991) 231.

${ }^{10}$ Lefebvre, The Production of Space (Cambridge, MA: Blackwell Publishers,

${ }^{11}$ Although I focus upon Lefebvre's understanding of absolute space, Joseph Rykwert's book, The Idea of a Town approaches the issue of the meaning associated with the founding of the city in greater depth, and is in line with Lefebvre's own understanding.

${ }^{12}$ Joseph Rykwert, The Idea of a Town (Cambridge, MA: MIT P, 1988) 202.

${ }^{13}$ See Lefebvre, 36-46 for his definition and explanation of spatial practice, representations of space, and representational spaces.

${ }^{14}$ For both Lefebvre and Rykwert the feminine sphere of meaning contains the reproduction of life, pleasure and pain, the earth and the abyss below, while the patriarchal or male space contains the imposition of the law of signs upon nature through writing and inscription.

${ }^{15}$ Lefebvre, 243.

${ }^{16}$ Absolute space contained contradictions as well, especially in regards to its plurality of meanings. But these can only be viewed as contradictory from a logical point of view, as they were accepted as a part of the formation of space during ancient times.

${ }^{17}$ Lefebvre, 263. Heterotopic should be understood here not only as strange and damned places, "places of sorcery and madness, places inhabited by demonic forces," but as divine spaces as well. For Lefebvre they are of contrasting nature to the prevailing form of space and are therefore tabooed within abstract space.

${ }^{18}$ Lefebvre, 256.

${ }^{19}$ Lefebvre, 268.

${ }^{20}$ Lefebvre, 271. Here I am referring to Lefebvre's discussion regarding Vitruvius, who in The Ten Books on Architecture never addresses the city directly as a whole. Although he is speaking of the city, he viewed it as an aggregation of 'public' monuments 
and 'private' houses.

${ }^{21}$ Lefebvre, 287.

${ }^{22}$ Anthony Vidler, Warped Space, 144.

${ }^{23}$ Marshall Berman, All That Is Solid Melts Into Air: The Experience of Modernity (New York: Simon and Schuster, 1982) 28-9. Marshall Berman provides a further description of Herbert Marcuse's 'One-Dimensional Man' as it relates to the view of the people as a mass; otherwise refer to Herbert Marcuse, One Dimensional Man: Studies in the Ideology of Advanced Industrial Society (Boston: Beacon P, 1964).

${ }^{24}$ Lefebvre, 259.

${ }^{25}$ Berman, 106.

${ }^{26}$ Vidler, Warped Space, 51.

${ }^{27}$ Lefebvre, 311.

${ }^{28}$ The 'disnification' of space implies a careful construction and staged sense of place, where citizens are increasingly alienated from the possibilities of "unmediated social interaction and increasing control by powerful economic and social actors over the production and use of space." Such spaces are similar to theme parks in their removal from the everyday life and experience of the city, providing relatively unthreatening and 'clean' environments for entertainment. Examples include: London's Covent Garden, Baltimore's Harbourplace and San Francisco's Fisherman's Wharf. In many instances the desperate pursuit for an improved place-image has led to a purification of some of the more unpalatable and problematic internal spaces of the city, using methods such as intensified police presence, zero tolerance tactics, renewal and gentrification programs, highly specific cleanup schemes such as Business Improvement Districts (BIDS). The goal of these is to reorder the visible disorder of vagrancy, homelessness, panhandling, and prostitution that exist as a part of the city. See Michael Sorkin, ed., Variations on a Theme Park: the new American City and the End of Public Space (New York: Hill and Wang, 1992).

${ }^{29}$ See M. Christine Boyer, The City of Collective Memory: Its Historical Imagery and Architectural Entertainments (Cambridge, Mass: MIT P, 1994) for an understanding of the place of image within the modern city.

${ }^{30}$ Merrifield, 13.

${ }^{31}$ Karl Marx, Capital, Vol. 1, (Moscow: Progress Publishers, 1967) 812.

${ }^{32}$ See Alberto Pérez-Gómez and Louise Pelletier, Architectural Representation and the Perspective Hinge (Cambridge, Mass: MIT P, 1997) for more on architectural representation. 
${ }^{33}$ Lefebvre, 104.

${ }^{34}$ Lefebvre, 308.

${ }^{35}$ Lefebvre recognizes the success of the cubist depiction of the fragmented space of modernity. Although I believe that this is important, we must not only be able to depict social and spatial reality, but must be able to operate and respond to it.

${ }^{36}$ Merrifield, 116.

${ }^{37}$ Lefebvre, 317.

${ }^{38}$ Berman, 245.

${ }^{39}$ Berman, 148-9.

${ }^{40}$ Berman, 153. 

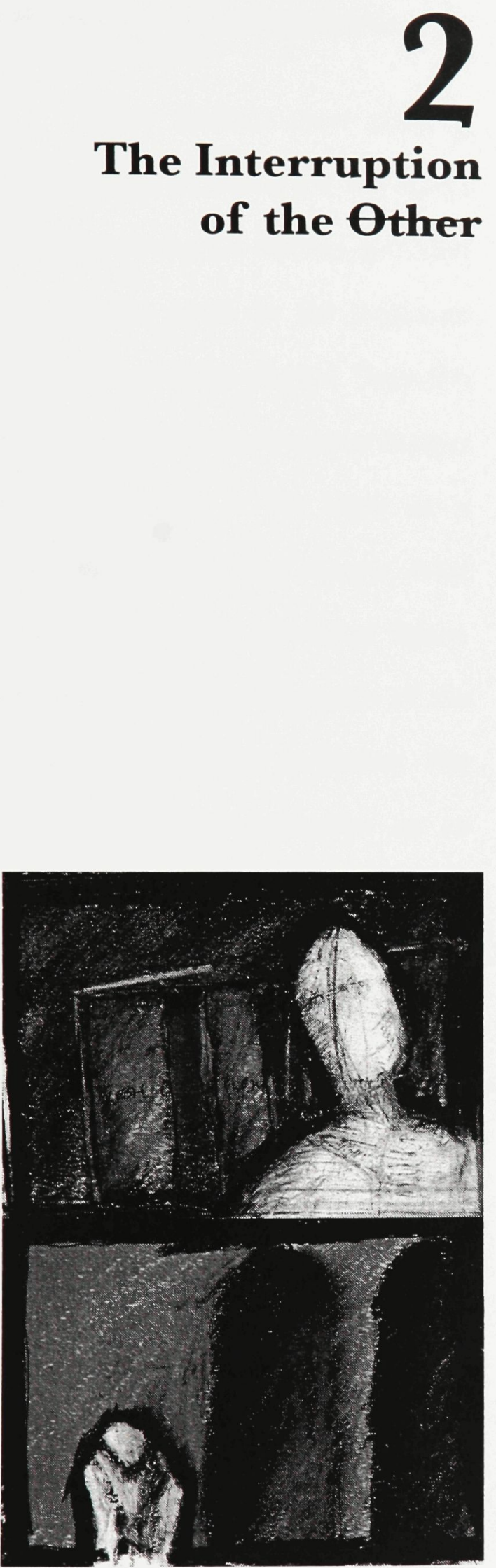

32: Experiencing the Frame: 'Framing' Storyboard Drawing

\section{Fantasy and the Other}

The experience of difference as an interruption in the abstract space of the city also constitutes the inter-subjective nature of public space, where the subject experiences the other who is (considerably) different from them. To comprehend this difference as it relates to space, there must first be an understanding of the subject's relationship to the other, and who the other is. What also needs to be addressed, then, is what form of otherness constitutes difference that is sufficient enough to cause a questioning of spatial reality in an existence made up of alterity, where "infinite multiplicity is the very medium of being itself."

When the topic of 'difference', or 'otherness' is discussed, usually there is an implicit or explicit indication of an ethical standpoint. An 'ethics of difference', where the other is recognized is an ideology that creates rights and tolerance towards the existence of difference in society. Emmanuel Lévinas, who in Totality and Infinity critiqued all of Western philosophy for its preoccupation with Being and universal totality at the expense of the 'Other', 
A Process of 40 Interruptions:

The Hunger Artist

Franz Kafka's short story, $\underline{A}$ Hunger Artist, as one of the few works published during his lifetime, provides the narrative basis for the proposed 'interventions' in the Market. Depicting the suffering of a professional hunger artist who fasts in his cage as a form of spectacle, the Hunger Artist presents a fictional hysterical figure, embodying the characteristics of the hysteric as artist and performer. The story portrays his imposition as an abject spectacle in the context and space of the city, while also playing

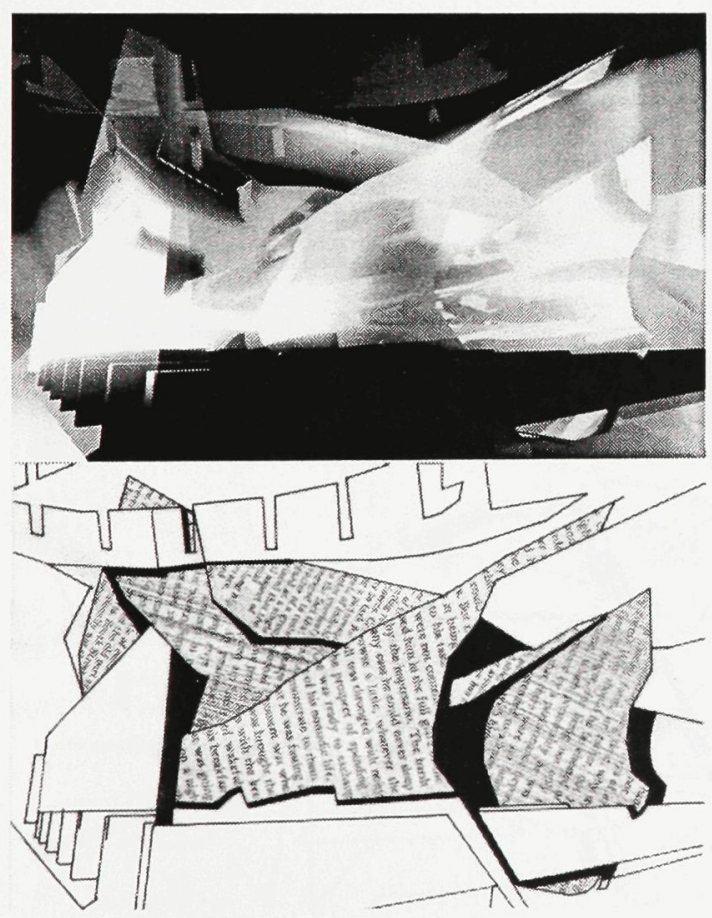

33: Site 23 - 'Flesh', Digital Collage and Ink Drawing on Mylar developed this form of ethics, thus foregoing philosophy for an ethical position. ${ }^{2}$ As a form of ethics, it is located in the subject's encounter with the strangeness of the other 'and his irreducibility to the I', which calls into question the normative view of the same, and in doing so recognizes the other for his difference. ${ }^{3}$ The French philosopher and psychoanalyst, Alain Badiou opposes such a view in his essay, Ethics: An Understanding of Evil. He believes that an ethics of universal truth is based upon the recognition of the same, and in doing so rejects the accepted argument that ethics should concern the other. His apparently antihumanist views are based upon an observation that the respect for difference "applies only to those differences that are reasonably consistent" with the subject's identity. ${ }^{4}$ Because of this, one can only be acceptably different by seeking integration in order to suppress their difference.

Both of these ethical views do not address the issue of infinite multiplicity, but rather the otherness of specific religious groups (the Jewish for Lévinas, and Muslim immigrants in France for Badiou). Rather, what is being addressed by discussing difference 
upon the metaphor of the suffering artist or religious martyr, depicting to the reader his internal angst caused by society's misunderstanding of his art. Unlike the cultural and clinical figure of the hysteric, whose experience has been mostly understood from within the institutional setting of the asylum, the story of the hunger artist presents the Symbolically limited body as a public spectacle in the context of the city and the public.

Although the Hunger Artist functions as the main character in the narrative, the other major figure, the

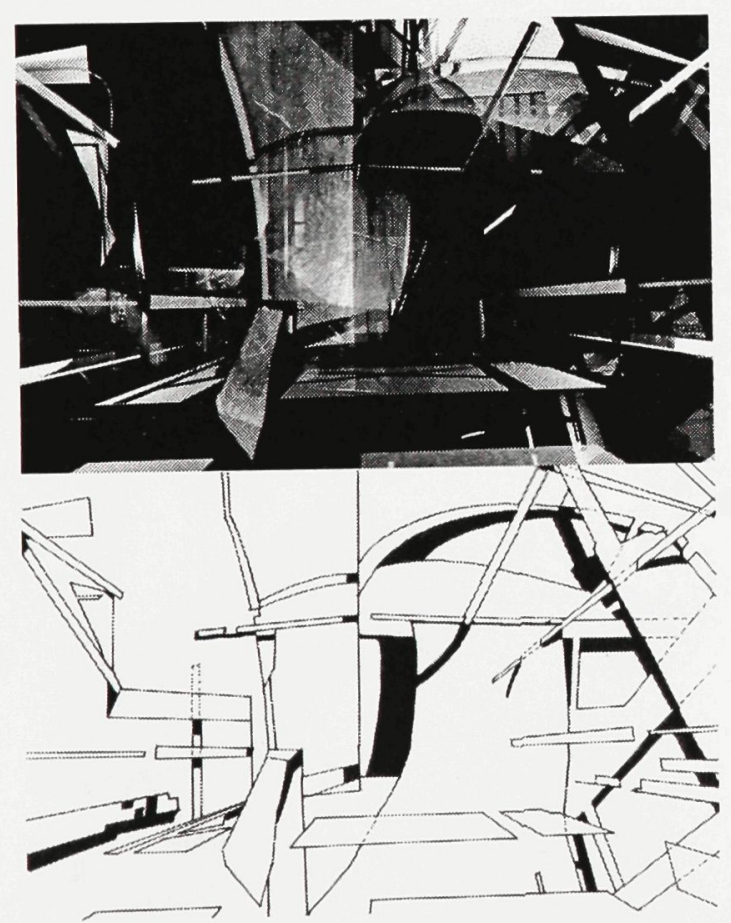

34: Site 24 - 'Frame', Digital Collage and Ink Drawing on Mylar in the context of relationships in space is not an ethical standpoint relating to tolerance in public space. Badiou has made it explicit that the other is not an ethical category, as there is a certain level of difference and acceptance that occurs between subjects. Rather than glorifying the nature of difference, what is of concern is the alterity that constitutes the experience of public space as a political experience. It is not an experience to be tolerated, but one that is entirely constituted by the confrontation and consequences that are implied by the inclusion of the dynamic experience, transcending difference and sameness through a foundation of shared experience. It is this experience as event that disrupts the apparent continuity of the abstract space of the city.

For Lévinas, the subject's relationship or access to the acceptance of the other addresses the issue of how he believes one is to be tolerant towards those who are different. He locates this access in the 'redoubled image' of self where the other is objectified by being viewed as 'me-myself-at-a-distance', thus allowing an "interiority accessible in its exteriority." This sense of self, which for Lévinas is constructed 
impresario or agent, imposes upon the artist the Symbolic Order. This figure is known in Lacanian terms as the Other. This individual limits the hunger artist's fasting to 40 days, which can be seen as a metaphor for Jesus' fasting prior to the temptation. Although we may attempt to view the fasting itself as the artists suffering, it is not in fact his art form that causes him suffering directly, as his reasoning is that he could never find any food that he liked, but is rather the alienation that occurs from being outside of the Symbolic, or being a

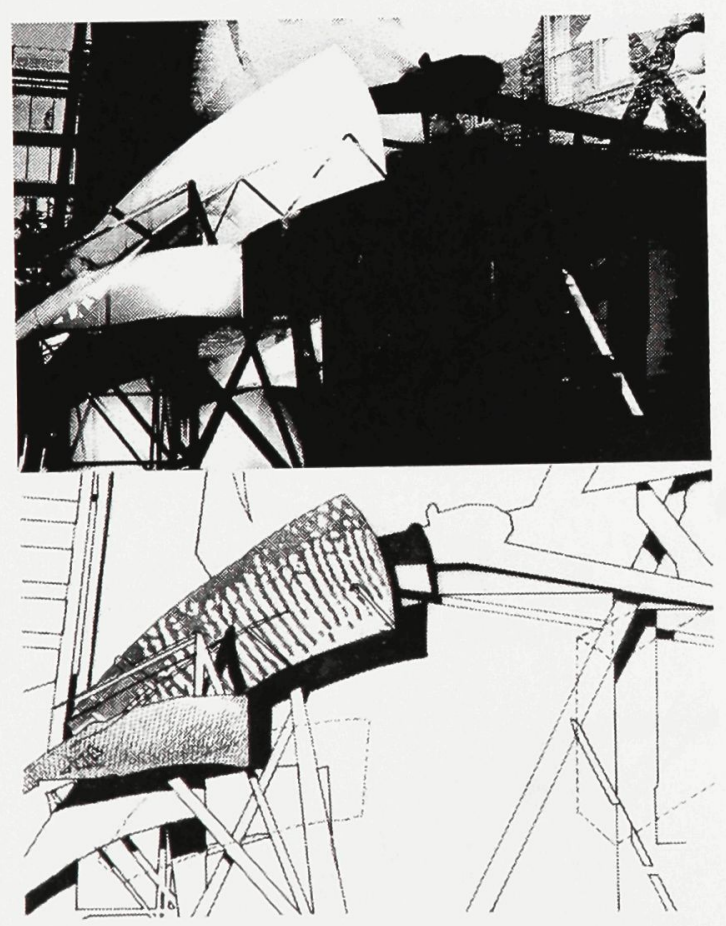

35: Site 25 - 'Discourse', Digital Collage and Ink Drawing on Mylar through identification with the other, exists as an interface with reality. It is a projected image, or frame, and is the means through which we communicate with another subject. But we are never able to "get to know what is behind the screen." ${ }^{\prime 6}$ Therefore, in this experience of the difference of the other the relationship is one of a self-relationship.

Through this there is no form of questioning that can take place, as it is a closed loop that does not allow for real or extreme forms of difference to be acknowledged. It does not act as an interruption to the continuity of abstract space, as it cannot allow anything foreign to alter ones perception. So then where does interruption take place in the intersubjective relationship? Such an understanding of the conflictual relationship may be achieved by looking at the cause of racism in the writing of Slavoj Zizek, an Eastern European intellectual who uses Lacanian psychoanalytic theory to discuss culture and politics. ${ }^{7}$ Although racism is referenced throughout his work in relation to nationalist views, he uses anti-Semitism as his key example. As the most distilled form of racism, it allows an understanding in relation 
The Lacanian Orders

From Tony Myers, Slavoj Zizek. 21-29.

The three Lacanian 'Orders' exist as a means through which to classify mental experience. The Imaginary, Symbolic and Real Orders act as 'screens' that permeate all mental acts, each with their own influence upon the individual.

\section{Imaginary}

The Imaginary Order is the Order through which the subject's ego is formed. Through the experience of the mirror stage the child identifies with the image of self or of another human. By giving the infant the image of a fully synchronized and united body, they achieve a coherency through which develops the ego. But this 'process of identification' challenges the very unity it seeks to impart as there is always an inconsistency between the sense of self and the image of whole to which the subject identifies. Because of this, one is ceaselessly attempting to reconcile the self, forever attempting to support the illusion of unity.

36: Definition of the Lacanian Orders
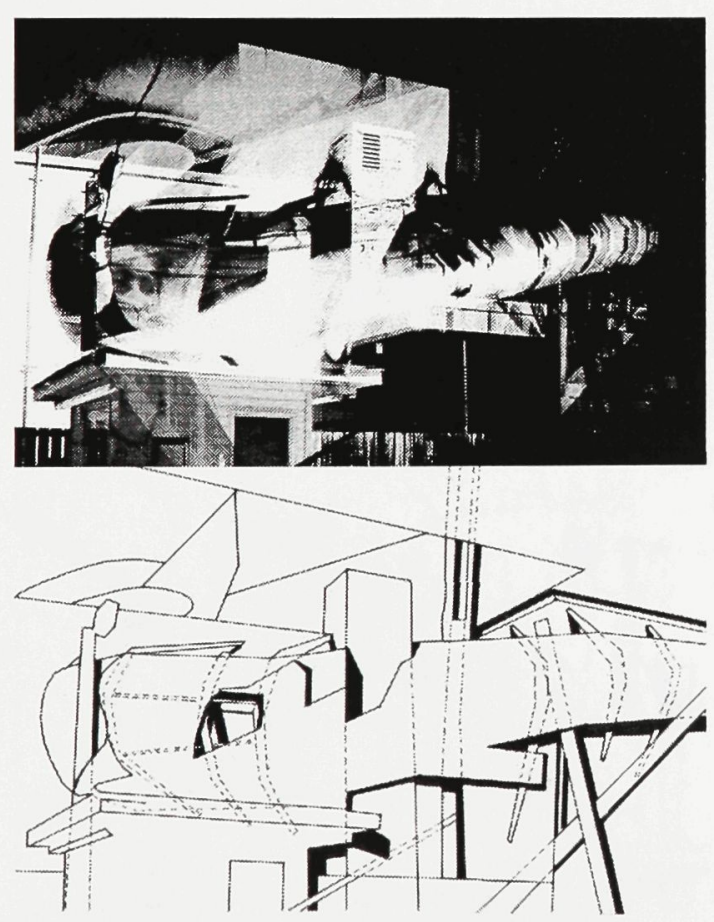

37: Site 26 - 'Impresario', Digital Collage and Ink Drawing on Mylar to the experience of the altogether other and difference in its lesser forms.

For Zizek, racism, as a prejudice or discrimination and superiority over a particular race, begins with the subject's question, 'What do you want from me?', addressed to the other. "This question arises from the arbitrary character of the Symbolic Order," as our roles within it are arbitrary since they are not "the direct consequence of our actual, real properties," and therefore there is a certain distance that we maintain towards our roles within it. ${ }^{8}$ In our relation to the other, this question, which Zizek writes in shorthand as 'Che vuoi?' invokes racism, as it is unclear as to what he really wants from us. In order to spare us the perplexity of not knowing what the other really wants, we create a fantasy to fill the void that is created by the question, thus providing us with a tangible answer. ${ }^{9}$ This fantasy is a created scenario, giving concrete form and meaning to the desire of the other, but in doing so creates anxiety within the subject due to racial, sexual, nationalistic, political, professional, or identity difference. It is through this created fantasy that one sees reality, and thus frames how one 


\section{Symbolic}

The Symbolic Order includes the impersonal framework of society, from language to the law, making up most of experienced reality. What binds it together is the signifying chain, which Lacan refers to as the law of the signifier. Based upon Ferdinand de Saussure's signifier and signified, Lacan's law of the signifier identifies language as differential in that a sign cannot be defined in isolation from other signs. Man is man because he is not woman. Thus, the second term fills the absence of the first term. Because of this, words only refer us to other words rather than to the world, cutting the subject off from the world and enclosing them in the closed system of language where experience is only comprised of words. This enclosed system is seen in how one signified object can have more than one sign associated with it. Through its differential nature, language carves up the world making it impossible assume a neutral position, which is how one develops their fantasy frame. Because the relationships between signifier and signified are arbitrary and unfixed, then the form of the Symbolic Order in which we live is neither permanent or necessary.

36 continued: The Lacanian Orders
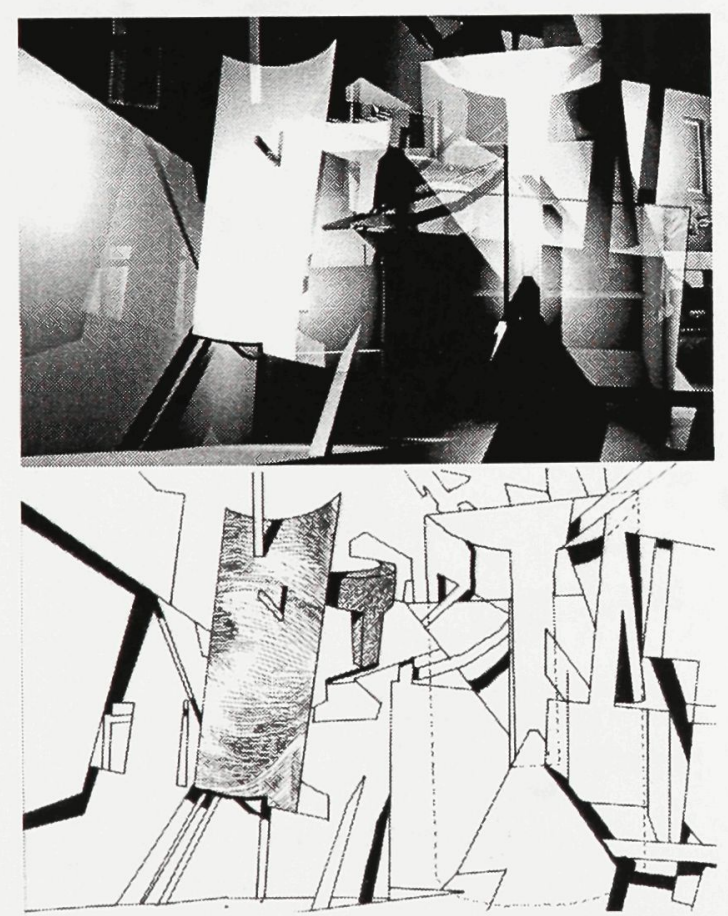

38: Site 27 - 'Discourse', Digital Collage and Ink Drawing on Mylar experiences those within it.

This fantasy is what Zizek terms as an inter-subjective relationship as it is produced by the interaction between subjects, but it is also what masks the inconsistencies of the Symbolic Order by providing an answer to the question 'Che vuoi?', thus maintaining its appearance as homogenous. These inconsistencies exist due to the signification of the body within the Symbolic. ${ }^{10}$ Through its admittance to the 'universal medium of language', we lose our bodily selves, thus limiting our relation to the indirectness of language, what Zizek refers to as castration. Language then causes us to become 'barred subjects', an empty subject barred from the body as the materialization of enjoyment, which is unrelated to the immaterial nature of the signifier. ${ }^{11}$ Therefore, in order for the subject to exist within the Symbolic Order, the enjoyment in the Real must be removed from the subject. This causes an inconsistency as it becomes structured around a lack of enjoyment. It is fantasy that conceals this lack, allowing for the subject to emerge within it.

In doing so, fantasy "designates an element which 'sticks out', which cannot be 


\section{Real}

The Order of the Real exists as those parts of life that are unable to be known, which is essentially everything since our understanding of the world is mediated through language. The Real then exists as both the world before and after it is carved up by language. Because one is unable to describe through language that which exists in the Real, it resists its symbolization. It is the Real then, which the Symbolic cuts up through signification, but it is also that which is left over as the excess from the process of signification, the object small a. 'Things' in the Real are meaningless in themselves, and are constantly interpreted in an attempt to symbolize them. In psychoanalysis, the traumatic cause of the displayed psychosis is seen to exist in the Real.

36 continued: The Lacanian Orders

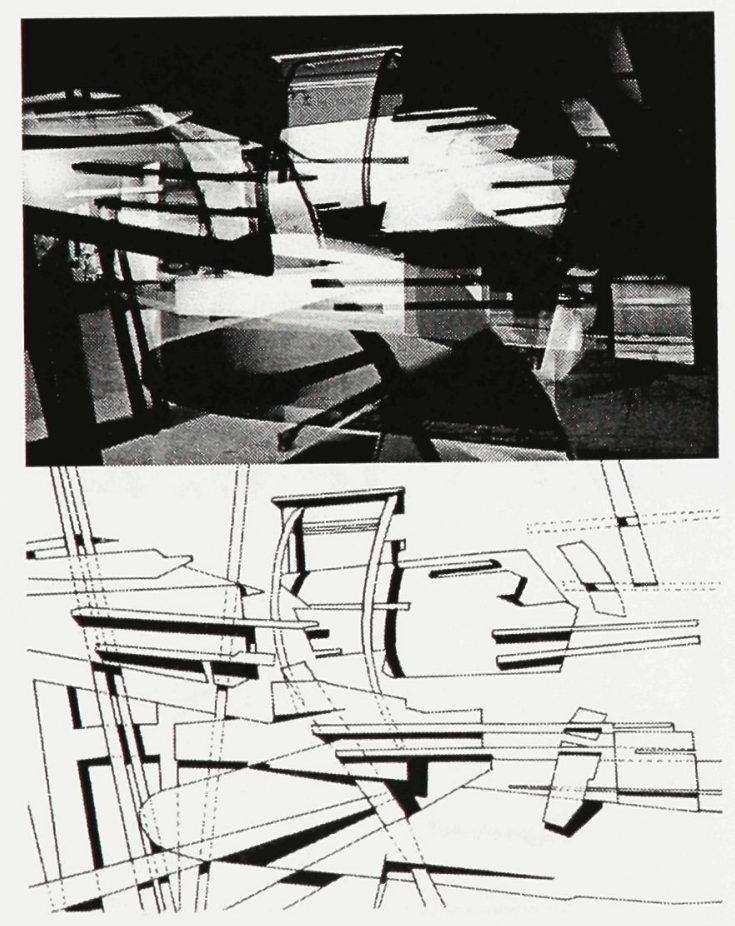

39: Site 28 - 'Impresario', Digital Collage and Ink Drawing on Mylar integrated into the given symbolic structure, yet which, precisely as such constitutes its identity." 12 The element of fantasy is a surplus knowledge that contaminates the gaze of the subject, making it impossible to look at a picture in an objective or neutral fashion. Because of this, fantasy acts as a representational frame around reality by creating a specific point of view through which one can only view the world. Therefore it is our fantasy frame that makes us into subjects within the Symbolic, as someone else may fill our roles within it, but it is our fantasy, our point of view, which makes us into unique subjects. This is also where the racist fantasy takes place as a conflict of fantasies in which we apprehend that 'the 'other' enjoys in a different way than 'us", where what bothers us is how he "organizes his enjoyment." It is also where the experience of the ethical decision takes place, by engaging a decision that is based upon the imposition of the 'superego' - as the imposition of social law - within the psyche. ${ }^{14}$

If our relation to the other, as well as the questioning of the Symbolic, is where the subject emerges as a self that is distinct from the Symbolic Order, then what consists of this 


\section{The Superego}

In psychoanalytic theory the superego is one of the three divisions of the psyche. As an only partly conscious part of the psyche, the superego represents the internalization of parental conscience and the rules of society, functioning to reward and punish through a system of moral attitudes, conscience, and a sense of guilt.

40: Definition of the Superego

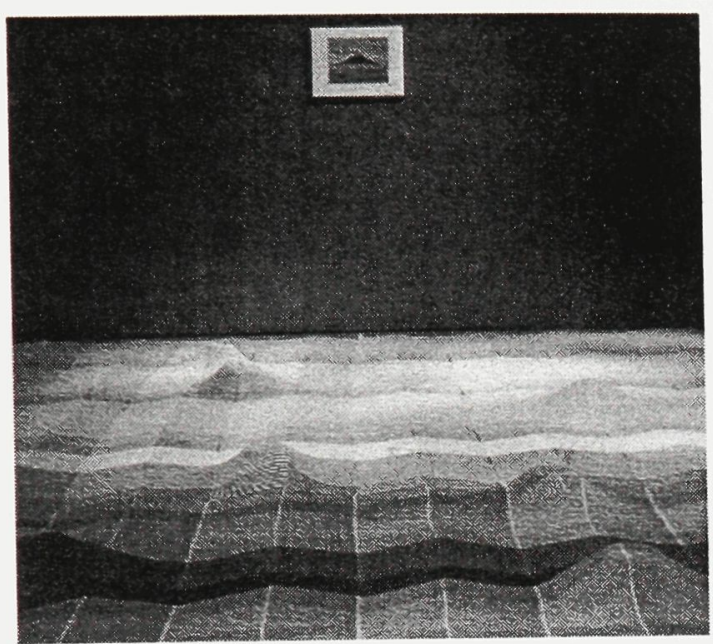

41: Abjection in art. Mike Kelley, Riddle of the Sphinx, 1971 from Rosalind Krauss, The Formless (New York: Zone Books, 1997) 249.
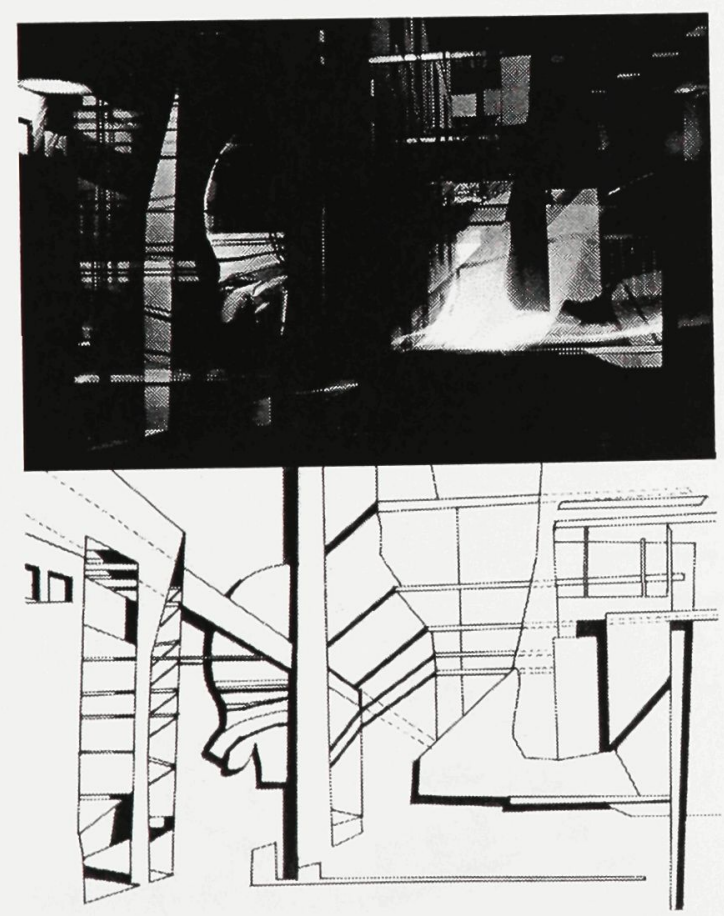

42: Site 29 - 'Frame', Digital Collage and Ink Drawing on Mylar 'other' to allow it to be seen as an extreme form of difference? In what form of otherness does a sufficient form of alterity exist for the subject to create a fantasy that saves them from symbolic castration and allows the possibility for this frame to be altered, but not destroyed (as it would therefore destroy the subject himself)? Such an extreme form of difference is located in the 'lumpenproletariat', or abject form of the other, who encompasses the cast-offs of society as well as those who exist outside of one's social reality, which allows for discrimination to exist in our reaction to them. ${ }^{15}$

\section{Abjection: Experiencing the Formless}

The lumpenproletariat, who Georges Bataille describes as an excluded non-class of the population in homogenous society, are excluded from the "processes of representation," $"$ and are defined by their abject nature. This is the most precise sense of the term: that which has been cast out of society or that "which has sunk to a low state or condition" $" 17$ within society, as is the case with racism (where a specific class is seen as abject). What is of importance to this understanding is not the lumpenproletariat itself 
non-symbolized or extreme form of the

other that is unable to be placed within

the Symbolic Order, and therefore a hysterical figure. The abject nature of the suffering image that the Hunger Artist portrays is also what causes the audience's fascination, presenting its image as one that is spectacular in nature.

As an image, the hysterical body of the Hunger Artist is limited in space and within the framework of the prevailing social structure by the imposition of the Symbolic Order. This limitation not only applies to a
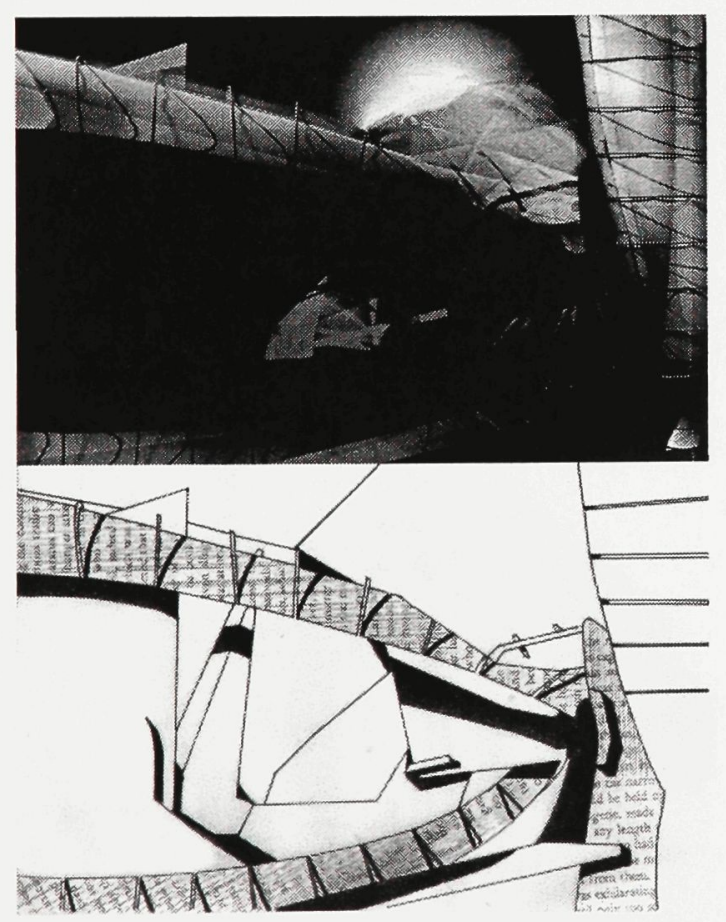

43: Site 30 - 'Flesh', Digital Collage and Ink Drawing on Mylar as a 'class', but the abjection horror that creates the fantasy frame, which is involved in our relation to it, as well as our inability to exclude it from reality. Rather than being a qualitative description of an object, the abject describes the subject's relation or reaction to that object as a condition of vile disgust. Julia Kristeva, in her essay on abjection, Powers of Horror, describes this relation as being something other than what we typically understand to be the cause for reacting to an object or body with disgust:

"It is thus not lack of cleanliness or health that causes abjection but what disturbs identity, system, order. What does not respect borders, positions, rules. The in-between, the ambiguous, the composite" 18

The object to which we attribute abjection is then something that acts with a certain disrespect for the law of the Symbolic, and it is through the instinctual reaction of abjection horror that we are able to come face to face with it, saving us from the risk of 'symbolic castration' or annihilation within the social network of the Symbolic Order. It can then be perceived as a safeguard, protecting us from recognizing the something as a thing, allowing us to maintain it as a fantasy outside of the reality 
restriction of actions within space, but also to the meaning or perception of those actions and the body itself by the viewing audience. The Symbolic Order creates for the viewer a frame through which they view and understand an image, but as a hysterical body, the hunger artist constantly acts outside of the symbolic structure, questioning its very basis by being unable to be placed within it. For the viewer this causes an abject reaction, one of apparent disgust mixed with intrigue, that makes them want to both turn away and to stare in amazement at

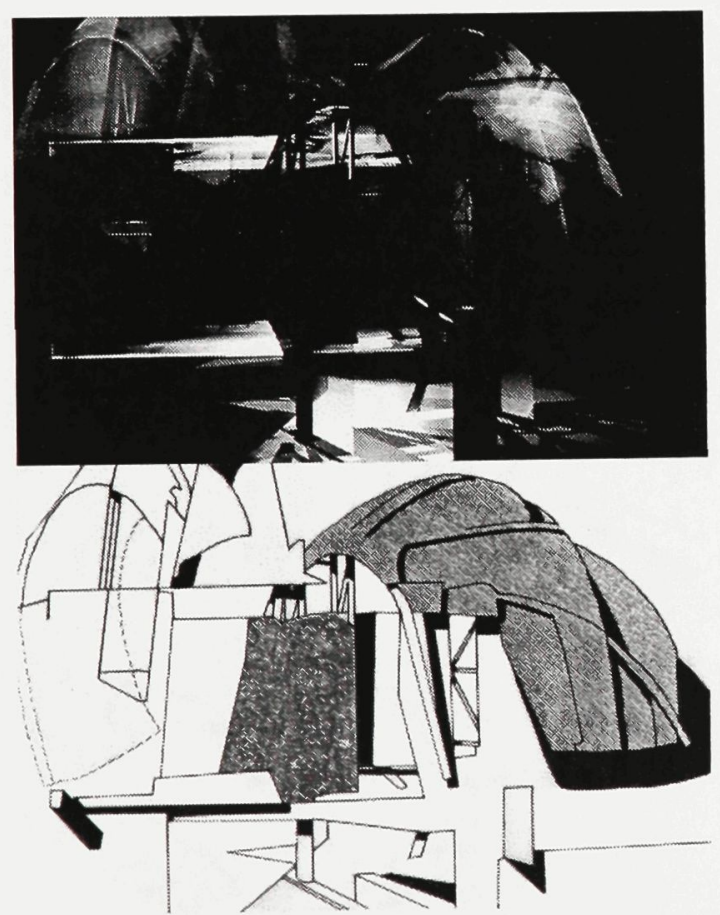

44 Site 31 - 'Discourse', Digital Collage and Ink Drawing on Mylar in which we exist, creating a distance between us and the object we perceive to be abject. This safeguard is that which creates the fantasy that frames reality, thus limiting our experience of the other as something that would otherwise denote the failure of the Symbolic. Without the safeguard of abjection the object would gain the ability to collapse meaning, dissolving the "firm and safe boundaries of the symbolic order," and destroying the meaning of the reality in which we exist. ${ }^{19}$ Because of this, naming takes on an important role in the experience of the abject as an element of the Real. Abjection takes the place of the other and allows us to place it within symbolized reality. ${ }^{20}$

The excessive nature of the abjected something as thing implicitly demands to be viewed. Although the viewer is horrified, they are also displaced in their daily existence, causing a certain fascination within the viewer. ${ }^{21}$ They are seduced to watch, to not turn away through the reaction of abjection to the foreign body, as the whole of oneself is put into a violent state of expulsion in order to banish the object and re-establish a state of homogeneity, or symbolic continuity. ${ }^{22}$ This occurs through the desire for 
the body's' ability to disturb order by existing in-between meaning. This experience is represented in the narrative-based interventions through the body as it is perceived as object, Impresario and cage as the Symbolic constraint of the body, and the audience as viewer.

The 'interventions' of Kafka's Hunger Artist, then, become a means through which to respond to these identified issues that occur in the experience of the extreme otherness of the hysterical body, existing as a representation of the experience

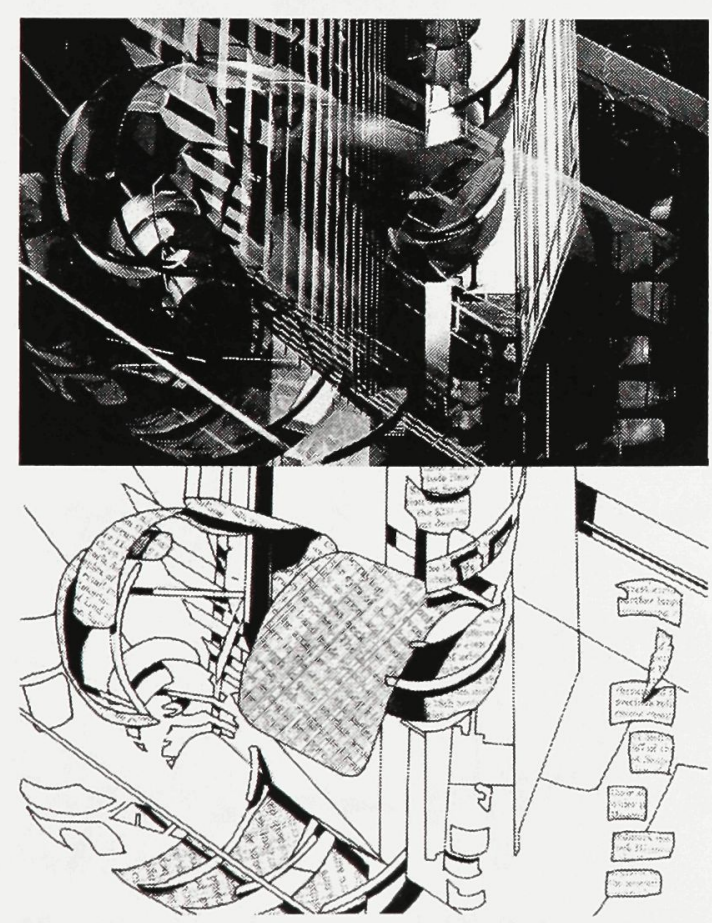

45: Site 32 - 'Flesh', Digital Collage and Ink Drawing on Mylar meaning, and as is the case in racism, an answer to the question it creates, allowing it to be given symbolized meaning.

Abjection as a reaction is most easily comprehended in the representation, where the creation of a mark is in and of itself a creation of something abject, representing something outside of our reality through the act of marking or creation. The 'plane of representation', in which the marks are placed, becomes a 'zone of marks' in that it is delineated from our reality through the use of a physical boundary, which in the case of a painting exists as the frame. This delineation through the use of a frame operates in a similar manner as the fantasy frame acts in the relation to the altogether other, creating a mask through which we view the other or object within our reality. Delineation between reality and what is being represented allows us to separate ourselves from it, creating a sense of fascination that is made up of intrigue, mixed with nausea, anxiety, disgust and repulsion. Thus racism is created through abjection, a reaction to the abject object or other that does not respect the borders of one's symbolized reality. 
of public space in the city. These

interventions occur as an abstract forty-point grid that is overlaid upon the area of the Market, and is analogous to the forty days of fasting to which the Impresario limits the Hunger Artist. By using the overlay of a grid upon a map, an abstract spatial understanding of the Market that has no specific relation to place allows the investigation of existing urban spaces to exist as being seemingly random (refer to appendix A).

The excessiveness of this number of interruptions in the city in the

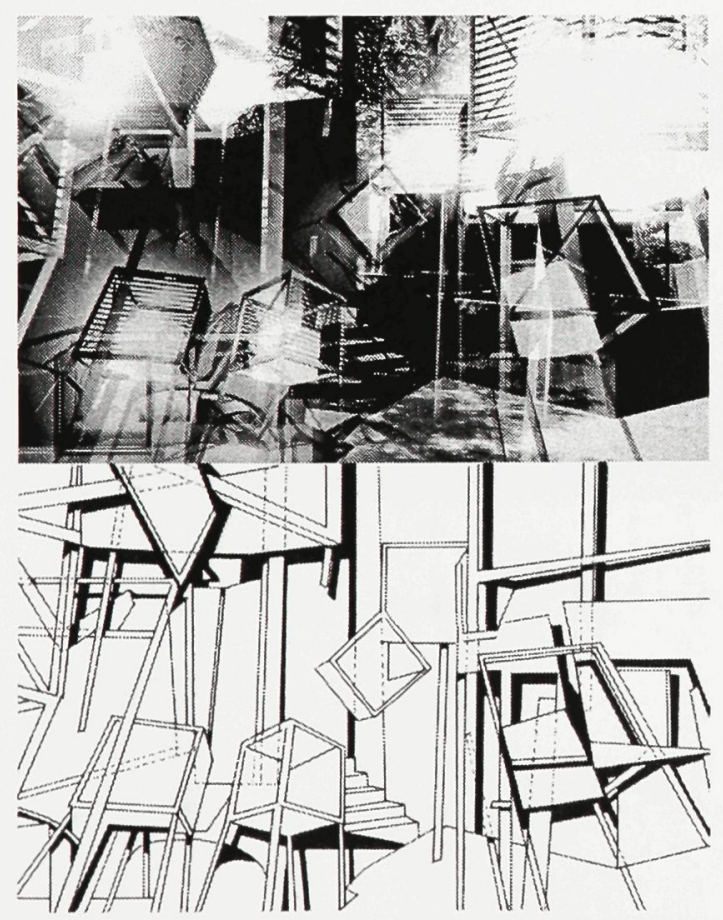

46: Site 33 - 'Impresario', Digital Collage and Ink Drawing on Mylar
Another form of what is perceived through abjection, and which is contained within the realm of marks, is the formless. As an object that is jettisoned outside the Symbolic, and therefore one that is non-symbolized, it is created through an operation of slippage in meaning, which allows for the creation of new meanings. Our relation to the formless object is one that is abject if we do not define abjection to be merely associated with what is dirt, obscene and scatological. Our relation to the formless is abject in that our reaction to it is one of disgust. $^{23}$

By stating this we are taking a different approach to the understanding of the abject in art, which Rosalind Krauss discusses in her conclusion to The Formless, when she states that the formless is opposed to abjection. What is lacking in her argument, and the reason for which she has difficulty in differentiating the two, is that she applies abjection to the object itself, which is not the case, but it is our reaction to an object or to what has been objectified. What she uses to describe the formless, spit and crushed spiders, are taken from Bataille, and can also be understood as objects that are 
architectural process relates directly to the excessiveness and ambiguity displayed by the hysterical body. In the act of creation, excessiveness releases the intervention's meaning from the author, removing any attachment that may occur due to the specific aesthetic qualities of a small number of images. In doing so it frees both the hand and mind through repetition as well as spatial and theoretical displacement. What is also created is a distinct architectural language that is separated from an existing spatial language.

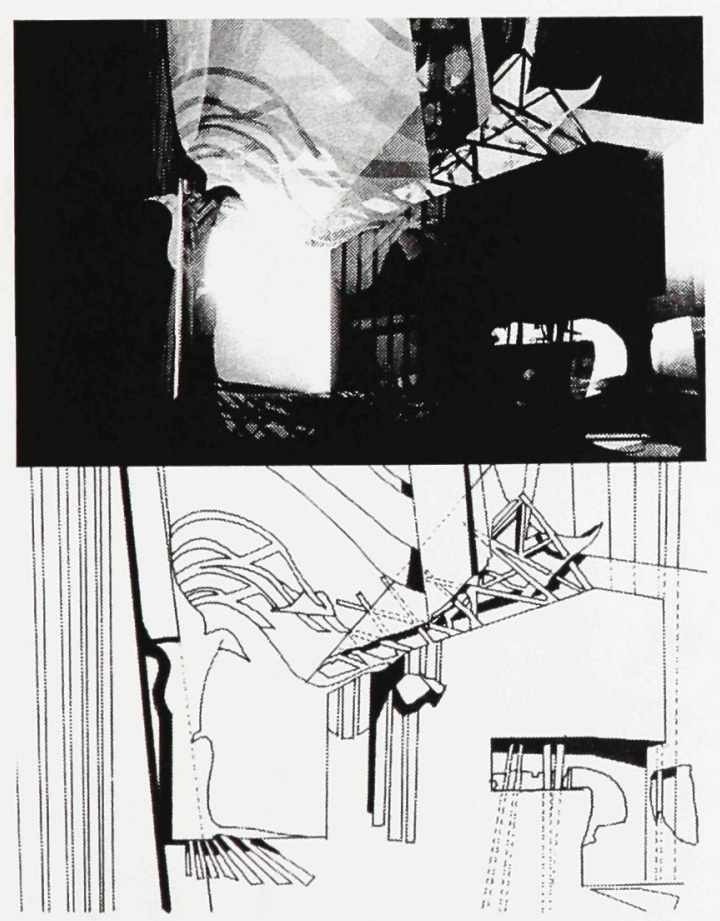

47: Site 34 - 'Frame', Digital Collage and Ink Drawing on Mylar abject in our reaction to them. Her difference in understanding of the nature of the abject is perhaps caused through the means that the abject has been represented in contemporary art, where there has been a focus upon the lack of cleanliness or low form of an object. This includes such things related to the maternal lining: blood, excreta and mucous membranes. The art to which she refers may be abject, but it only covers a small portion of what we have defined as such. Her collaborator in the book, Yve-Alain Bois makes this point in his introduction by noting that the contemporary works associated to abjection that were chosen for the exhibit on the formless "exceed the thematic horizon within which 'abjection' is enclosed at present..."24 [my emphasis] (Fig. 41). The focus of contemporary art's use of the abject is thus one limited to an association with the female and the wound. Defining the abject as a quality rather than a reaction limits it from encompassing the formless.

\section{Abjection: 'Suffering' the City}

If we release the discussion of abjection and formlessness from being solely limited to 
By responding to the existing context of a specific site located by these forty points, these interventions become possible interruptions in the everyday existence of the city, altering the spatial and programmatic relationships that exist by overlaying the relationships between the Artist, Impresario and audience within the sites. Each of the interventions then takes the essential qualitative and quantitative characteristics of the site, and through the use of digital modeling, both the site and the imposition of the Hunger Artist were modeled
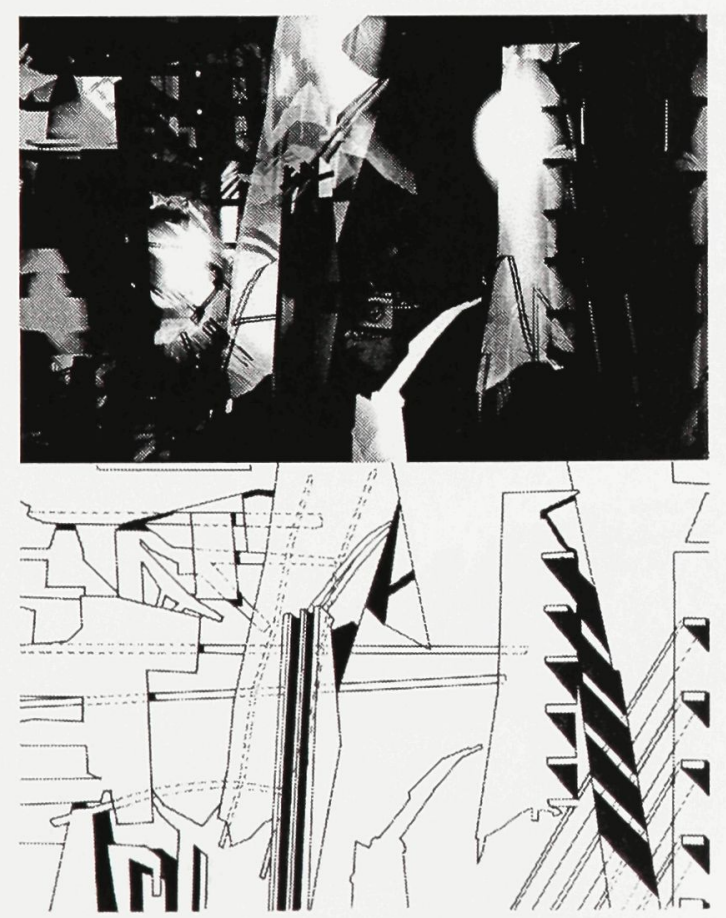

48: Site 35 - 'Impresario', Digital Collage and Ink Drawing on Mylar art as the production of 'aesthetic' objects and perceive it as an experience within everyday life, we are able to differentiate how abjection in the context of the city is differentiated from the abjection in art. At the level of the subject in the city the experience of abjection is one that is political, as an inter-subjective relation in society that occurs in both time and space, becoming a part of the 'incessant flow of history'. In this context the abject other as uncanny stranger includes those things that are excluded from representation, including the squatter, the panhandler, the vagrant, and the dissident. These forms of the altogether other disturb, erode, contradict, and ignore the continuity of social and physical boundaries that are set up to maintain spatial stability and its meanings within the city. ${ }^{25}$ Thus, display of the body in the context of the city is not a politically neutral activity, but draws together many issues relating to society as a whole.

At the spatial level, the experience of that which is non-symbolized occurs through the experience of those spaces cast-off from society and from abstract space as the prevailing spatial organization. These spaces are the contradictory 
and rendered, spatially and formally responding to the relationships (refer to appendix $A)$.

From these models, forty digital collages were created in Photoshop as a means to concretely represent these relationships, allowing for the identification of specific categorizations within each collage, while also representing the fragmented formal and qualitative nature of these spaces through a layering of material and space. These categories, based upon the existing three relationships included: Impresario as the existing
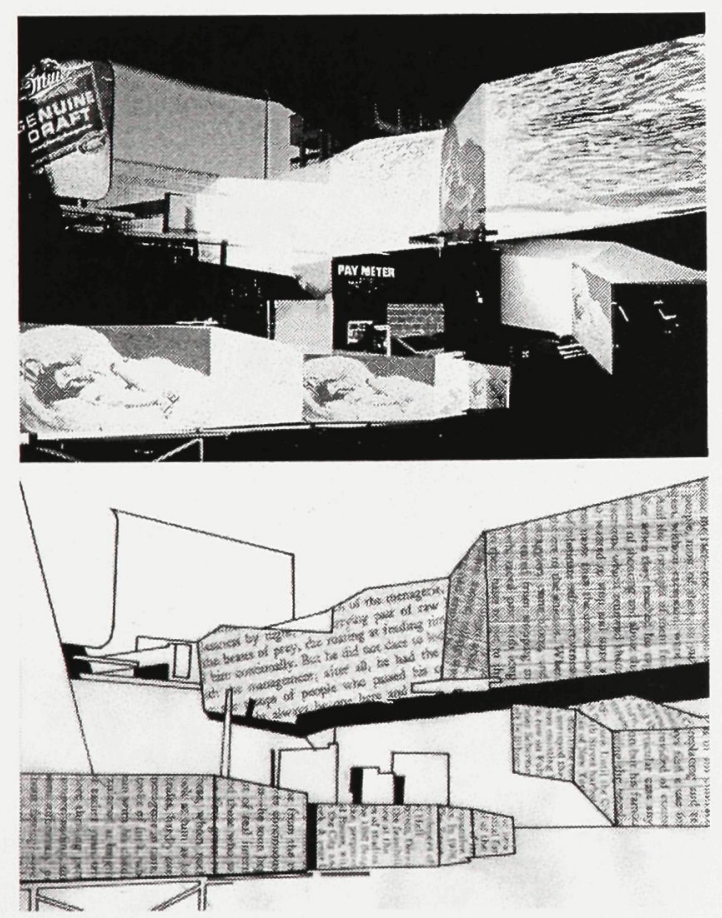

49: Site 36 - 'Flesh' Digital Collage and Ink Drawing on Mylar spaces of the city, the heterotopic spaces that point to the fragmented and contradictory nature of the city. And through their existence, they erode conventional boundaries, and as such they are tabooed by the imposed image of homogeneity within abstract space that masks its lack in continuity. These spaces escape the Euclidean nature of the abstract space of modernism, affirming its expression as the experience of the event that allows access to the Real. ${ }^{26}$ Thus, this event takes form as one that is violent, a conflict in the continuity of spatial experience in the city, and in doing so reveals the underbelly of abstract space in the city. ${ }^{27}$

As a celebration of difference, this experience of space as interruptive event is much like Georges Bataille's carnival, where the "I lives itself as loss," where "time's emptiness is experienced," and where bottomless guilt is rediscovered. ${ }^{28}$ This carnival acts as a gap in the homogeneity of society, a celebration of the "gaps and holes" in the individual, in space, and in society itself. It is not an affectionate relationship to difference, in that it is not only about pleasure and enjoyment, but allows for a suffered experience as well. This celebration 
symbolic structure, Framing as the gaze of the viewer, Discourse as the interaction with the other, and Flesh as the objectified and non-symbolized body of the other. Each of the forty collages was then identified as representing the spatial and material quality of a specific category, and from them forty ink drawings on Mylar were created over top of them allowing for both the form and relationships relating to the category to be focused upon.

Taking the collage as material and space and the drawings as form

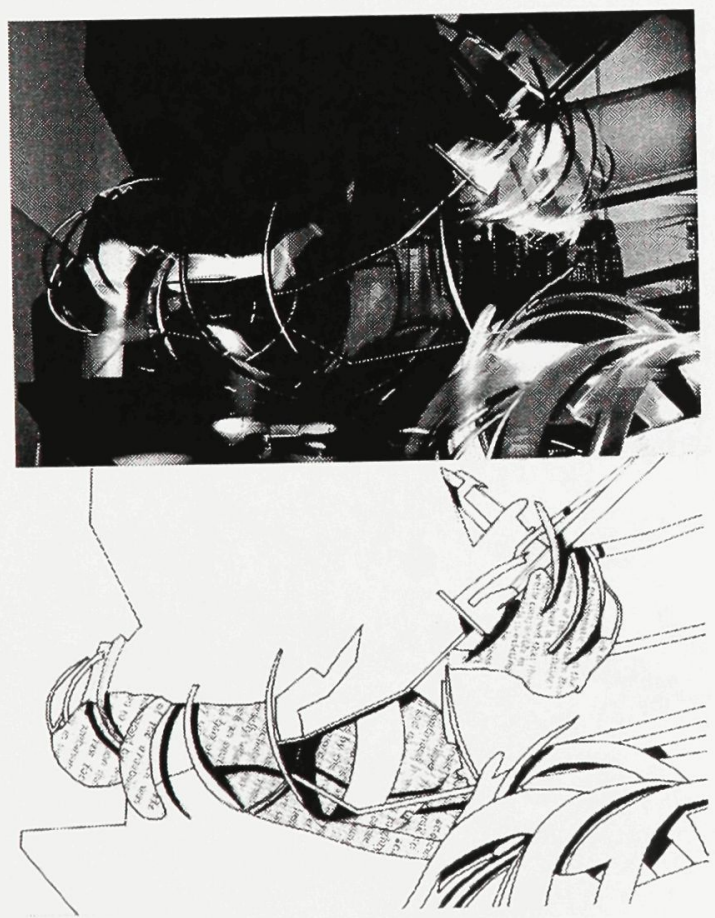

50: Site 37 - 'Flesh', Digital Collage and Ink Drawing on Mylar cannot occur without a loss, as it involves what is not symbolized to the individual and society. Thus, the experience of space becomes an experience of the shifting meanings associated with it, where a lack of meaning may have previously existed.

\section{The Excessive Otherness of Hysteria}

Through an understanding of abjection, there also exists a spatialized understanding of our relationship to the other, through which we can confront the social and political aspects that are present in authentic forms of public space. Due to the nature of abjection as an incredibly vast topic, dealing with the relations between subject and object or between self and other, there is a need to identify a specific example of the experience of abjection in inter-subjectivity that allows the issues of public space to be addressed through its displacement. ${ }^{29}$

As a contradictory cultural figure the hysteric addresses these issues through its existence outside of the Symbolic, allowing us to reduce the scope of abjection to those aspects that are characteristic in the hysterical body. In fact, the hysteric can be associated to the 
and relationships, both a physical and digital model were created for each of the categories, at once both distilling and representing the particular category. Although each model focuses upon and depicts a specific category, each of the relationships associated to each category exists within all of the models. By condensing the categories into singular representations, the models allow themselves to become the basis for creating a video installation that represents the experiential quality of public space.

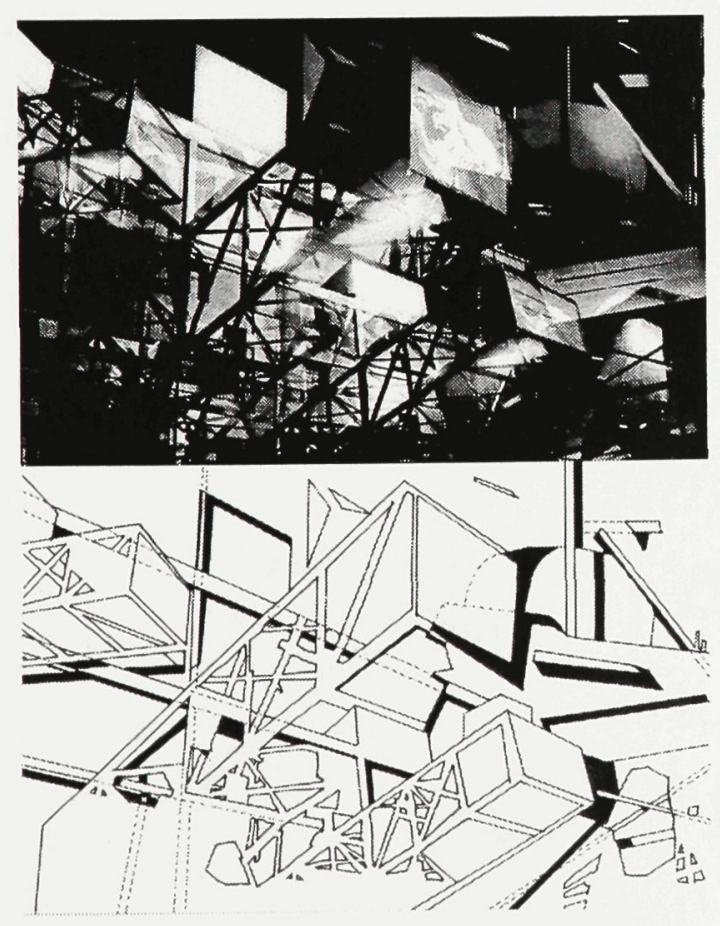

51: Site 38 - 'Impresario', Digital Collage and Ink Drawing on Mylar extreme form of the lumpenproletariat, cast out from representation in society, thereby allowing the relationship to the hysteric to be viewed as synonymous to the subjects' relation to the other. Also, this allows an investigation into the spatial conditions that are implied by the welldiscussed and specific nature of the hysteric, as well as its spatial representation through the mimetic communication of its body. Thus, in the investigation at hand, it is through the hysteric that the architectural and spatial relationship to the difference of the other can be addressed. This seems even more appropriate due to the association of hysteria, otherness and abjection to the female or maternal body of both creation and formlessness. To do so, it is important to recognize that we are basing our relation to the hysteric as one that is abject, which means that it must be differentiated from previous clinical and cultural uses (see Appendix B).

To define the relation to the hysteric as an abject one in this sense means that we must not take the hysteric as being limited to a female figure, as it has been done clinically, academically and culturally, but rather as a condition of the subject. Rather than revisiting 

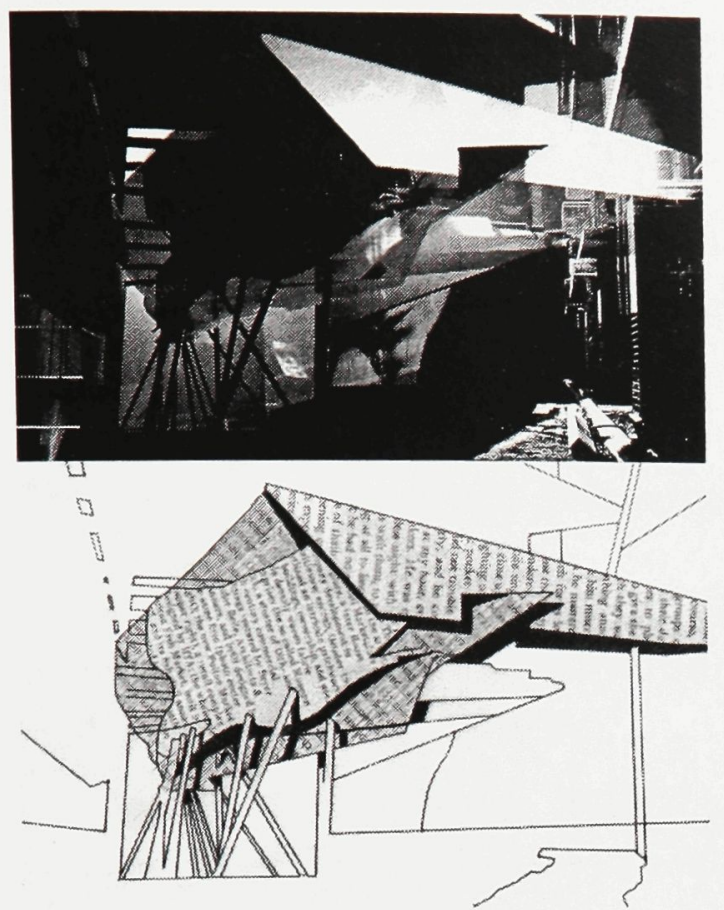

52: Site 39 - 'Flesh', Digital Collage and Ink Drawing on Mylar

the sexual origins or seductive nature of hysteria, it is more revealing in this context to view it for its traumatic and tragic nature. By taking into account the male hysteric we are able to understand hysteria for its subversive quality, as its unknown traumatic origin takes on the meaning of being the non-symbolized other whose expression of repressed symptoms acts in defiance of the law (of language, the father, society). In doing so the hysteric must be viewed for both its clinical and theoretical associations, as well as its cultural associations to the artist, philosopher, witch, and dissident due to the questioning of its placement within the Symbolic Order. ${ }^{30}$

When discussing abjection in relation

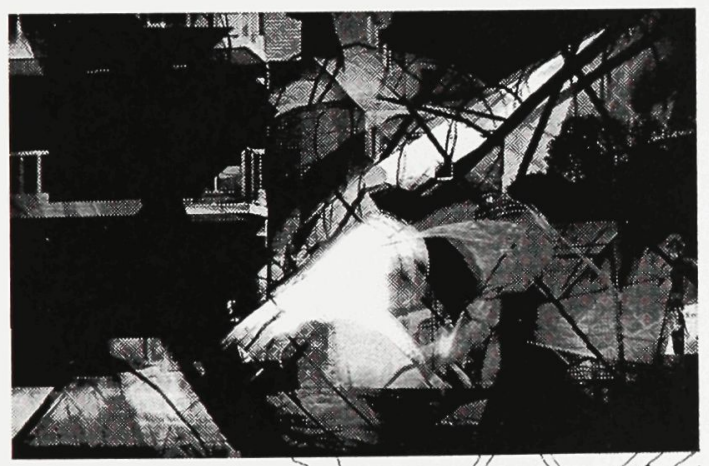

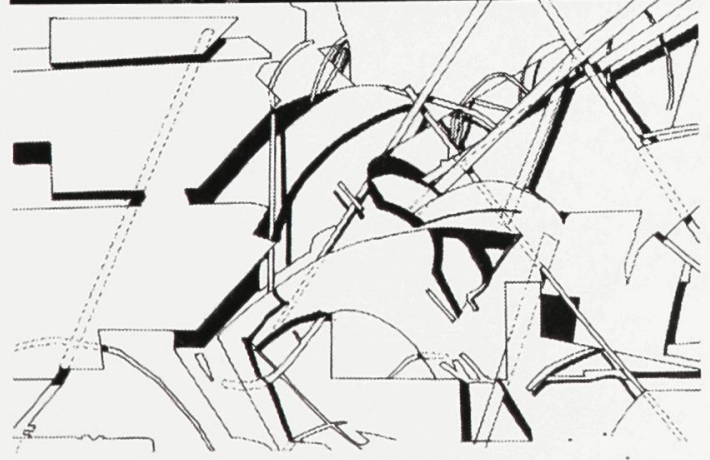

53: Site 40 - 'Impresario', Digital Collage and Ink Drawing on Mylar to the hysteric, it is not intended to imply that the hysteric's symptoms are caused through abjection. Rather, the repressed trauma from which the hysteric suffers is exhibited so that it can be cleansed of it, by 'vomiting' it out unlike abjection where there is an immediate denial of the object. ${ }^{31}$ It is this vomiting out, this expression of the non-symbolized trauma that exists in hysteria, which causes our relation to it to be an abject one. 


\section{The Interruption of the Other Notes:}

'Peter Hallward, "Translator's Introduction," Ethics: An Essay on the Understanding of Evil (New York: Verso, 2002) xxxvi. Also refer to pages 25-6 for Alain Badiou's discussion of issue of difference.

${ }^{2}$ See Emmanuel Lévinas, Totality and Infinity: an Essay on Exteriority (Pittsburgh: Duquesne U P, 1969) His critique is focussed upon Heidegger and Husserl whom Lévinas had studied under in Germany.

${ }^{3}$ Lévinas, 33.

${ }^{4}$ Alain Badiou, Ethics: An Essay on the Understanding of Evil (New York: Verso, 2002) 24 .

${ }^{5}$ Badiou, 21.

${ }^{6}$ Zizek, Organs Without Bodies: On Deleuze and Consequences (New York: Routledge, 2004) 118. This also applies to the subject himself, as the membrane which he presents is not only an 'active mediator', but also produces the effect of depth. This screen is derived from the development of self within the Imaginary Order. See definition in Chapter 2.

${ }^{7}$ I wish to note that I will be using Slavoj Zizek's interpretation of Jacques Lacan's writings throughout this thesis.

${ }^{8}$ Tony Myers, Slavoj Zizek (New York: Routledge, 2003) 93.

${ }^{9}$ Myers, 94 .

${ }^{10}$ Zizek states that fantasy is what conceals the inconsistency of the Symbolic Order. This inconsistency occurs when the body enters the Symbolic Order as a signified object. At this point it becomes castrated, losing the Real of our bodies, being "condemned to an indirect relationship with it via the medium of language." See Myers, 97.

${ }^{11}$ Myers, 97. Myers also notes that "not all enjoyment is completely evacuated by the process of signification (some of which persists in what we call erogenous zones), most of it is not Symbolized." 
${ }^{12}$ Slavoj Zizek, Enjoy Your Symptom! : Jacques Lacan in Hollywood and Out (New York: Routledge, 1992) 89. As quoted in Myers, 99.

${ }^{13}$ Myers, 105. Zizek suggests that to 'traverse the fantasy' we need to view its as a screen to the inconsistency of the Other. To traverse it we must see that there is nothing 'behind' it. It is fantasy that marks this nothing. This is also the secondary step in the psychoanalytic process, follows the interpretation of symptoms."

${ }^{14}$ Hallward, xxxvi.

${ }^{15}$ See Karl Marx, The Eighteenth Brumaire of Louis Bonaparte (Moscow: Foreign Languages Publishing House, 1950-1959) for his view of the lumpen proletariat as the cast-offs of society: "Alongside decayed roués with dubious means of subsistence and dubious origin, alongside ruined and reckless cast-offs of the bourgeoisie, were vagabonds, discharges soldiers, discharged jailbirds, escaped galley-slaves, swindlers, impostors, lazzaroni, pickpockets, bamboozlers, gamblers, maquereaux, brothel keepers, porters, literary hacks, organ-grinders, ragpickers, knife-grinders, tinkers, beggars - in short the whole amorphous disintegrated mass of flotsam and jetsam the French call la bohème."

${ }^{16}$ Krauss, Rosalind. The Formless: A User's Guide (New York: Zone Books, 1997) 246. Her discussion of the lumpenproletariat as abject refers to Bataille's political texts, especially "The Notion of Expenditure," Visions of Excess: Selected Writings, 19271939, (Minneapolis, MN: U of Minnesota P, 1985) 116-29.

17 "Lumpen." Merriam-Websters Collegiate Dictionary, $11^{\text {th }}$ ed. (2003).

${ }^{18}$ Kristeva, Powers of Horror: An Essay on Abjection (New York: Columbia U P, 1982) 4 .

${ }^{19}$ Niall Richardson, "The Queer Activity of Extreme Male Bodybuilding: Gender Dissidence, Auto-eroticism and Hysteria," Social Semiotics: 14-1 (April 2004): 60. This paper examines the practice of extreme, or competition bodybuilding as a form of hysteria through its association to gender confusion and lack of symbolization of the body in relation to the phallic, or Symbolic Order. He makes the connection between hysteria and abjection through the ambiguity of the body.

${ }^{20}$ Kristeva, 53.

${ }^{21}$ I will discuss this displacement through abjection further in Chapter 3 in its relation to the defamiliarization implicit in the experience of the uncanny.

${ }^{22}$ David Lomas, The Haunted Self: Surrealism, Psychoanalysis, Subjectivity (New Haven: Yale U P, 2000) 144.

${ }^{23}$ David Lomas makes a similar point regarding the relation of abjection to the formless in his chapter on abjection in the work of Dalí. See Lomas, 143-86. 
${ }^{24}$ Yve-Alain Bois, "The Use Value of "Formless", The Formless: A User's Guide (New York: Zone Books, 1997) 23.

${ }^{25}$ Anthony Vidler, Warped Space: Art, Architecture, and Anxiety in Modern Culture (Cambridge, MA: The MIT P, 2002) 135.

${ }^{26}$ See Vidler, "X Marks the Spot," Warped Space: Art, Architecture, and Anxiety in Modern Culture (Cambridge, MA: The MIT P, 2002) 123-32, for the criminal or violent nature of space in Bataille.

${ }^{27}$ By the underbelly of abstract space, I am referring to the heterotopic, contradictory, or differential spaces that exist due to the processes of abstraction. It is these spaces that exist "beneath" the space of abstraction in that they are veiled through the image of homogeneity that it represents.

${ }^{28}$ Denis Hollier, Against Architecture: The Writings of Georges Bataille (Cambridge, MA: The MIT P, 1992) xxiii.

${ }^{29}$ Displacement in this sense occurs as an operation that uses analogical associations as a generative process to discover new and alternate understandings and meanings to an issue that can be approached as a lens through which one can make.

${ }^{30}$ See Slavoj Zizek, "Hysteria, Certainty and Doubt," For They Know Not What They Do: Enjoyment as a Political Factor (New York: Verso, 1991) 141-56. Zizek uses Lacan's designation of Hegel as "the most sublime of all hysterics" for a basis to examine the proximity of Hegel and Wittgenstein through their use of the procedure of 'staging'.

${ }^{31}$ Kristeva, 45. 

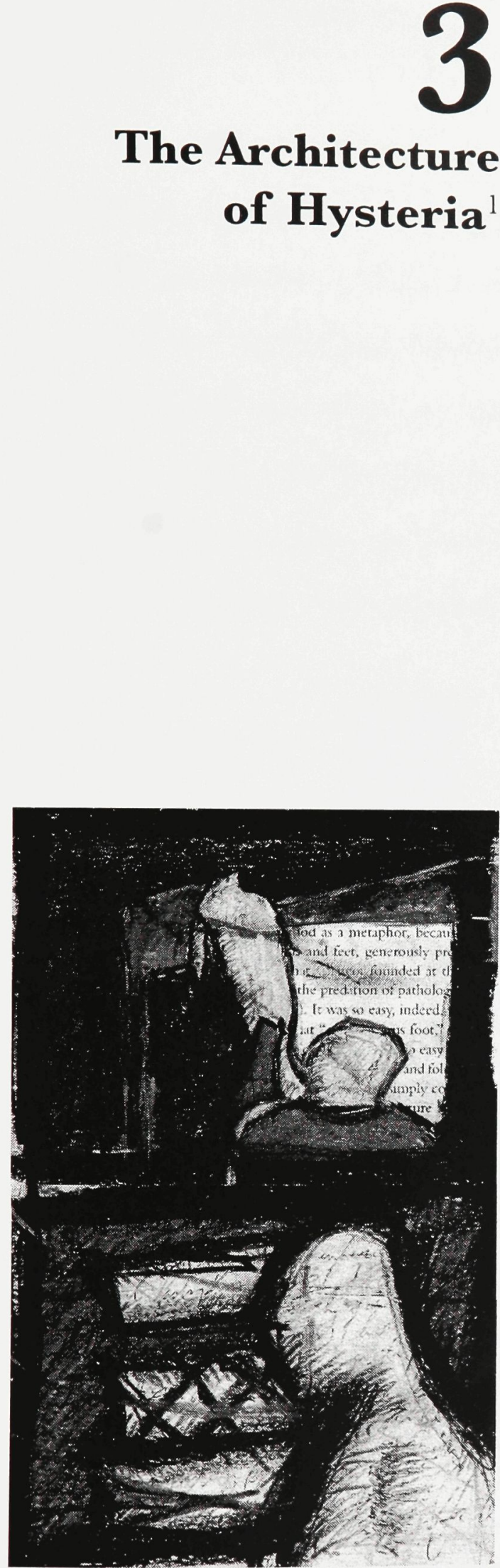

54: Inhabiting the Frame: 'Discourse' Storyboard Drawing

\section{A Marked Spectacle in the Symbolic}

In its act of creation, the hysteric externalizes, or converts its repressed trauma into physical symptoms, where the interior 'reality' of the original trauma becomes visible through its external representation (exhibiting, experiencing and mimicking various culturally accepted forms of physical illness for no logical medical reason). This act of mimetic creation has been used as a metaphor for making, as well as the "androgynous nature of the creative process" due to the fact that the un-signified psychic content, which is analogous to the artists imagination, is 'converted' into a signified medium (painting, architecture, writing, etc.); a form of language. But we are not concerned here with the hysteric as a metaphor for creating, although through this same metaphor, an architectural process could be discussed as one that is hysterical. It is in identifying our relation to the hysteric that will allow us to view architecture's relation to a confrontational experience of difference in space.

\section{The external representation of} symptoms through conversion, as a means of 
The Experience of Publicness:

Creating Place in the City Through Interruption

A video entitled The Architecture of Hysteria culminates the 'hysterical' process undertaken to investigate the relationships inherent in experiencing the body of the hysteric in space, and therefore the public experience of the city. Based upon the previous investigations,

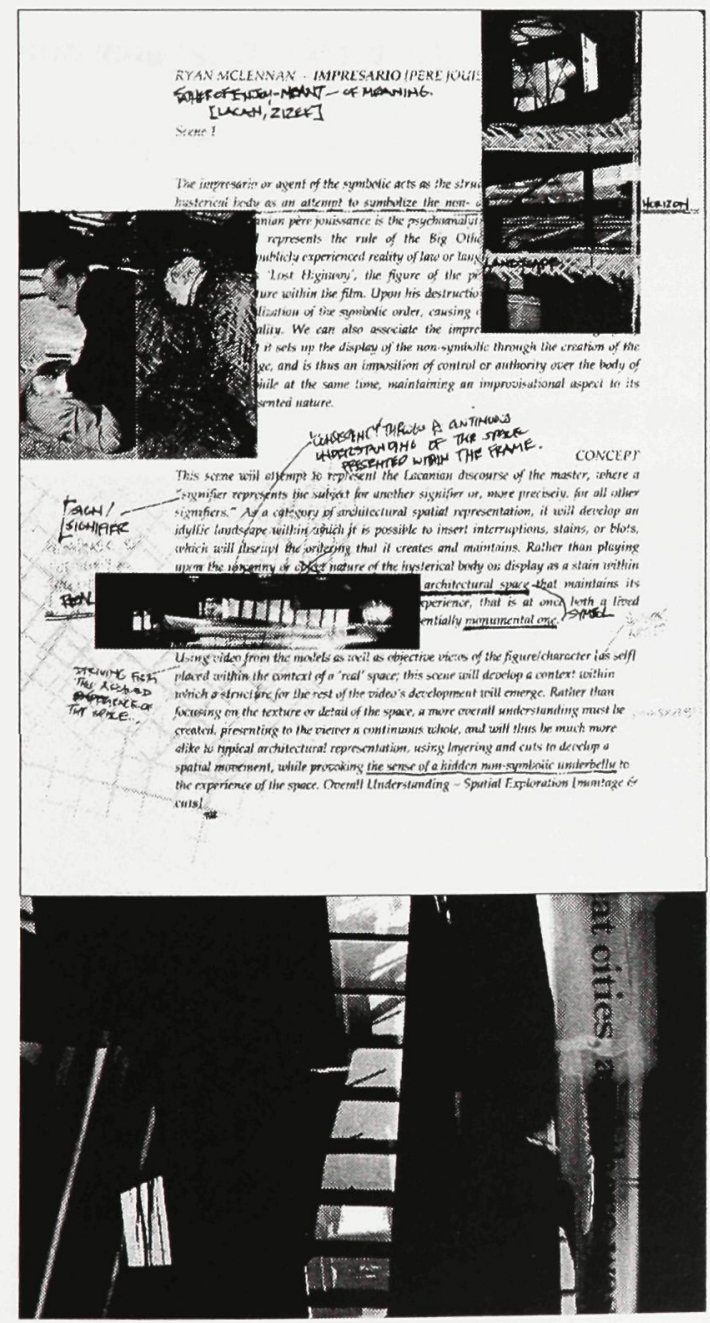

55: Impresario - Script Collage, Video Still creating, is the hysteric's mark. These marks act as a language of signs or 'indications', leaving their visible 'impressions' on the body as a canvas, and therefore point to the pain involved in the original trauma. Consequently the body becomes a 'zone of marks', which in painting is referred to as a 'plane of representation'; an optical device experience by the viewer indicating a reality that exists beyond it, as architectural theorist and professor Donald Kunze explains in his essay Marks of the Abject Artifact. ${ }^{3}$ For Kunze, this zone and the marks it contains are abject as they are 'cast off' from reality through the creation of a physical boundary that frames or limits the mark from contaminating an unmarked us. This boundary implies that there is a distance, and therefore a spatial attribute to abjection. Distance is then "the means we have of distinguishing ourselves from what we would avoid," and is what allows for us to avoid it in its actuality. ${ }^{4}$

When this boundary or frame, as a form of distinction, becomes violated, destroyed, or removed a 'zero state of meaning' ensues. The "representational meanings of the abjected work" - in the case of the hysteric, the body as a visible 
and as a part of the architectural theoretical process, the video contains four scenes, each representing and addressing one of the four previously identified categories and their specific issues: Impresario, Framing, Discourse, and Flesh. The video was created for a projected installation within the Market, furthering the spatial investigations by reinforcing the issues of image, spectacle, and publicness. In doing so, the previous investigations take on a political and especially speculative nature, questioning existing typologies and understandings of public space in the

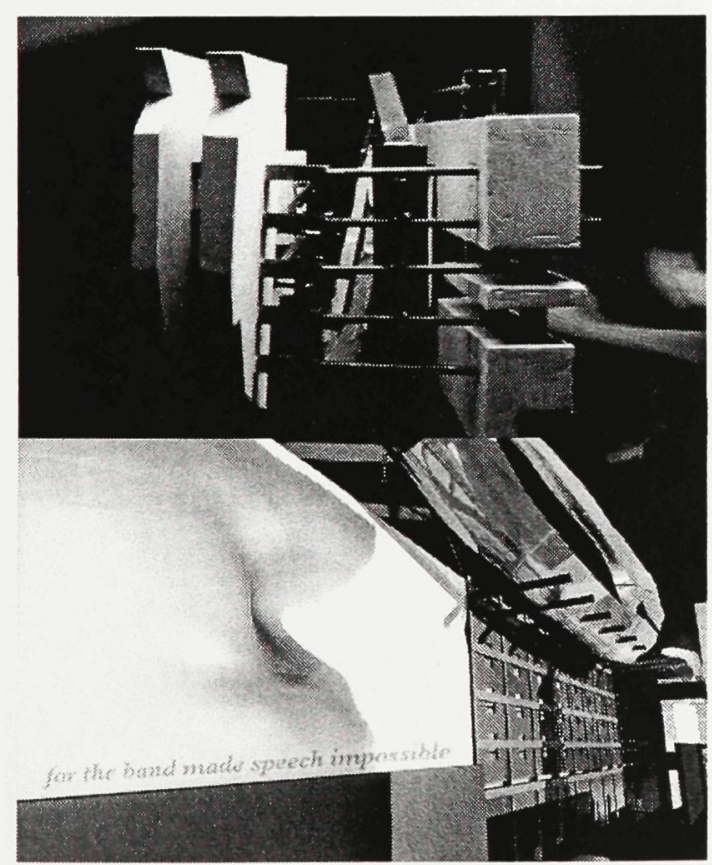

56: Impresario - Model, Video Still sign - "are de-stabilized and the semantic stability of surrounding 'reality' is equally unsettled", thus calling into question the semantic stability of the Symbolic Order (the symbolized reality in which we exist through the law of language). ${ }^{5}$ As a mark, this zero degree of meaning is defined through an absence of meaning, derived from its context. In architecture, such an absence can be seen in the physical absence of an element in an architectural language that is an indicator of what is 'normal', such as the lack of mouldings on Adolf Loos's stripped façades. ${ }^{6}$

A form of abjection in architecture (as the making of marks) comes through the experience of a shift in scale, one of relative difference to reality, which causes it to be experienced as abject, and thereby separated it from our reality. In this difference it embodies either more or less meaning than it should. Kunze notes that this is typical in the aspiration for buildings to act as a microcosm, an enclosed reality or where "the part stands for the whole," known as collation. ${ }^{7}$ Such an experience of abjection can also be found in the enlargement of an object to architecture, as a grotesque deformation and distortion of something much smaller. 


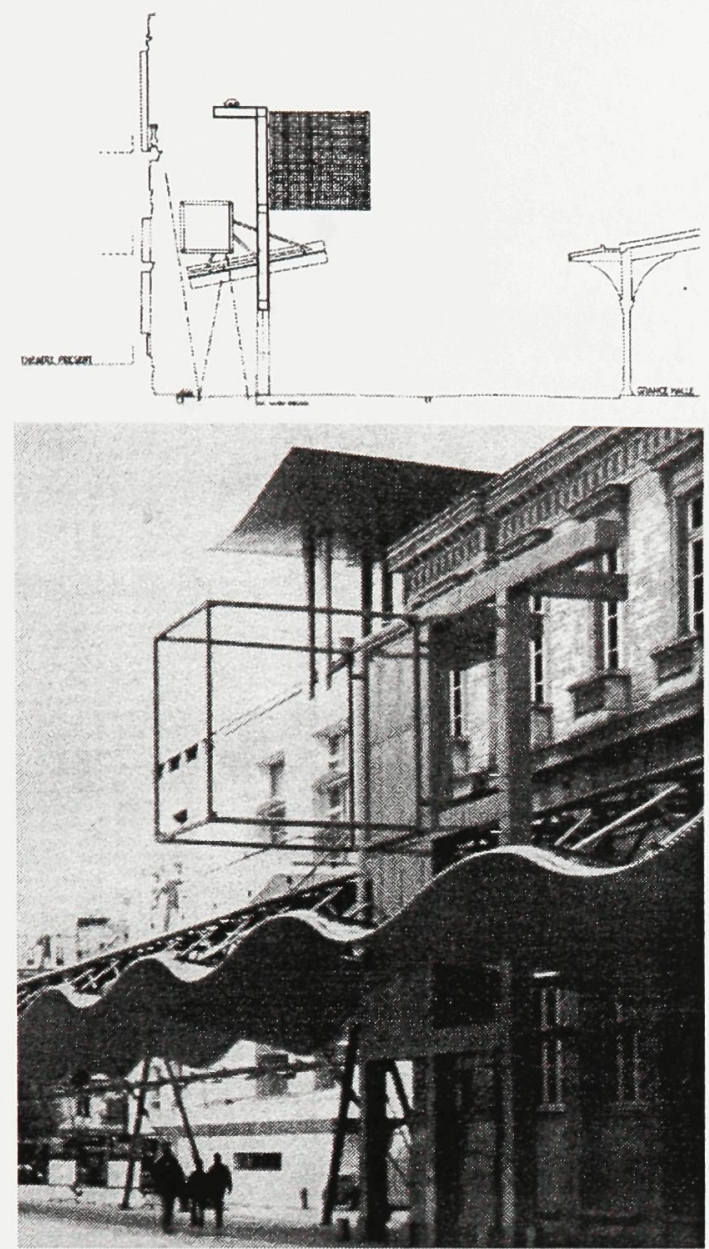

57: Bernard Tschumi, Folie L8 (No Program) from Event-Cities 2 (Cambridge, MA: MIT P, 2000) 198-9.

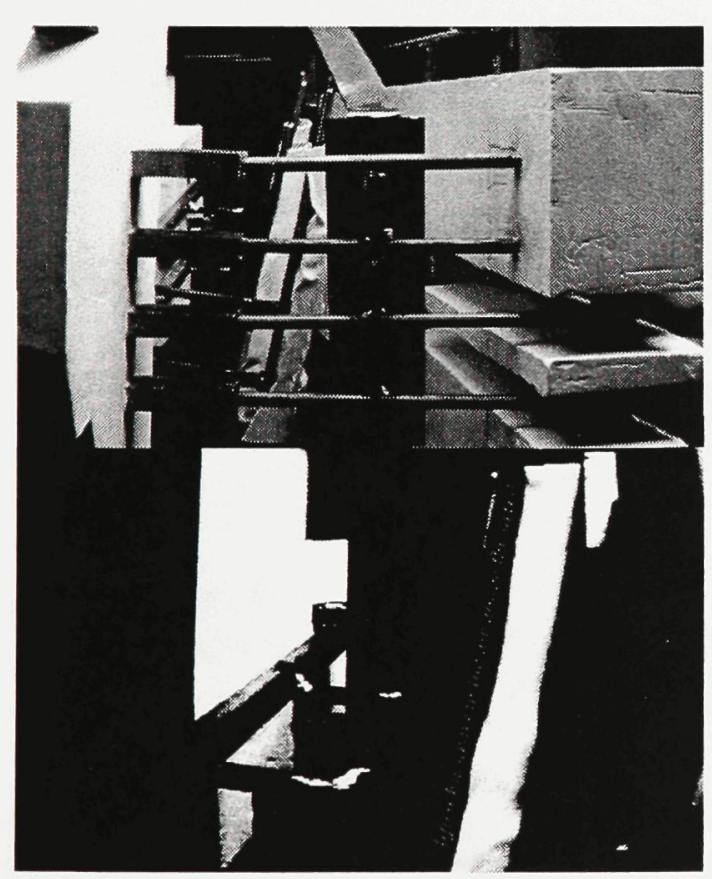

58: Impresario - Model, Video Still
Such an example of can be seen in Bernard Tschumi's Parc la Villette, where 'toys' "are enlarged to the point of being monuments." ${ }^{\prime 8}$ Because of this scale shift, Tschumi's folies exist without symbolic meaning, as he suggests that they are signifiers without signifieds; marks without meaning (Fig. 57, 59, and 60). By holding no symbolic connotations, the folie exists as a means to destabilize meaning. In doing so, they "put into question, dislocate, destabilize or deconstruct the edifice" that is the architectural design of the park. ${ }^{9}$ This lack of symbolic meaning is further enforced through the absence of, or logical connection to program in the design of each folie. Rather, the use of the 'cubes' is left open to chance, to invention and transformation, and in doing so chance will define the programs through event, thus both anticipating and risking its existence as architecture. In lacking a defined program, the folies lack apparent usefulness as architecture, which is what normally creates a bounded condition or frame its experience. By "assigning it a mundane role," it avoids becoming art as a mere representational mark. ${ }^{10}$ Through the removal of program from the experience of the folie as 'architectural object,' there is a shift in 


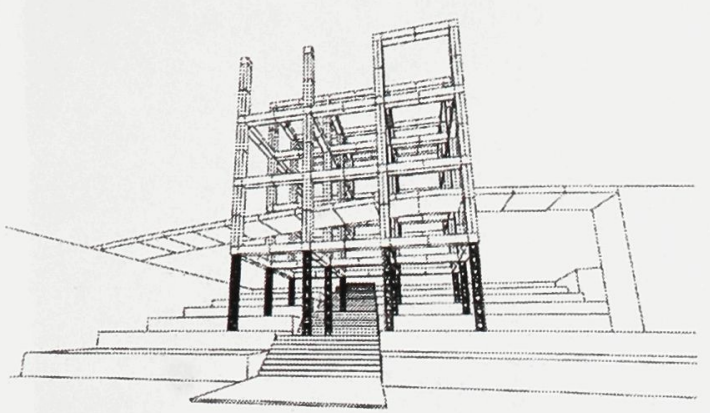

59: Bernard Tschumi, Folie R4, "Folies are like a mirror: you project your own fantasy on them," from Event-Cities 2, 131.

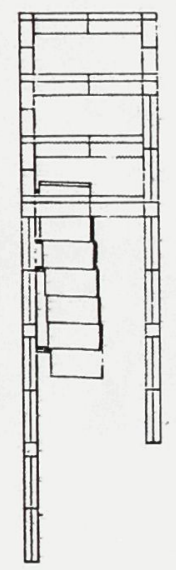

60: Bernard Tschumi, Folie N8 (No Program), from Event-Cities 2, 197.

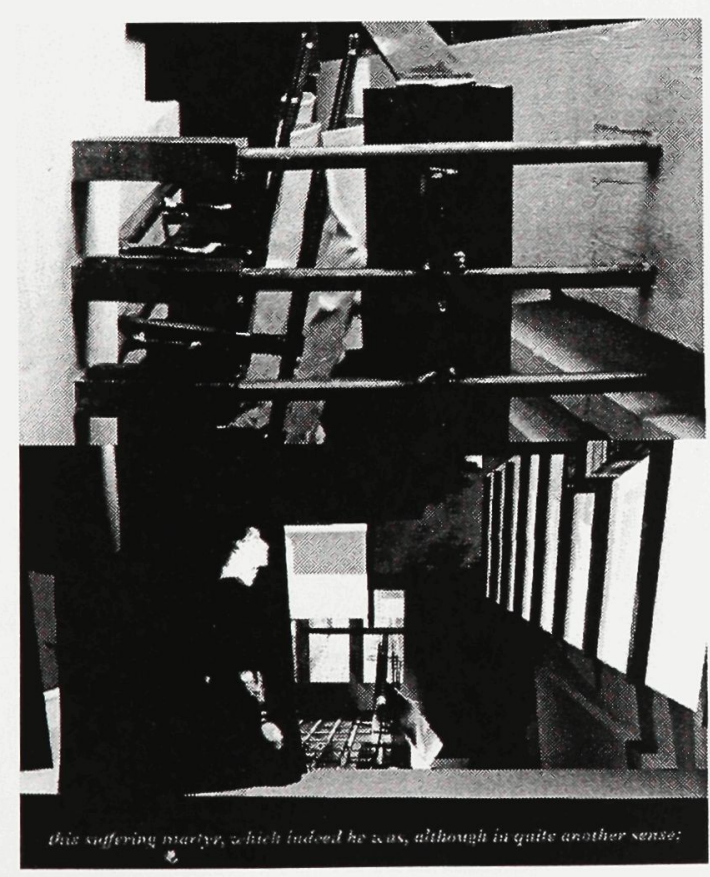

61: Impresario - Model, Video Still perception that occurs to avoid it from existing outside of the 'zone of marks', shifting the frame within which we view the object in order to limit its disturbance to merely one of anxiety. As understanding is shifted and reframed, we can no longer understand it as architecture, or as building; instead it becomes art or monument. Therefore, as Peter Eisenmann expresses, the object no longer needs "to look ugly or terrifying to provoke an uncertainty; it is now the [symbolic] distance between object and subject... which provokes this anxiety." I

In hysteria, the distancing from the objectified body occurs because it has no body, but instead possesses only a body made up of represented symptoms rather than organs. ${ }^{12}$ It exists only as an image, a symbolic image that points towards the original memory, comprised of the repressed trauma. This image-symptom projected by the hysteric is mimetic; it imitates culturally accepted forms of physical distress, and as a result exhibits potentially plural symptoms of disease. In doing so hysteria becomes an unconscious form of simulation. ${ }^{13}$ Through imitation, it en-acts a lie, its body becoming a player in a mimetic theatre of 


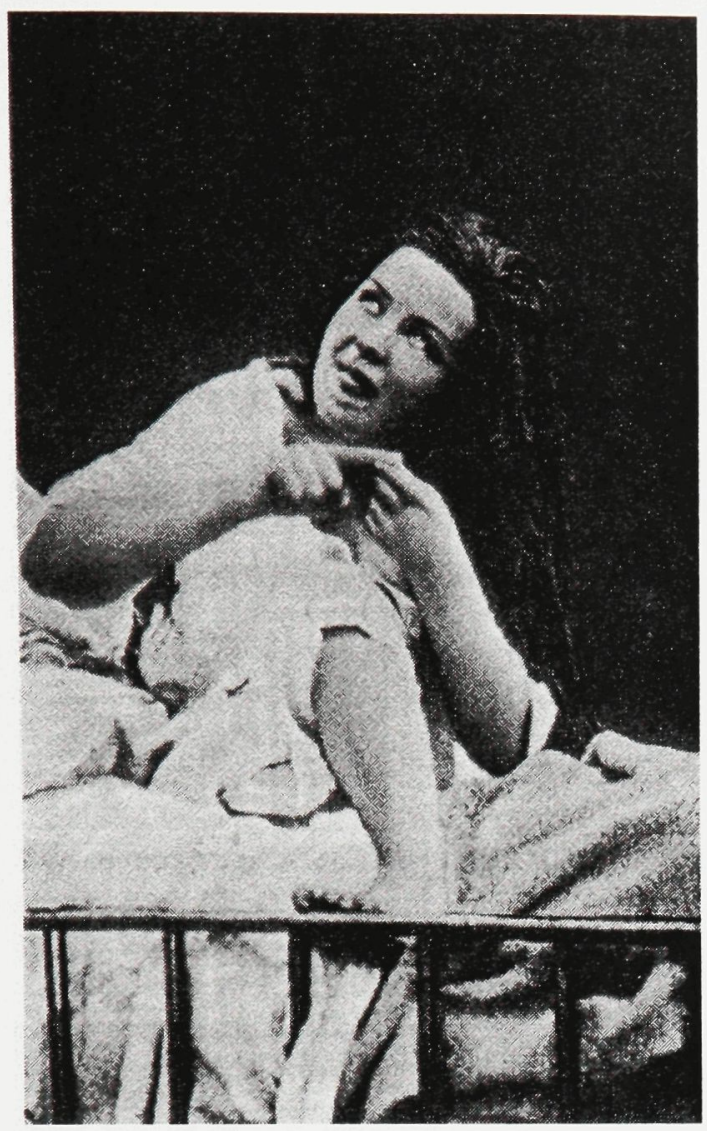

62: Régnard, photograph of Augustine, "Attitudes passionneles: Mockery" from Georges Didi-Huberman, Invention of Hysteria (Cambridge, MA: MIT P, 2003) 168.

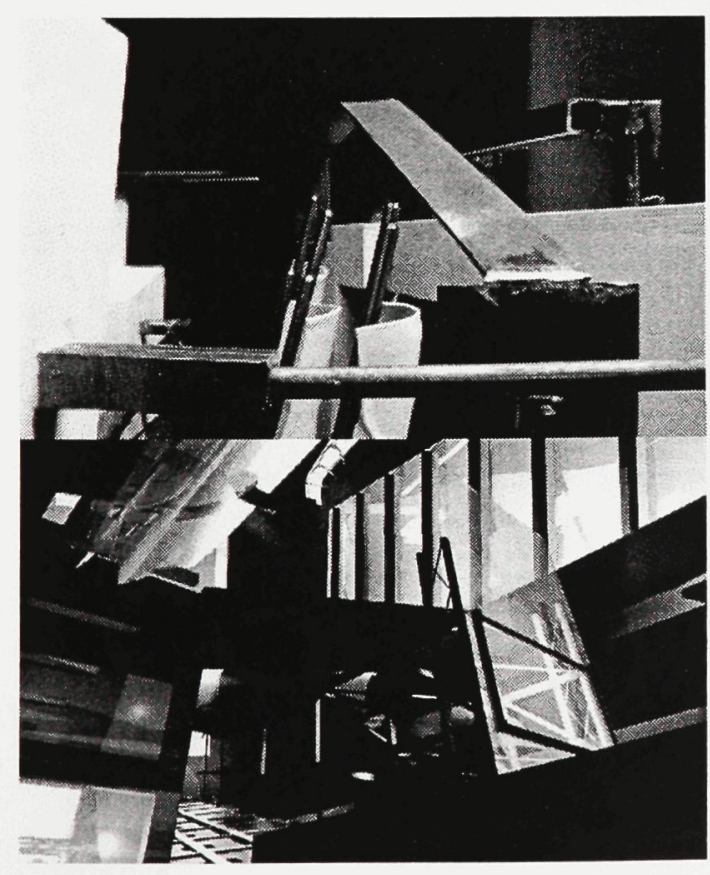

63: Impresario - Model, Video Still subversion. Simulation becomes a protest against the discourse of the master - of medical or scientific authority - causing hysteria to become subversive, calling into question authority by threatening "the difference between 'true' and 'false', between 'real' and 'imaginary"' ${ }^{\prime 4}$. By refusing the possibility of a symbolic or signified diagnosis, while creating visibly 'real' physical symptoms, hysteria questions the very nature of illness.

In order to incorporate the abjected figure of the hysteric within the Symbolic Order, the viewer attempts to create a distance towards it through denial, thus maintaining the illnesses' distance from reality. By denying the very real symptoms that the hysteric imitates for us, we endeavour to create a boundary that will save us from the effects of a zero state of meaning. In identifying the hysteric through naming we attempt to establish its place within the Symbolic Order, limiting its meaning to something that is defined beyond the object itself. But this denial cannot be successful, as the pain that is remembered "and externalized in symptoms and complaints [is] not contrived, but truly felt." 15

It is the traumatic 'kernal', or Lacanian 
context of the city.

Through the use of rendered and real video footage from the aforementioned models, as well as audio, image, text, and the reality of the aural and visual backdrop of the everyday city, the installed projection presents to the viewer the conflictual nature inherent in the experience of public space. By returning the architectural process, as represented within the video, to the reality of the city, there is a transformation of actual space through its appropriation into a place that exists as public through the experience of the installation. The

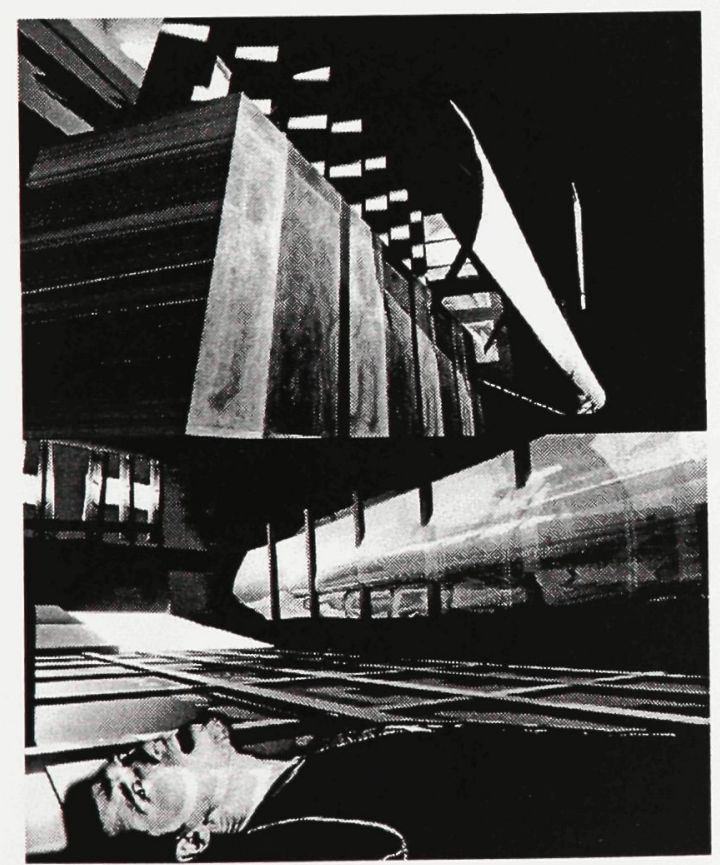

64: Impresario - Digital Model, Video Still 'object small $a,{ }^{16}$ that limits the viewer's denial, while also causing the representation within the body. This original trauma, then, does not, and cannot, exist within the language of intersubjective communication, as it is a leftover from the process of symbolization. Because of this it remains non-symbolized, or without symbolic meaning. Zizek believes that this traumatic 'kernel' exists in the Real in that it "is precisely that which resists and eludes the grasp of the Symbolic and, consequently, that which is detectable within the Symbolic only under the guise of its disturbances," which in the hysteric are its external representations. ${ }^{17}$ Because of this, the Real then becomes the absent cause that interrupts the causality of symbolic law.

As a non-symbolized object, or nonobject, this traumatic or non-symbolized 'kernel' can be understood, as Kunze has described it: a formless or amorphous glop that is the ectoplasm. ${ }^{18}$ As the object that causes abjection, it is a representation without cause within the Symbolic Order. The hysteric's trauma is a representation of the interior reality that rejects placement within the science of medicine, thus resisting symbolic meaning. This understanding 
reality of the projected image within the reality of the now politicized space of the Market allows for the installation to both address the public as viewer, while also allowing for the creation of place through the experience of the event. The installation is made up of both the projected image itself, as well as the projector booth (Fig. 117). In doing so, a dialogue is created within the space between the meaning of the image and the meaning of the object, allowing for a new meaning of space to be achieved through the interaction between both elements.

As a whole, the video

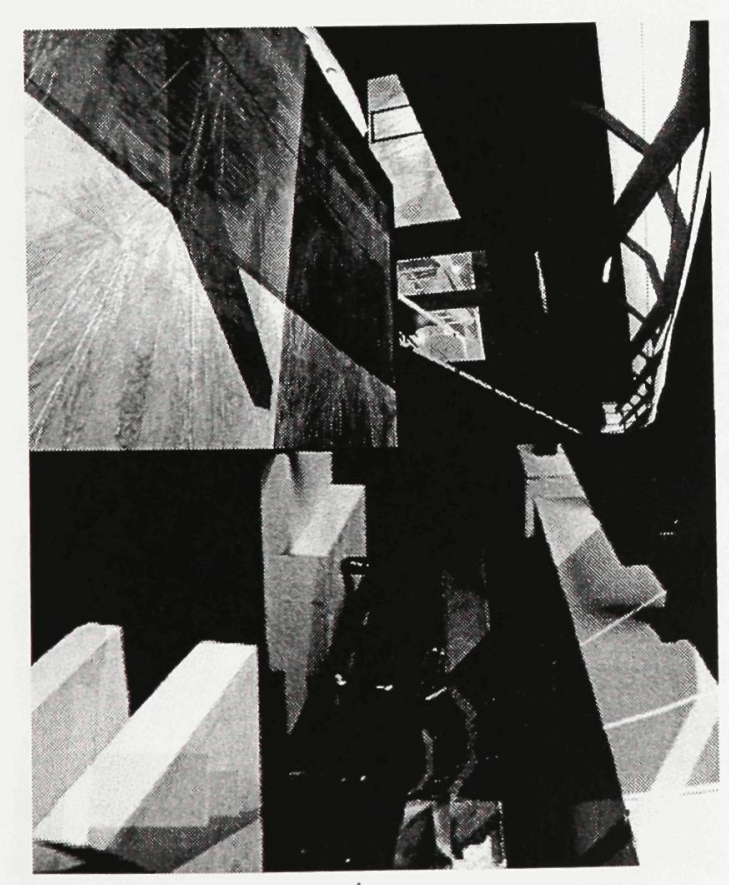

65: Impresario - Digital Model, Video Still of the trauma as disturbance occurs only when we view it from within the logic of the Symbolic Order. Once we view it from through the anamorphic view, or else from the side or a specific viewpoint, rather than through the distorted or framed view of symbolic space, the traumatic object-cause (the Lacanian object small a) "evaporates into nothingness." ${ }^{19}$ In other words, once meaning can be given to the object without its denial (once we gain knowledge about the object), the disruption that it causes to the subject fades. In psychoanalysis, the function of the analyst is to discover such an insight will allow him to reveal that the cause really consists of nothingness. Theoretically, this allows the hysteric to overcome their trauma, returning them to a 'normal' state of mind.

\section{A Violated Theatre of the Body}

The mimetic re-presentation of symptoms that the hysteric enacts, or to be more precise, re-en-acts for the viewer, causes its body to give the appearance of being an actor in its own public performance. Because of this, Elisabeth Bronfen, in The Knotted Subject, reveals that the body appears to be 
presents and questions how we relate to the body of the other within space, occurring both within and against the social and spatial structure emplaced by the Symbolic Order and as represented by the Impresario. This form of questioning occurs within a discursive context, investigating the types of spatial relationships that occur within the inter-subjective network of communication. In doing so it presents a graphic representation of the spatial experience and interruption involved in the experience of public space.

The video is structured a similar manner to Alfred Hitchcock's

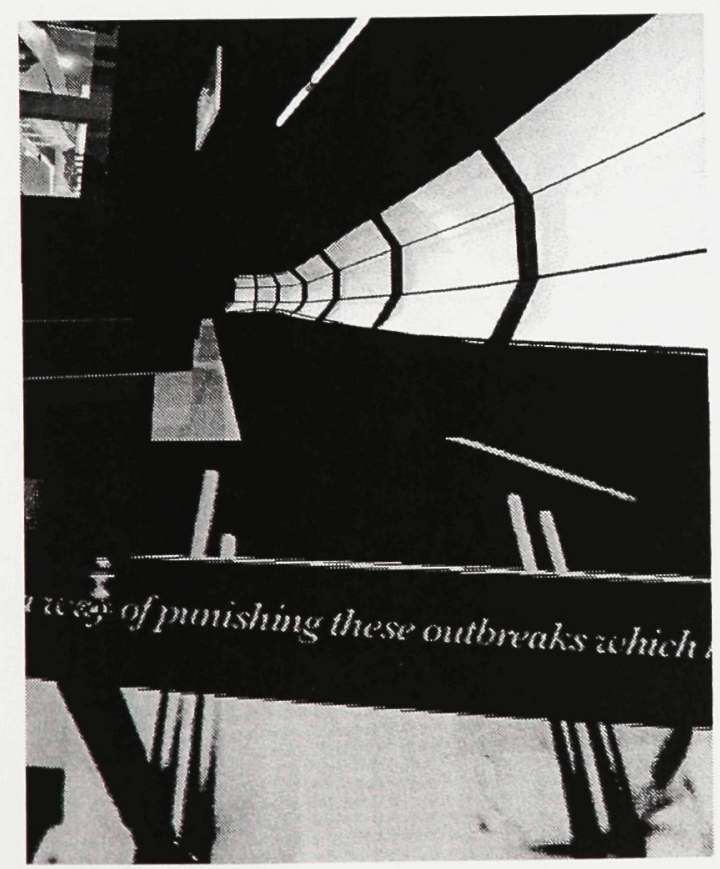

66: Impresario - Digital Model, Video Still saying: "I am a performance, indeed, I am only as performance," and I am made up by the symbolic structures that have determined me. ${ }^{20}$ This perception of the hysteric as a performer in some form of gestural theatre is what causes the viewer to attempt to frame its mimetic behavior as a lie, as something that is fictional. Such a view upon the representational nature of the hysteric is furthered by the question posed by Georges Didi-Huberman's in Invention of Hysteria, by looking specifically at hysteria's most famous patient, Augustine, and the relationship to her neurologist, Dr. Jean-Martin Charcot and the photographic camera. He questions how much the hysterical fits exhibited were directed for their documentation within the Iconographie Photographique de la Salpêtrière and for their re-presentation to the public within the medical theatre. ${ }^{21}$

What Charcot was observing and documenting through these photographs that depict what was apparently extreme agony as well as ecstasy, was the most violent form of clinical hysteria known as la grande hystérie. In this form, self-representation becomes excessive, and mainly gestural. The exhibited symptoms, 
tracking shot; developing the idyllic and therefore symbolized scene as architectural space, progressing through the gaze and discourse to the abject experience of the disrupted symbolic structure enacted by the hysterical body. Throughout the video the representation of the Flesh as Other acts as a meaningless demark, existing beneath the linear plot development of the overall video, and of which glimpses occur through the use of montage and layering, exposing the viewer to the Real that is hidden beneath the symbolic structure. The experience of the video, is then similar

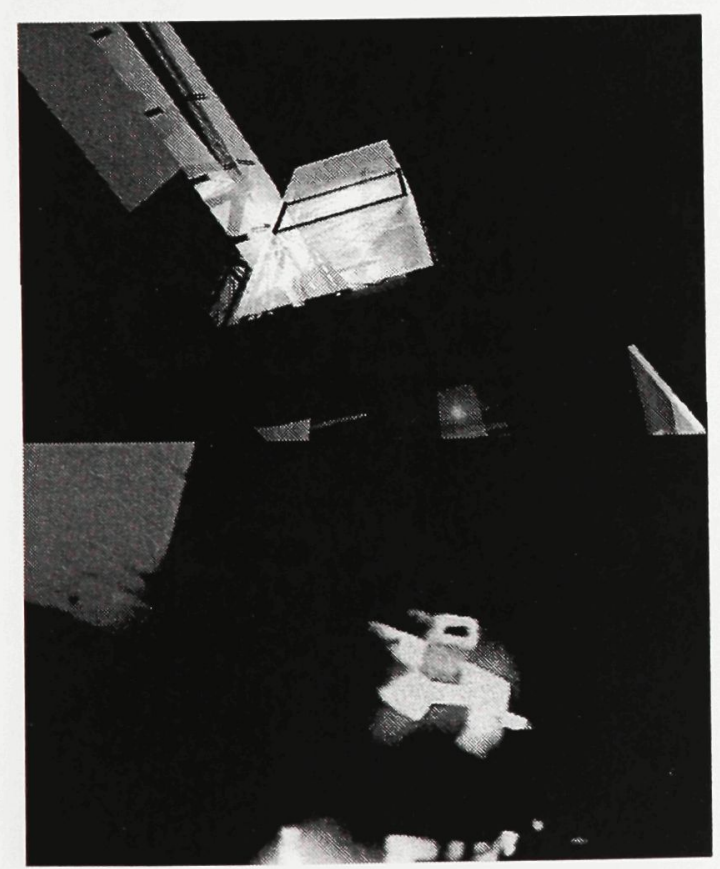

67: Impresario - Digital Model, Video Still rather than being a cough or persistent headache, which is what constituted Freud's studies of la petite hystérie, would become violent uncontrollable and spastic movements known as 'tetanism'. But what furthers the theatrical association of these movements is the fact that there was apparently a 'narrative' development to Augustine's attacks:

"[...] what made Augustine one of the great stars of the Iconographie photographique de la Salpêtrière was above all the temporal progression of her attacks, always showing welldelineated periods of 'repose' and 'entr'acte'; the sort of dramaturgical cutting of her symptoms into acts scenes, and tableaux: the so-called plasticity regular intermittence. ${ }^{22 "}$

The narrative or theatrical quality of such movements allows us to view the hysteric (or at least its body) as an art. Its symptoms are representational marks that utilize the body as a stage or place of representation of/for action. With Augustine this unconscious art form was brought to the level of a masterpiece, although Didi-Huberman suggests that her movements remained alike to those of a marionette, where their direction appeared to be coming from elsewhere. He suggests that this came 
to that of the Mobius strip in that at one moment the viewer exists within their own fantasy frame, and are thus distanced from the object, and at the next moment they are face to face with the meaningless object itself. Through its lack of signification in the reality of the Symbolic Order it causes the viewer to reframe reality through its absence. In the experience of the video, the knowledge gained through

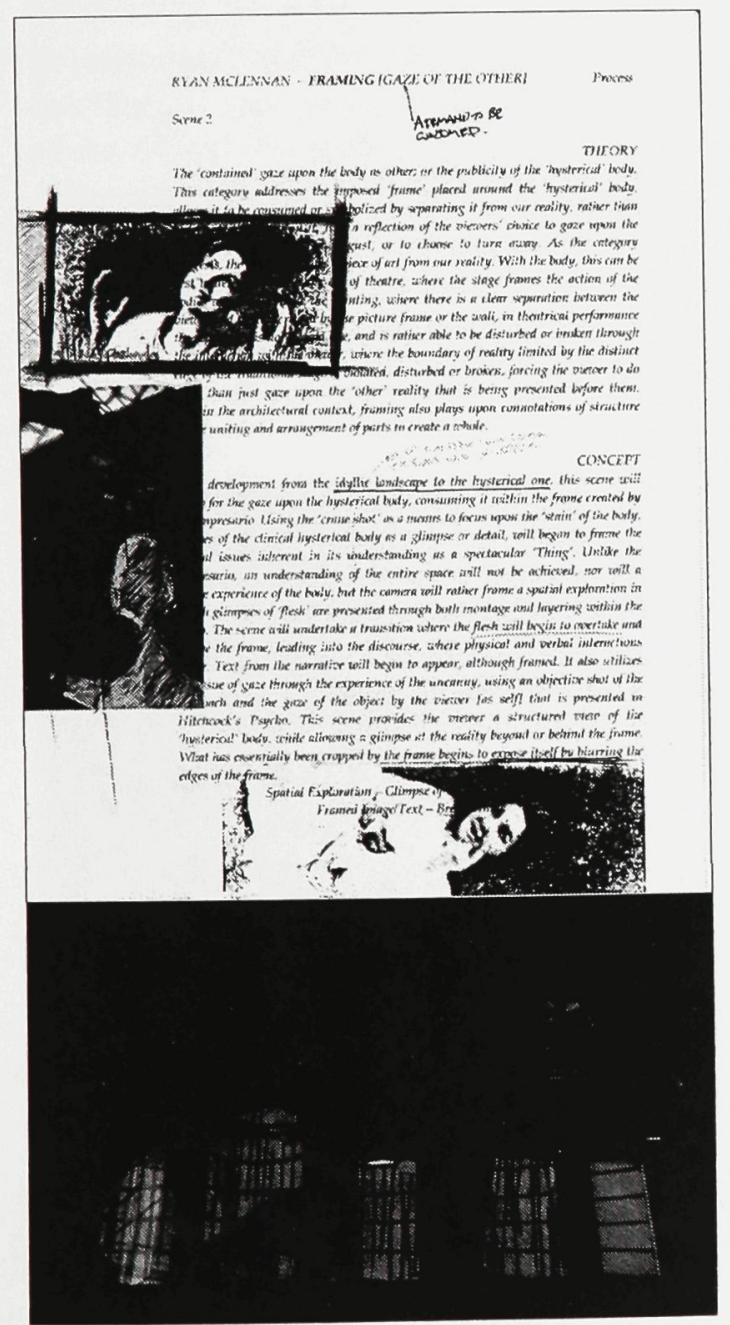

68: Framing - Script Collage, Video Still from Charcot, her physician, as she was his masterpiece. ${ }^{23}$ Within the theoretical context of the hysteric, we understand this 'direction' to come from the repressed trauma itself, from the Real that exists in the hysteric's unconscious.

Nonetheless, the body becomes a spectacle to its viewers, demanding a theatre for its representation, what is a spatialized existence. This 'hysterical' theatre, "which the art of theatre itself would have trembled to encounter", stimulates a "painful kind of theatrical essence," a suffering enacted within both the actors and viewers. ${ }^{24}$ Such a theatre is similar to Antonin Artaud's 'Theatre of Cruelty,' where it addresses the audiences 'total existence', where they would "not leave intact morally or emotionally." 25 It is an experience that was not to be dominated by the text as language, but would exist between gesture and thought, or the unconscious. It would be a new form of symbolic language defined by the dynamic expression of space through movements, attitudes and gestures, instead of through expressive dialogue. There is an implied affinity between this experience of the 'hysterical theatre', and the political experience of public space that I have been discussing, as it 


\section{The Theater of Cruelty}

"Instead of continuing to rely upon texts considered definitive and sacred, it is essential to put and end to the subjugation of the theatre to the text, and to recover the notion of a kind of unique language halfway between gesture and thought.

This language cannot be defined except by its possibilities for dynamic expression in space as opposed to the expressive possibilities of spoken dialogue. And what the theatre can still take over from speech are its possibilities for extentsion beyond words, for development in space, for dislocative and vibratory action upon the sensibility. [...]

THE STAGE - THE AUDITOIRIUM:

We abolish the stage and auditorium and replace them by a single site, without partition or barrier of any kind, which will become the theater of the action. A direct communication will be re-established between the spectator and the spectacle, between actor and the spectator, from the fact that the spectator, placed in the middle of the action, is engulfed and physically affected by it. The envelopment results, in part, from the very configuration of the room itself."

69: Quote from Antonin Artaud, The Theatre and Its Double (New York: Grove P, 1958) 89-96.

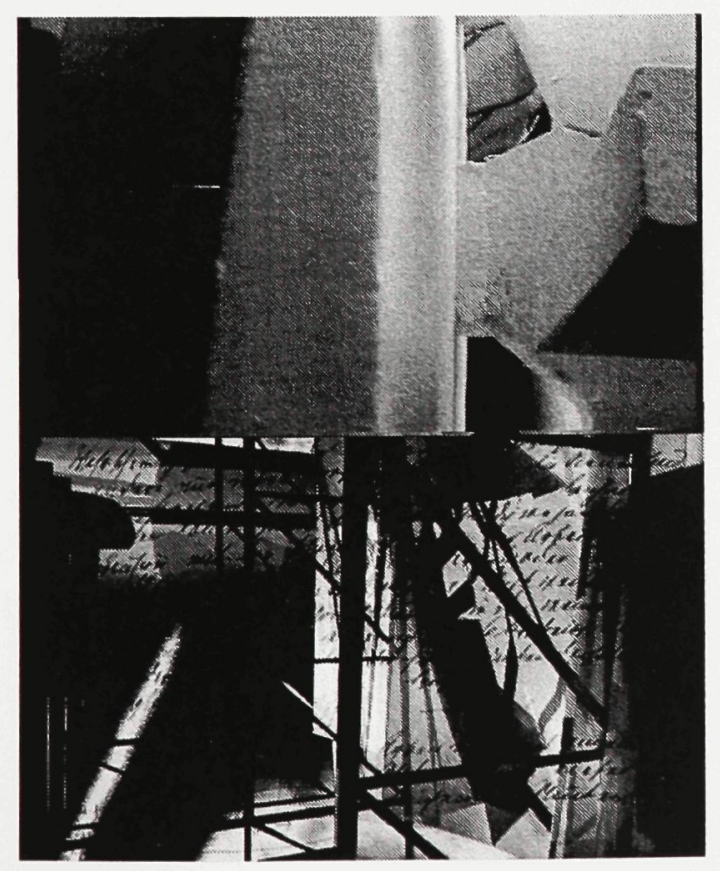

70: Framing - Model, Video Still is an experience that questions the subject's very existence in symbolized reality, thus affecting or altering the viewer's fantasy frame.

For the hysteric, these symbolic gestures that constitute its language are a mode of communication clearly aimed at an addressee (physician, analyst, family, public audience, etc.) who perceives their actions to be false. As a theatrical manifestation, the spectacle that the hysteric causes, allows the viewer to devour them with their gaze. In turn the hysteric responds through its 'submission' to the gaze of the viewer, devouring their gaze in return, to such an extent that it challenges the viewer himself. Thus, the submissive gaze becomes one that is subversive and cruel through excessiveness of what is being presented. It is not an essential substance, but rather a 'too-much-matter', which is caused by the repressed trauma. ${ }^{26}$ Thus, as a leftover or excess from the process of symbolization, the object small a exists within the Real, and is something that the hysteric has no conscious control over. Because of this there is hatred of its gaze, as it constantly questions our frame upon reality. But there is also a degree of fascination towards its cause, which is beyond grasp. 
This indication towards the existence of

\section{The Uncanny}

The sense of the uncanny, or unhomely is an anxiety based in the fearful invasion of an outside presence, causing the familiar to become unfamiliar, turning upon its owners. For Freud, its symptoms included spatial and temporal fear arising from the "transformation of something that once seemed homely into something decidedly not so." The uncanny is not a property of space itself, but rather an experience of space that occurs within the psyche provoking a disturbing ambiguity between what is real and unreal.

71: Definition of the Uncanny

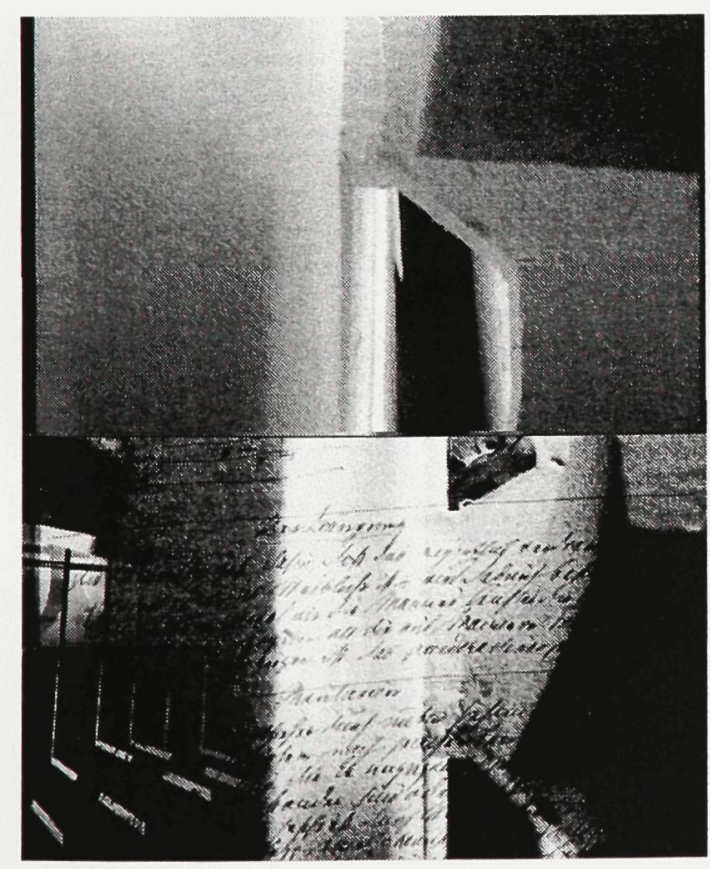

72: Framing - Model, Video Still the traumatic Real that subsists in the hysterical body is a form of mask. It is an "inconsistent multitude of masks" that confronts and deceives the viewer, causing anxiety through the "impossibility of discerning behind the masks a consistent subject manipulating them." ${ }^{27}$ What is perceived is a nothingness, or else nothing more than the formless ectoplasm of lifesubstance; a non-symbolized cause that remains hidden as the irretrievable 'truth meaning' to the hysteric's discourse, a truth existing in the Real. As an experience of the hysterical body, the experience of what exists behind the mask takes the form of a non-symbolic anatomical model, where the body appears as a transparent canvas, however the trauma contained within, or the object-cause, remains opaque to meaning altering the perception of the surface. In this spatial organization, "everything is reduced to inside and outside," while "the inside is also the outside". ${ }^{28}$ Thus, the outside causes for the viewer an anxiety, a sense of the uncanny (Fig. 71) created by the opacity to meaning of what disrespects boundaries within the thinness/ thickness of the representational plane of the mask. 


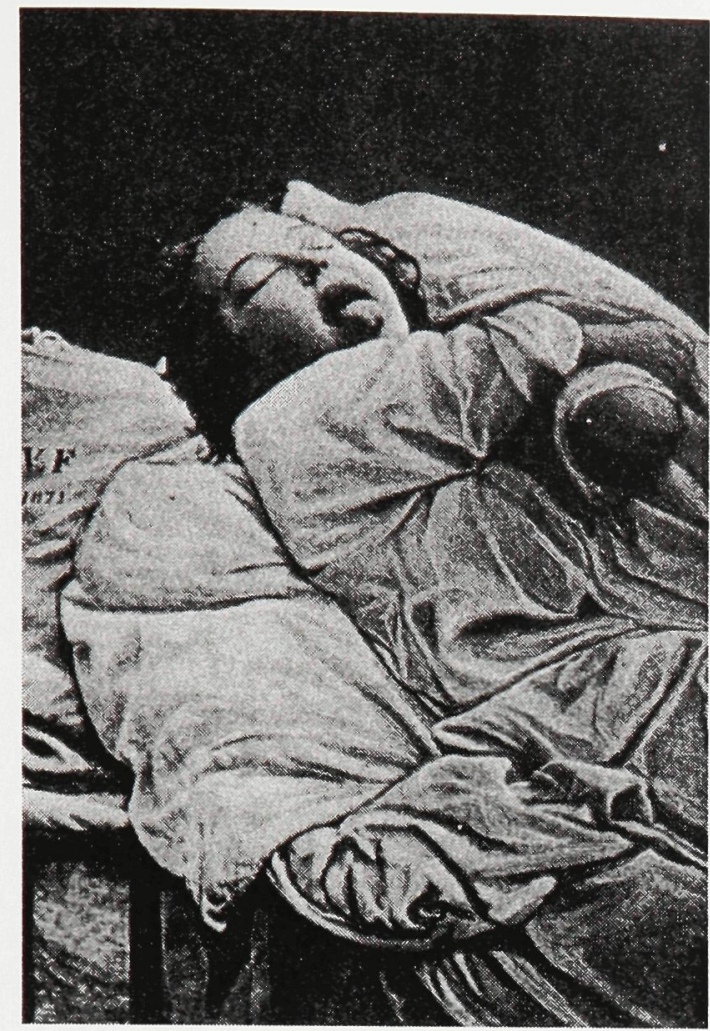

73: Régnard, photograph of Augustine, "Onset of an Attack: the Cry" from Georges Didi-Huberman, Invention of Hysteria (Cambridge, MA: MIT P, 2003) 260.

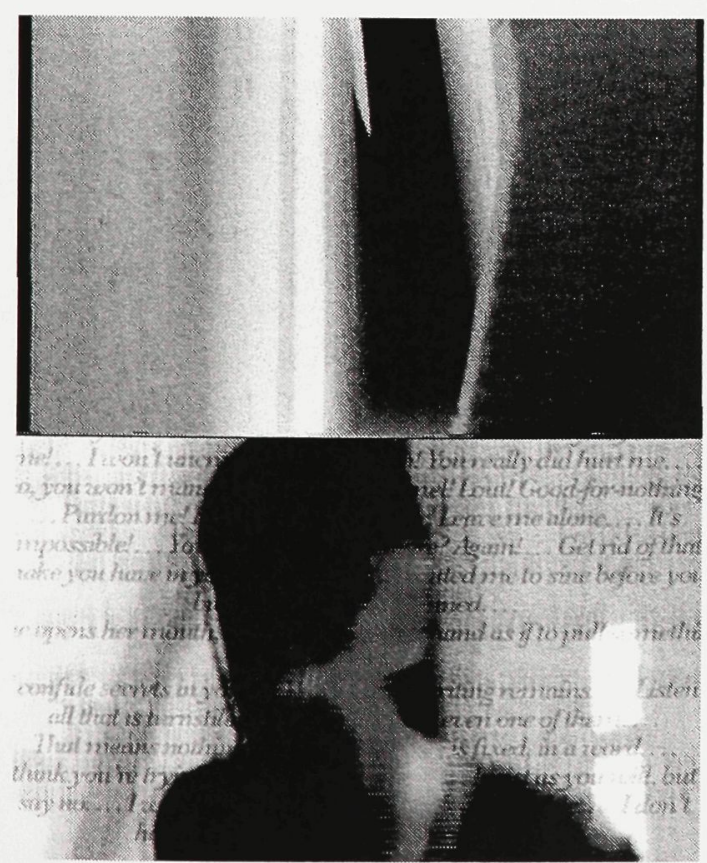

74: Framing - Model, Video Still
For Didi-Huberman, this mask is made up of the cry $(c r)$ of the hysteric. In this violent cry, as represented symptom, subversion exists by undermining every expected cause. The cry exists as the statement, "that's not it!" It is then an act that takes the place of something else. As a representation, the cry as mask must be understood in the sense that Georges Bataille gives it in Le masque, as:

a 'nocturnal terror' linked to every masquerade... the very thing that is normally reassuring suddenly takes on an obscure will to terror - when the human is masked, only animality and death are present... A MASK IS CHAOS TURNED FLESH. ${ }^{29}$

In this uncanny form of terror, there is a certain fascination towards what is appears to be contained behind the mask, its logical or symbolized cause. The lack of symbolized meaning creates anxiety within the viewer as there is an inability to place meaning to these actions, and every attempt to do so is denied by the further persistence of the representation. The meaning then remains unattainable as a lack within Symbolic reality, where the symptoms continue to persist as an indication of something that exists beyond our grasp, constantly striking 
anamorphosis provides the viewer a point through which to interpret the whole, allowing for the artifact-demark to become associated to a signifier.

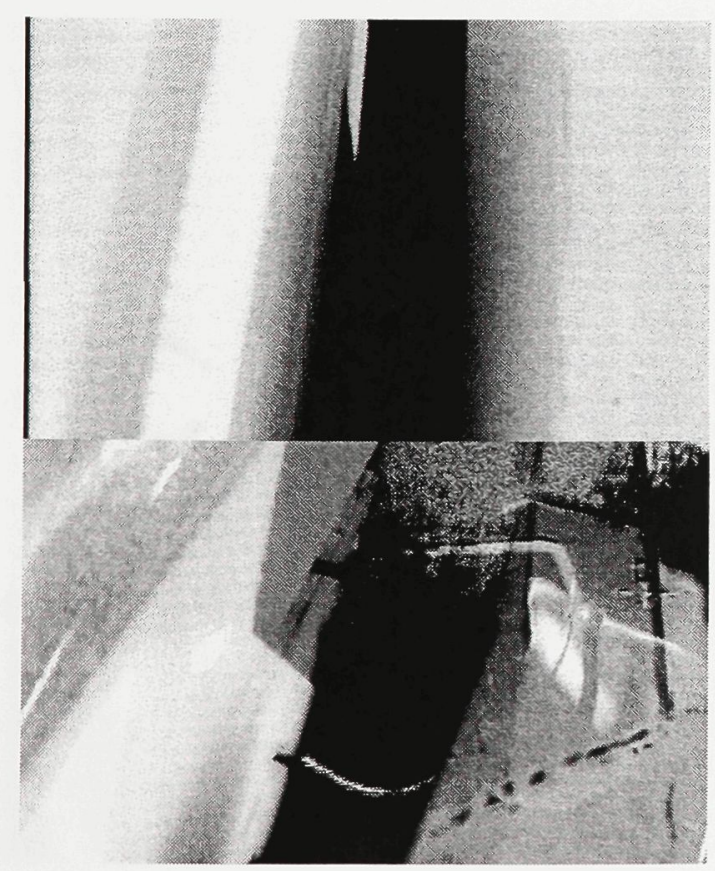

75: Framing - Model, Video Still down any attempts to symbolize it or to translate it into the language of inter-subjective communication. ${ }^{30}$ The symptoms continue to point to the unattainable traumatic real, and by doing so violate the boundary between viewer and viewed, thus alienating both through the representational process of abjection. ${ }^{31}$ This interaction with the hysterical body creates a 'zero degree' of meaning, in that its representation as an abjected body is de-stabilized, affecting the semantic stability of surrounding reality, thus calling into question the semantic stability of the symbolic order and violating the fantasy frame of reality through the excessiveness of the Real.

This violation functions considerably different than conventional representational marks, as one is unable to assign a fictitious quality to it, but rather it occurs through what Kunze refers to as 'tropes of abjection'. In the conventional relationship between viewer and viewed, "marks work in the direction of the 'saggital', the imaginary line connecting viewer and viewed." 32 In this relationship, the mark requires for the creation of a zone of representation, which veils the meaning of the 'thing-in-itself', and is linked to our particular 


\section{Scene 1 - Impresario}

The Impresario or agent of the Symbolic attempts to structure or contain the hysterical body as a means to symbolize it within the Symbolic Order. In psychoanalytic theory, the equivalent of this is the Lacanian Other who maintains the law of the Big Other upon which the signifying chain of the Symbolic Order is based. The destruction of such a presence causes for the symbolic structure within which we exist to be altered through the non-symbolized object itself; referred to by Lacan as symbolic castration. This category

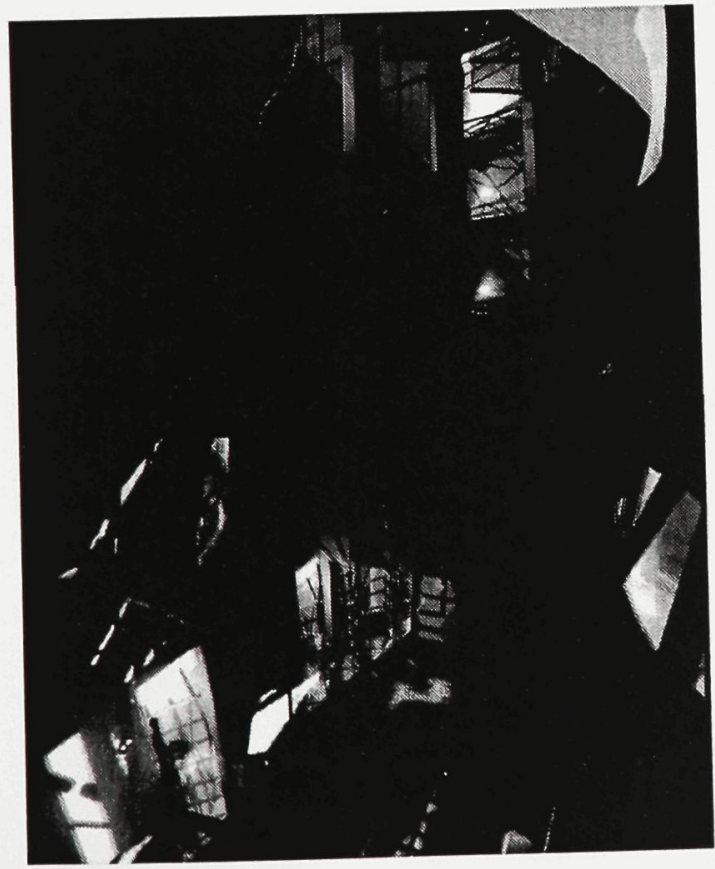

76: Framing - Digital Model, Video Still fantasy frame. As a vector relationship, the conventional mark limits motion along the saggital, controlling what is being represented and limiting or terminating meaning at a point outside the mark itself. ${ }^{33}$ In this form, the abjection reaction to the mark, which would give the possibility of alternate meanings through the deflection of the saggital, leads directly to the vector's correction through its reframing. This form of interaction limits the mark to a strictly symbolized existence, thus allowing for the superiority of the viewer over the meaning of the viewed.

But there is another possible vector that can exist within a mark, which Kunze refers to as motion within the artifact, occurring within the plane of representation itself, and is therefore perpendicular to the vector of the saggital. Unlike the conventional mark, where abjection causes the mark to be resolved through its representation, abjection occurs in the process of representation, through movement within the artifact, "where a reciprocal process of collation and closure terminate within the artifact itself, by opening up 'self-cancelling' levels of alternative meaning (polysemy, polymorphy)." ${ }^{.34}$ What allows 
is associated to Framing by setting up for the experience of the nonsymbolized through the creation of a frame, which is the ideal. It is thus an imposition of control and authority over the body, while at the same time maintaining the improvisational and theatrical nature of display through framing.

This scene creates for the viewer the Lacanian discourse of the master, where a the process of signification objectifies the subject within language. As a spatial representation of this discourse, the scene develops what I refer to as

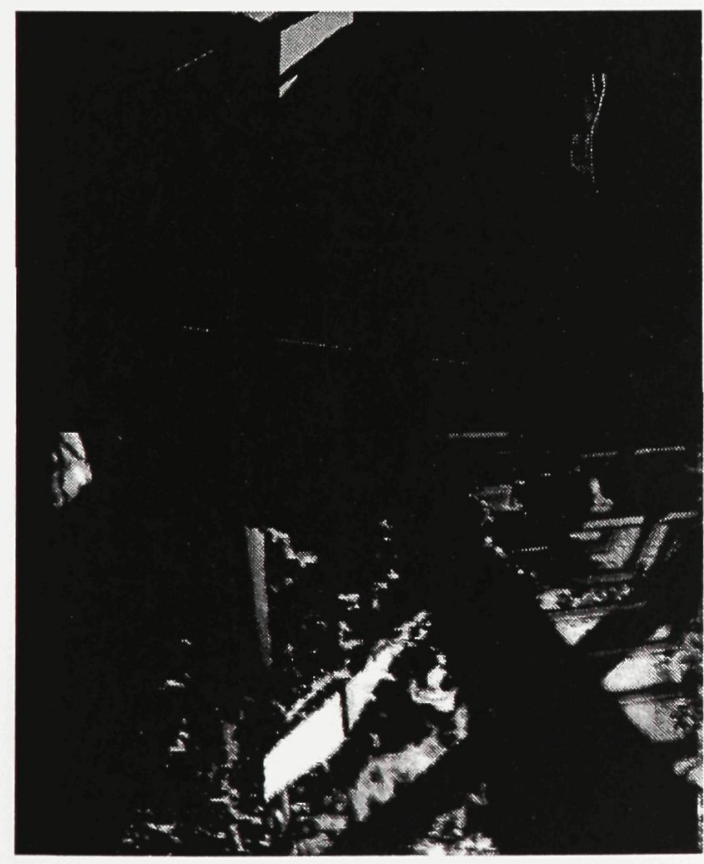

77: Framing - Digital Model, Video Still for this multiplicity of meaning, also allows for the displacement of symbolized representation in the object itself by its mediation through metaphor, or 'tropes'.

For Kunze, there are two types of 'tropes' that control motion and closure within the artifact: tropes of division and tropes of abjection.

Tropes of division call attention to boundaries, doubles, cases of ambiguity and rivalry (ambiguity, semblance), situations of exchange, incompletion, discontinuities, moments of passage and initiation, and other cases where space and time are disrupted in order to effect an opening and closure of events. Tropes of abjection delineate a zone of 'zero degree' meanings where marks cease to perform their representational tasks and become non-marks. ${ }^{35}$

Both forms of tropes appear to exist in the experience of the body of the hysteric.

The return of repressed symptoms, as a form of doubling and the boundary condition of the representational surface in the hysteric causes it to act as a trope of division, calling attention to the ambiguous nature of the represented symptoms. Although it disrupts the meaning of the represented symptoms, the 'sway' that it produces within the work itself can only be 
the idyllic landscape, in which it is possible for interruptions or demarks to occur, disrupting the ordering which the discourse creates and maintains. Rather than presenting the uncanny or abject nature of the body as demark, this scene presents a clear spatial experience that maintains its consistency through a continuous symbolic understanding of the space presented within the frame.

Using video from the models, text from Kafka's Hunger Artist, as well as objective views of the figure of self who inhabits the space, this scene depicts a scaled experience

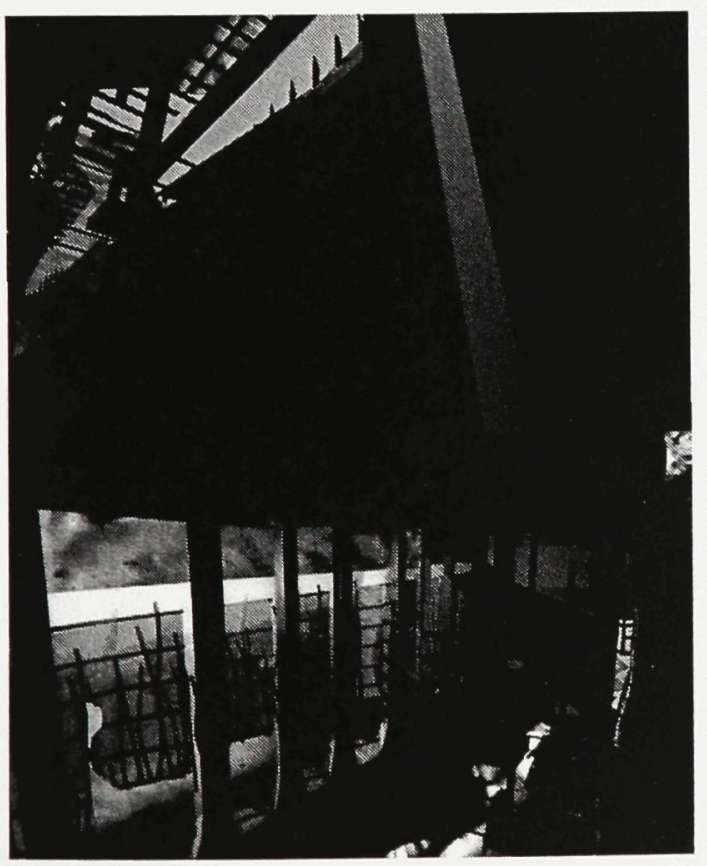

78: Framing - Digital Model, Video Still understood in a fictional nature, as a simulation or lie. The hysteric as a trope of abjection on the other hand also displaces meaning, but in doing so points to an absence, to the apparent nothingness, or 'zero degree' of meaning that exists at the hysteric-artifacts's center. In such a trope, closure, what would be the knowledge of the hysteric's trauma, is not a positive object from which meaning is produced, but rather a negative event where meaning appears as absent. Closure is empty and non-symbolized, existing in the absence that is the Real.

In the fragmented body of the hysteric, multiple bodies and multiple meanings exist and are presented to the viewer as a body in pieces. It is no longer the singular body of the Cartesian subject who has their body but is not their body. ${ }^{36}$ Such ownership and symbolization of the body (to the self) allows for a gap to exist where enjoyment is lost through the process of signification. In hysteria, it is rather a loss of the body altogether, where the hysteric is no longer their body, but also no longer even has it. They no longer exist as subjects' conscious of their own bodies; rather ownership lies in the unconscious mind, the un-signified Real, which allows them 
of space that develops the context within which the structure for the rest of the video emerges. Through this, an overall understanding is created, presenting a continuous whole that is similar to typical forms of architectural representation. The scene uses layering and montage to develop an understanding of space, while at the same time provoking the sense of a hidden non-symbolized underbelly to its experience.

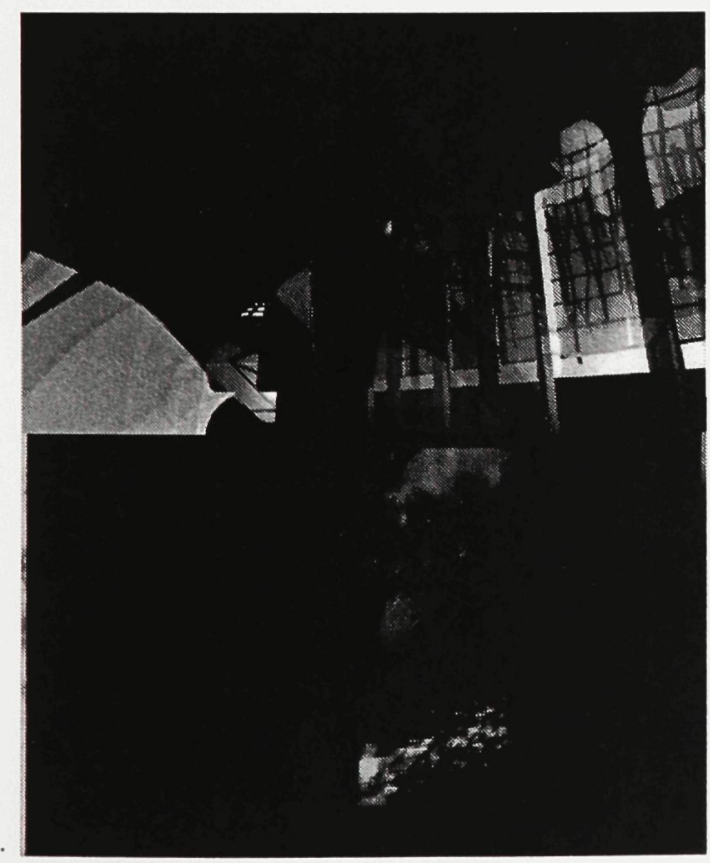

79: Framing - Digital Model, Video Still access to an extreme enjoyment unavailable to the subject. This is radically represented as something beyond our understanding through "a loss, a poignant, tetanized loss."

The fragmented modern subject, created through the process of abstraction exists as a 'body' in pieces, much like the fragmented nature of the modern city. The representation of such a reality has been accomplished in cubism through the representational realm of painting and sculpture. In architecture, Coop Himmelblau has represented this fragmented experience by re-inscribing, or re-marking the body in their work as a corporeal metaphor that is considerably different than the one that was "at the center of the humanist tradition." 38

Other than the apparently fractured, and angular formal quality to their buildings, as can be seen in the well-known UFA-Palast Cinema in Dresden (Fig. 80), their metaphoric use of the fragmented body is perceived through how they describe and act upon the design of their buildings. Rather than understanding transparency as a means of making meaning present through the use of a visual logic, Coop Himmelblau deliberately views the surface of 


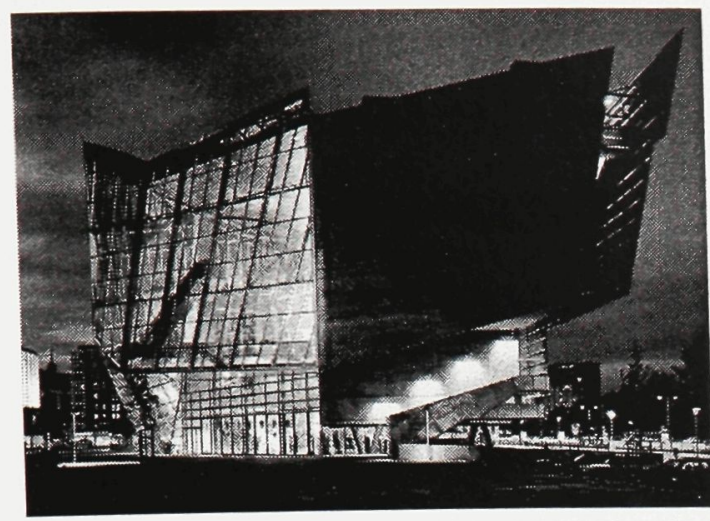

80: Coop Himmelblau, UFA Cinema Center, view from the south-west at night from Frank Werner, Covering + Exposing (Boston: Birkhäuser, 2000) 125.

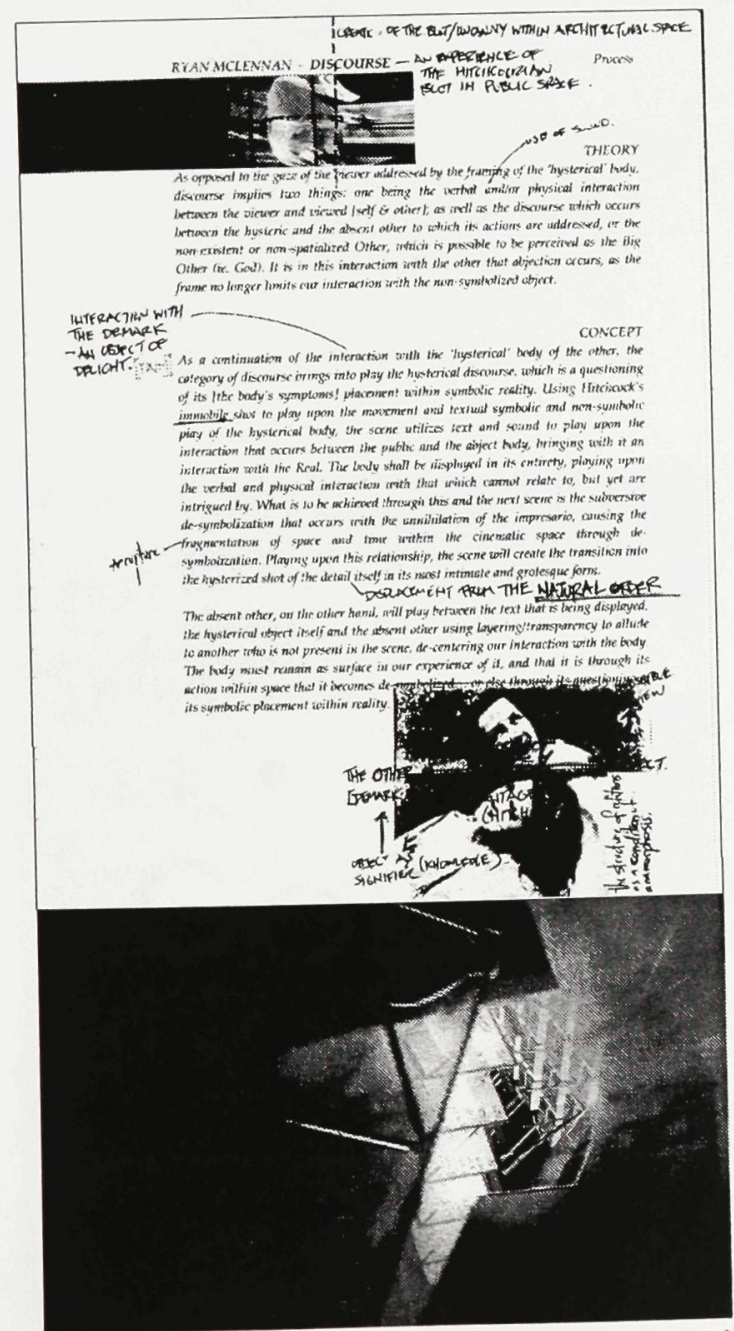

81: Discourse - Script Collage, Video Still the building as a skin, where openings become surgical acts that are somewhat sensual in nature. Transparency occurs only "where the skin is pushed back, opened up, folded away" allowing a glimpse of what is contained beneath, what is beneath the face. ${ }^{39}$ In doing so transparency becomes the disruptive view indicating what is contained within or behind, rather than a logical means of display.

Although Coop Himmelblau's return to the metaphorical use of the body in architecture is apparent in their language and morphology, it is not a return that does not occur without causing a sense of anxiety, as it had once been repressed through the modernist tradition. Their use of this metaphor follows from a belief that architecture should not exclude or repress everything that is disquieting. This parallels Artaud's view of theatre, as a place to present the shadows of our existence to the modern consciousness. ${ }^{40}$ For Artaud this form of theatre would have the ability to heal the split between language and flesh, and therefore return enjoyment to the subject by allowing an unconscious access to the Real through an identification with and experience of the non- 

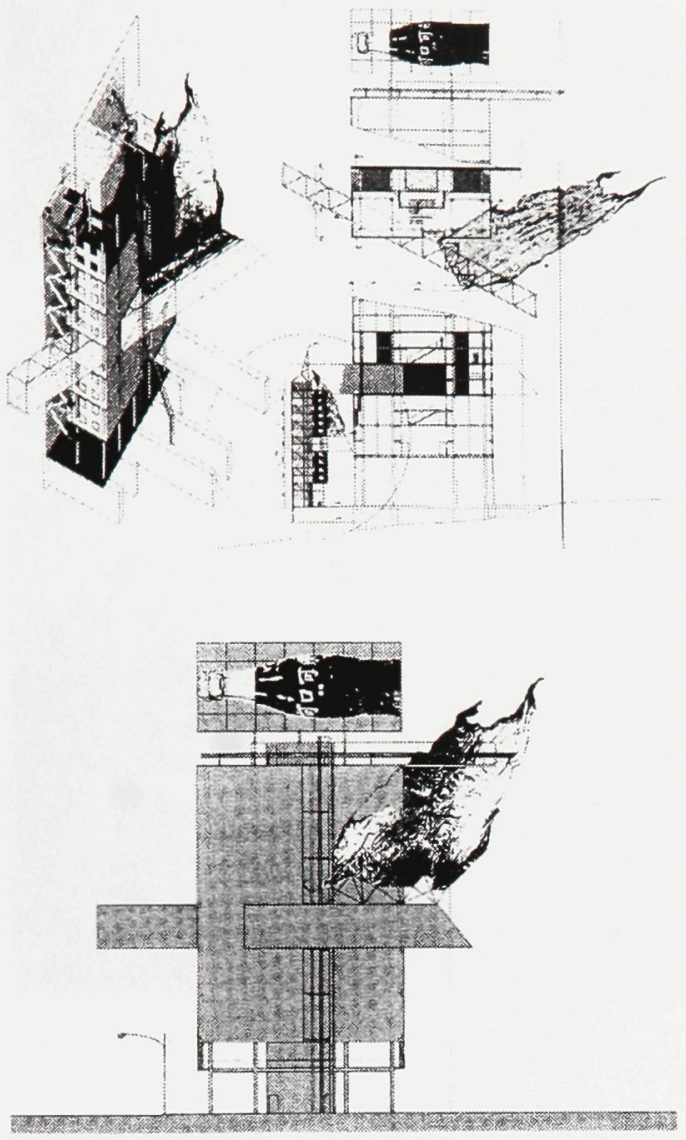

82: Coop Himmelblau, Vienna, Austria. Hot Flat, city apartment building, 1978, isometric drawing, typical floor plan, full and partial section, partial view, elevation drawing from Werner, 11.

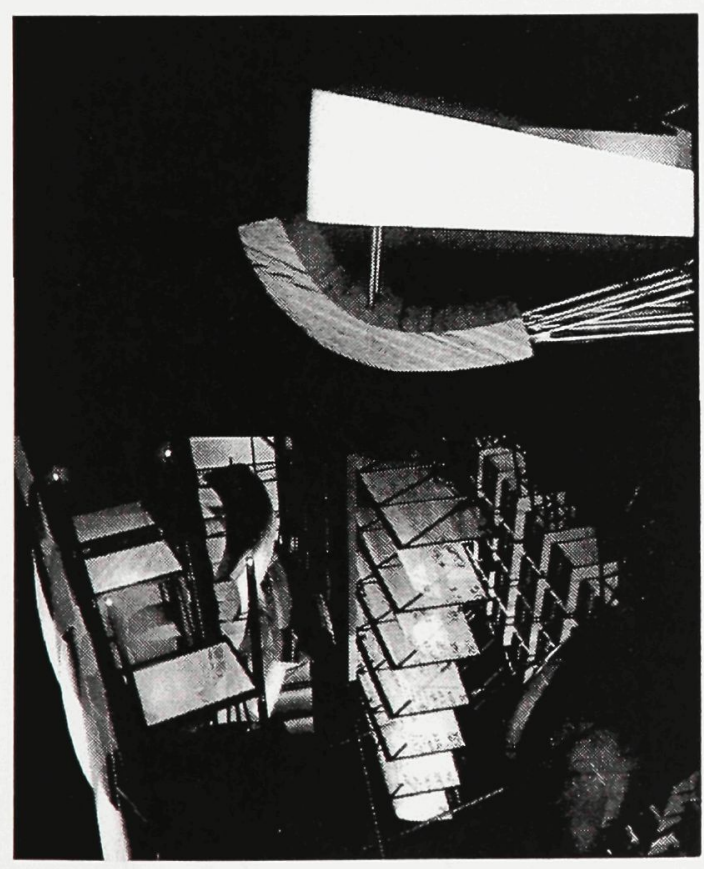

83: Discourse - Model, Video Still symbolized. Thus, in their disillusionment with historical masks, Coop Himmelblau have turned to represent that which modern architecture has attempted to cover over, which is that which makes us uneasy: an 'architecture of desolation' that "fully embraces the solitude of squares, the desolation of the streets, the devastation of the buildings." 41

Their architecture operates as both a representation of the space that their building inhabits, as well as spaces that are both at once invented and continuous with the contemporary city, and a space of 'disquiet and unease', 'estrangement and distance'. Such an approach can be seen in most of their projects, but is prevalent in their unbuilt project, Hot Flat in Vienna, Austria (Fig 82 and 84). As a subversive residential project study, this project is built upon the notion of inflicting injury upon the city itself, rather than the box as an architectural typology. Like in Tschumi's folies, this architecture is not focused upon its programmatic function, but rather on an architecture that creates an emotional response, while at the same time critiquing the false aesthetic that is used to beautify the disquieted. This view stems from 


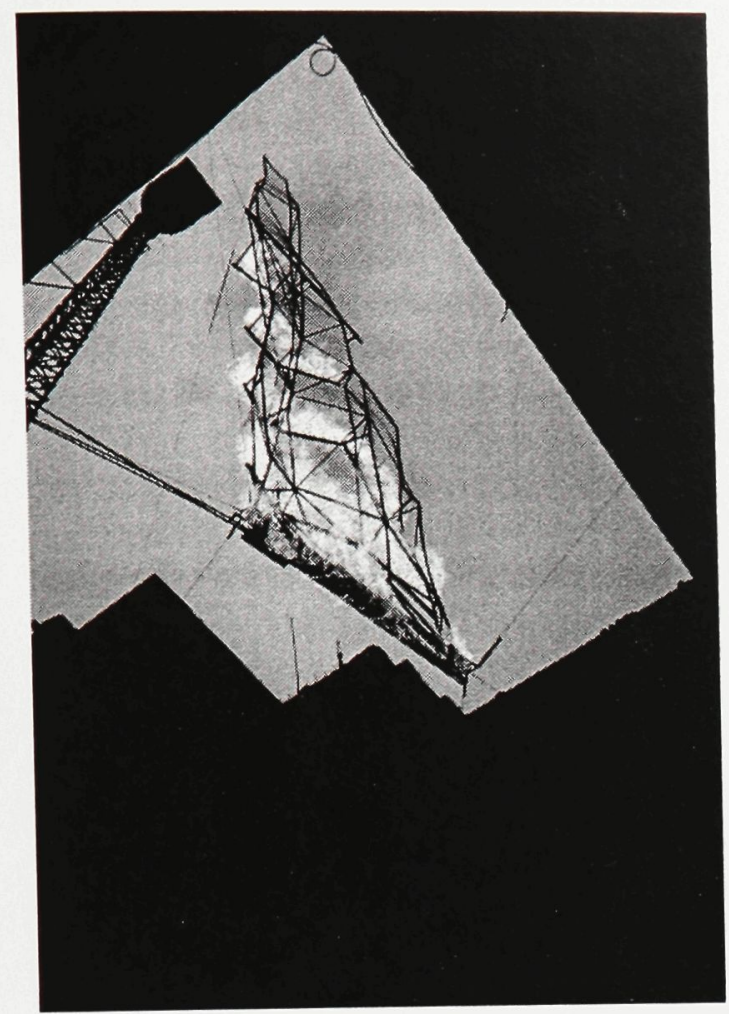

84: Coop Himmelblau, Graz, Austria, Blazing Wing, 1980 from Werner, 78.

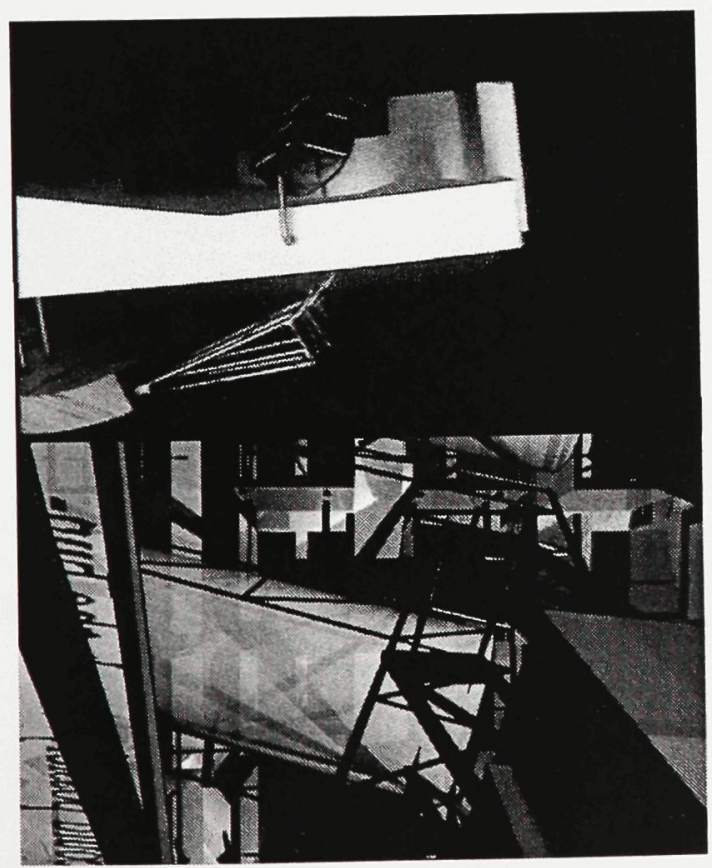

85: Discourse - Model, Video Still
Himmelblau's belief that "architecture gains meaning from desolation, which comes from the act of inhabitation and interaction. ${ }^{42}$

The block of flats contained in the project, although rough shells, are not what causes the most disruption in the project. Rather what is most striking is the 'pier-like structure' diagonally piercing the building, containing the communal areas, but also sending enormous flames into the night sky. ${ }^{43}$ Although this gesture is extremely spectacular in nature, it is also intended to act as a symbolic re-interpretation of the coldness of urban architecture into a symbol of life. As a proposed re-use of an existing parking garage, it is both a provocation towards the historic context of Vienna, while also a questioning of both mediocrity in architecture and the city. It presents to us the vulnerability of abstract space in the city, re-inscribing its inherent contradictions by presenting to the inhabitant "transitory, socially inefficient 'nonplaces" " 44 ithin the city, what Lefebvre describes as heterotopias.

\footnotetext{
'Why Am I What You are Saying That I Am?'
} 
The 4 Lacanian Discourses

From Slavoj Zizek, Looking Awry, 130-31.

The discourse of the master originates from Hegel's master/slave paradox, where one man first imposed mastery over another, and in doing so caused the advent of history. This discourse then is the struggle for mastery and domination, and as Zizek states "a certain signifier $(\mathrm{S} l)$, represents the subject (\$) for another signifier or, more precisely, for all other signifiers (S2). But this operation of signifying representation creates a leftover or remnant that is unable to be signified, known as object small a.

The discourse of the university is objective knowledge that is at the service of the master discourse, and attempts to place the leftover from the master discourse, trying to symbolize it by placing it within the Symbolic Order. But the knowledge can never be impartial, and always has the ideology of the Master.

The discourse of the analyst is opposed to that of the master. In order to place the symbolic object, he first identifies with it, starting a discourse with the element that escapes the 'discursive network'.

86: Definition of The Lacanian Discourses

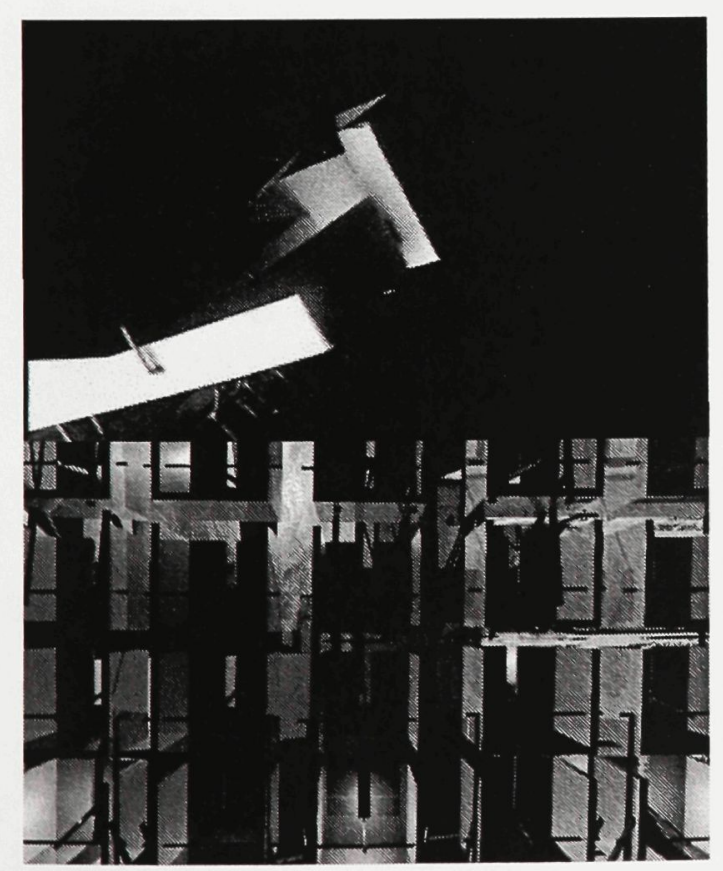

87: Discourse - Model, Video Still
The vulnerability of the abstract symbolic structure of law, language, and space is the message that the hysterical body broadcasts through the inability to find a symbolized cause for its symptoms. As a malady of representation, it also acts as a mode of communication perceived by the viewer, one that also questions the overarching structure of the big Other, a relationship set up with the so-called Master "in response to whom the subject's identity is constituted." ${ }^{45}$ This discourse of the hysteric is one of the four discourses (master, university, hysteric, analyst) that the psychoanalyst Jacques Lacan set out as his limits of discourse, as psychoanalysis is defined as the 'discourse of the other.' In Lacanian theory, this questioning of the master is addressed as "Why am I what you are saying that I am?" As Zizek notes, this is the hysteric's reaction to the 'founding word'. It is the act of naming and defining me that places me within the Symbolic Order. ${ }^{46}$ The question itself is not one that occurs verbally, but is rather exhaustively asked by the hysterical body itself, through its language of inaccessible representational gestures.

By constantly pointing to the unattainable 
The discourse of the hysteric is based upon the question addressed by the barred subject who is determined by the inaccessible object of knowledge, the object small a, to the master: "Why am I what you are saying that I am?" also referred to in shorthand as "Che vuoi?' This question points to the division of subject and object in language arising from the act of naming me, placing me within the symbolic network, thereby objectifying me. What this question articulates then is the gap that exists between the signifier that represents me and the non-symbolized Real of my existence. All answers provided by the master are unable to master the object, ending by proving that "all of what I am you cannot say," which points to the deficiency in the masters knowledge.

Because of this constant separation from the discourse of the master, the hysteric accounts for the position of the speaking subject within the Symbolic Order. As a fundamental form of speech the discourse of the hysteric discloses the structure of speech itself, along with its gaps and inconsistencies.

85 continued: Definition of the Lacanian Discourses

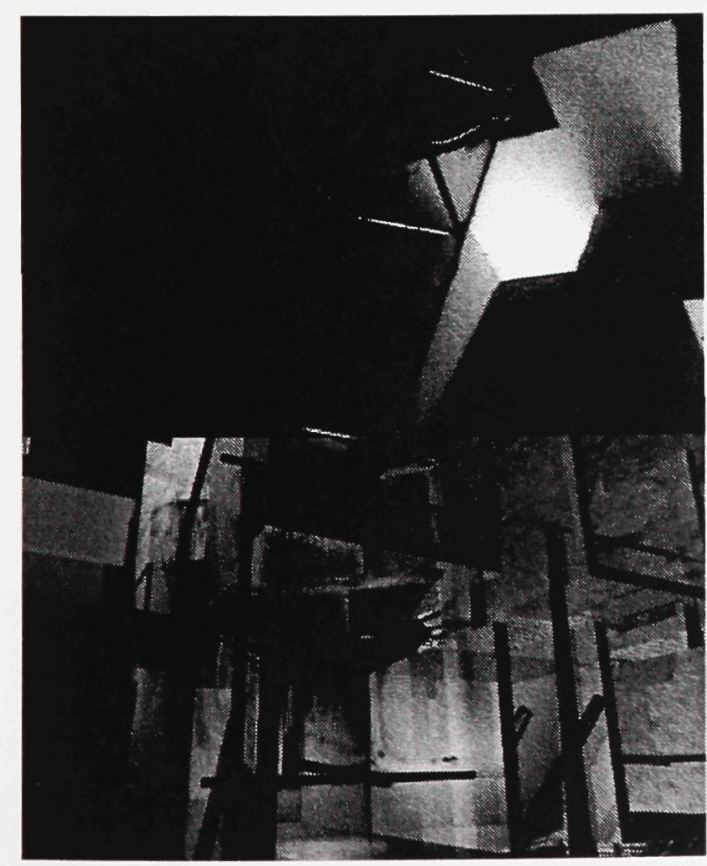

88: Discourse - Model, Video Still trauma through its question, the hysteric asks the master the same question that occurs in racism: 'Che vuoi?', 'What does the big Other want from me?'47 This questions the consistency of the master's law, "endlessly demanding that he prove the authority of his power," and in doing so also designates the "vulnerability of the symbolic (law and social bonds); the vulnerability of identity (the insecurity of gender, ethnic, and class distinctions); or, and perhaps above all, the vulnerability of the body, given its mutability and mortality." ${ }^{\prime 8}$ Therefore, the unidentifiable nature of the traumatic origins constantly pushes to prove the lack that exists in the master's knowledge by persistently negating his theories, and for that reason is a trope of division. As in racism, this questioning of the Symbolic is also where the 'authentic subject' lies, as subjectivity denotes an inability to be integrated into the Symbolic Order, while remaining a part of the socio-symbolic network. ${ }^{49}$

When such an inconsistency is made apparent, there is, much like in Franz Kafka's fiction, a realization that all along "at the heart of the subject there is nothing, the 'nothing' 


\section{Scene 2 - Framing}

Framing presents the framed gaze of the 'body of the other' as well as its spectacular nature, allowing for it to be consumed or symbolized by separating it from our reality. As the name suggests, the frame is a means through which to separate an object from ourselves, allowing it to be gazed upon in disbelief or disgust. In the case of the body, this can be best understood through the example of theatre, where the stage frames the action that occurs within it, allowing it to be viewed as fantastical. Unlike the painting, where there is a

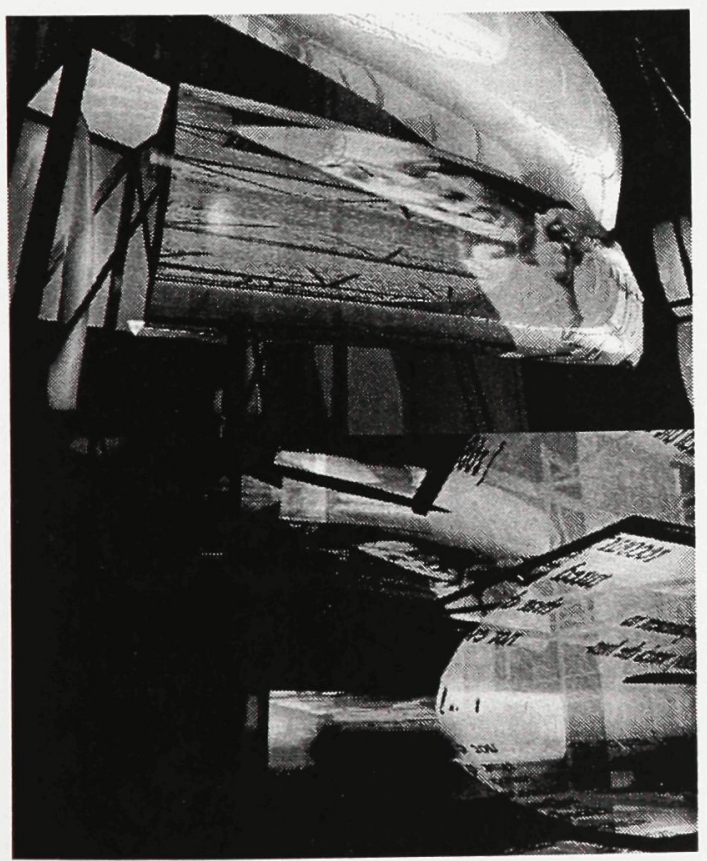

89: Discourse - Digital Model, Video Still that is precisely the failure of Symbolization. ${ }^{150}$ In this failure exists the Real, as that which is left over after symbolization, the Lacanian small object $a$ as the traumatic, irreducible, essentially asocial and non-symbolic object of the Real that is particular to the hysterical subject, and therefore resists its incorporation into the Symbolic Order. ${ }^{51}$ As 'normal' life is structured around the repression of the Real, maintaining the apparent consistency of the Symbolic Order, the recognition of its failure causes a questioning within the subject himself. For Badiou, this is the essential encounter that allows us access to the Real. It's experience, although questioning the semantic stability of the Symbolic Order, also questions but does not destroy the subjects' frame on reality, thus causing it to become an ethical question "articulated from the point of view of the location of man in relation to the Real. ${ }^{952}$

\section{The Return of the Real}

Rather than acting as a repression of the Real, hysteria brings forth its return to everyday reality through non-symbolic representation. ${ }^{53}$ Such a return of the original trauma into 
clear separation between viewer and viewed, the frame in the theatrical performance is not a rigid one, and is able to be disturbed or broken, much as was the case with the theatrical productions of avant-garde playwright and theatre director Antonin Artaud. As an architectural term, framing also has connotations of the structuring or uniting and arrangement of parts to create a whole. This is analogous to the use of a language to create an oeuvre, thus remaining within the symbolic structure.

As a development from the idyllic landscape to the hysterized

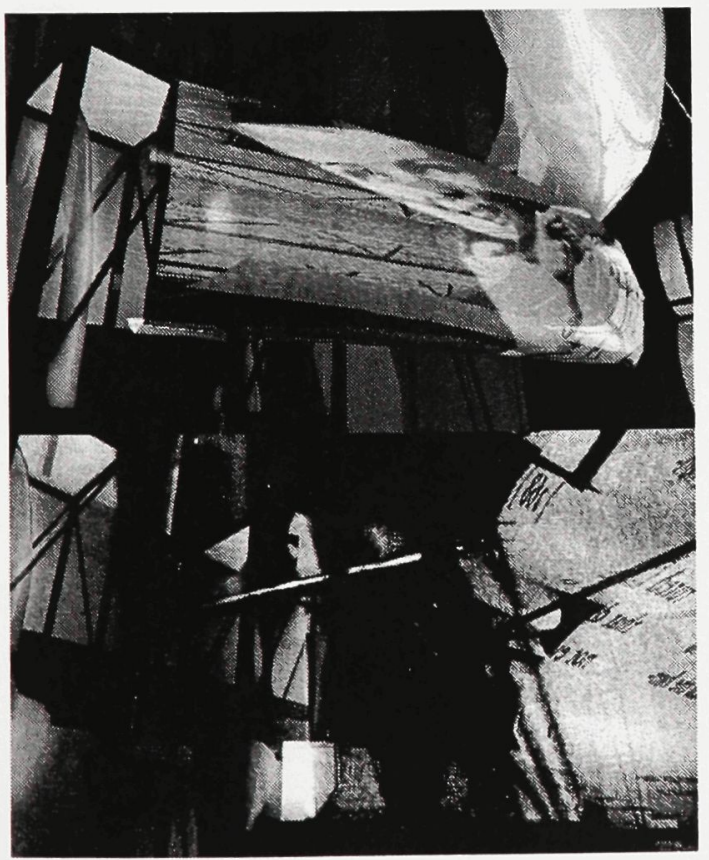

90: Discourse - Digital Model, Video Still symbolic reality occurs as a doubling, as a representation that denotes (marks) the boundary between the viewer's experience of the represented symptom and the existence of the Real, therefore causing a disturbance in Symbolic reality. As this return occurs in a different form, it becomes a double existence, which can also be described as a doppelgänger or monster. In this sense, the perceived identity of the hysteric is constituted of both self and other, not of a unity of the self, but an uncanny and analogous relationship that involves the radically other: that of the Real. ${ }^{54}$

Sigmund Freud noted an analogous relationship between such a doubling that exists in hysteria through the trauma/mnemonic symbol and the monument and its experience in the city. ${ }^{55}$ For Freud, these monuments bear a likeness to hysterical symptoms, as they too are mnemonic symbols commemorating a prior memory, one that is potentially a traumatic experience. But this affinity between the two does not exist any further than that, as the symbolic nature of the monument is not unknown, and our experience of the monument is also not hysterical as there is a knowledge 
landscape, this scene focuses upon the body as an object as perceived through the gaze of the viewer. Through the use of video from the models and photographic images of the clinical body of the hysteric, this scene begins to frame the spatial issues inherent in the understanding of the body as a spectacular unsymbolized object. Unlike the first scene, a whole spatial understanding is not achieved, nor is an experience of the whole body, but the camera rather frames a spatial exploration in which glimpses of the body are presented through both montage and

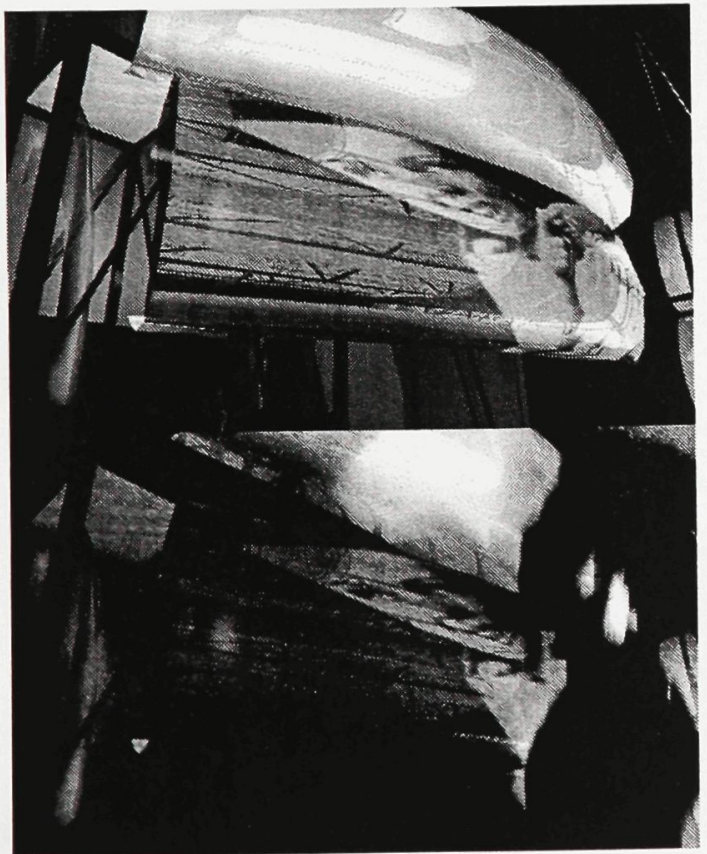

91: Discourse - Digital Model, Video Still

of the traumatic cause of the representational nature that exists within the monument. In this 'paradigm of Hysteria', Freud believes that all citizens of the city behave like hysterics in that they remember and cling to painful experiences of the past emotionally, which he believes must be cured through suppression.

Freud's analogy is then imprecise, yet his view on the citizen's experience of the city points to the nature of the symbol in the city, something prevalent in Joseph Rykwert's The Idea of a Town, where he quotes Freud. Rykwert is concerned with the "town as a mnemonic symbol, or at any rate a structured complex of symbols; in which the citizen, through a number of bodily exercises, such as processions, seasonal festivities, sacrifices, identifies himself with the town, with its past and its founders." ${ }^{\prime 56}$ By becoming associated, and therefore attached to one's environment, one does not repress past memories associated with the city, but rather commemorates them releasing (rather than suppressing) emotion in what Freud believes to be appropriate signs: word and action. What Rykwert is really pointing to, is an apparent lack 
layering.

As a bridge into the experience of the body itself, Framing exists as a crucial stage of development within the narrative of the film providing the viewer a framed and scaled view of the hysterical body, while allowing a glimpse of what exists beyond the framed and symbolized reality. By the end of the scene a transition occurs leading to the interaction with the body, where what has been 'cropped' by the frame begins to expose itself by blurring it's edges.

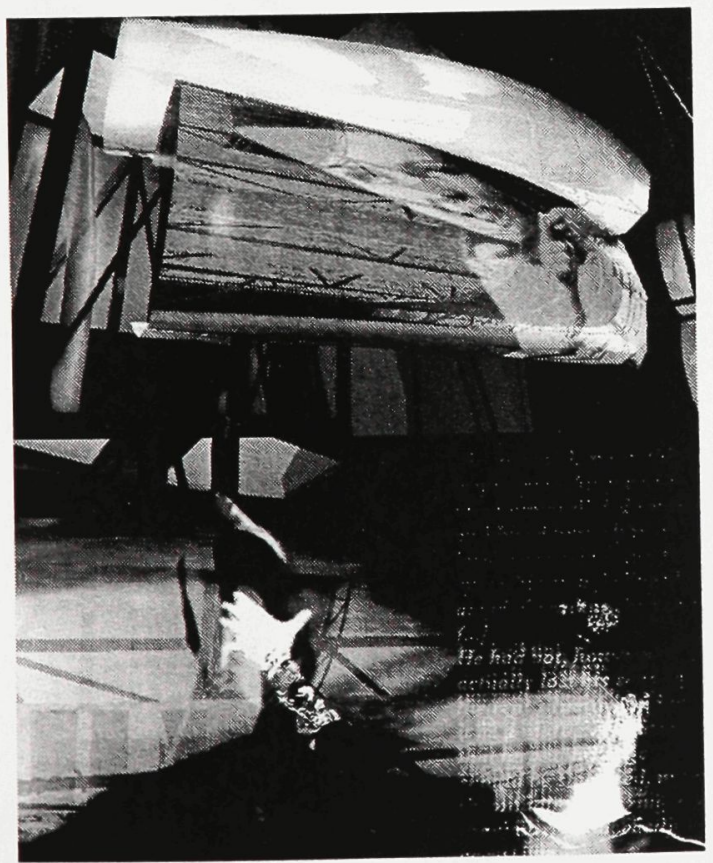

92: Discourse - Digital Model, Video Still of plural and metaphorical meanings within the city, that instead it has become an efficient instrument of production and consumption negating any symbolic meanings. By an absence of movement within the artifact,${ }^{57}$ an abjection reaction that questions or alters the viewer's boundaries is entirely impossible, limiting the experience to a meaning that exists within the framed reality of the viewer, even if it is multiple in nature.

\section{The Demark: Enjoy What Cannot Be Integrated Into Symbolic Reality}

This discussion regarding the existence of the Symbolic within the city still maintains itself within the social network of symbolic relationships as an agreed upon meaning, thus negating what Kunze refers to as the asymbolic: the non-symbolized object. ${ }^{58}$ This object, one that is prevalent in Alfred Hitchcock's films, functions in the same manner as the hysteric's traumatic Real does in inter-subjective relations. Because of this, Kunze describes this object, referred to by Gilles Deleuze as the demark, as the hysteric's 'source and object of delight'. The demark operates within a set of relations between viewer and object, in what Deleuze refers to in 
Scene 3 - Discourse

As opposed to the gaze implicit within the framing of the hysterical body, 'Discourse' implies two things: one being the interaction between viewer and viewed as an experience of the demark, as well as the discourse or questioning that occurs between the hysteric and the absent or Big Other. As a continuation from the previous scene, the hysterical discourse is

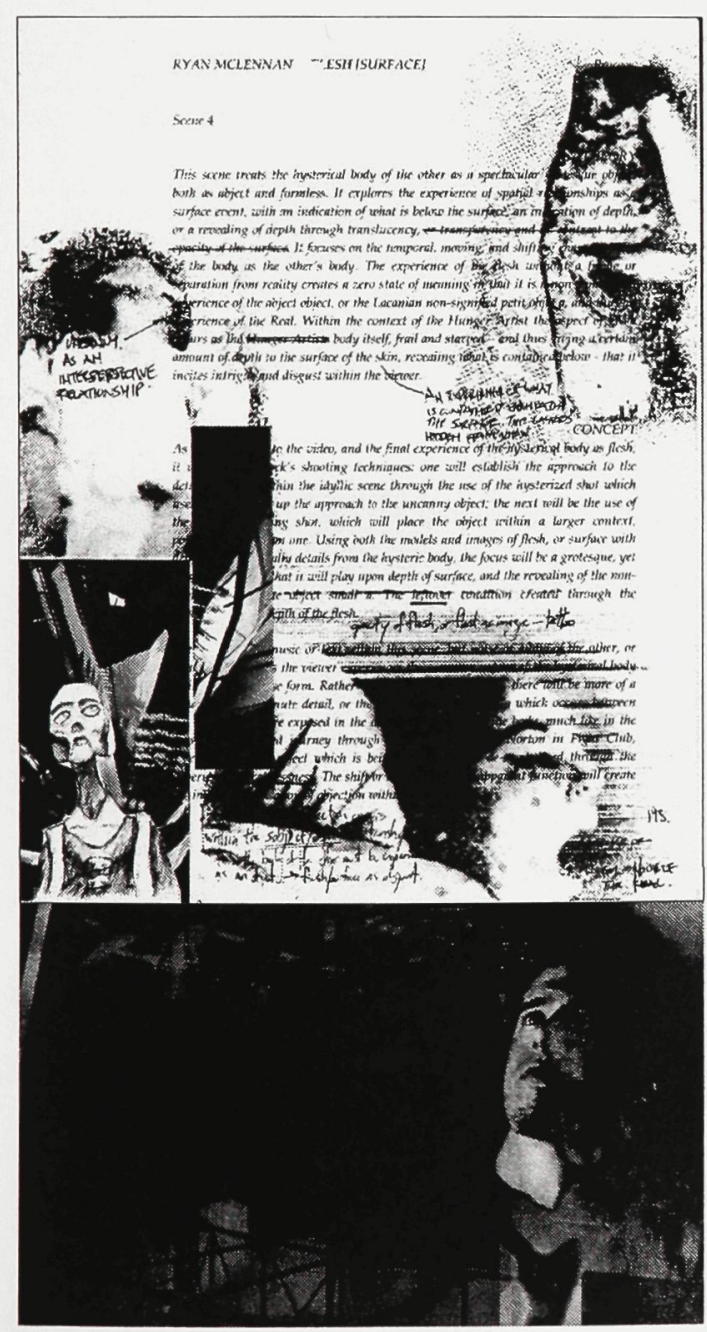

93: Flesh - Script Collage, Video Still cinematography as the 'mental-image'. ${ }^{59}$

Within the mental-image, Deleuze notes that Hitchcock creates two types of signs based upon two forms of relations that occur in philosophy: natural and abstract. In the natural relation, a "term [or object] refers back to other terms in a customary series such that each can be 'interpreted' by the others: these are marks." ${ }^{\prime 60}$ They are habitual forms of marks whose relationship occurs along the saggital, and therefore marks of representation. The demark on the other hand occurs within abstract relations, existing when a term (object) departs from the network of relations, appearing in a new context, or else becoming contradictory within the existing context. ${ }^{61}$ In order for the demark to function it must then be an ordinary object, occurring in an ordinary set of relations for it to be able to be removed or relocated.

Although it is common in Hitchcock's films, it is in Foreign Correspondent that we not only see one of the demark's most famous examples, but also one of the most effective (Fig. 94). In pursuit of kidnappers, the hero arrives in an idyllic Dutch landscape of fields and windmills, only to find that the criminal has 


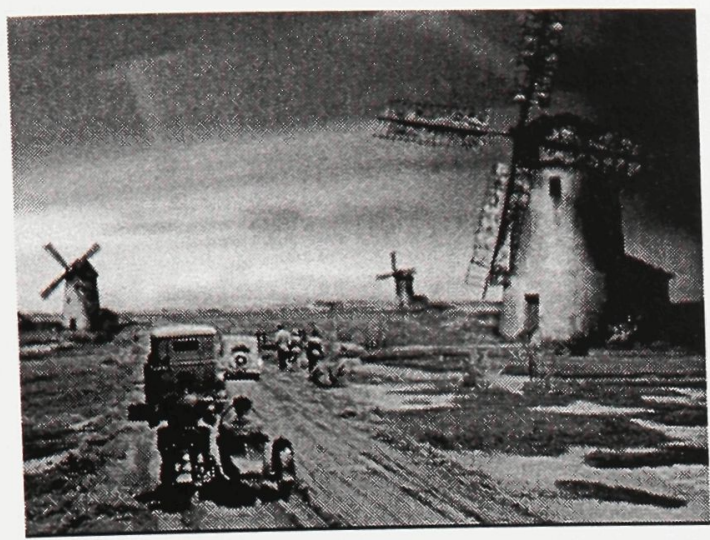

94: Idyllic Dutch Landscape from Foreign Correspondent, Dir. Alfred Hitchcock (1940, DVD, Warner Brothers, 2004)

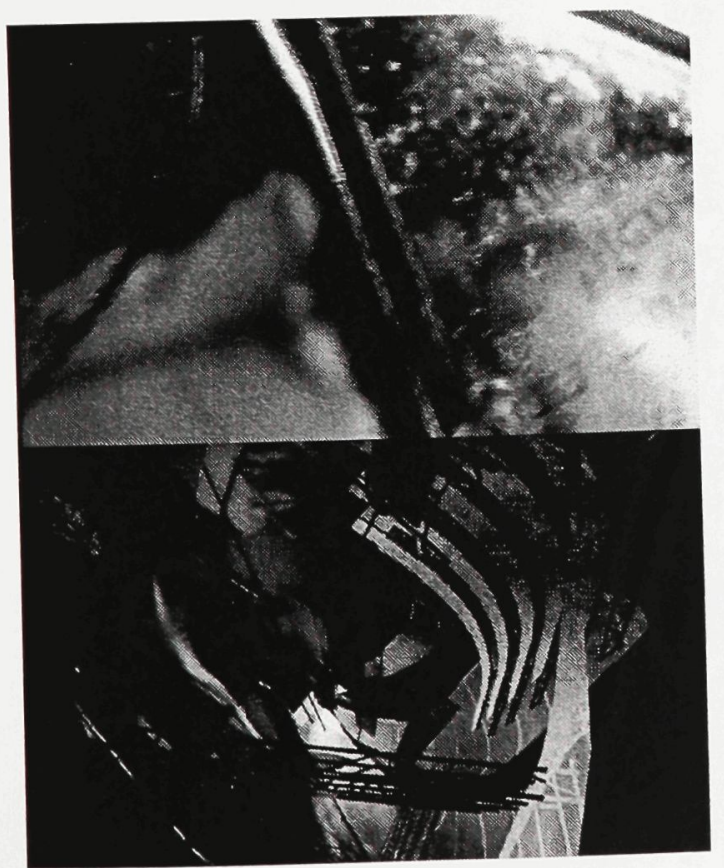

95: Flesh - Model, Video Still disappeared. All of a sudden he realizes that one of the mills is rotating against the wind. Once he detects this, the Lacanian point de capiton (the quilting point) comes into play, denaturing "a perfectly 'natural' and 'familiar' situation", causing it to become 'uncanny', "loaded with horror and threatening possibilities."62 This uncanny nature comes from the additional placement of the detail that is out of place into the idyllic landscape: the demark. Through its introduction it becomes a negative of its original, an absence that inverts the order within the image, especially the order of center and periphery, inside and outside as in the case of the hysterical body.

We might compare the demark to a fragment that can only function within the image if it is a recognizable object, where one can visualize where it was taken from. The original context is not lost, but rather it is the association of the object to its original context that allows the scene to become uncanny. This use of the fragment can be seen in collage, especially those of Max Ernst whose collages remain as apparently ordinary spatial representations. These scenes are denatured by the introduction 


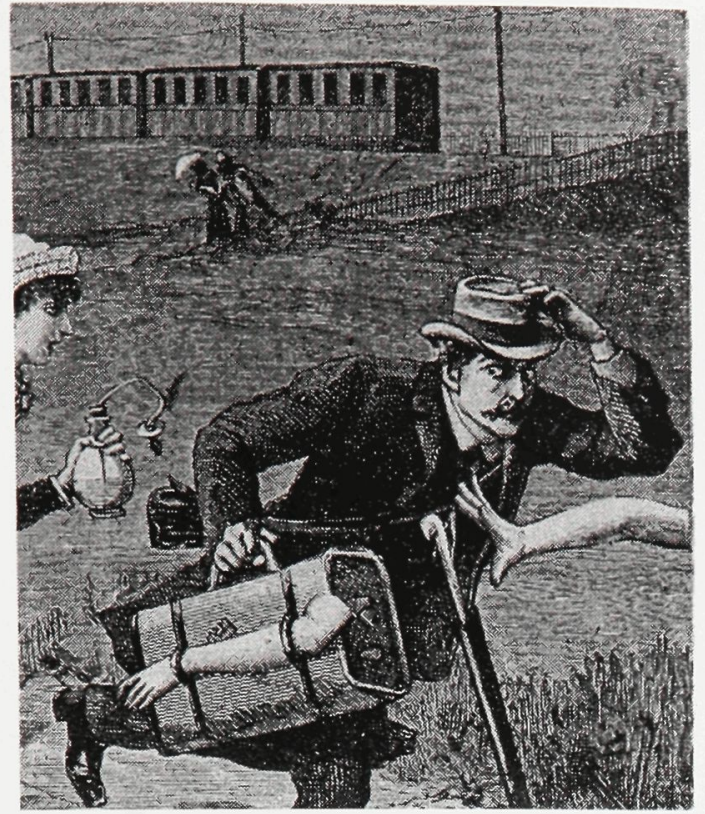

96: Max Ernst, La Femme 100 têtes (Paris: 1929), Chapter 3, plate 2. 'Open our bag my good man.' from David Lomas, The Haunted Self (New Haven and London: Yale UP, 2000) 90.

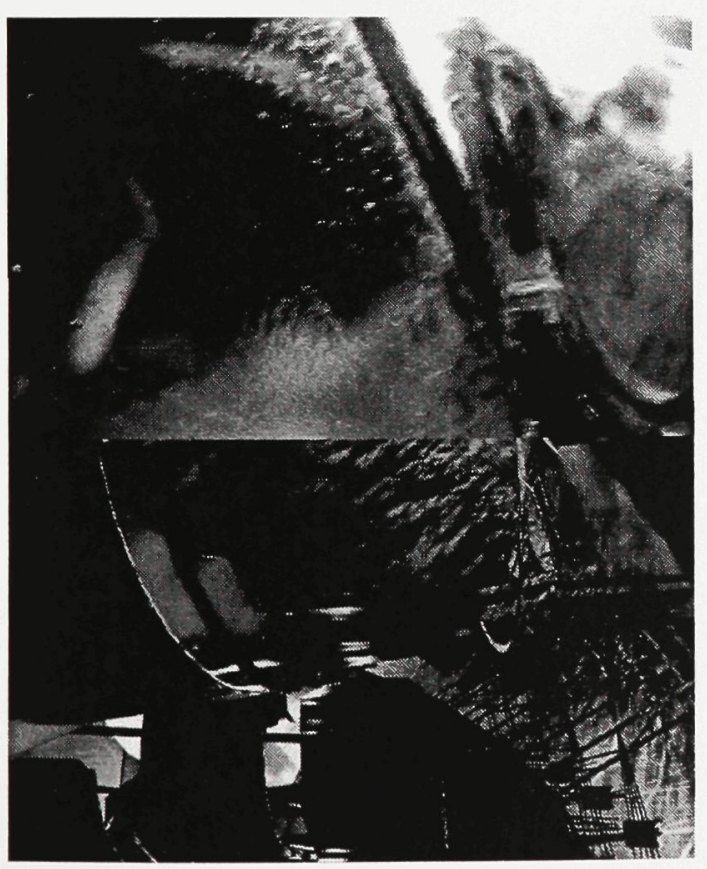

97: Flesh - Model, Video Still of one or several foreign objects into the image, literally cut and pasted from a different scene altogether. This use of collage, in a sense subverts the premise of realism by altering the very reality of the scene. David Lomas, in the Haunted Self, finds that a parallel can then be drawn between this form of collage and hysterical conversion, not only due to its pictorial or representational language, but because it is a pictorial language pointing to the repressed underside of the Symbolic Order. In doing so, both 'outplay', the signified, functioning along the thinness of the surface-image, while signifying depth and space. ${ }^{63}$

As an abstract relation the demark operates upon of the basis of comparison between two images that are not logically united. It then becomes a contradiction between the ideal scene of homogenous reality and the object serving an outside or non-symbolic function within the scene, causing the image to become heterogeneous. In this case the demark does not function as a symbol (as a set of abstract relations) but rather dislocates a series of relations, which of course are a key element within logic, and is why the hysteric's lack of 


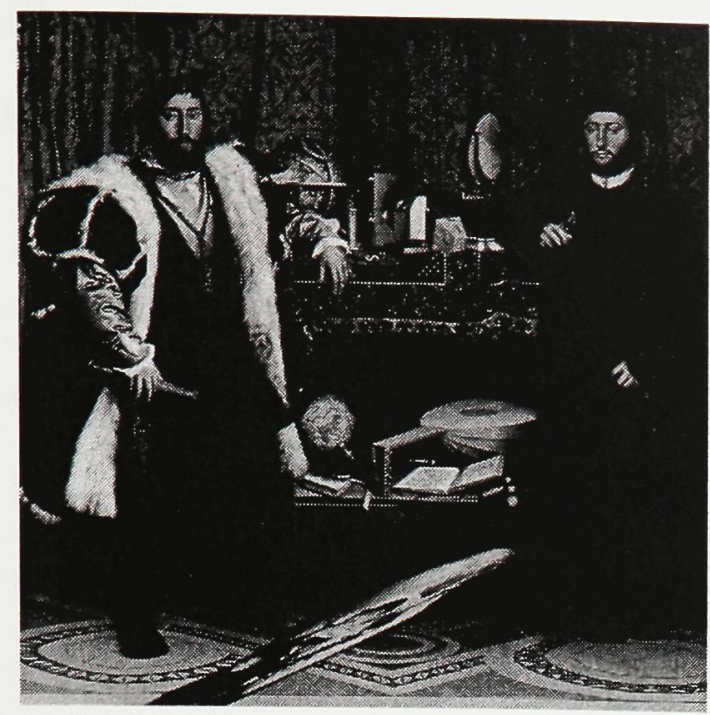

98: Hans Holbein, The Ambassadors, 1533 from artarchive.com (2005, <http:// www.artchive.com/artchive/h/holbein/ambassadors.jpg.html >)

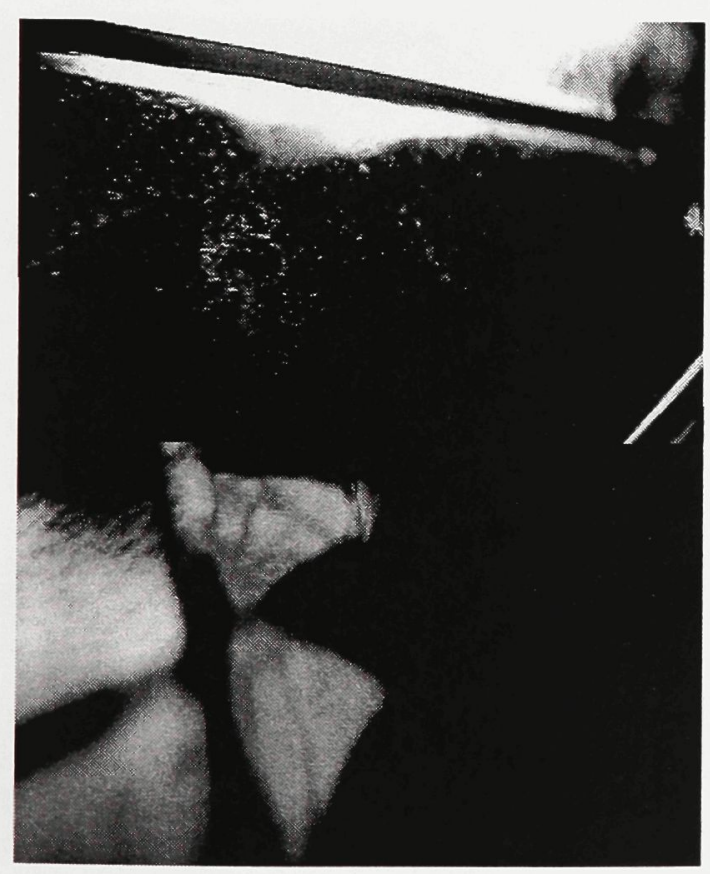

99: Flesh - Model, Video Still causality due to dislocated symptoms, disrupts symbolic continuity. ${ }^{64}$

Much as in Tschumi's folies, the demark is a 'pure' signifier without signified, creating supplementary, metaphorical meanings for all other elements in the scene. What before had seemed completely ordinary, now becomes completely strange. As a stranger in the scene, double meanings arise, and are sought out and interpreted by the gaze of the man who knows too much, the man who recognizes the demark and its value. The effect of the surplus knowledge is that 'truth' in the subject, the representational fantasy frame, is repressed in search of new meaning. Zizek refers to this point of the demark in the image as a 'point of anamorphosis', as it is what remains a meaningless, abject stain until it is viewed from the precise tangential position where its 'truth' is revealed, which occurs through the acquisition of excess knowledge (Fig. 98 and 105). ${ }^{65}$ In the existence of the stain, the subject no longer exists as a neutral, objective viewer, but becomes fixed to the object itself. ${ }^{66}$ Therefore, it is the process of representation that becomes abject, rather than the representation itself. The demarked landscape then exists as a movement 
brought into play, questioning the bodies place within the Symbolic Order. Using Hitchcock's immobile shot to identify the body as a demark within the scene, an interaction with the body towards which we have an abject reaction is created through both image and sound. In this scene the representation of the hysterical body is displayed in its entirety, though there is a distance towards it, allowing for a transition through montage into the hysterized shot of the demark itself in its most non-symbolized form as an object displaced from its natural order. Although there is an

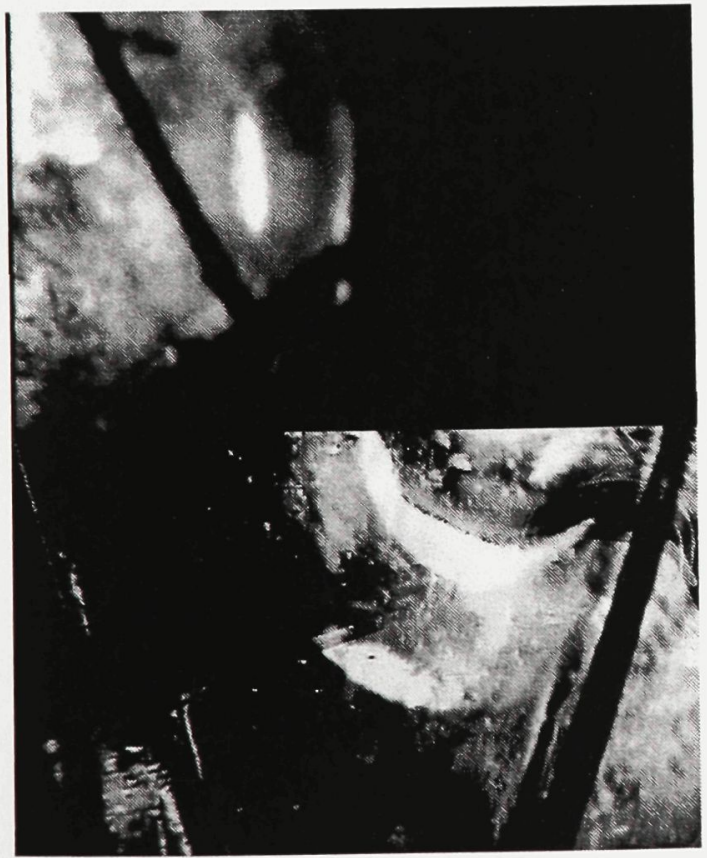

100: Flesh - Model, Video Still within the artifact-image, producing ever new 'hidden' meanings, while the demark itself acts as a trope of abjection delineating where marks cease to perform their representational task and become non-marks; what is an absence within the image.

Identifying the presence of the demark within the scene leads to a state of anxiety, where the scene itself suddenly become uncanny. This anxiety occurs within the frame of the scene itself, where what was already expected, or what existed beneath it, inhabits the frame. Anthony Vidler, in The Architectural Uncanny, states that for Freud, the uncanny, or 'unhomeliness' "was more than a simple sense of not belonging; it was the fundamental propensity of the familiar to turn on its owners, suddenly to become defamiliarized, derealized, as if in a dream." ${ }^{67}$ Much like the stranger, these things that we perceive to be uncanny, creating our anxiety, are much closer or similar to us than we wish to realize.

In part, this anxiety subsists because the gaze exists on the side of the object. The demark, then, exists as the gaze, a "point in the object [in the scene] from which the subject viewing it is 
interaction with the body as demark, it remains as an experience of surface, and it is only through its action and framing within space that allows for it to be recognized through the "point de capiton,' allowing for it to question its placement within the scene itself.

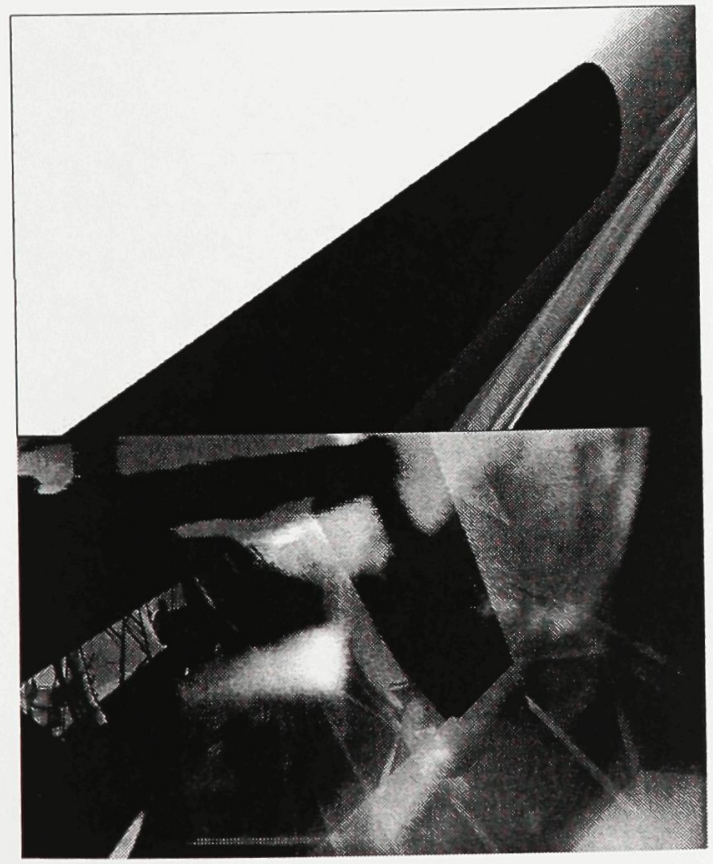

101: Flesh - Digital Model, Video Still already gazed at, i.e., it is the object that is gazing at me."68 This point then disallows the subject from inhabiting an objective distance toward it, forcing them to leave their neutral position and to become a part of what they observe. This is in itself a political experience, as the viewer is forced into an inter-subjective experience, causing them to participate with the scene in front of them, and therefore to reconcile it both in reality and their fantasy. The interaction with the demark forces a questioning of the subjects' desire: what the subject really wants from this interaction. This is the Che Vuoi? that occurs both in racism and the hysteric.

The Hitchcockian method for isolating the demark, as the object of the Real (object small a) is through his famous tracking shot. ${ }^{69}$ Although this formal procedure takes many forms, the key to it is that the scene must circulate around an empty object that can only be approached too quickly or too slowly, because in normal time it exists as nothing. Only through its specific framing can it become identified. Therefore, to produce the demark as a stain in the idyllic scene the tracking shot relies upon an absence; the absence of the object small a from reality, 

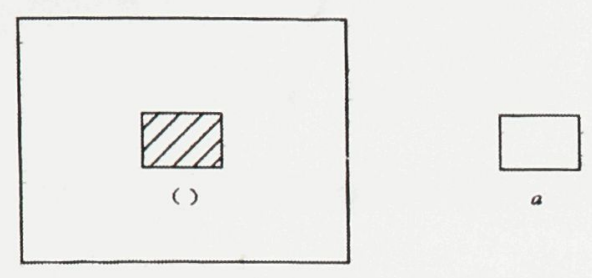

102: 'Object small a' Diagram from Slavoj Zizek, Looking Awry (Cambridge, MA: MIT P, 1992) 94.

\section{The Object Small A}

The object small a or objet a is the Lacanian term for the object that cannot be symbolized within the Symbolic Order. It is the leftover from the Master's Discourse, which is understood in psychoanalysis as the unknown traumatic origin of the exhibited symptoms. It is not a real object, but rather an imaginary structure that is the 'object' of desire. The object small a is associated to the formless object that causes an abjection reaction, as one of disgust due to its blurred nature: "The petit a could be said to take a number of forms, with the qualification that in itself it has no form, but can only be thought of predominantly orally of shittily" Because of this, they are the closest to the uncanniness of the Real, as it is non-relational. It is a hole that cannot be combined or compared with another object.

103: Definition of the Object small a

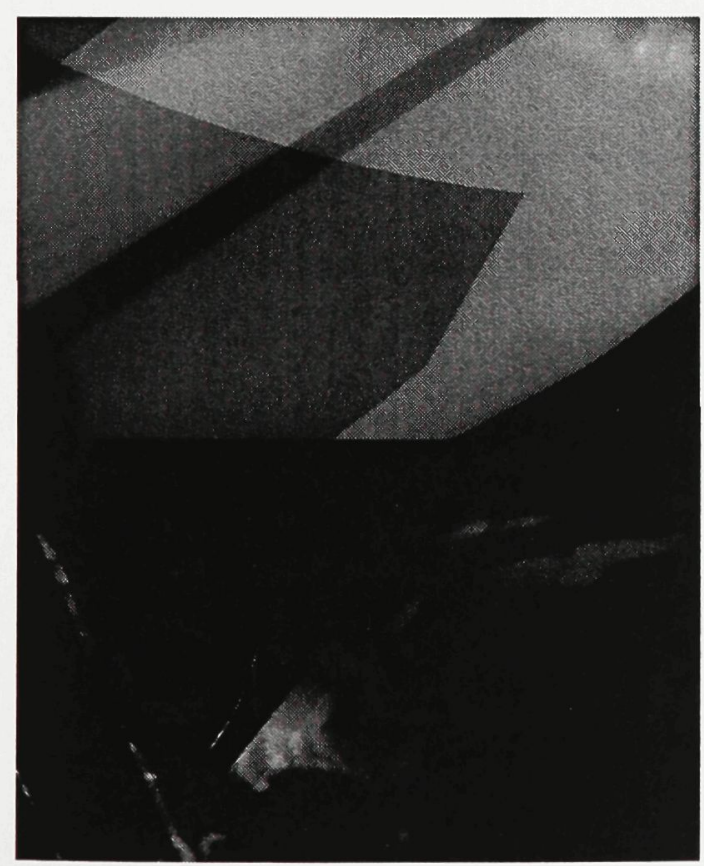

104: Flesh - Digital Model, Video Still which also frames it (Fig. 102):

We understand that the covert setting aside of the object as real conditions the stabilization of reality, as a 'bit of reality'. But if the object a is absent, how can it still frame reality?

It is precisely because the object $\mathrm{a}$ is removed from the field of reality that it frames it. If I withdraw from the surface of this picture the piece I represented by a shaded square, I get what we might call a frame: a frame for a hole, but also a frame of the rest of the surface. Such a frame could be created by any window. So object a is such a surface fragment, and it is its subtraction from reality that frames it. The subject, as a barred subject - as want-of-being - is this hole. As a being, it is nothing but the subtracted bit. Whence the equivalency of the subject and object a. ${ }^{70}$

Zizek sees this schema as the schema of

the Hitchcockian tracking shot: a movement from overall view of realty towards the stain provides it with its frame. Through the dynamic process of approaching, or identifying the demark-stain within the scene, we come face-to-face with the absence, the object small $a$. In order for the image to remain consistent within symbolic reality, this heterogeneous element must remain a formless, 
Scene 4 - Flesh

As the final scene of the video, 'Flesh' presents the viewer the body of the other as a spectacular and formless object. The experience of spatial relationships becomes a surface event, where there is an

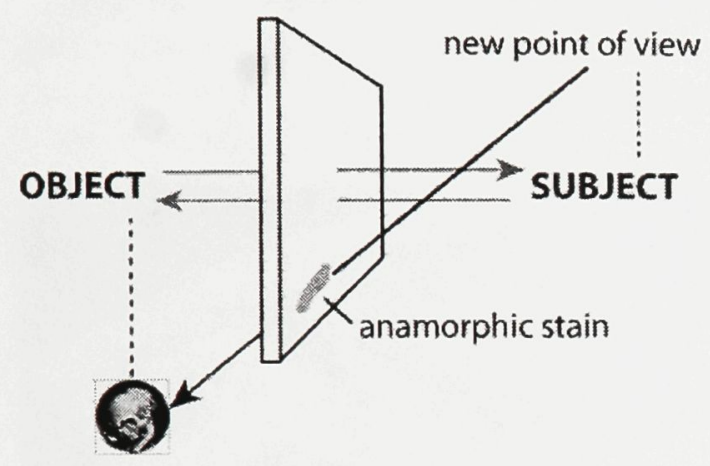

105: The 'anamorphic flip' of the point of view, from Donald Kunze, art3idea.psu. $\underline{\text { edu }}<2005$, http://art3idea.psu.edu/ boundaries/index.html>.

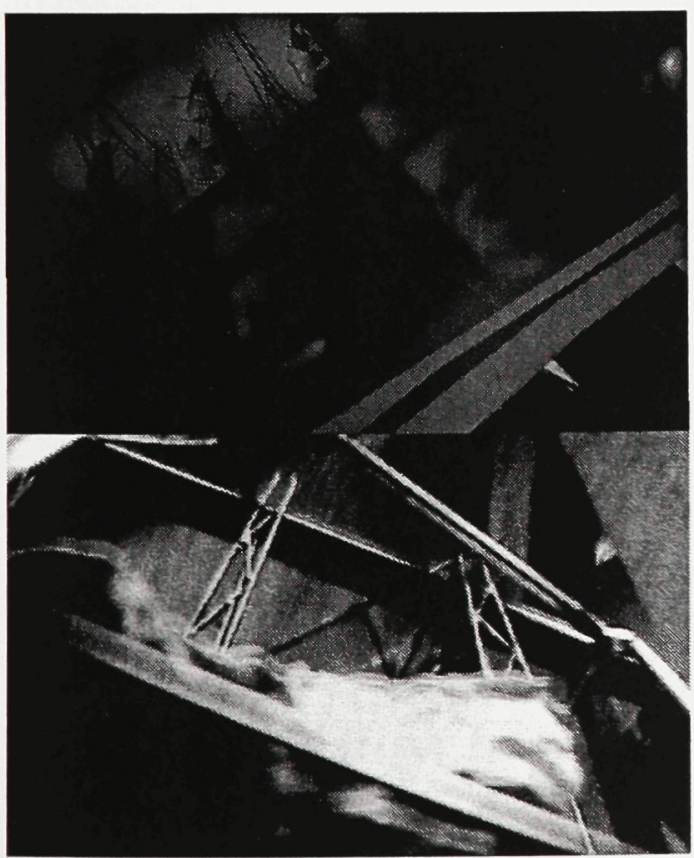

106: Flesh - Digital Model, Video Still abject stain. This cannot occur though, as we are constantly faced with the question that it asks us, constantly forcing a questioning of reality around us, imposing upon the viewer the effects of the Real.

\section{The Demarked Face of Architecture}

What is at stake in the relations that occur in the experience and identification of the demark is not merely an issue of representation, but also an issue of space, and therefore an architectural and political one. Yet in architecture the demark becomes considerably more difficult to identify than in art, where the literal thinness of the representational plane allows for it to be framed as such. But like in art, representational marks are common both in the representation, construction, and building itself.

\section{John Hejduk's Masques, especially} Berlin and Lancaster/Hanover (Figs. 107, 108, 110,112 , and 114), use their narrative and fictional quality to evoke the essence of the carnival, a troupe of architectural objects that "overturn daily routines and commonplace thoughts, upsetting hierarchies and crowning fools." " In doing so, it becomes threatening 


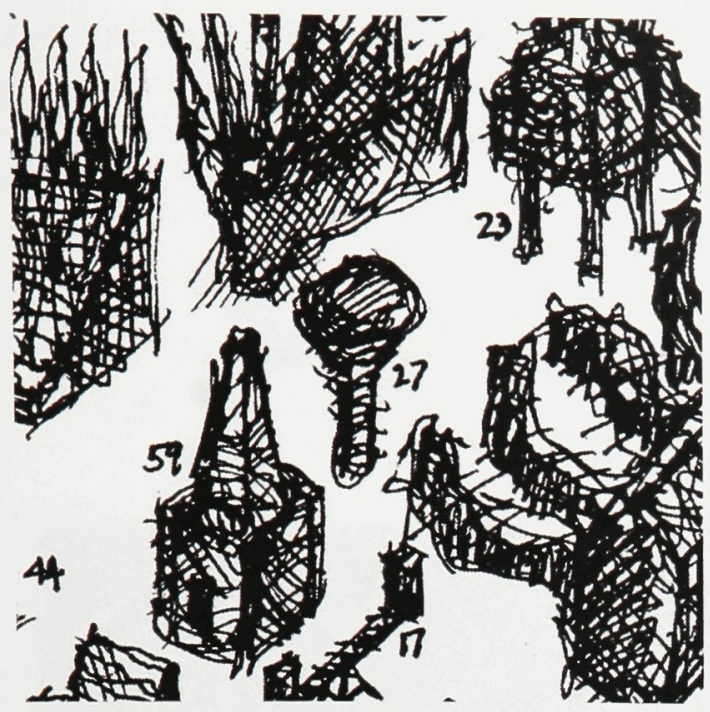

107: John Hejduk, Berlin Masque,

Drawing Detail, 1983 from Mask of Medusa (New York: Rizzoli, 1985) 195.

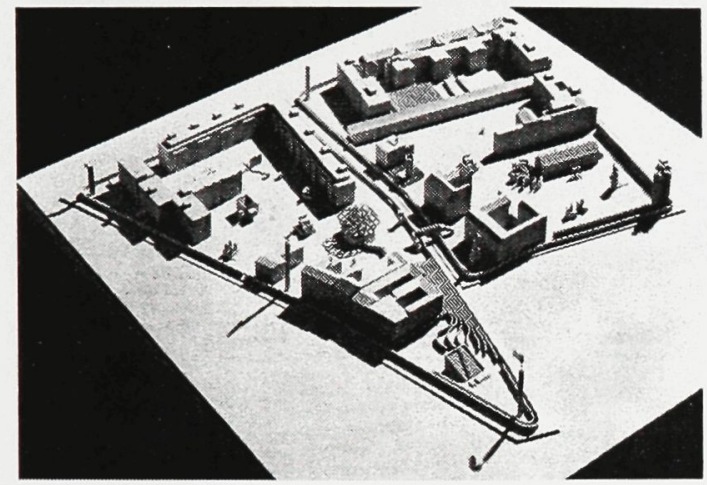

108: John Hejduk, Berlin Masque, Model, 1983 from Mask of Medusa 384.

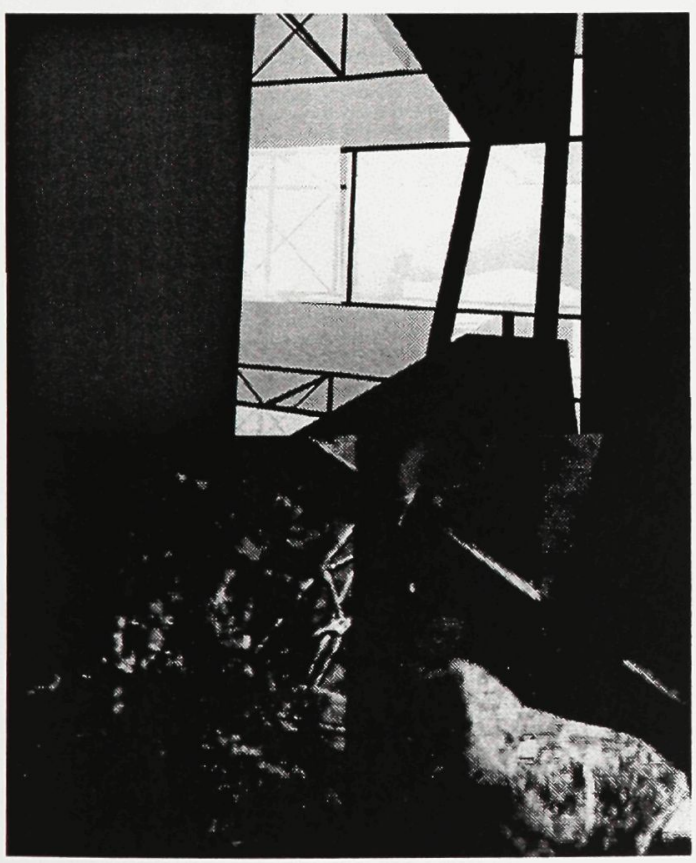

109: Flesh - Digital Model, Video Still in nature, occupying the city as a vagabond or stranger, much like the demark, disquieting the Symbolic order. A parade of signifiers without signifieds impose themselves upon the existing apparently homogenous spatial structure, and in a similar fashion to Bataille's carnival, Hejduk's carnival becomes an experience of the gaps in the homogeneity of the social construct. Such recognition of the inconsistencies in the Symbolic Order comes from creation of "sites for public discourse, and potentially, redemptive reoccupations and imaginative transformations."72 The Masques do not coexist with their surrounding contexts, but are out of place, becoming radical architectural interventions through disruption, inciting uncanny anxiety and critical reflection through the questioning they initiate.

Implicit in the Masques is their theatrical nature, much as is the case in the hysteric. This allows for the symbolic and monumental form given to them to be lost through the appearance of chance. But along with this theatricality, the masques are associated to their other meaning, which is the mask. As a mask these architectures become monstrous, through a 'refusal of 

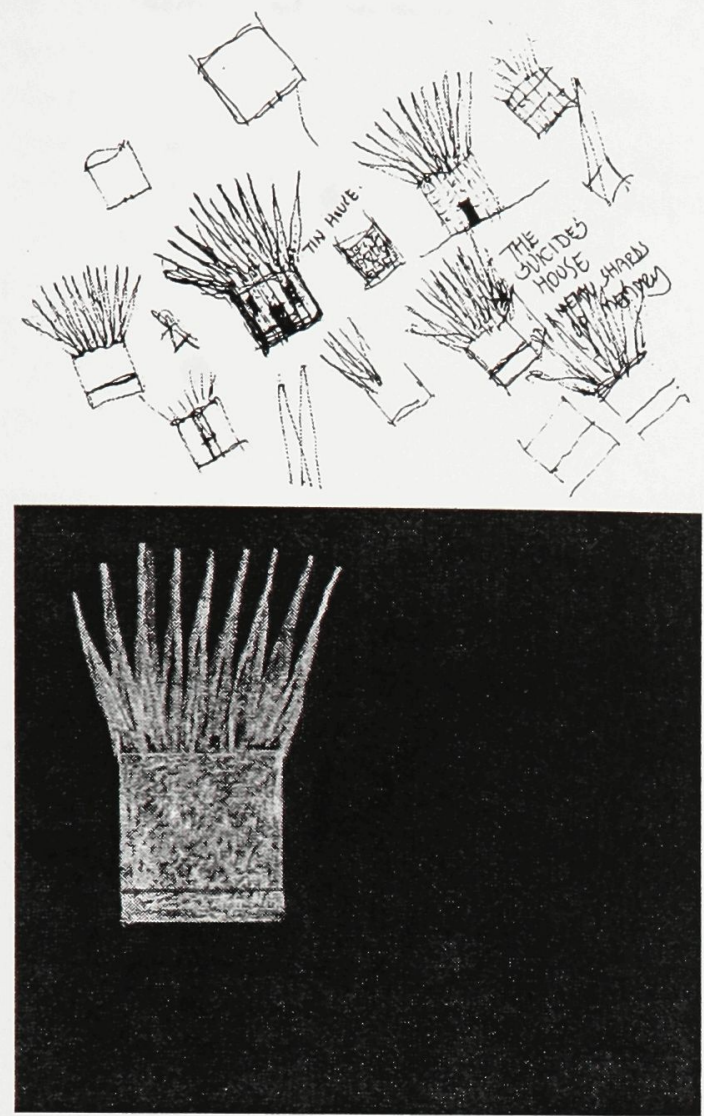

110: John Hejduk, The House of Suicide, Lancaster/Hanover Masque, Drawings from Mask of Medusa, 440-4.

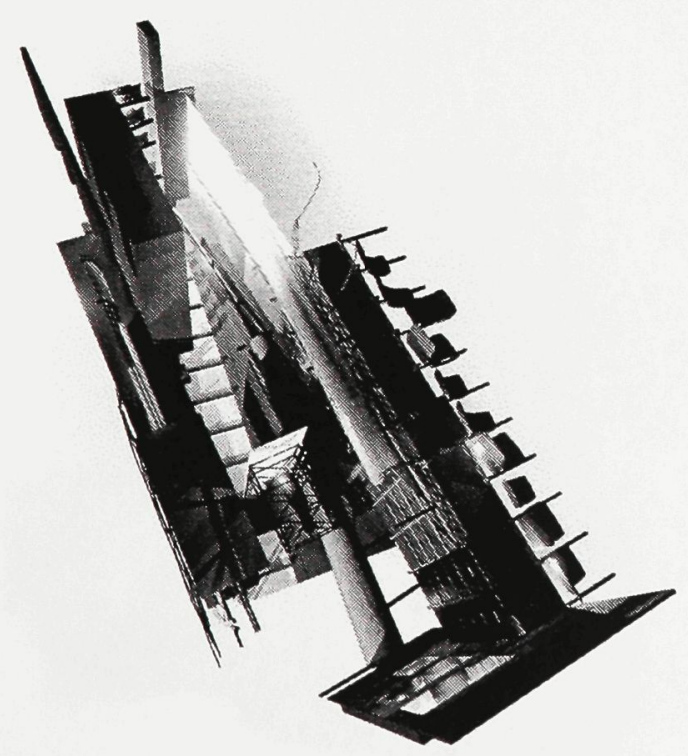

111: Impresario Digital Model categorization,' and therefore through the "reinscription of modernist opacity back into representation itself."73 Like the demark, the mask indicates an element of the Real that did not exist before its representation within the landscape. Architecture as mask denatures and transforms the landscape in the same fashion as it does the face (or body).

In its opacity of meaning, the masque as architecture, protects "the interior from physical and psychic penetration," not only protecting the reflections of the creative self that exist within, but also creates "the aura and mystery so important to Hejduk's safeguarding of the unknowable, the ostensible locale where essences reside."74 That is, the uncanny nature of the Real's existence within the Symbolic.

The masks relation to the face becomes an important issue for both Hejduk's mask and for the demark. As opposed to the "transcendental figure-ground gestalt of [Colin] Rowe's planar collage urbanism," which is a modernist conceptual abstraction of lived reality, Hejduk uses the "elevational pair subject-object", the face or façade, to imply an 'experiential relation' to the ground plane. ${ }^{75}$ Much like the mask, the 


\section{The House of the Suicide}

Structure:

Made of steel panels factory painted white enamel. There is an eye slit in one elevation. A door in the other. Roof is made of vertical volumetric triangular slivers diminishing to a tiny top opening. He likes to watch the points of light move along the wall and floor. The Farm Community in agreement with the family sealed up the door by welding.

\section{The Suicide}

When alive he was obsessed with Cézanne. He believed that the Farm public missed essential and important characteristics about Cézanne. He felt that Cézanne did not want to be touched. The Suicide could even imagine that Cézanne in his privacy put on white gloves that buttoned down at the inner wrist. He knew that Cézanne dealt with the major themes of murder, rape, incest, fear, foreboding, voluptuousness, suicide, sexuality, and night's silent horror. [...] Cézanne landscapes had an aura of dread in them, particularly the ones of rocks and pines. Cézanne's woods were places of premonition and were filled with redemption [...]

112: John Hejduk, The House of Suicide, Lancaster/Hanover Masque, Text from Mask of Medusa, 436-7.

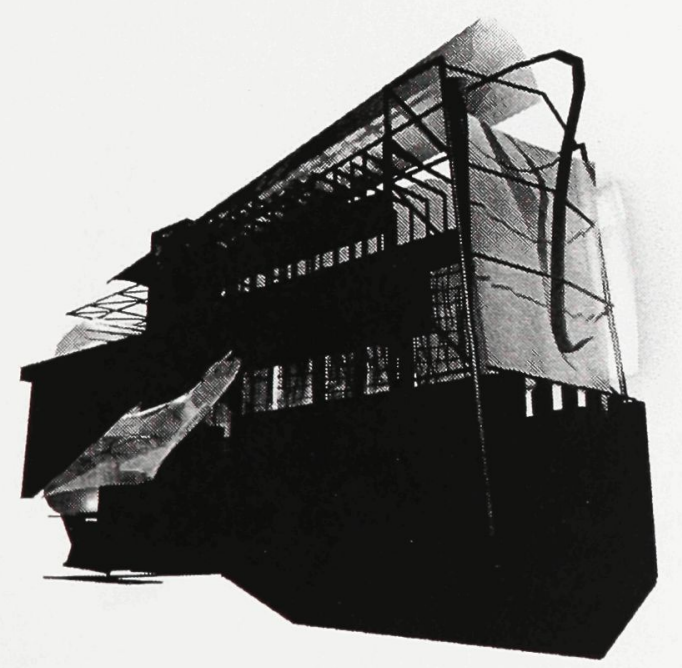

113: Framing Digital Model demark, which is associated to the object small a, functions as a face, and therefore a sectioncondition as something that is representational, but secretive suggesting an interior reality, thus providing the viewer an object of desire. Much like the demark, the face-section suggests to us an absence that frames the viewers reality, causing them to confront it directly. Kunze refers to this frame as the 'fourth wall', "a wall never literally seen without destroying the spell of an illusion." ${ }^{\prime 76}$ Much like the mask/masque and the demark, the section also has a theatrical meaning to it as a scene, where dynamic relations occur between the object and viewer.

Hejduk's Masques then become what K. Michael Hays calls an 'architectural mirror stage', where we recognize that our subjectivity within the Symbolic Order is based upon a loss. He explains this as follows:

We see not so much a reflection of ourselves as a shadow or a distortion, an image that disturbs our narcissistic gaze through what might be called an 'inmixing of otherness,' presenting itself as other to our body and subjectivity. ${ }^{77}$

This is precisely the consequence of the experience of the demark: an experience 

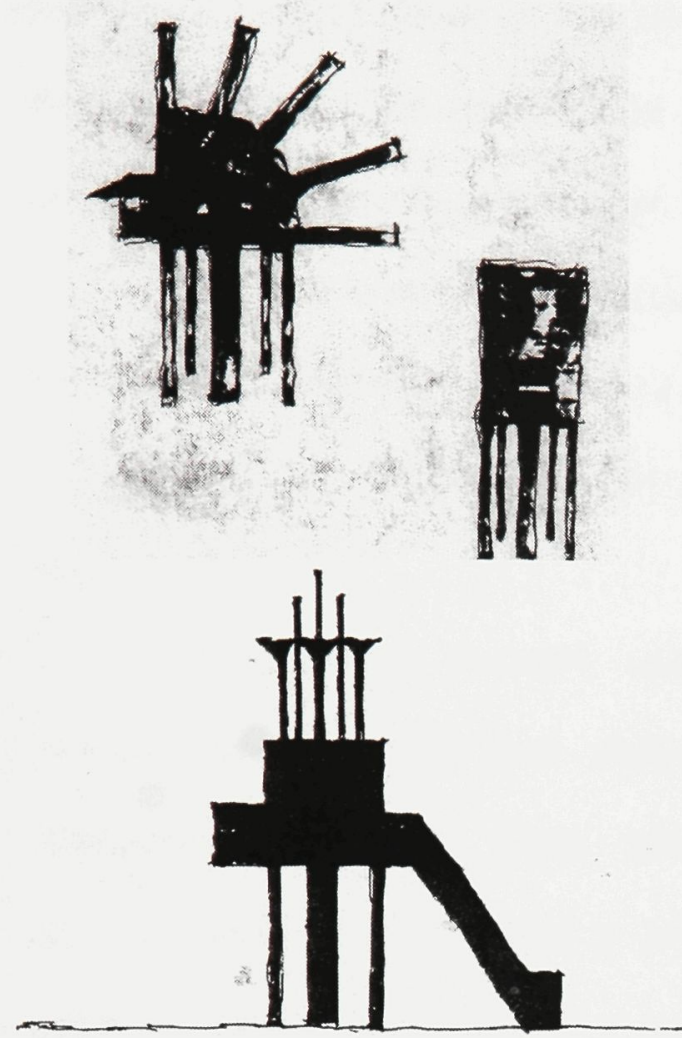

114: John Hejduk, The House of Suicide, Lancaster/Hanover Masque, Drawings from Mask of Medusa, 444-9.

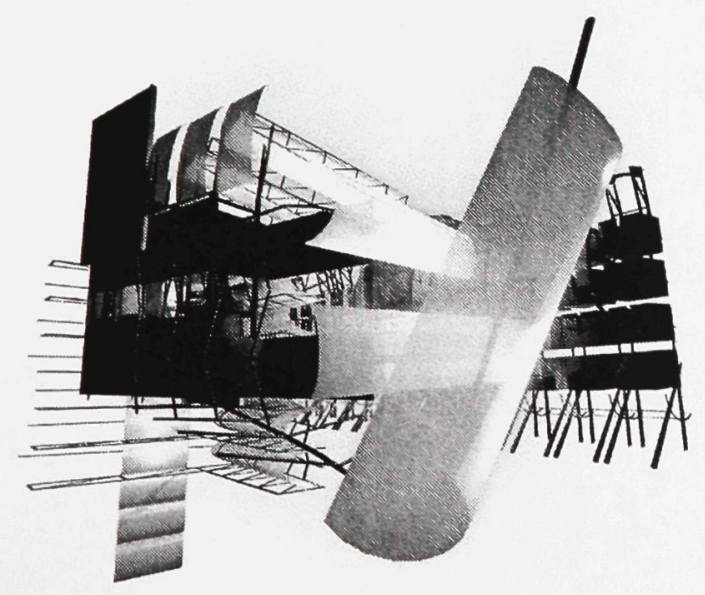

115: Discourse Digital Model of otherness in our 'normal', idyllic reality. Thus in this relation between viewer and object there exists a 'becoming other' in society as a political experience, which through its uncanny interruptions not only causes the subject to question society and architecture's place within it, but also allows for the recognition of the "violence and repression ordinarily suppressed by modern social and spatial institutions" ${ }^{278}$ by existing as a gap between signified and signifier.

\section{The Face of Public Space, and the Demarked Spaces of the City}

As an interruption within the Symbolic space of the abstract city and its specific representations of space that present and strive for an image of homogeneity through reduction, the experience of the demark causes the viewer to recognize that it is not homogenous. Such a realization caused by the unsignified object allows one to identify the fractures and gaps that exist in and because of the abstract space of modernity by pointing to its inconsistencies.

This interaction between objectified viewer and other appears as one that is conflictual, displacing the viewer through an uncanny abjection reaction to the demarked object. It 
indication through depth of the Real that exists within the opacity that is presented by the surface as image. It is an experience of what is contained beneath the surface, where layers of meaning are hidden due to its apparent opacity.

The camera focuses upon the temporal, moving and shifting characteristics of the body, while its experience nears that of a zero state of meaning in that it is a nonsymbolized experience of the object.

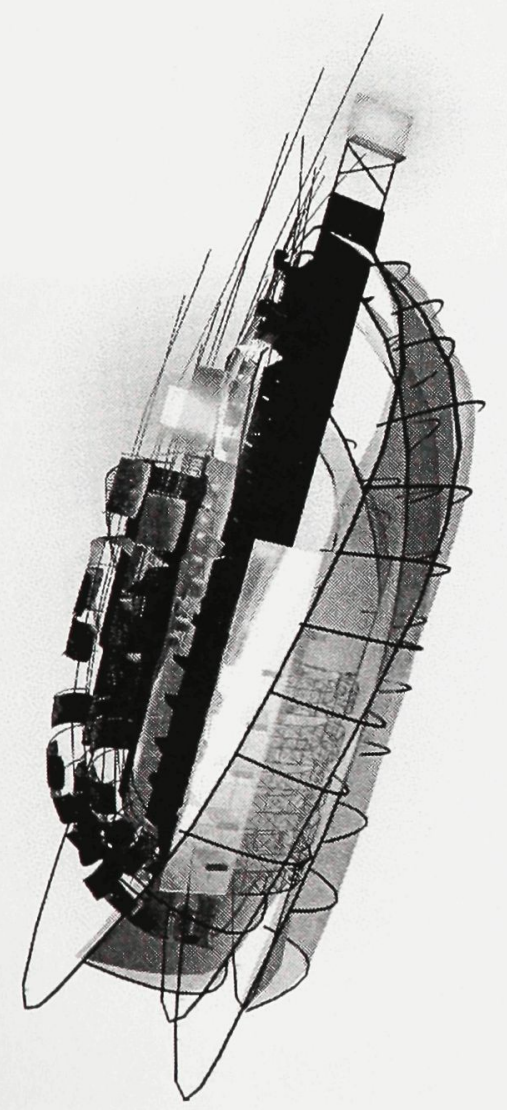

116: Flesh Digital Model is this very displacement through confrontation and realization of the gaps that allows the viewer to question the current abstract orders under which we exist and take for granted, questioning how we frame reality in relation to absence and loss (of meaning).

As an inter-subjective experience, the experience of the demark is also a spatial relationship that reveals a public experience of the city. These spatial conditions (re)frame the inter-subjective relationships in space, causing one to experience the uncanny terror that which lies beneath symbolized reality (the heterotopic, contradictory, differential), an experience of the Real normally veiled within the abstraction of the Symbolic. It is this event that allows for one to partake in the political experience of the city, as the viewer participates in an inter-subjective relationship, forcing them to reconcile the event in both reality and within the fantasy frame. By causing the viewer to alter their fantasy frame, the abjection reaction to the process of representation causes the viewer to no longer inhabit the neutral position of the gaze, but to separate themselves from the Symbolic Order through its questioning. This 
By using both the models and images of flesh, the focus of the camera upon the body itself allows for an excessive experience of the un-symbolized body. Rather than a concentration upon the spatial quality of the scene, there is rather a focus upon the detail as a scaleless spatial condition that occurs between the surface layers, allowing for its de-symbolization. This shift in and lack of scale and inhabitation creates the important abjection reaction within the viewer that can only occur when the other is perceived as an un-symbolized object.

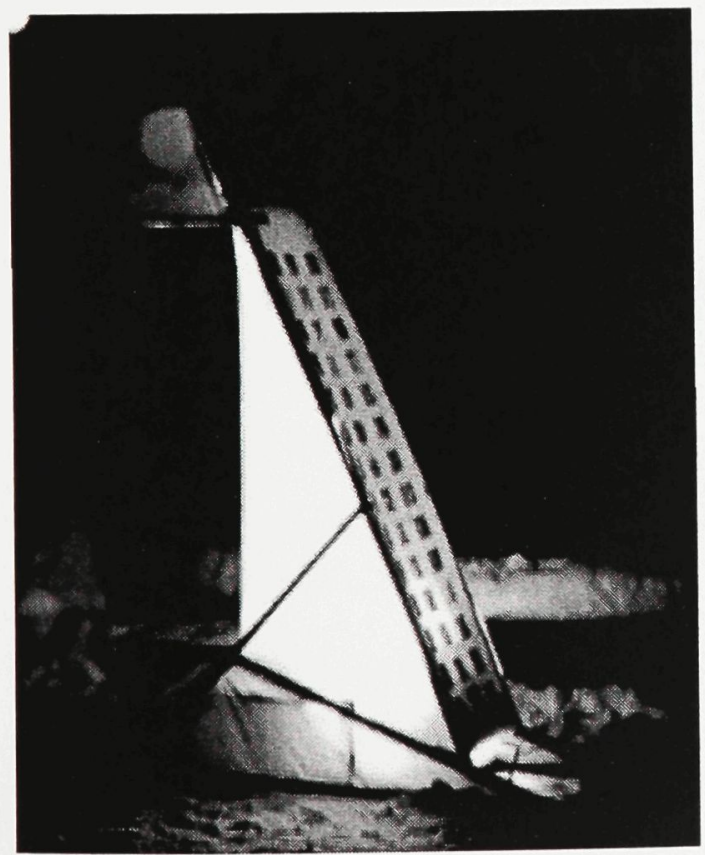

117: Projector Booth reframing constantly attempts to confront and give meaning to the un-signified object, but one is always met with the resistance of being unable to go outside the Symbolic Order where it would become nothingness. Instead it remains a disruption as our fantasy always encased our view. Therefore, the experience of public space allows for the creation of the subject as a distinct entity within the Symbolic Order.

This subjective experience of the city is then a suffered experience between the viewer and the other, much like in Bataille's carnival, celebrating the gaps and holes in society, space, and the individual. The spatial and intersubjective relationship is then not one that is affectionate in nature, but a suffered and conflictual experience that causes the subject disquiet. It is then a hysterical experience of the city, as its experience is a subjective one that enjoys both the pleasure and suffering caused by the experience of this gap in the processes of abstraction and signification. This gap is also where an architecture of public space can develop and exist, creating and allowing for the possibility of a spatial and political experience as and of the hysteric. 


\section{The Architecture of Hysteria Notes:}

1 This is the title of one of Sigmund Freud's draft manuscripts on hysteria, in which he uses architecture to refer to the relation of exhibited symptoms to repressed trauma. As a title of both this chapter and this thesis, I, like the surrealist and modernist writers who have done so before me, am freeing hysteria from its chains as a clinical syndrome, allowing for its possible creative uses as a cultural construction within the reality of architecture.

${ }^{2}$ Elaine Showalter, Hystories (New York: Columbia UP, 1997) 95. Many writers have used this metaphor, including Baudelaire, Flaubert, Mallarmé and Sartre. Hysteria was also used by the surrealists for its subversive nature, in that which is converted into a sign cannot be read as such; the meaning is denied. 2005) 3 .

${ }^{3}$ Donald Kunze, "Marks of the Abject Artifact" (Working paper, n.d. 27 May

${ }^{4}$ Kunze, "Marks" 3.

${ }^{5}$ Ibid.

${ }^{6}$ Kunze, "Marks" 11.

${ }^{7}$ Kunze, "Marks" 4.

${ }^{8}$ Ibid.

${ }^{9}$ Jacques Derrida, "Point de Folie - Maintenant L'Architecture," Rethinking Architecture: A Reader in Cultural Theory (New York: Routledge, 1997) 328.

${ }^{10}$ Kunze, "Marks." 3.

${ }^{11}$ Frank Werner, Covering + Exposing: The Architecture of Coop Himmelb(l)au (Boston: Birkhäuser, 2000) 194.

${ }^{12}$ Ned Lukacher, "The Epistemology of Disgust." Hysteria from Freud to Lacan: Body and Language in Psychoanalysis (Ithaca: Cornell UP, 1989) Xiv. For Lukacher, the hysteric does not have a body as "something in the history of her body could not be formulated, except in symptoms." What is perceived then is the symptoms and when those are unable to be logically signified, the reaction is one of abjection saving the viewer from 
the un-signified object small a, which exists in the Real. In this sense, unlike most subjects the experience of the Hysteric's body, existing wholly in enjoyment and the Real, is more separated from self, as self remains within the Symbolic. For more on subjectivity and the body, see Slavoj Zizek, Organs Without Bodies: On Deleuze and Consequences (New York: Routledge, 2004) 121. For more on the Hysteric and the body without organs, see Gilles Deleuze, Francis Bacon: The Logic of Sensation, Trans. David W. Smith (Minneapolis: U of Minnesota P, 2004) 39-47.

${ }^{13}$ David Lomas, The Haunted Self: Surrealism, Psychoanalysis, Subjectivity (New Haven and London: Yale UP, 2000) 71. Lomas refers to the unconscious simulation of the hysteric as a demi-simulator. 1983)

${ }^{14}$ Lomas, 73. Quoted from Jean Beaudrillard, Simulations (New York: Sémiotext(e),

${ }^{15}$ Kunze, "The Anxious Landscape: The Role of Hysteria in Perception and Portrayal of the Landscape," art3idea.psu.edu (2005. The art3idea) 5. "This [ectoplasmic nature of the externalized symptoms] is hysteria's most scandalous, disgusting form, where the externalization of interior reality refuses and possible symbolic diagnosis." This ectoplasm is then an object beyond possible symbolic representation, but is able to enter the Symbolic as something that is formless.

${ }^{16}$ The object small a or objet a is the Lacanian term for the object that cannot be symbolized within the Symbolic Order. It is the leftover from the Master's Discourse, which is understood in psychoanalysis as the unknown traumatic origin of the exhibited symptoms. It is not a real object, but rather an imaginary structure that is the 'object' of desire. Although it is something essentially unrepresentable, it is associated to the erotogenous zones of the body where "the distinction between inside and outside is both marked and blurred by an anatomical border: lips, the enclosure of the teeth, the rim of the anus, the tip of the penis, the vagina, the slit formed by the eyelids, even the horn shaped aperture of the ear" and the naval. There are also those 'objects' that are impossible to be represented, including: the mamilla, faeces, the phallus (imaginary + symbolic), the urinary flow. As such the object small a is associated to the formless object that causes an abjection reaction, as one of disgust due to its blurred nature: "The petit a could be said to take a number of forms, with the qualification that in itself it has no form, but can only be thought of predominantly orally of shittily" Because of this, they are the closest to the uncanniness of the Real, as it is non-relational. It is a hole that cannot be combined or compared with another object.

${ }^{17}$ Slavoj Zizek, The Metastases of Enjoyment: Six Essays on Women and Causality (New York: Verso, 1994) 30.

${ }^{18}$ Kunze, "The Anxious Landscape," 3.

${ }^{19}$ Zizek, Metastases of Enjoyment, 31.

${ }^{20}$ Elisabeth Bronfen, The Knotted Subject: Hysteria and Its Discontents 
(Princeton, New Jersey: Princeton UP, 1998) 41.

${ }^{21}$ See Georges Didi-Huberman, Invention of Hysteria: Charcot and the Photographic Iconography of the Salpêtriere (Cambridge, Massachusetts: MIT P, 2003)

${ }^{22}$ Didi-Huberman, 117.

${ }^{23}$ During this early period of medical history there was a great deal of competition between physicians for the latest discoveries in medicine. Because of the fame associated with new discoveries, they became spectacles in the theatres of medicine, where ailing subjects were brought in to illustrate the symptoms being presented. Because of this patients such as Augustine would become their physician's masterpieces, which allows us to question the reality or validity of the exhibited symptoms, especially in the case of hysteria.

${ }^{24}$ Didi-Huberman, 163.

${ }^{25}$ Susan Sontag, "Introduction," Antonin Artaud, Selected Writings (Berkeley, California: U of California P, 1988) Xxxiii.

${ }^{26}$ Didi-Huberman, 252.

${ }^{27}$ Zizek, Metastases of Enjoyment, 150.

${ }^{28}$ Anthony Vidler, The Architectural Uncanny: Essays in the Modern Unhomely (Cambridge, Massachusetts: MIT P, 1992), 222.

${ }^{29}$ Georges Bataille, Oeuvres Completes, Vol. 2 (Paris: Gallimard, 1970) 403-6. As quoted by Didi-Huberman, 263.

${ }^{30}$ Zizek, Metastases of Enjoyment, 27.

${ }^{31}$ Kunze, Abject, 5 .

${ }^{32}$ Kunze, Abject, 7.

${ }^{33}$ Ibid.

${ }^{34}$ Ibid.

${ }^{35}$ Ibid.

${ }^{36}$ Zizek, Organs Without Bodies: On Deleuze and Consequences (New York: Routledge, 2004) 121. Zizek notes that this is opposed to the unity of body and subject described by such thinkers as Maurice Merleau-Ponty and Heidegger. In this instance the subject 'is' their body.

${ }^{37}$ Didi-Huberman, 149. By a tetanized loss, Didi-Huberman is referring to the spastic (tetanized) movements that the hysteric exhibits.

${ }^{38}$ Vidler, Architectural Uncanny, 69. 
39 Werner, 37.

40 Sontag, xxxv.

${ }^{41}$ Vidler, Architectural Uncanny, 76.

${ }^{42}$ Werner, 11. Quoted from Gerd Hatje, ed., Coop Himmelblau, Architecture is Now: Projects, (Un)buildings, Actions, Statements, Sketches, Commentaries, 1968-1983 (New York: Rizzoli, 1983) 107.

${ }^{43}$ Werner, 12.

${ }^{44}$ Werner, 24.

${ }^{45}$ Bronfen, xii.

${ }^{46}$ Zizek, Looking Awry: An Introduction to Jacques Lacan through Popular Culture (Cambridge, MA: The MIT P, 1992) 131.

${ }^{47}$ Tony Myers, Slavoj Zizek (New York: Routledge, 2003) 89.

${ }^{48}$ Bronfen, xiii.

${ }^{49}$ Zizek, Metastases of Enjoyment, 22.

${ }^{50}$ Myers, 91.

${ }^{51}$ Peter Hallward, "Translator's Introduction," Ethics: An Essay on the Understanding of Evil (New York: Verso, 2002) xvii.

52 Ibid.

${ }^{53}$ By asymbolic or non-symbolized representation, symbolic I am referring to representation of the formless object, object small a, which in itself is an element of the Real, which is the cause of our desire.

${ }^{54}$ Lomas, 98. Quoted from Elza Adamowicz, "Monsters in Surrealism: Hunting the Human Headed Bombyx", Modernism and the European Unconscious (New York: St. Martin's P, 1990) 299. In artistic creation, it is the radical otherness of the monster identity that allows access to those things psychically inaccessible to the artist.

55 This lecture on psychoanalysis was given by Freud at Clerk University, Worcester, Mass., in 1909, and is quoted in Joseph Rykwert, The Idea of a Town: The Anthropology of Urban Form in Rome, Italy and the Ancient World (Cambridge, Massachusetts: The MIT P, 1988) 188.

${ }^{56}$ Joseph Rykwert, 189.

57 The architectural artifact in the urban context can be compared to the sense that Aldo Rossi gives it in The Architecture of the City (Cambridge, Massachusetts: MIT P, 1982). 
${ }^{58}$ Kunze, "Anxiety," 12.

${ }^{59}$ Gilles Deleuze, Cinema 1: The Movement-Image (Minneapolis: U of Minnesota $\mathrm{P}, 1986)$ This book looks at specific cinematographic concepts, as a composition of images and signs of the movement-image.

${ }^{60}$ Deleuze, Cinema 1, 203.

${ }^{61}$ Ibid.

62 Zizek, Looking Awry, 88. The uncanny nature of the scene inhabited by the demark is directly related to defamiliarization in art.

${ }^{63}$ Lomas, 83.

${ }^{64}$ Deleuze, Cinema 1, 204.

${ }^{65}$ Zizek, Looking Awry, 90.

${ }^{66}$ Georges Bataille uses tache (stain/spot) to designate a 'mark'; a sign that can be either good or bad. In this context I wish it to be understood as that which makes this abject, which does not necessarily mean dirty.

${ }^{67}$ Vidler, The Architectural Uncanny, 7.

${ }^{68}$ Zizek, Looking Awry, 126.

${ }^{69}$ Zizek, Looking Awry, 93.

${ }^{70}$ Jacques-Alain Miller, "Montré à Premontré," Analytica 37, (1984), 28-9. As quoted in Zizek, Looking Awry, 94-5.

${ }^{71}$ Vidler, Architectural Uncanny, 209.

${ }^{72}$ Detlef Mertins, "The Shells of Architectural Thought," Hejduk's Chronotope, Ed. K. Michael Hays (New York: Princeton Architectural P, 1996) 27.

${ }^{73}$ K. Michael Hays, ed., "Hejduk's Chronotope (An Introduction)," Hejduk's Chronotope (New York: Princeton Architectural P, 1996) 11.

${ }^{74}$ Mertins, 40.

${ }^{75}$ R.E. Somol, “One or Several Masters?” Hejduk's Chronotope, Ed. K. Michael Hays (New York: Princeton Architectural P, 1996) 103.

${ }^{76}$ Kunze, "The (Architectural) Section," art3idea.psu.edu (2005. The art3idea)

${ }^{77}$ Hays, 18.

${ }^{78}$ Mertins, 29. 


\section{4 \\ Architecture and Looking Awry}

\section{The Anamorphic Lens of Theory}

The architectural process is a process of making through language, image and form. It is a means through which an issue can be redefined within the conventional practice of architecture. The use of analogies and the exploration of related theoretical premises displace an issue allowing access to a resolution that would not have been conceived or generated prior to its undertaking, and one that can be achieved only through a questioning of that which is generally accepted in practice. In attempting to address and understand the issue of the creation and fundamental nature of making architecture in the abstract spatial construct of the city - specifically that of public space - process becomes a means through which the issue can be displaced in making in order to obtain new and alternate understandings of its formative qualities and architectural associations. Such a use of process as the development of a theoretical approach differs considerably from a dogmatic and instrumental form of theory, which creates a rigid frame within which one functions. Rather, theory as process allows for the creation of a lens through which one is able to view the making of architecture. 
The use of displacement in the architectural process, as a means to investigate and generate a theoretical approach towards the fundamental concern, is analogous and potentially identical to the role of anamorphosis. Meaning the "projection of forms outside their visible limits," anamorphosis is an image intentionally distorted through perspective that, when "viewed from a precise vantage point (the convergence point of a geometrical construction), the distorted image recovers a recognizable form." image that is created from this process is a formless object in which there is the possibility to allow for a slippage or overturning of meaning to occur from the original image (or issue) expanding the image in such a way that the original meaning contained can no longer exist in the same form, but is forever altered through its re-contextualization. By manipulation of the image, anamorphosis is also "manipulating the theory of perspective (perspectiva artificialis)," thus "revealing the potential discontinuity between an object present to perception and its visual appearance." 2

In the theoretical approach of anamorphic displacement the topic of concern itself reveals the discontinuity between it and its original meaning, due to a slippage in the process of signification, while also pointing to the gaps in the social constructs that frame the issue and limit it to a specific meaning. Therefore, much like anamorphosis, one uses displacement to 'look awry' at an issue, allowing the real issues inherent in ones concerns to come to the forefront by looking at it through a specific point of reference.

The use of the experience of difference and hysteria in the critical architectural process, as a means to displace the issue of the making public space, are both "analogies specific to sets of interest that will shortly fade and be replaced"3 through the creation of architecture. As Donald Kunze states, "because the logic of architecture as an art is eternal, in the 'non-sentimental' sense of that adjective, we can use analogies in the 'good faith' that they are ironically self-destructing, but that in their evaporation from the stage of our concerns, they leave behind a residuum." ${ }^{\prime 4}$ The residue or remnant that is created 
by the use of analogy in process maintains its existence in the form and quality of the work itself rather than as a direct reference that is needed to justify the work. Representations of these analogical associations do not take on a formal or generative process, but rather persist in the work through the creation of a lens existing as a stain in the architecture. As in the demark, these analogies refer to an absent order that existed in the creation of the theoretical lens. Analogy stains the process of making both in construing and constructing architecture.

The architectural project in this thesis is a topos of investigating the use of the anamorphic lens of theory in the making of architecture. It approaches the issue of making architecture that relates to the public experience of the city through the stated theoretical lens. The architecture is then no longer merely concerned with a theoretical understanding of the issue of public space, but attempts to concretely engage the issue within the context of the ByWard Market in Ottawa. The proposal takes into account the existing conditions of the site, as well as the city as a whole. The program is both derived from the lens (due to the speculative nature of the thesis), as well as the specific nature of the site and its social context.

\section{Architecture and Looking Awry Notes:}

'Alberto Pérez-Gómez and Louise Pelletier, "Introduction," Anamorphosis: An Annotated Bibliography (Montreal: McGill University Libraries, 1995) xi.

${ }^{2}$ Pérez-Gómez, xii.

${ }^{3}$ Donald Kunze, Marks of the Abject Artifact (Working paper, n.d. 27 May 2005) 6.

${ }^{4}$ Ibid. 


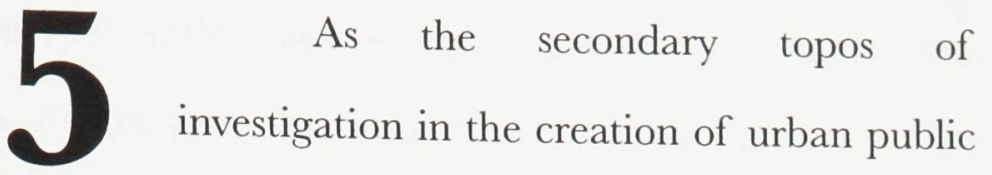

\section{Addressing the Cut space, the architectural investigation exists as} A Mixed-Use Building in an inquiry that is at once distinct from the Ottawa's ByWard Market theoretical process from which it follows, while also acknowledging it as a theoretical and speculative precedent. Although nongenerative in the systematic or derivative sense of the expression, the process and theory developed prior to the architectural design serves the purpose of a specific theoretical and intuitive knowledge that both marks the architecture itself, while informing

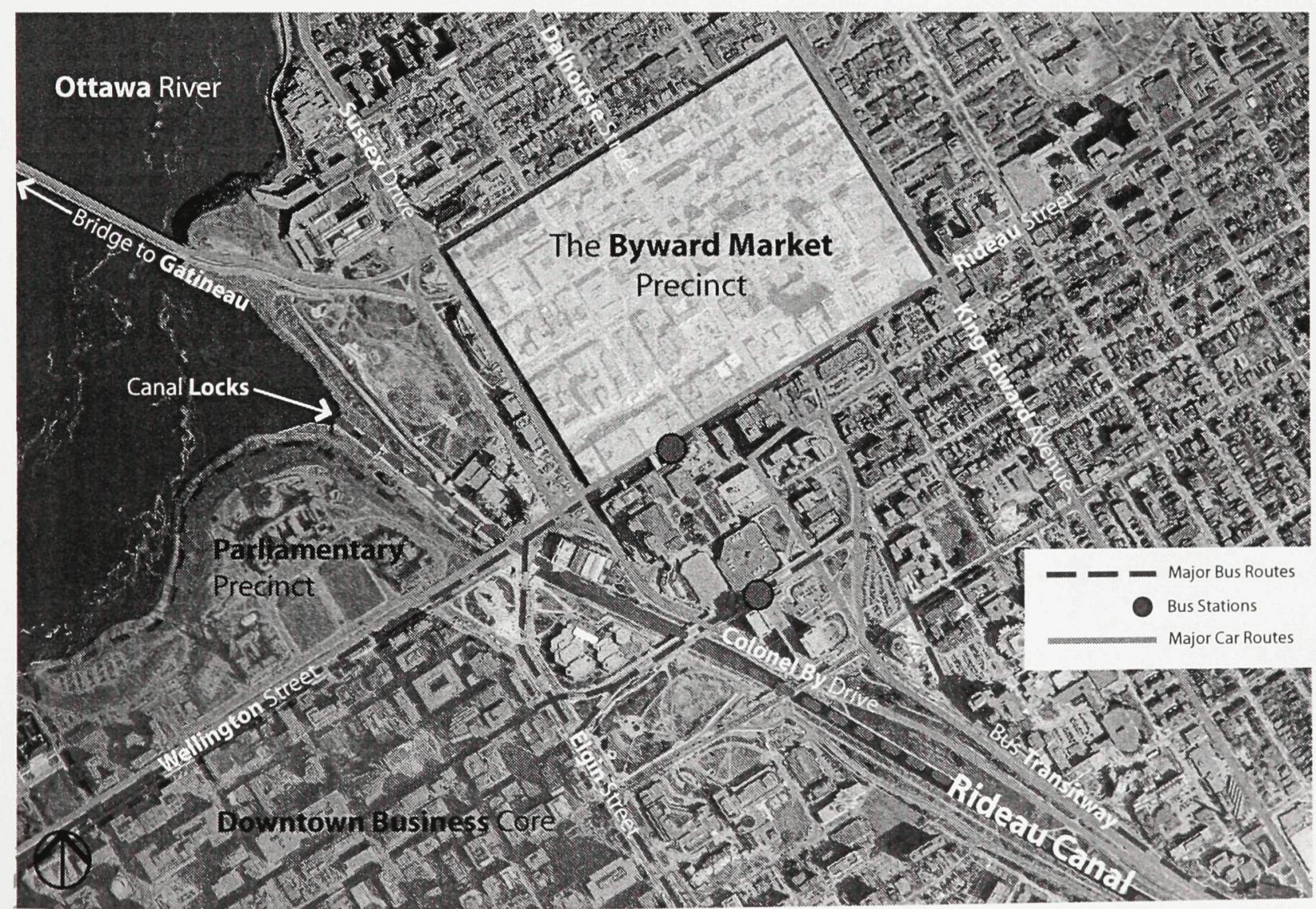

118: Location Map of the ByWard Market in Downtown Ottawa. 
an understanding of the city in which it resides. The making of architecture, as the design of a building, consequently becomes intrinsically associated to the preceding work through the lens that it creates. Despite this, it must be viewed as a distinct topos of investigation that references the understandings gained prior to its undertaking.

As an investigation into the relation of architecture to the making of public space - as defined previously through the theoretical topos of speculation - the project for this thesis is as a multi-use building, as a building typology in the ByWard Market. It is placed within two adjacent and currently vacant sites, spanning the city block bounded by Clarence and York Streets to the North and South and Market and Sussex Streets to the East and West.

\section{Site: The ByWard Market, Ottawa}

The Byward Market, historically known as Lowertown, is the place that 'Ottawa

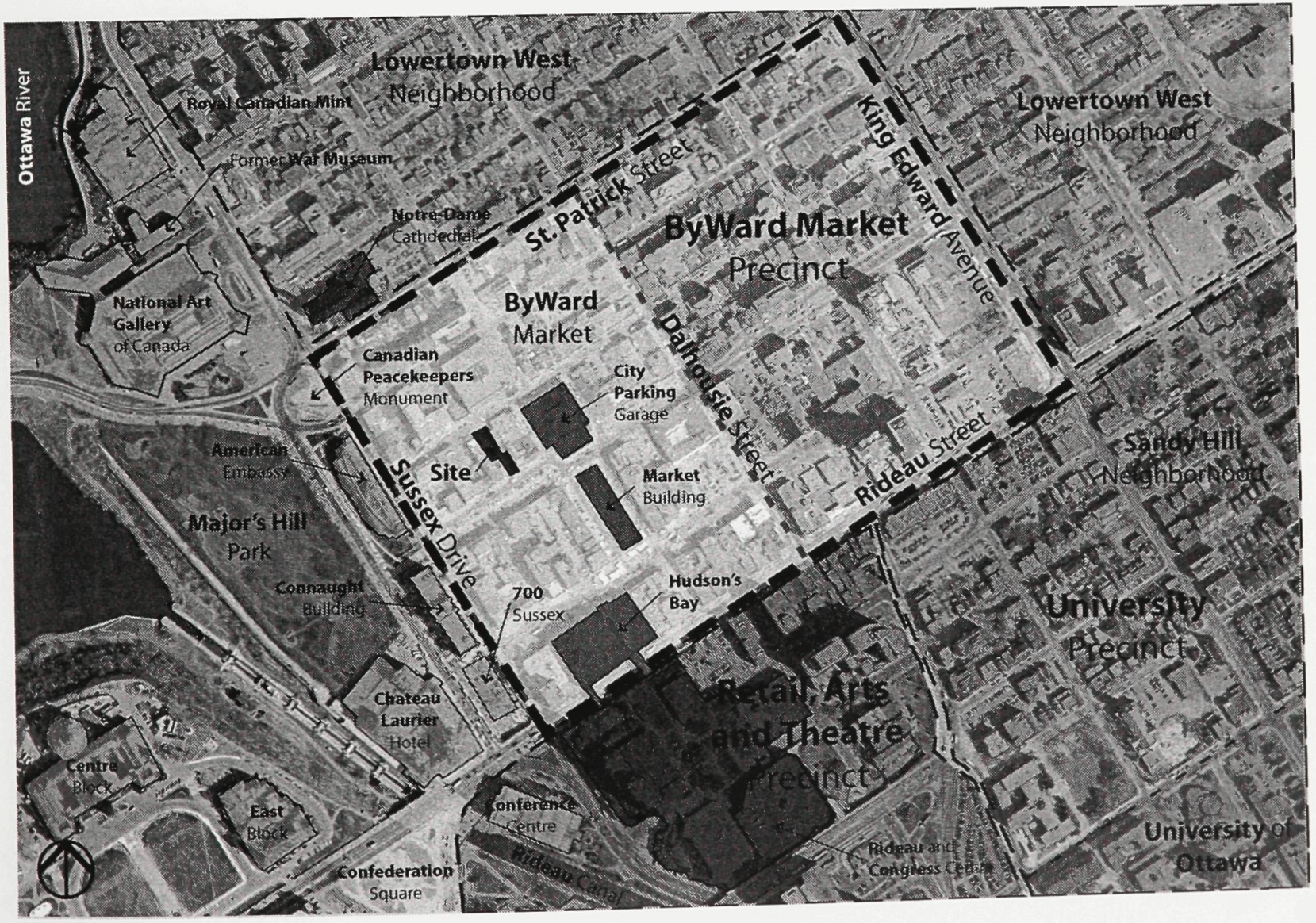

119: Map Showing the Immediate Context of the ByWard Market Precinct. 
was born,' and occurs as an atypical urban condition within the whole of Ottawa. Located to the Northeast of the Canal, the Parliamentary Precinct, and the main downtown business core, the Market (as it is affectionately known), was Ottawa's oldest blue-collar neighbourhood. At its founding, Lowertown was largely constituted of inexpensively built wood shacks, but was replaced by brick and stone buildings once the lots were sold rather than leased by the Crown. ${ }^{1}$ Although mainly serving an industrial and residential function within Ottawa, the Market also contained modest stores, workshops and related businesses, allowing the area to emerge as both an industrial centre and farmer's market. Its importance within the city developed due to its proximity to Union Station (now the Government Conference Centre), which surrounded the Market by its many rail yards.

The main commercial streets during this period in history were Rideau Street, York Street, Clarence Street and Sussex Street. York Street was the location of the farmers' market, and acted as the markets extension, permanently embodying a carnival

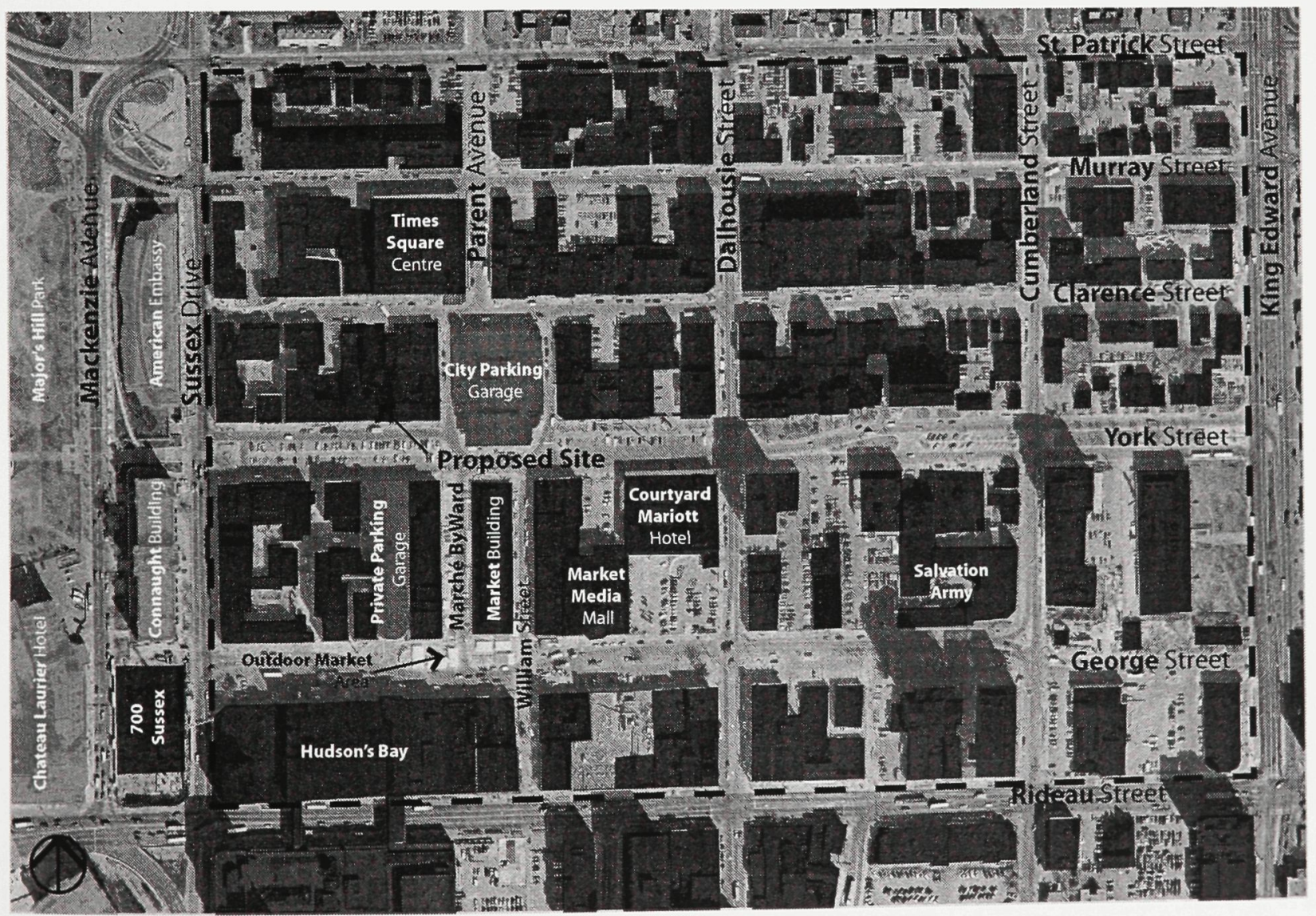

120: Area Map of Market Showing Existing Built Context. 
atmosphere, which was in part due to the taverns and pubs that lined the street. Clarence Street, as a inferior area, was made up of taverns, hotels, small shops, tradesmen, tinkerers and supply stores, and was where could be found prostitution and street fights, causing it to be known as the 'Queen of Pleasure' to the raftsmen who inhabited it. Sussex Street was one of the original commercial thoroughfares, becoming more elegant once the federal government arrived. Until early in the $20^{\text {th }}$ century both sides of the street were lined with ever-popular imported-good-stores, good clothiers, furniture stores, utilitarian shops and apartments. The ByWard Market building itself - originally occupying both the sites of the current building and the City-owned parking garage - and the Market square were at the heart of Lowertown, and brought with them booming business due to the availability of produce, cattle, livestock. Although all of these areas have always maintained their uses and importance within the cultural and commercial centre of Ottawa, the National Capital Commission (NCG) decided to revitalize these areas (especially those around

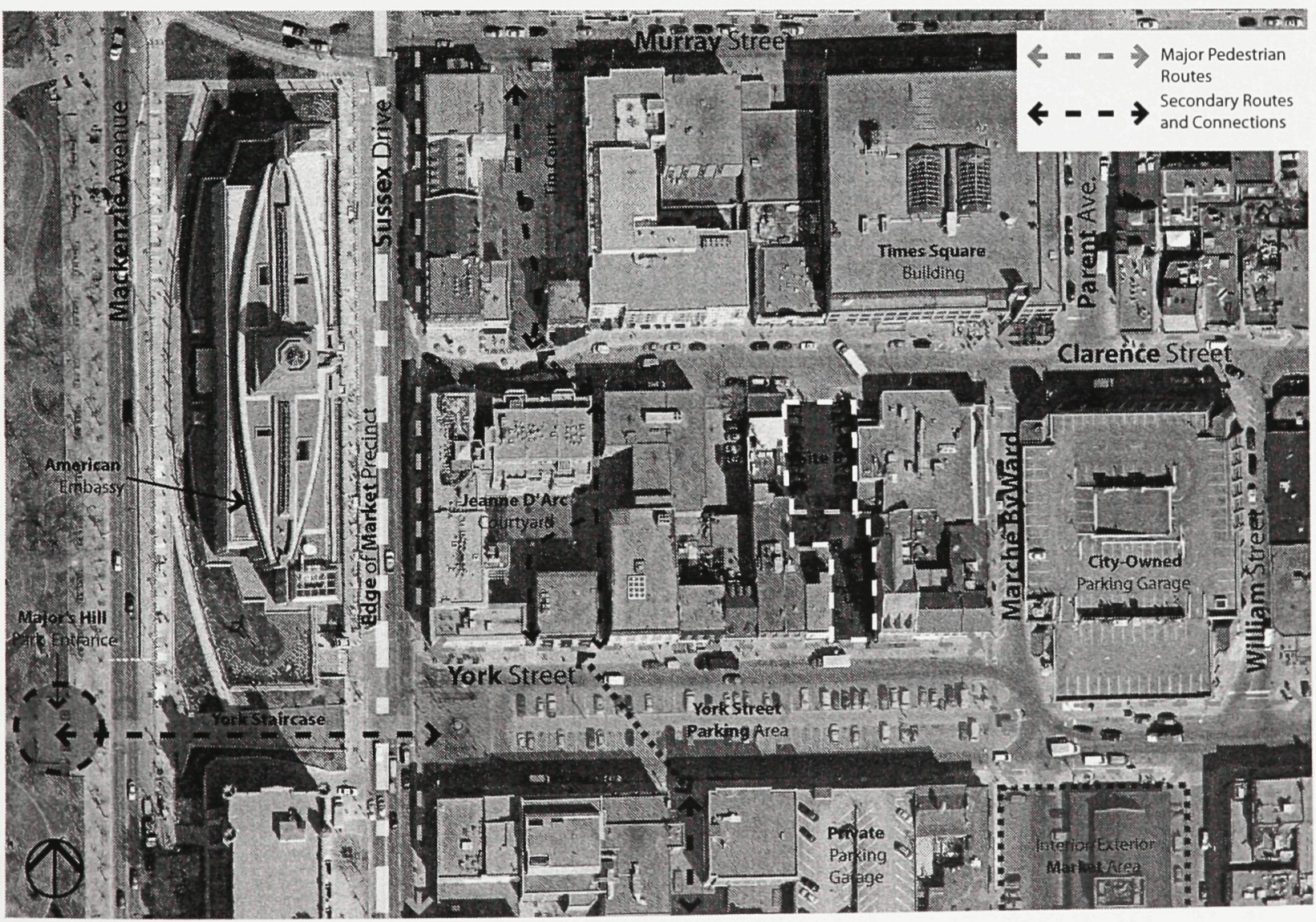

121: Area Map of Surrounding Context Showing Major Pedestrian Routes Through the Market Area. 
Sussex) during the 1970s.

Today, the ByWard Market is known as a 'trendy' location to live, shop and 'play' for both its inhabitants and visitors, flourishing as such since the development of the old rail yards at the corner of Rideau Street and Colonel By Drive into a 'suburban shopping mall,' known as the Rideau Centre. Although having always existed as a specific locale within Ottawa, the Market has more recently begun to exist as an area distinctly separated from the rest of the city, in part due to a set of very specific zoning requirements as developed by both the NCC and the City of Ottawa. This has led to an attempt to both save the historic structures and character of the neighbourhood, while at the same time attempting to remove its seedier and contradictory aspects. In doing so it is moving towards the homogeneity of gentrification, and the higher-end cultural, commercial and residential re-developments that come with it.

As a precinct area within the City of Ottawa Downtown Urban Design Strategy,

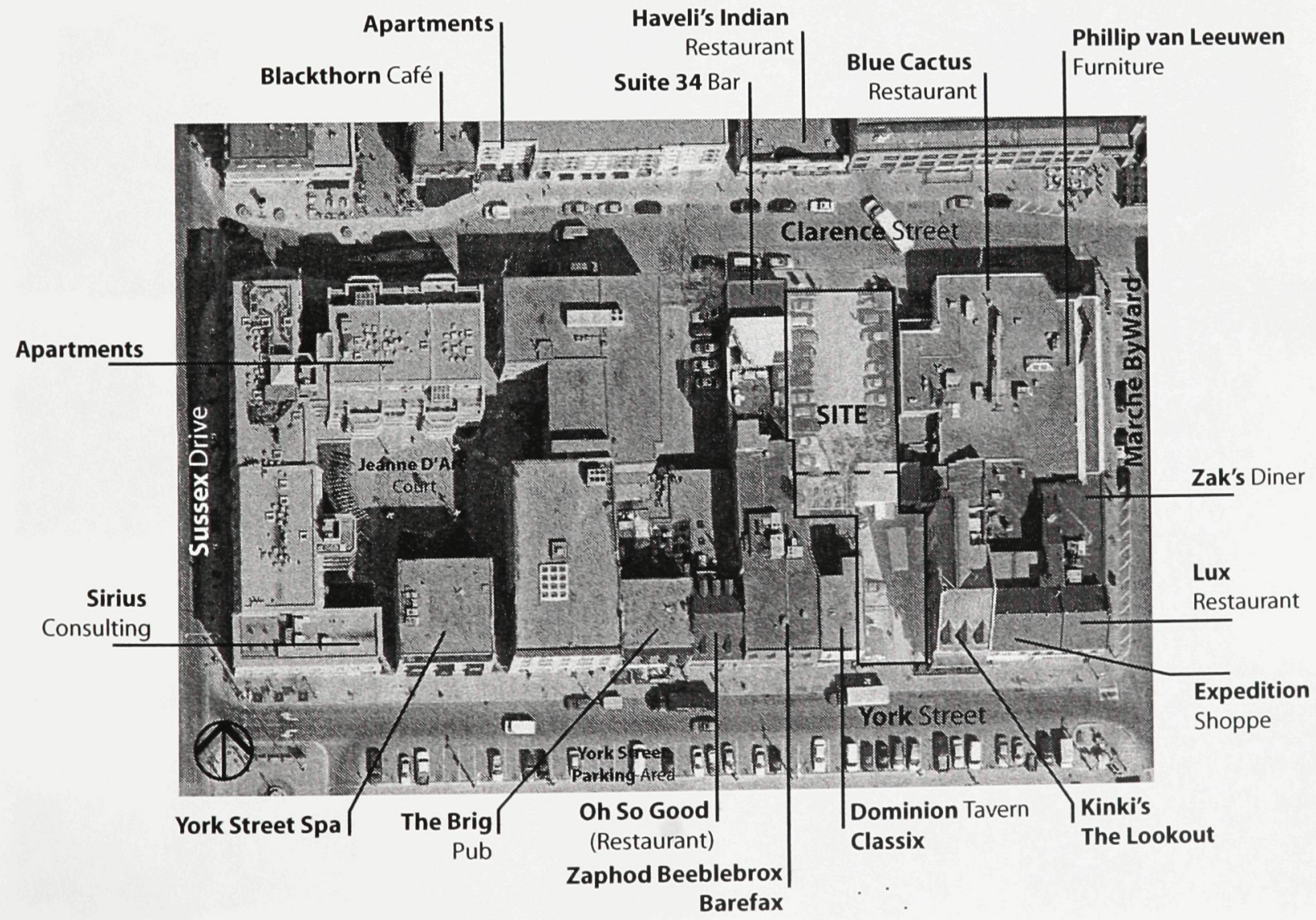

122: Area Plan of Surrounding Block Showing Existing Programs. 
the Market is denoted as the area bound by Sussex Street to the West, St. Patrick Street to the North, King Edward Street to the East, and Rideau Street to the South. ${ }^{2}$ To the North exists the Lowertown West neighbourhood, consisting of residential and some institutional buildings, as well as cultural buildings including the National Gallery, the Royal Canadian Mint, and the Former War Museum Building, providing some tension between the active and heterogeneous uses of the Market, and the quiet setting of the mainly residential district. To the East of Dalhousie - the traditional edge of the market - is mixed and lower residential and commercial developments, and includes a large number of parking lots and under-used open spaces as is characteristic throughout large portions of the downtown area. To the Southeast is the University Precinct, which includes Ottawa University, the Sandy Hill neighbourhood and some small-scale commercial uses. The South end of the Market, known as the Retail, Arts and Theatre Precinct, includes the introverted programs of the Rideau and Congress Centres (including the Hudson's Bay), a complex

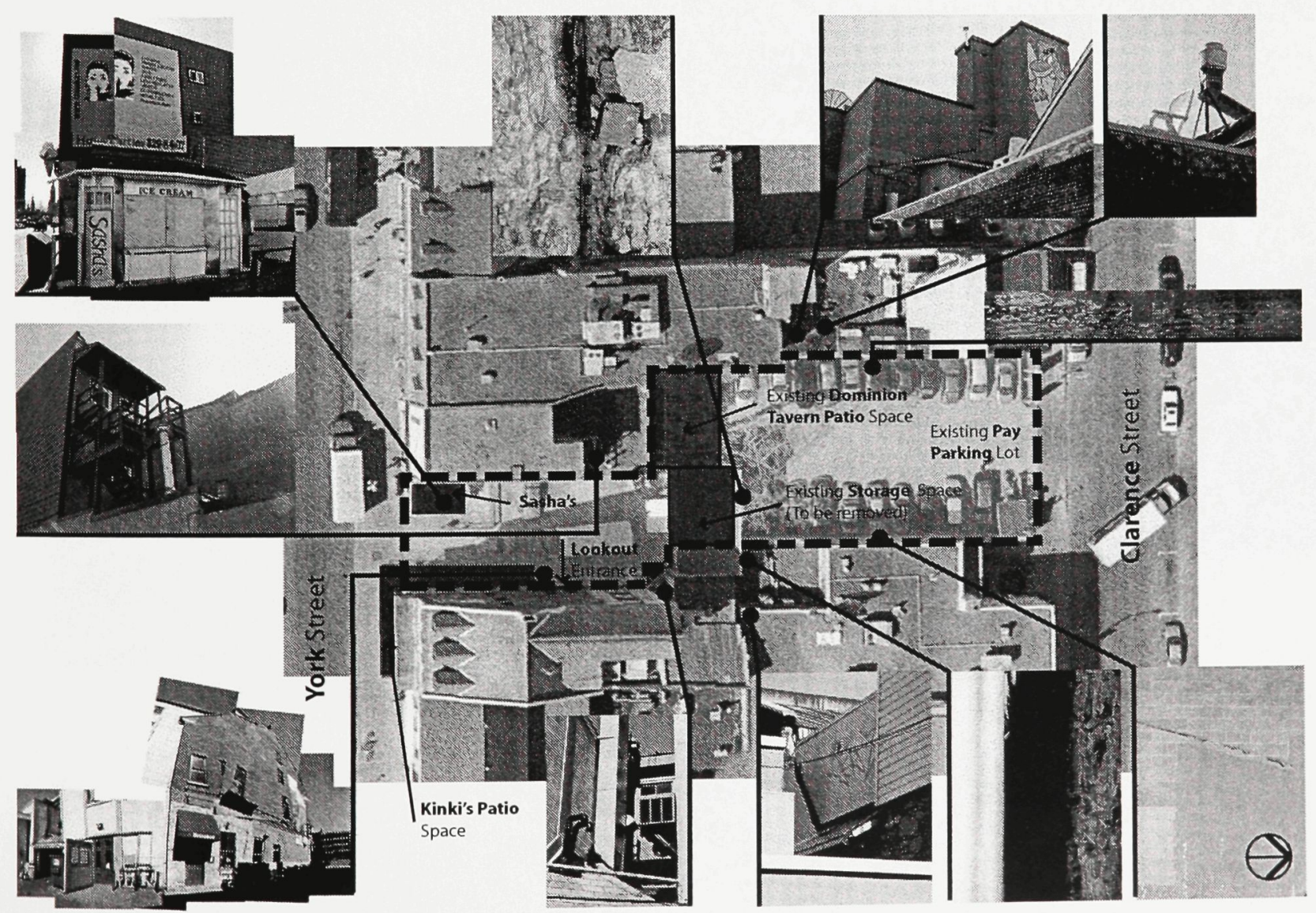

123: Site Plan Showing Photographic Documentation of Overlapping Spaces and Programs. 
of theatre and arts buildings to the south and east of the Rideau Centre, the Government Conference Centre (formerly the Union Train Station) and the Rideau Canal. To the West of Sussex Street is NCC's Confederation Boulevard, occupied by the monolithic edifices of the Connaught Building (Canada Revenue Agency Headquarters), the new Embassy of the United States of America (occupying a former railyard site), 700 Sussex (former Daly Building Site), and the Chateau Laurier, creating a wall-like condition that is pierced only by the York Street Staircase that connects the Market to Majors Hill Park to the West.

The Market, although apparently focused around the centralized ByWard Market Building, is not perceived as such, but rather develops as a gradation of programmatic uses from the Southeast to the Northwest corners with the Market at its centre. Within this generalized gradation is a layering of programmatic uses that, due to their temporal inhabitation, change the urban context and experience of the Market throughout the day, the week, and the year. This becomes evident when the abstract distinctions of 'low' and

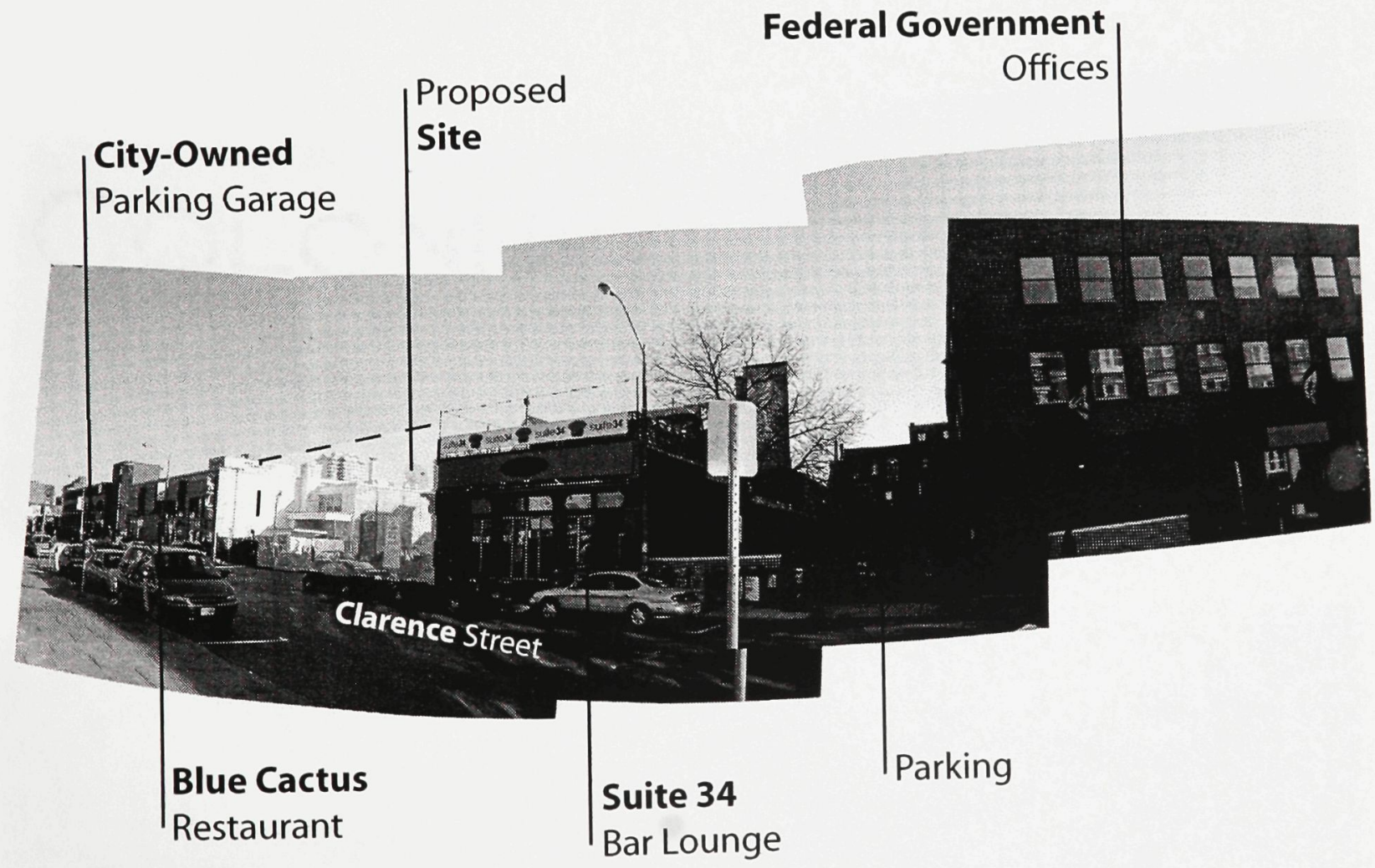

124: Daytime Photo Montage of Existing Clarence Street Elevation. 
'high-end' programs and their clientele spill out onto the sidewalk and street, allowing for the space to take on a socially contradictory nature. This heterogeneity and proximity of programs also creates with it a contradictory experience of space that is experienced in its spatial and inter-subjective relations.

The sites selected for the architectural topos - two adjacent asphalt parking lots, separated by a small structure - exist as two of the very few open sites left in the original ByWard Market area, and are adjacent asphalt parking lots, separated by a small structure. The first site occurs along York Street, and is currently inhabited by a semi-permanent chip wagon (Sasha's) and grade-level private parking. The location also providing access to the Lookout same-sex club as well as office and residential spaces located above Kinki Asian Fusion Restaurant, while also providing access to the storage and garbage disposal for these programs. As one of the liveliest streets in the Market, York maintains its original
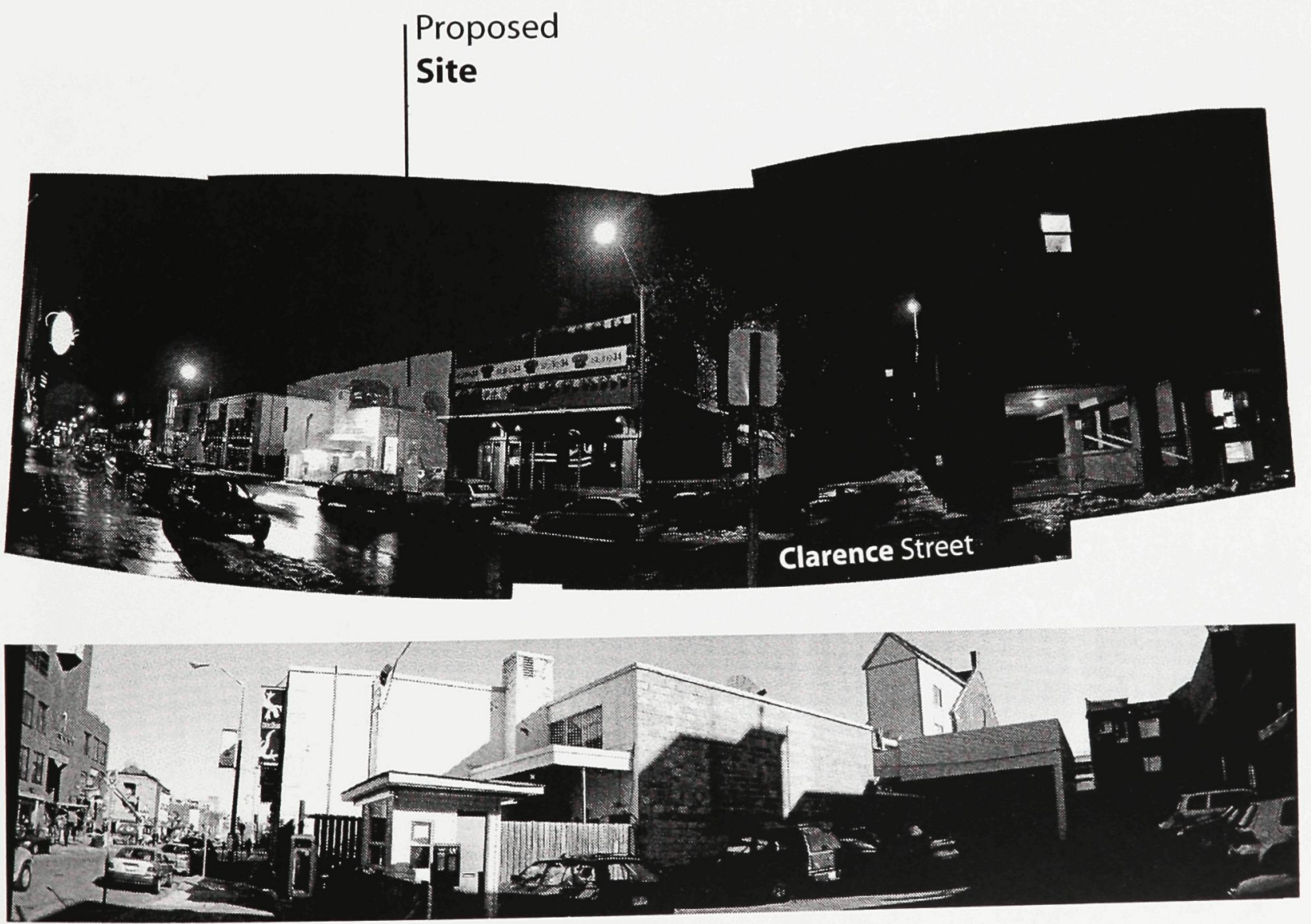

125: Daytime and Nighttime Photo Montages of Existing Clarence Street Facade and Parking Lot. 
carnivalesque character by being predominately constituted of bars, clubs, and restaurants, all of which generally contain residential and/or office spaces above. The width of the street has allowed for the placement of parking down its centre, causing the street to encounter a great deal of vehicular and pedestrian traffic. The site itself exists as a part of a popular section of the street where trendy restaurants (Kinki's, Lux, etc.) mix with bars, pubs, music clubs (The Dominion Tavern, The Brig, The Lookout and the Zaphod Beeblebrox) and as well as sexually associated clubs and shops (Barefax Gentlemen's Club and Classixxx Adult Shop). Such a diversity of programs, mixed with some smaller shops, creates a captivating and thought-provoking street atmosphere of display, interaction and conflict.

The second site is located along Clarence Street, which, unlike York, has departed from its original seamy associations, accommodating recent residential, commercial and office developments that have changed the character of the street at its West-end,

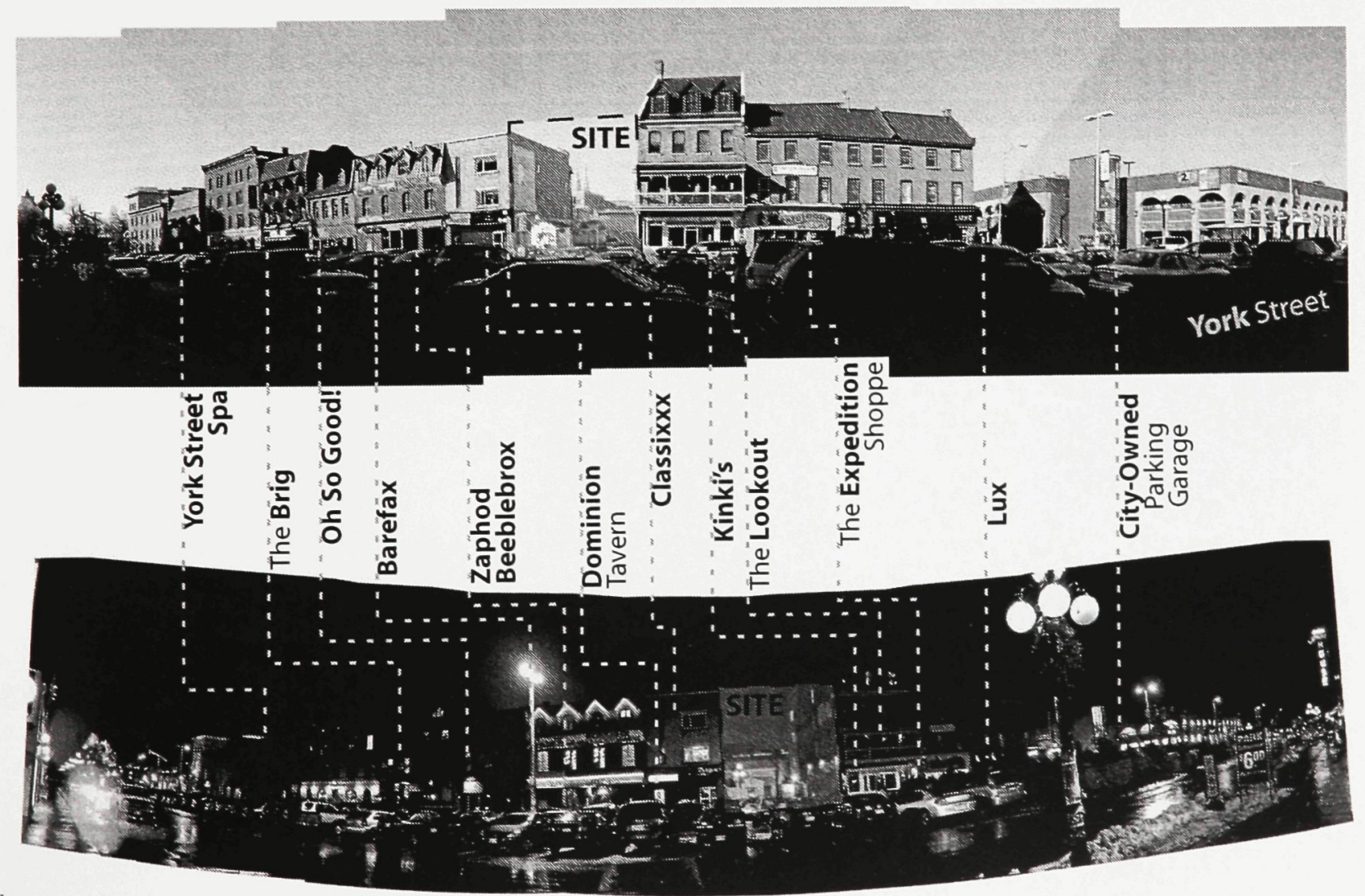

126: Daytime and Nighttime Photo Montages of Existing York Street Elevation. 
to one that is much less frequented, yet remaining densely developed. Located between the Suite 34 Bar and the Blue Cactus Restaurant, the site is currently a pay-parking lot that is proposed for redevelopment as a multi-use building. As a much smaller-scale street, there is a greater dialogue between the South and North sides of the street, which contains residential, ethnic-style restaurants, parking and small-scale specialty shops.

Within these two sites there is a specific and inherent revealing of the contradictory nature of the Market as a social and spatial construct, due to its adjacent co-existing programs that condense themselves within the identified sites themselves. The proposed multi-use building, as an 'intervention' within them, will make apparent the existing contradictions, rather than hiding them. In so doing the architecture resists the NCC and the City's future intentions for the 'disnification' of the Market, and thereby the elimination of the very contradictions and heterogeneous nature that make it such an exciting and trendy place to live and visit. This project at once attempts to reveal the contradictions,

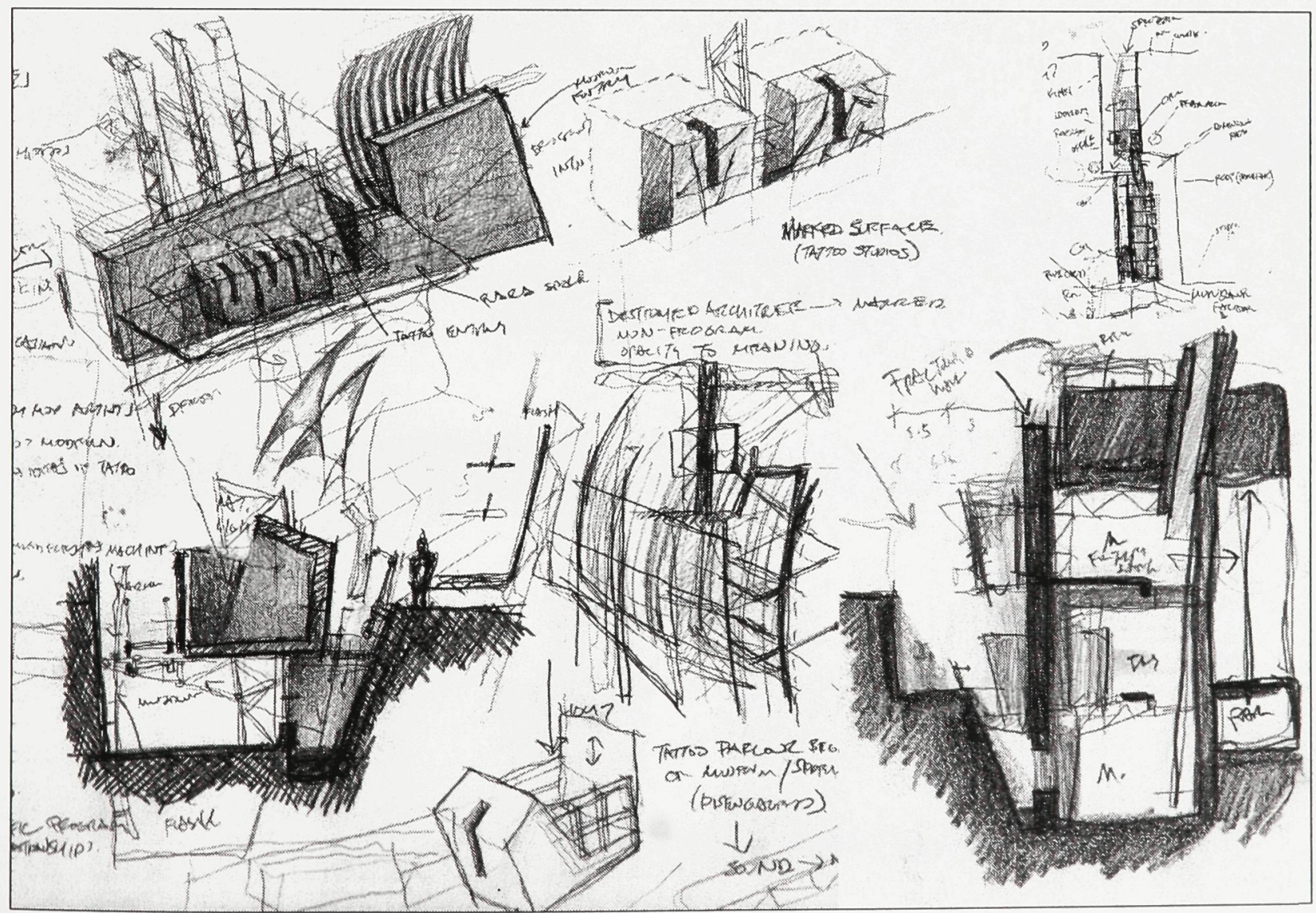

127: Early Design Sketches. 
while also politicizing the experience of the city for its inhabitants (whether citizens or strangers) by making space for new contradictions to arise, creating a sense of place through the experience of the conflictual event.

\section{Design: Demarked Architecture}

As a typological form of building within the ByWard Market, the multi-use building forms the greatest portion of the urban landscape, and is therefore a location to begin to look at architecture's relation to the creation of public spaces in the city. The program for the proposed building, as a form of architectural speculation, is derived from the previous investigations themselves, and are therefore understood and interpreted through the lens of theory. The four main programmatic elements are derived from the experience of public space and the demark that was investigated within the video, The Architecture of Hysteria, and in previous models and drawings. These are the mundane 'everyday' spaces

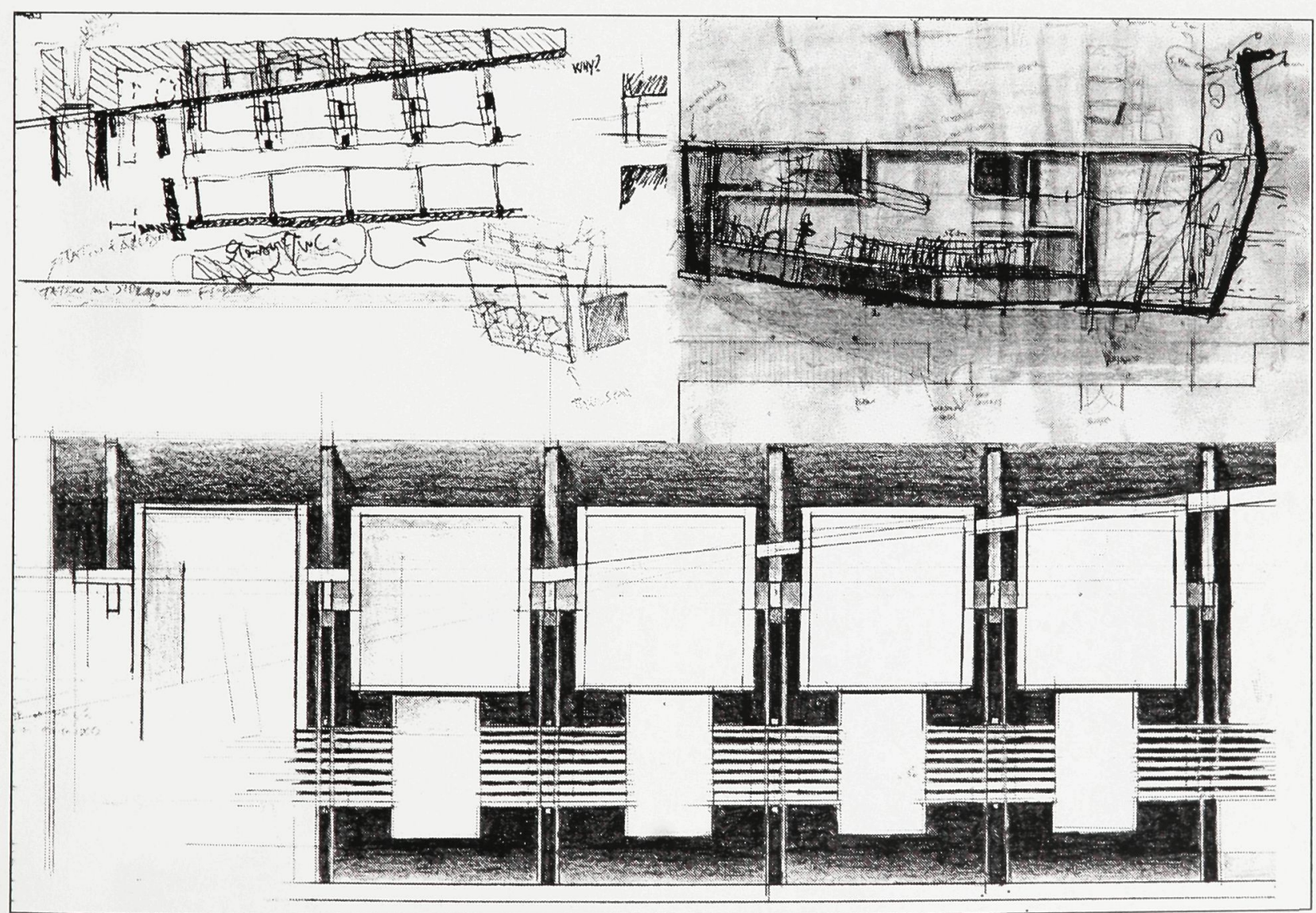

128: Grade Plan Development Drawings. Graphite and ink on paper and trace. 
(Impresario), 'The Museum and Gallery of the Mark' (Framing), interstitial and open spaces (Demark), and a tattoo parlour (Flesh). ${ }^{3}$

\section{The Building as Specific Programmatic and Formal Relations}

The building as it exists within the site, appears to the viewer from the exterior as two interconnected forms that are each separated on one side from the existing context, providing gaps through which pedestrians and service vehicles can pass through the site from York to Clarence. In doing so, they create a courtyard space into which the various existing and proposed programs can overlap through their defined or undefined inhabitation of the exterior spaces. These two forms are connected both above and below ground on three of the six storeys in which the four programs reside, allowing programs to span through the North and South sections of the building. The ground floor of the two forms contains the entrance to the Museum and Gallery as well as a café in the South form, while the North

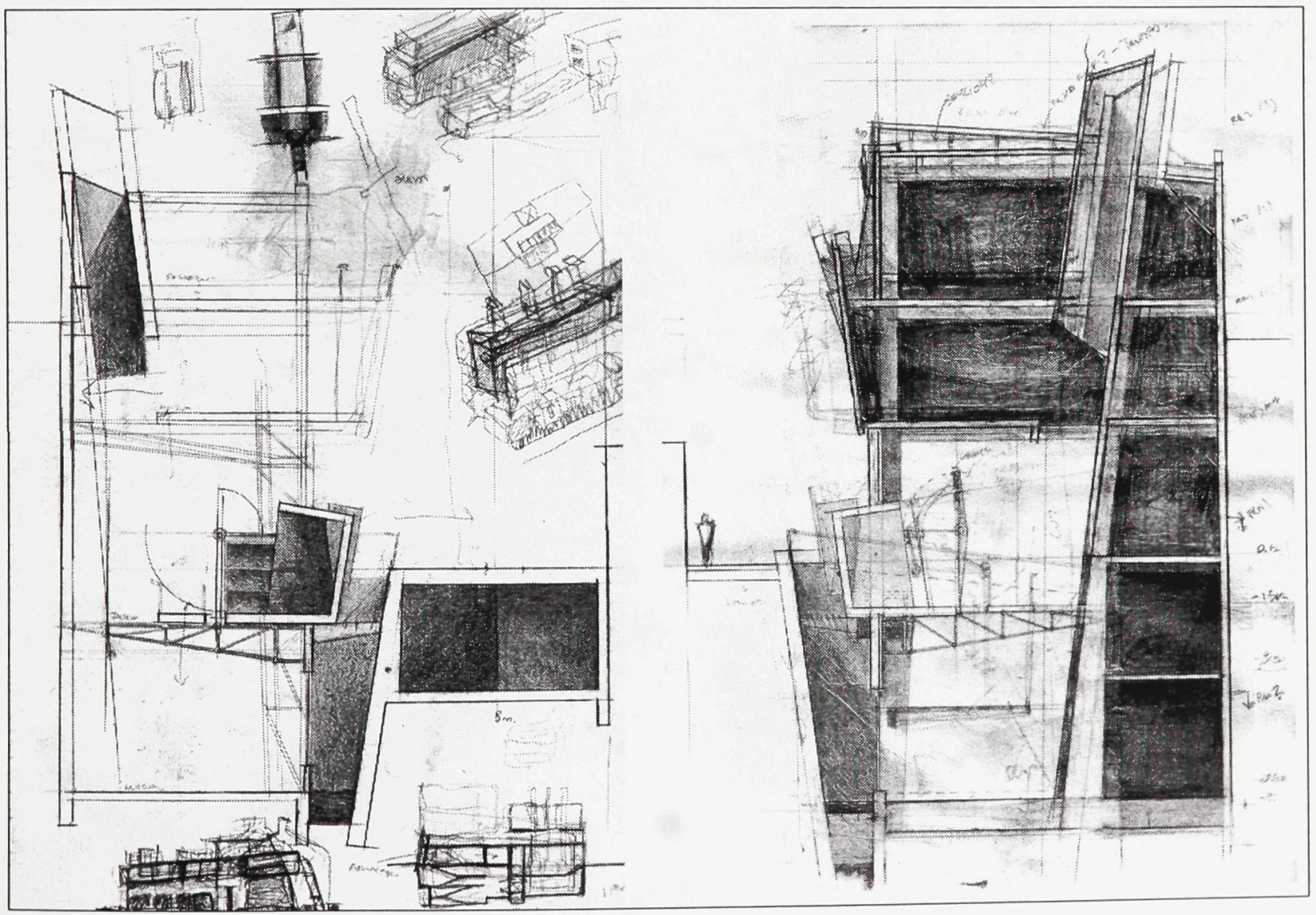

129: Cross Section Development Drawings. Graphite on paper and trace. 
form contains the tattoo parlour as well as the entrance to the 'mundane' spaces from Clarence Street. The three upper levels contain the Gallery and mundane spaces in both the North and South volumes, while a research and administrative space inhabits the top floor of the building along York Street. The two storeys that exist below grade exclusively contain the Museum of the Mark.

As a diagram, the building is composed of a sunken steel and concrete frame structure wrapped in a continuous bent image-surface, all of which is attached to an angled concrete tattoo flash wall.

\section{The Museum and Gallery of the Cut: A Framed Experience}

Making up the largest portion of the building, the museum and gallery inhabit four of its floors. These programs reside within the heavy steel and concrete frame structure, sunken and separated from the ground plane by a concrete lightwell, which allows light

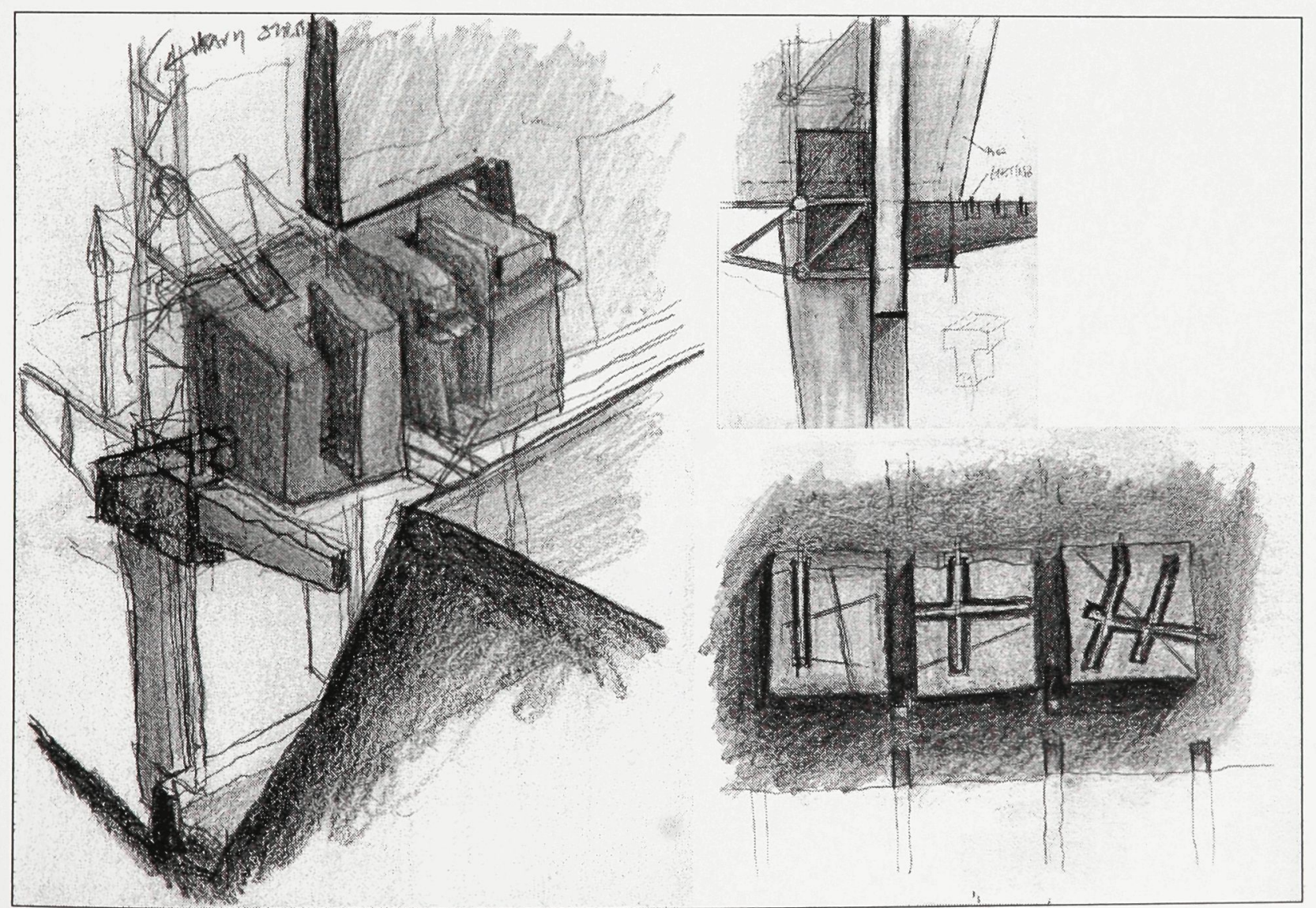

130: Sketches of Tattoo Studio's Relationship to Exterior Surface. Sectional axonometric, section detail, and elevation. 
to seep into the museum spaces contained below. This frame is enclosed by a bent surface of worn copper slats that is continuous from the York Street façade through to Clarence Street, joining the two forms that inhabit the site into one. Onto this surface an oversized image of the marked flesh is permanently imprinted, indicating the nature of the program within, while also lending itself to the spectacular nature of its image and form. This 'skin' at once creates a visual opacity to the building, which is broken up through both form and image, while also being pulled away from the frame and the ground plane to allow light to slip into the museum and gallery spaces, blocking out any direct light from entering these spaces. Functionally protecting the art and artefacts contained behind its surface, the bent image-surface is representative of the framed understanding of the marked flesh, as it is presented within the museum and gallery spaces.

The entrance to the 'Museum and Gallery of the Mark' occurs on the East side of the South structure, where the image-surface of the museum pulls away to reveal a glazed

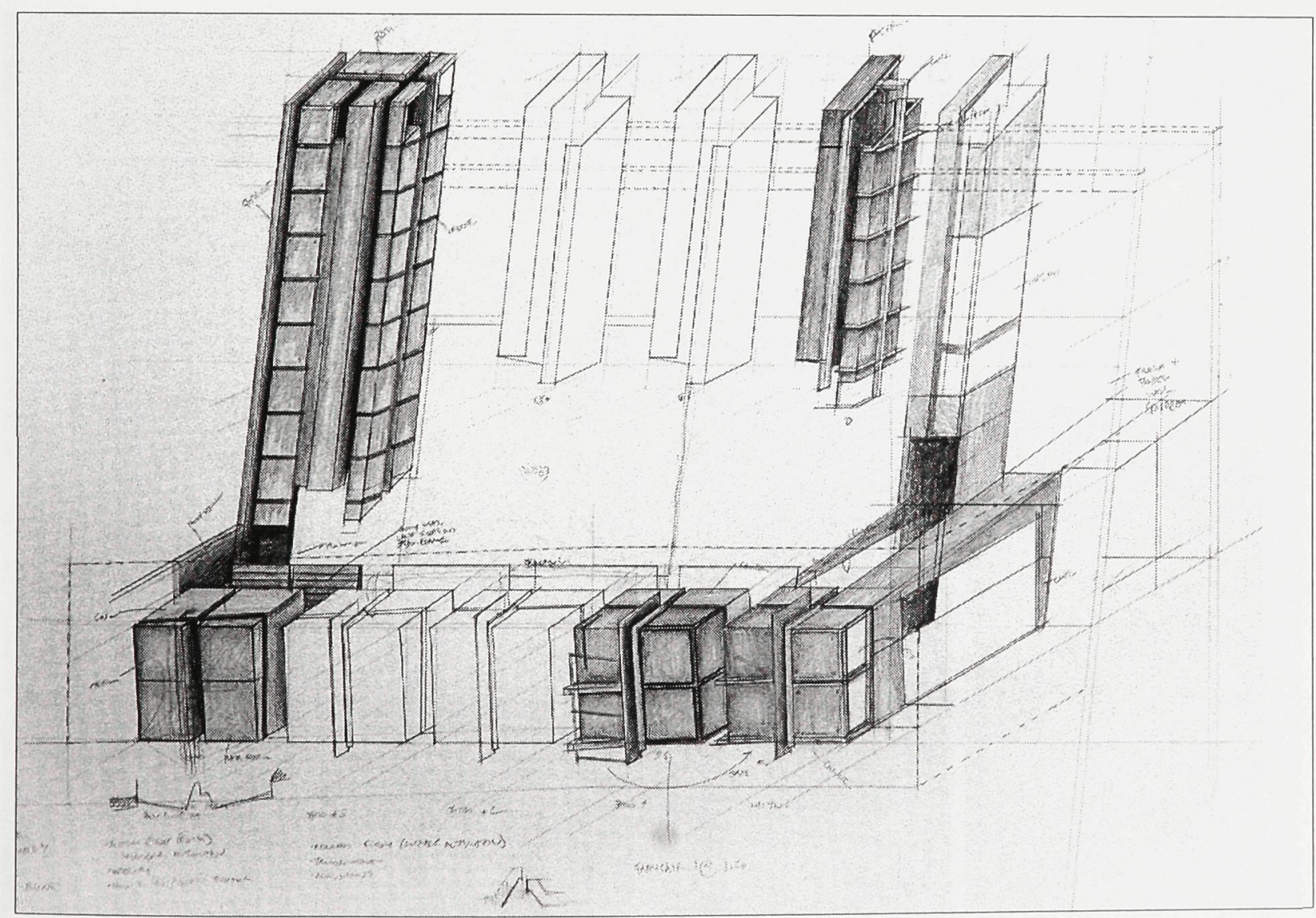

131: Axonometric Drawing of Tattoo Studios and Lightstacks. Graphite on Stonehenge paper. 
reception area. This entry exists as a steel and concrete 'bridge,' crossing the gap created by the lightwell, to the framed structure of the museum/gallery, contained beneath the copper skin. Upon entering the building and the compressed space of the reception area, the visitor is visually connected both to the gallery that exists above, the museum below and the café beyond, allowing both light and sound to fill the space. A staircase placed against the expansive glass wall - allowing passers-by one of the few experiences of the interior space of the building, while also permitting light to enter the building - connects the visitor to the gallery and museum space's that exist above and below. The café, serving the museum and gallery, as well as outside patrons, opens during the summer months to the courtyard space.

The Gallery of the Mark on the second level exhibits contemporary works of art involving the marked body and it's questioning. Inhabiting both the North and South structures on the site, the gallery presents to the viewer a framed and categorized experience
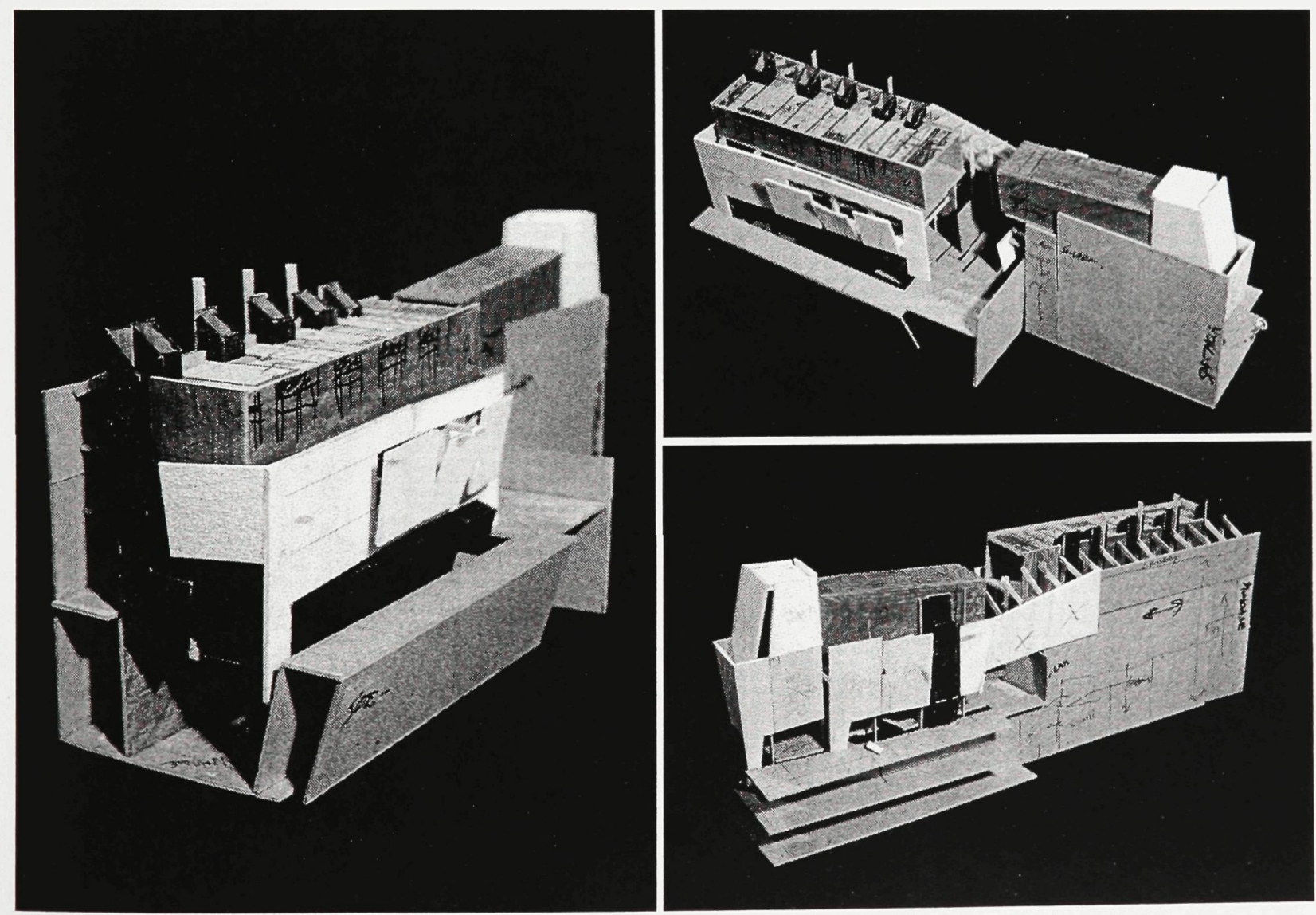

132: Views of Sketch Model. Cardboard and basswood. 1:200. 
of the marked flesh, locating the marked object within the knowledge and acceptance of society through its very display. The South gallery, open to the entry below, contains a permanent collection of flat works lit by skylights that are created by the gap between the exterior surface and the steel frame. Located above and accessible through the gallery at its South end is an administrative space used for archival research. This side of the building rises to its highest point, formally addressing the spectacular nature of York Street.

The South gallery space is connected to the North by an interior bridge from which one can view the courtyard inhabited by the Dominion's patio. The second half of the gallery, due to its slightly larger size, presents three-dimensional works, and is also used for installations. Like the rest of the gallery, it is lit through skylights as well as cuts in the façade. A secondary steel frame system above allows for this space to accommodate one or several exhibits. Sectionally this half is linked to the tattoo gallery below by an angled concrete wall of 'tattoo flash'4 that is lit from above by five light-stacks that illuminate

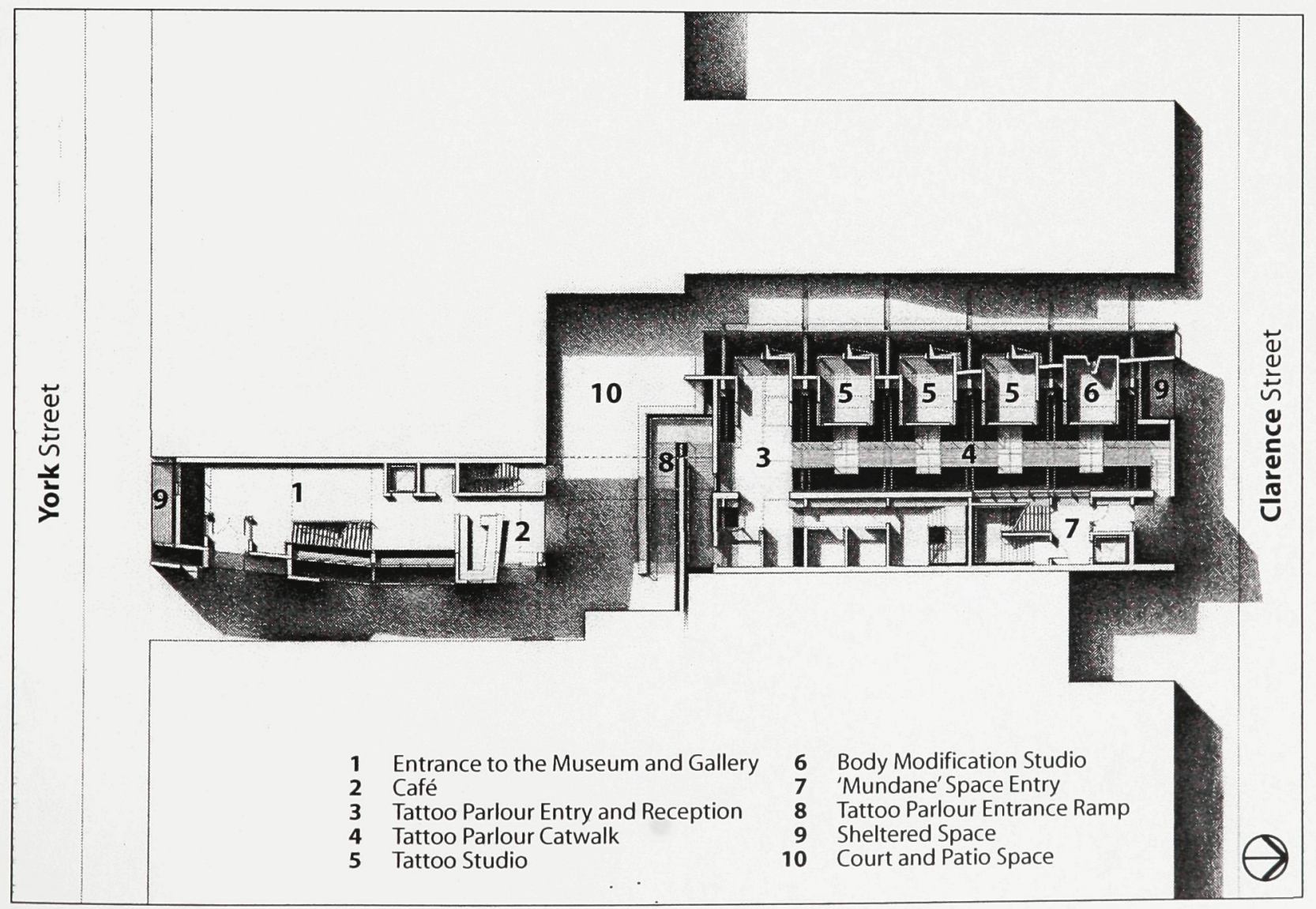

133: Grade Level Plan, Annotated. 
its surface. The gap that exists between the gallery floor and the angled wall allows for an encounter with the interstitial space of discourse, and thereby an interaction with the demark, as the hum of the machines emanating from the tattoo parlour below fill the space, disrupting the visitor's framed experience of the work on display, forcing them to question its very nature within their symbolized existence. This same gap extends to the North end of the gallery space, placing the body modification studio below on display to the visitor, recreating a similar experience to that of the operating theatre, while placing the ever shifting 'exhibit' of clientele on display. In both of these experiences there is a disruptive experience, one aural, and the other visual. Both suggest that something is amiss, causing the scene to become uncanny, as something other has inhabited the scene, something unsignified.

Below the entry in the South form, and inhabiting the two levels beneath the ground plane, is the Museum of the Cut, displaying the contextualized and framed history

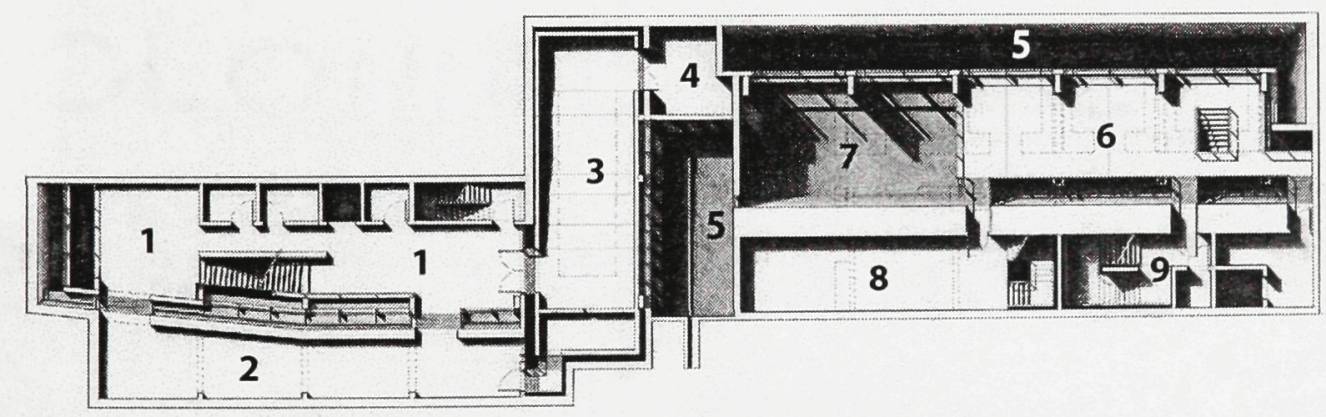

Museum - Contextualization Museum - Artifact Room

Museum - Theatre

Storage

Lightwell

134: Below Grade Plan, Annotated. 
of the marked body, focusing upon the art of tattooing and its recent history since the $19^{\text {th }}$ century. ${ }^{5}$ The museum is made up of four types of space contained on both levels. The space that is first entered upon circulation between the floors, existing directly beneath the entry, is the 'space of contextualization.' In this space text and images provide a historical framework to the works on display in the museum. Located to the East of this space on both levels is the solid and dimly lit artifact room. Accessed by passing through an opening in the concrete retaining wall of the lightwell, this space presents photographic images and small artefacts (sculptures, tools, etc.) from the pre-modern era of body marking. Also entered from the 'space of contextualization,' and located only on the first floor below grade, is a small auditorium that shows documentary films and lectures dealing with the marked flesh in both contemporary and historical terms. This theatre is physically separated from the rest of museum, and supported by a series of trusses, allowing light to pass in the gap between it and the foundation walls. This creates an imposing and disjunctive form upon

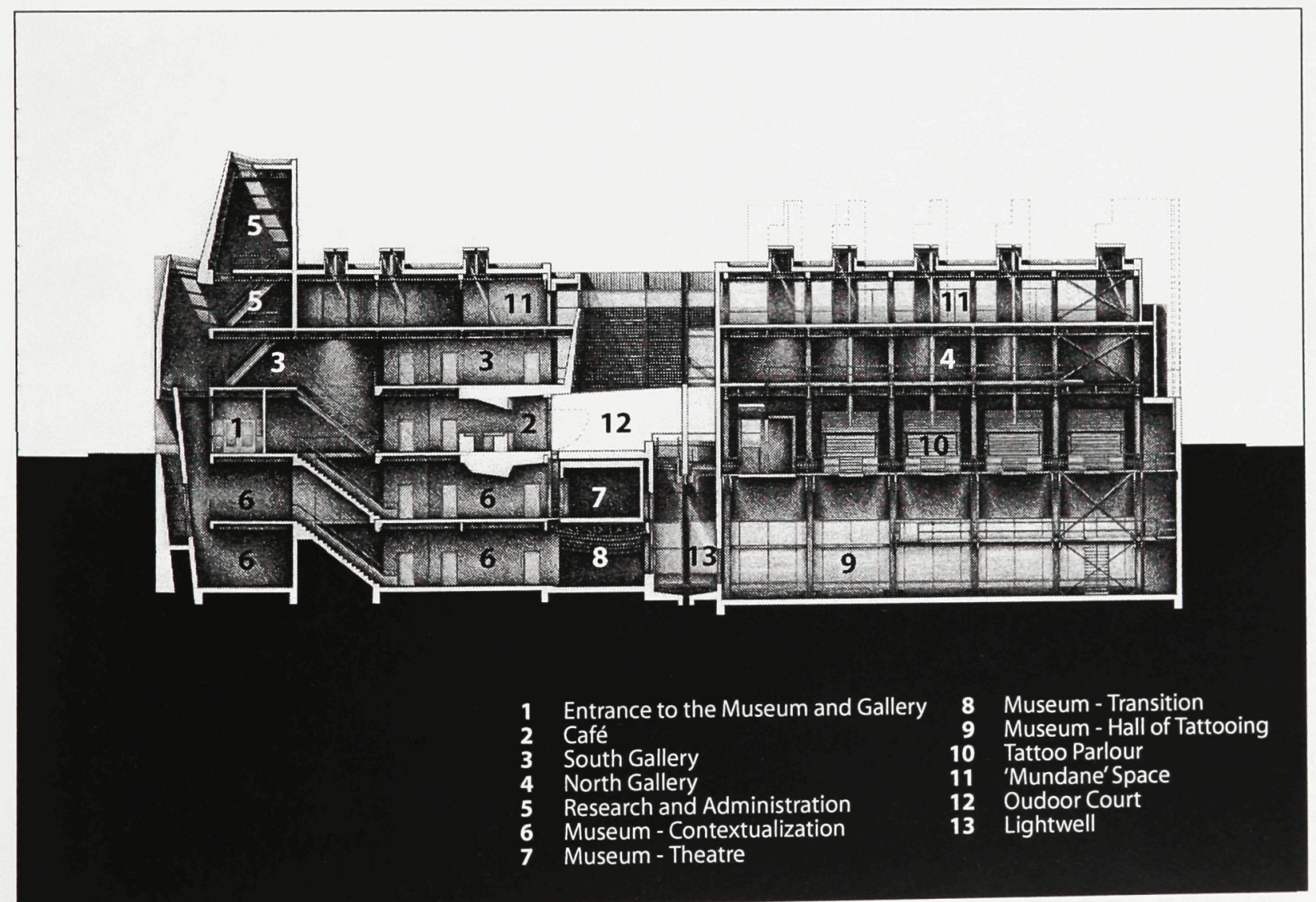

135: Longitudinal Section, Annotated. 
the space below. This space, as a transition space between the contextualized museum and the hall of modern tattooing, is lit from the exterior by a large wall of glazing that looks onto a reflecting pool that allows light to pass into the space. A single projected film installation along the West wall presents interviews with various tattoo enthusiasts.

Beyond this transitional space is the final and largest exhibit space in the museum, that of the Hall of Tattooing. As a dramatic and indirectly lit space containing a mezzanine level, this hall contains exhibits of spectacular and larger displays from modern tattooing history, including: 'jagger's' ${ }^{\prime 6}$ tools, displays from carnival tattoo artists, modern tattoo equipment and other paraphernalia, as well as re-creations and actual tattooed skin from various eras and styles, displayed in no categorical order. Colliding with the floor in this space is the angled wall of tattoo flash, which at once displays the flash as exhibits within the museum, while also drawing the visitor's eye to the tattoo parlour above. This connection, which is nearly transparent due to the grated flooring of the tattoo parlour, allows both
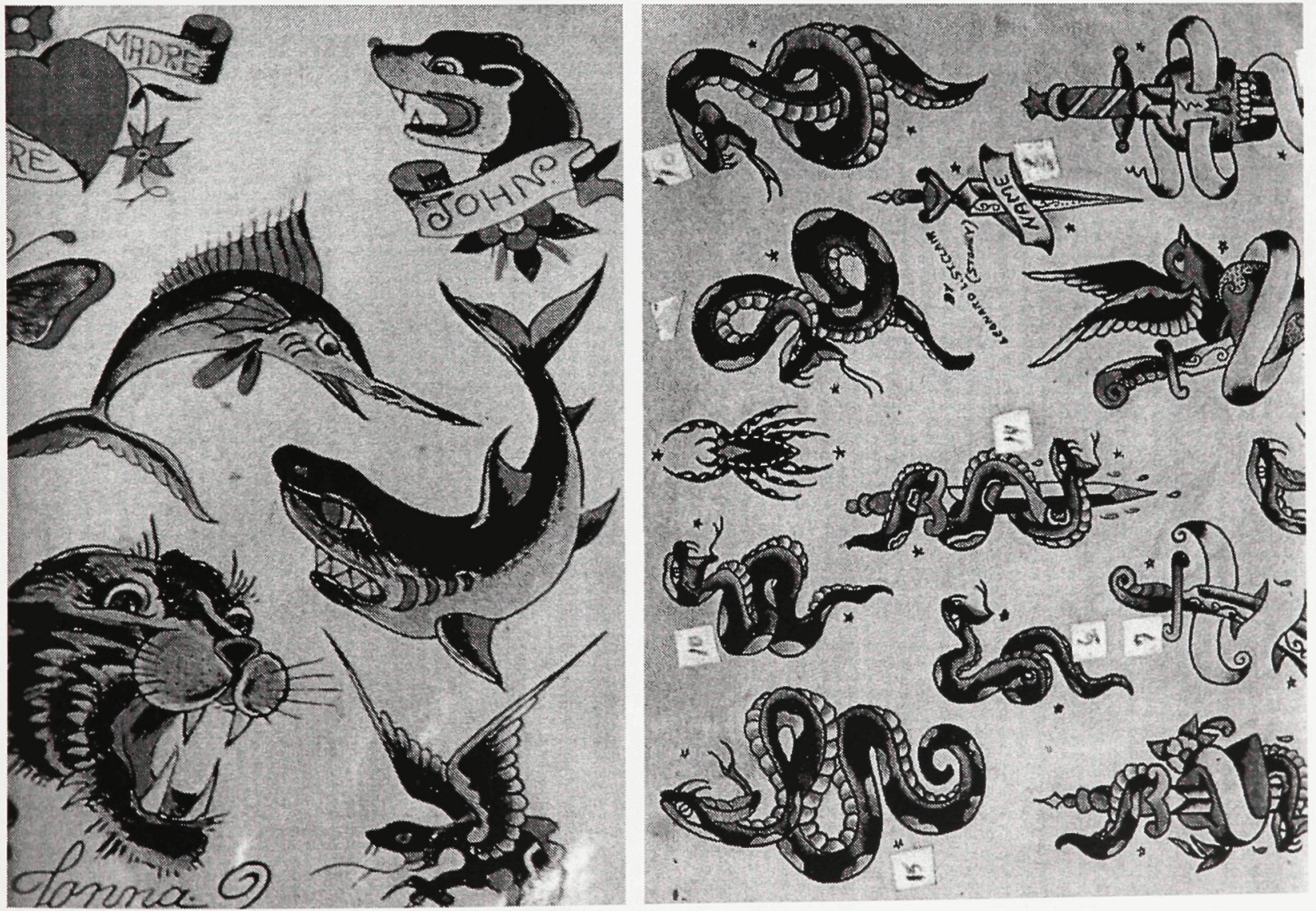

136: Tattoo Flash - Joseph Hartley, Bristol, Great Britain, 1930s; and L. Stoney, St. Clair, USA (Ohio) from Henk Shiffmacher, 1000 Tattoos (Köln, Germany: Taschen, 2005.) 129, 94. 
light and the sound of the mechanical buzzing of the tattoo to fill the space. Much as in the gallery above, this re-contextualizing disrupts the previously framed experience of the museum. Unlike the gallery, visitors are able to view into the tattoo parlour above, although they are unable to view the source of the sound itself, as it emanates from the tattoo studios; containers suspended from the steel frame of the building.

\section{The Tattoo Parlour: An Experience of the Flesh}

The secondary and conflictual program within the building, and the one that allows for the experience of the interruption caused by the demark in space, is the tattoo parlour. As a space in which one is marked by the tattoo, the cut and body modification, it is associated to the spectacle of difference. Through this its users and the architecture by association becomes an interruption within the homogeneity of the city. The act of getting tattooed defies the surface of the skin itself, occuring as a resistance to its Symbolization.

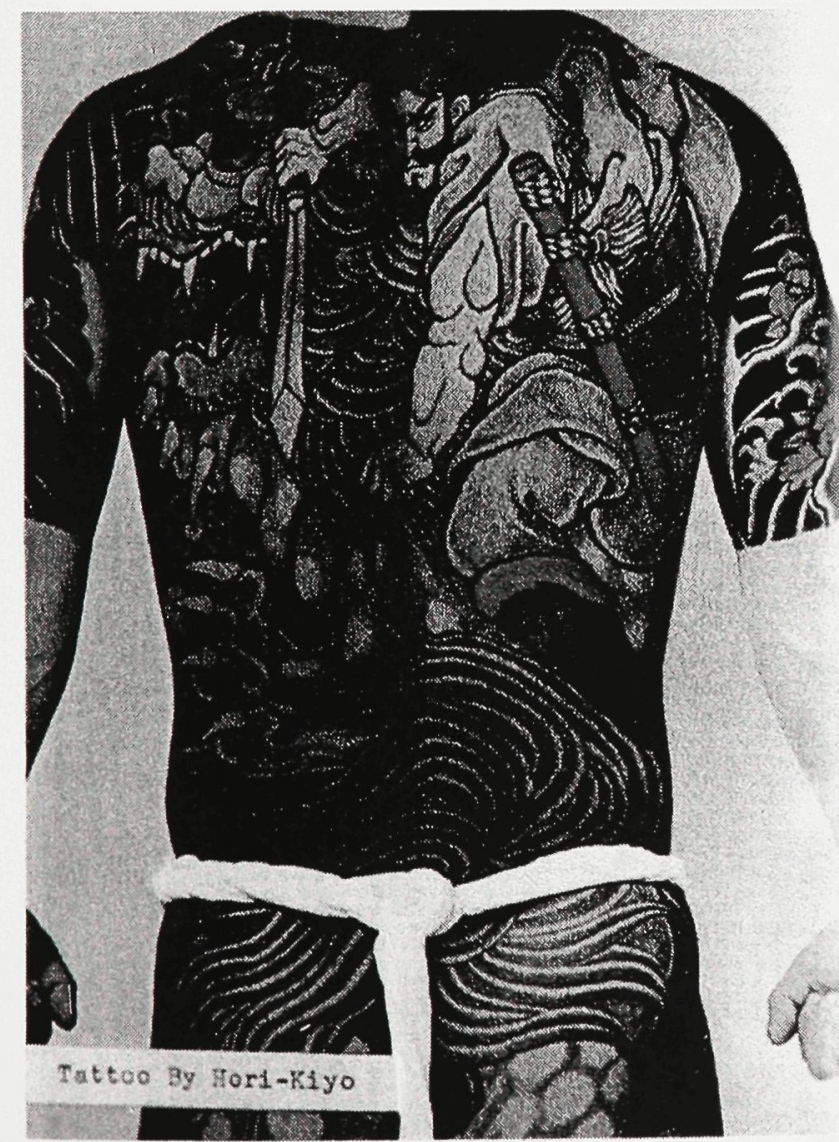

137: Japanese-Style Tattoo by Hori-Kiyo from

Schiffmacher, 420.

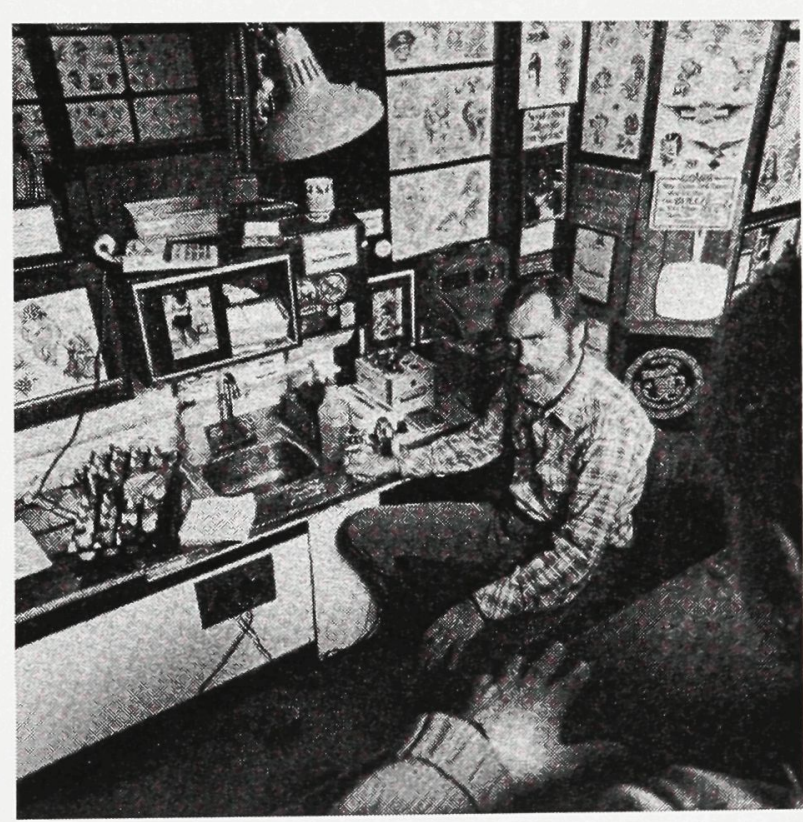

138: Bert Grimm's Tattoo Studio, Long Beach, California from Clinton R. Sanders, "Drill and Frill," Marks of Civilization (Los Angeles: Museum of Cultural History, 1988) 227. 
This differs from the purpose of the traditional cut, as Zizek states in The Ticklish Subject:

"[...] the traditional cut ran in the direction from the Real to the Symbolic, while the postmodern cut runs in the opposite direction, from the Symbolic to the Real. The aim of the traditional cut was to inscribe the symbolic form on to the raw flesh, to 'gentrify' raw flesh, to mark its inclusion into the big Other, its subjection to it; the aim of postmodern sado-maso practices of bodily mutilation is, rather, the minimum of the bodily Real in the universe of symbolic simulacra. In other words, the function of today's 'postmodern' cut in the body is to serve not as a mark of symbolic castration but, rather, as its exact opposite: to designate the body's resistance against submission to the sociosymbolic law." [my emphasis] ${ }^{7}$

In the act of the tattoo or cut, the tattoo parlour becomes an unframed experience, unlike that of the Museum and Galley. Its architectural space draws upon the mystery associated with its experience, providing both depth and opacity to its meaning.

The entry to the tattoo parlour is found at the centre of the site as a steel grate

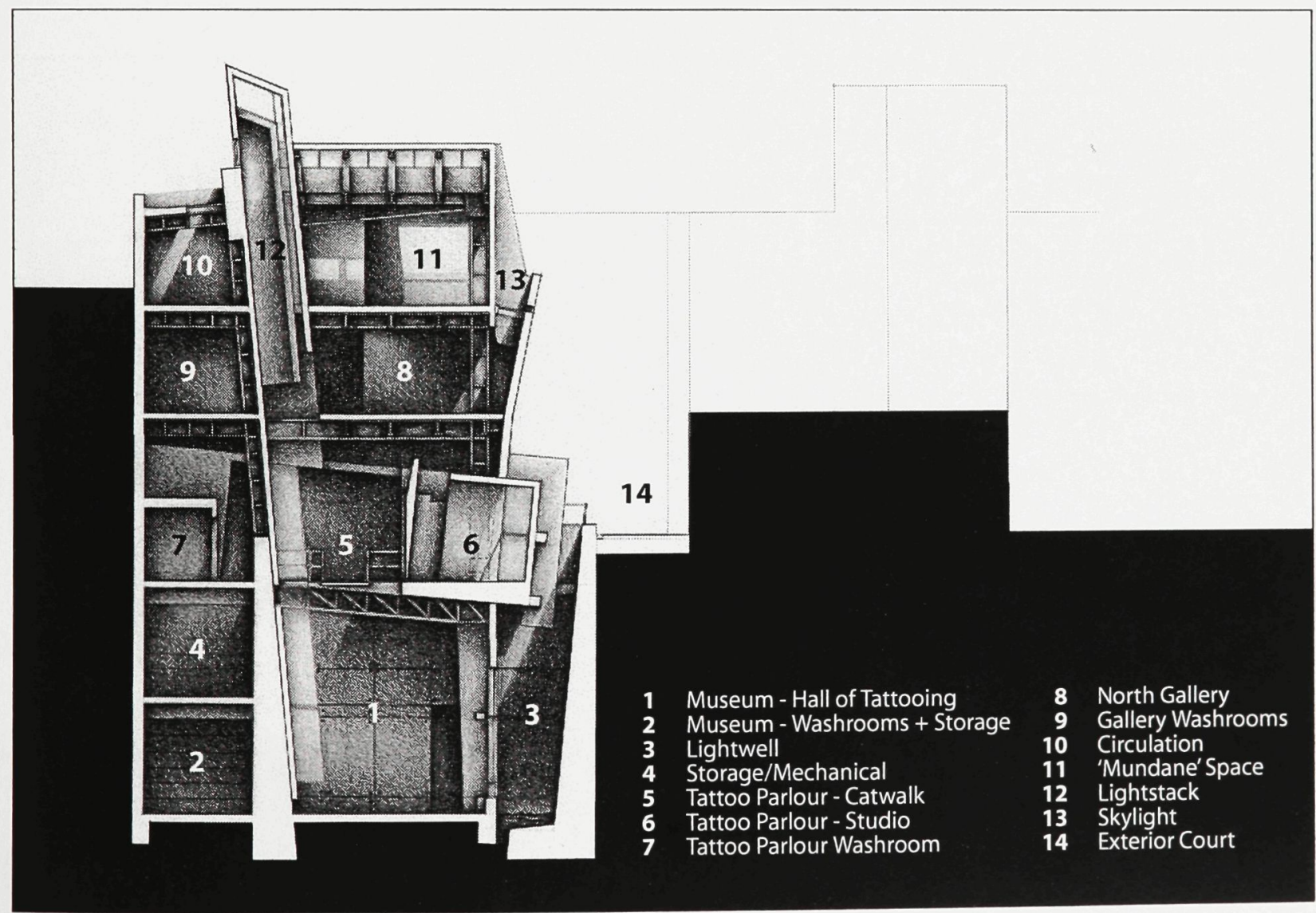

139: Cross Section, Annotated. 
ramp that descends a metre and a half underground, passing around an existing stonewall that is supported by a steel beam that also supports the ramps. As one descends the ramp, they pass over a reflecting pool below, slipping around the stonewall and into the tattoo parlour. This entry sequence, absent of any signage other than a small steel sign mounted on the concrete beside the entrance door itself, maintains the mystery associated with the act of tattooing. By shielding the entrance, it creates within the viewer a sense of curiosity regarding the use, and therefore the meaning of the space. This entrance also reveals the existing physical gaps within the site itself by framing the roofscape of the existing buildings to the East, and the gap that exists between these buildings.

To enter into the reception area, the client or visitor passes through the angled concrete wall of tattoo flash into a well-lit reception area where the sound of tattooing fills the space, but is hidden from view within the enclosed studios themselves. In this space, connected in section to the Gallery above and the Museum below, exist the reception area,

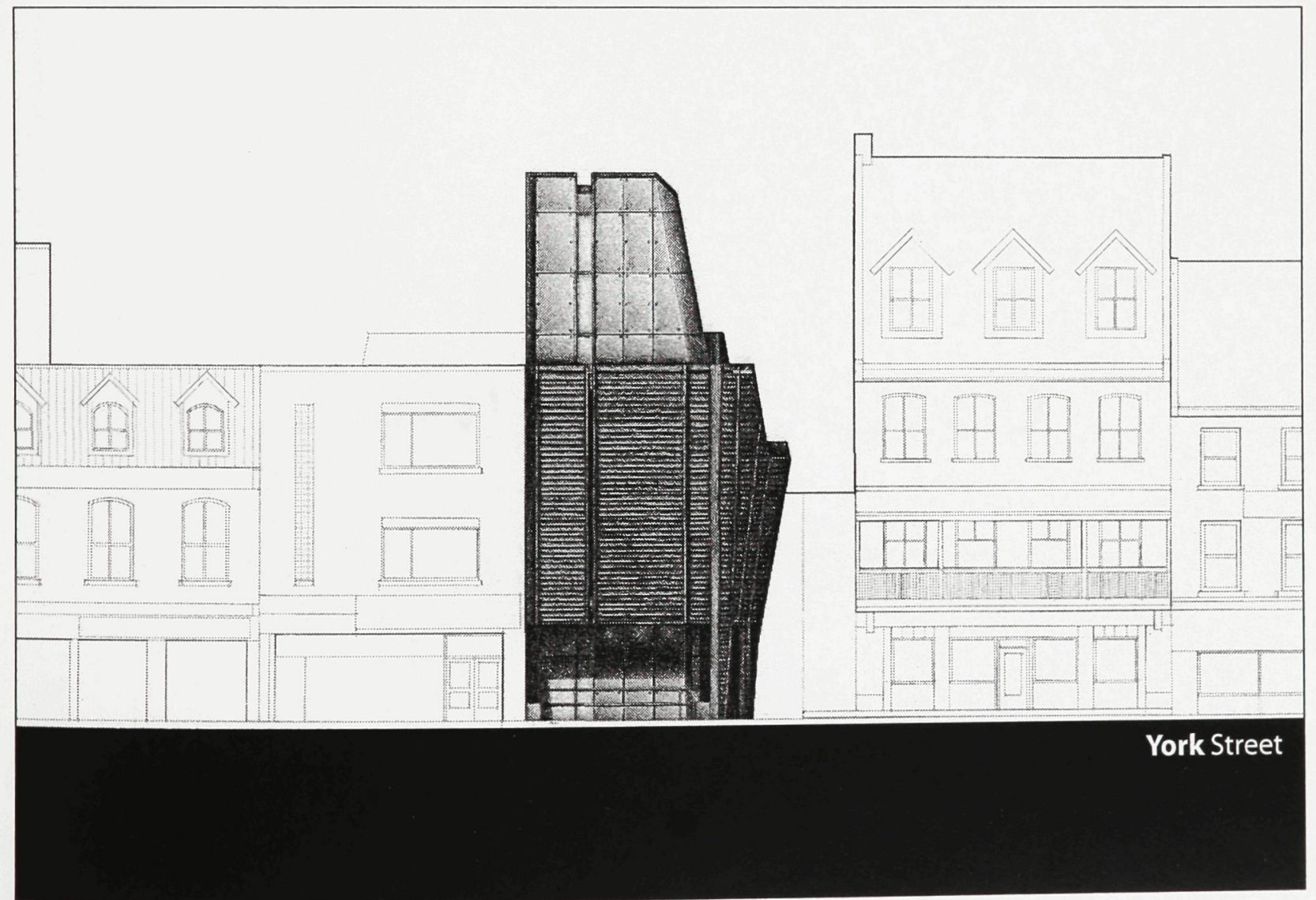

140: South Elevation, Annotated. 
three tattoo studios, and one body modification studio. These five 'rooms' are formally represented as technological boxes, referencing the traditional carnival studios that were transported in a case. These studios are suspended from the steel and concrete structure, while piercing the bent copper surface of the Museum and Gallery, formally disrupting the framed image-surface. The studios are connected to the entrance by a dimly lit steel catwalk where clients pass over the museum below to both access the steel plated studios, and to view the wall of flash, which also contains artworks by the tattoo artists. The studios themselves are never completely separated from the vertical space of the parlour/gallery/ museum, but always present one open surface, allowing for the sound of machines to emanate throughout the space. Unlike many tattoo parlours, the studios do not display the act of tattooing, but allow it to remain a mystery, hidden behind the steel walls of the studios. This allows for the disruption to take place within space, making its meaning unknown.

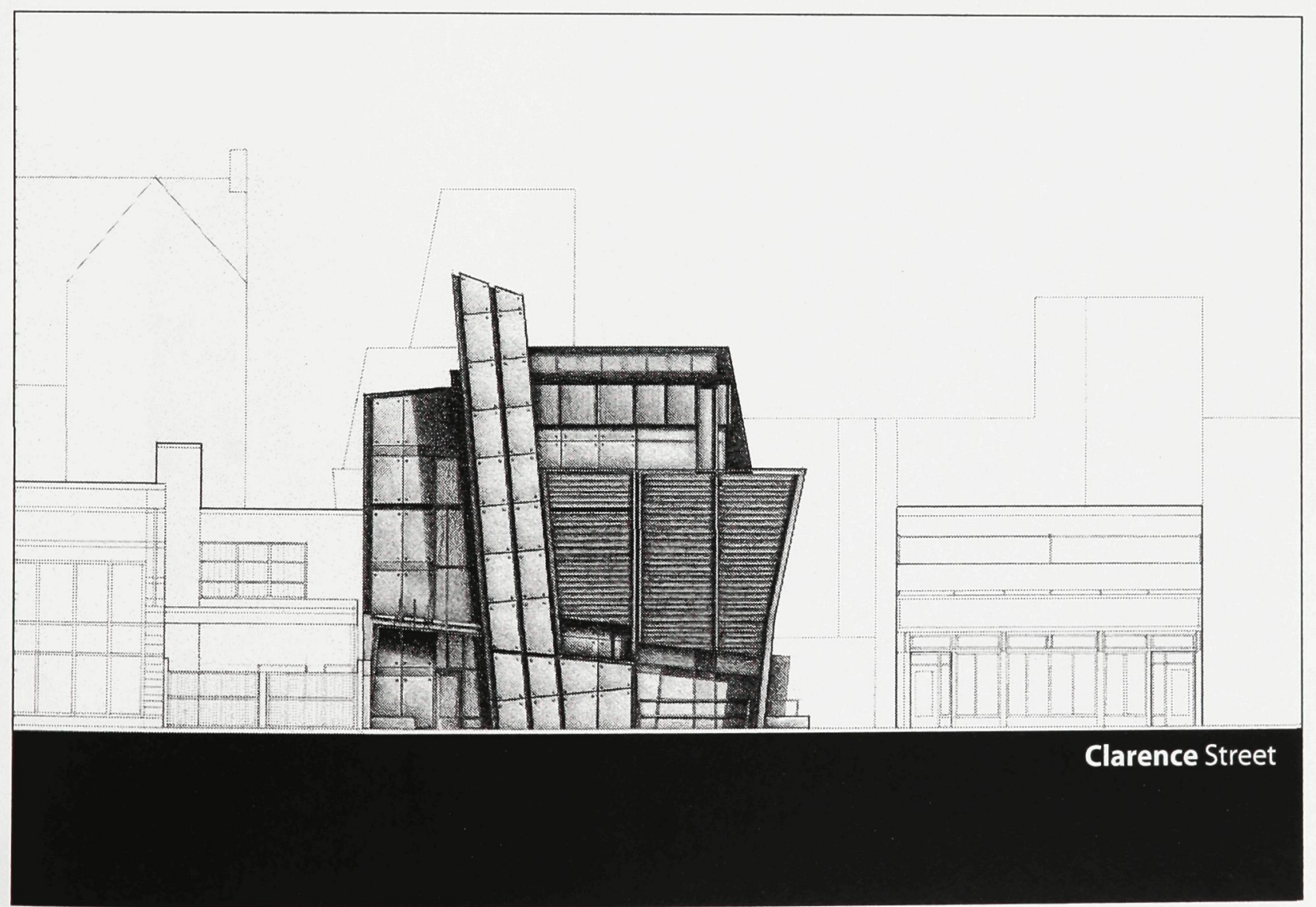

141: North Elevation, Annotated. 
The interruption caused by the tattooing occurs on the exterior façade as well, where the studios pierce the bent image-skin, but remain opaque to meaning. Existing as metallic technological objects that disallow the viewer a line of sight into the spaces, while allowing light to enter into the studios through both small gaps and translucent screens. As the studios contain operable windows, the artists are able to allow the aural experience of the act of tattooing to radiate into the exterior open spaces, creating a conflictual, nonsymbolized experience of both sound and form as the experience of the demark in space.

\section{Mundane Space: An Everyday Experience of the Market}

Resting above the gallery spaces is the mundane or ordinary residential/office space that exists within the program as a continuation of the everyday experience of the city, thereby allowing the ideal landscape to exist within the microcosm of the site/ building itself. Existing as the only entrance along Clarence Street, the glass slit in the

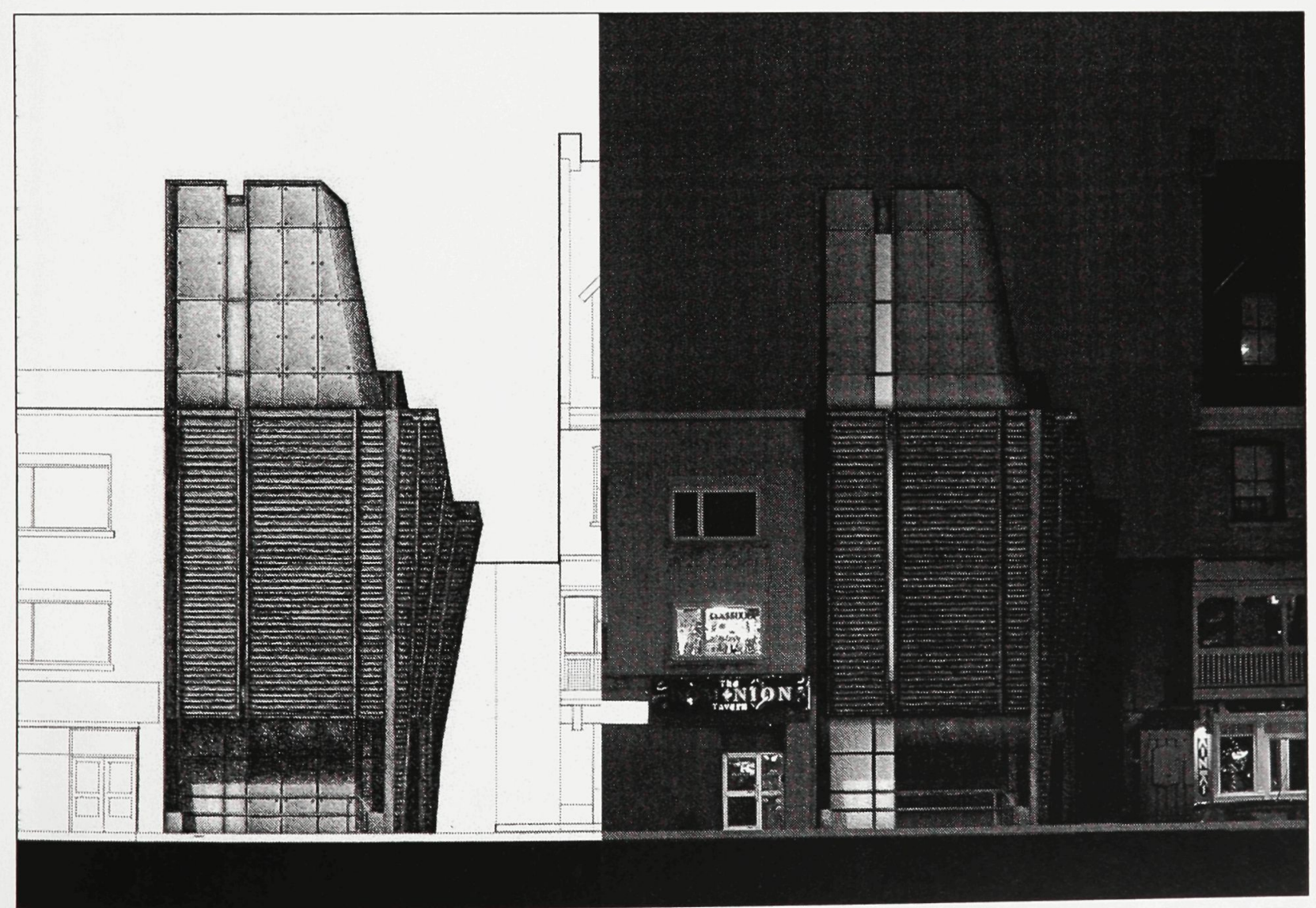

142: Vignette Showing York Street Daytime and Nighttime Façades. 
façade contrasts with the rest of the mainly opaque yet suggestive façade. This entry occurs behind the angled wall, which imposes itself upon the circulation, storage, and washroom spaces contained behind its solidity. As the visitor passes up the two flights of stairs to the mundane space above, they experience a translucent gap in the angled tattoo flash wall. This creates an indirect interaction between the tattoo parlour and gallery, and the stairwell, allowing the inhabitants to experience the tattoo flash contained on the other side of the wall. Much as in the other programs, the hum of the tattoo machines is present, while the clients in the tattoo parlour and the visitors to the gallery can view the shadow of the visitor as the proceed up the stairs. This translucent glass wall allows for an awareness of the other programs that exist within the building rather than acting as a separation.

The upper corridor, lit only from above by a skylight, allows access into the units, while a the interior bridge connects to a second stairwell as well as another unit within the South half of the building. The spaces themselves, also lit by skylights and large windows
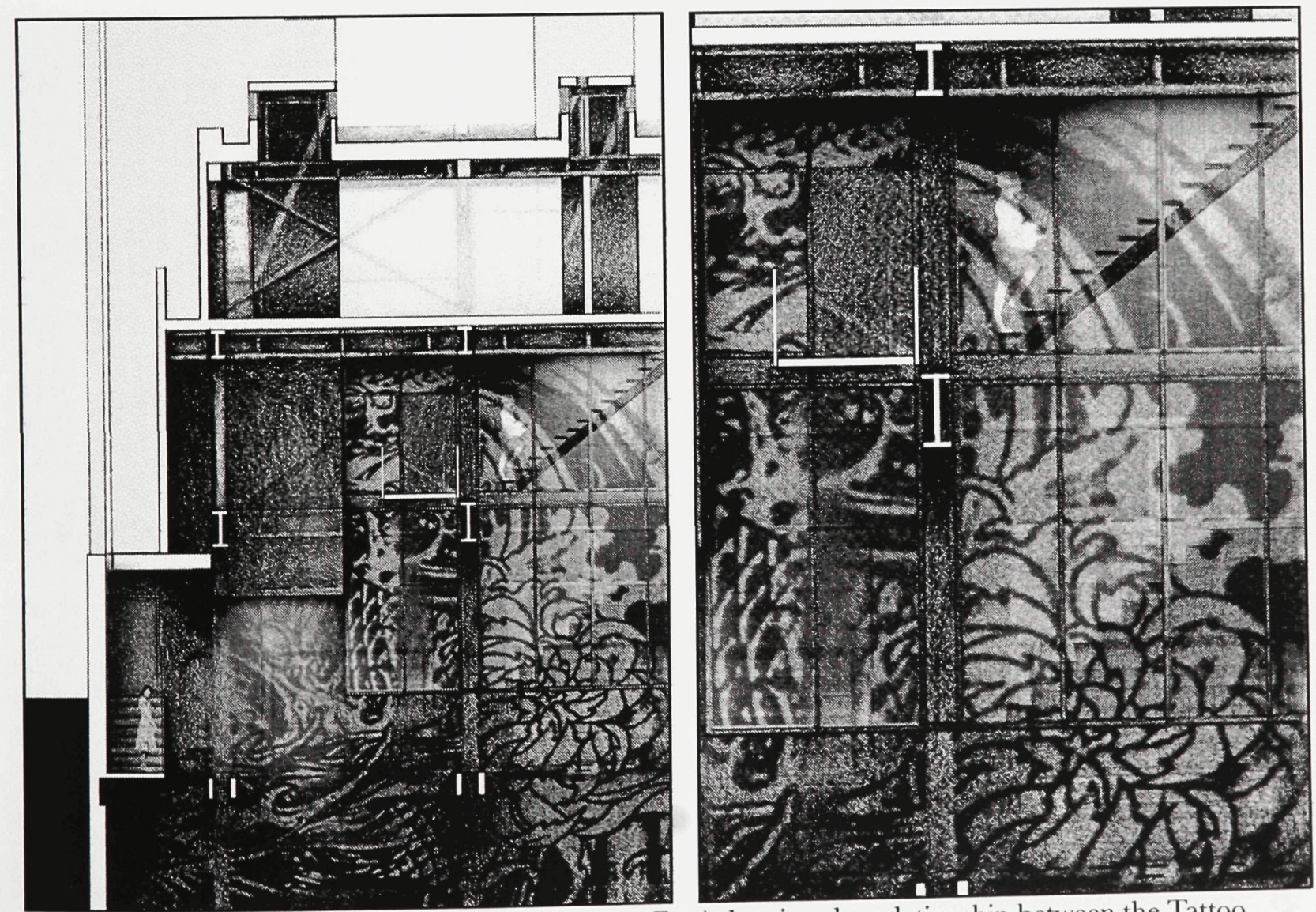

143: Vignette of Section at North Façade (looking East) showing the relationship between the Tattoo Parlour, Gallery and the 'Mundane' Spaces. 
that access exterior balcony spaces, are undesignated generic spaces that accommodate various inhabitations. As an extension of the museum-gallery's frame structure below, these spaces are perched above, and thus separated from the interruptive experience that occurs below, all but for the lightstacks that literally pierce the space, where translucent panels allow a subtle light to enter the units.

\section{Open/Interstitial Space: The Experience of Discourse and the Demark}

These spaces, most of which I have described in the aforementioned programs, are the interruptive experiences where there the experience of public space - as the intersubjective experience of the un-signified - occurs within the site and building. These spaces do not permanently exist as a form of public space, but become as such through the interruptive event as created by the demark in the scene, causing the ideal landscape that existed before to transform into one that can be considered hysterical. Therefore they exist
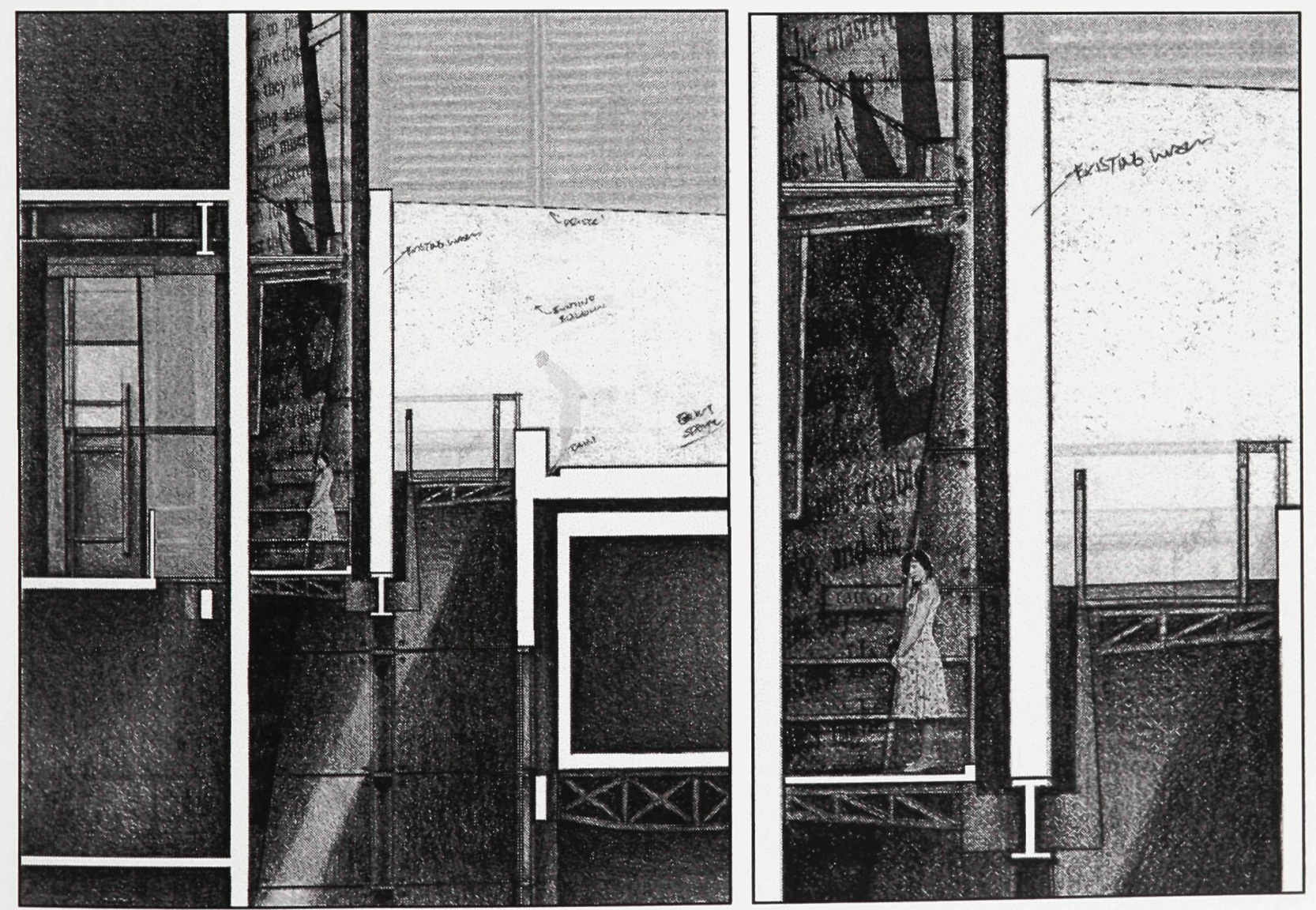

144: Vignette Showing Section of Entry to the Tattoo Parlour (Looking East). 
as extensions of typical forms of space in the city into which the interruptive nature of contradictions imposes itself upon the space.

As such, these spaces in the programs exist more as connections, or interstitial spaces between programs. This includes connections between the exterior programs that already exist within the site, allowing for programmatic overlaps to occur within the 'open' (functionless) and potentially scaleless form of space. This occurs in the pedestrian space that exists between the two footprints of the building, and into which all of the new/existing programs connect, and in doing so it either physically or visually reveals to the visitor the contradictory nature of space. This space is comparable to the existing typological courtyard spaces within the Market that have become both spaces to gather and to move through. But unlike these spaces, the proposed courtyard space is much more suggestive of the multiplicity of functions contained in the original nature of the courtyard as an alleyway space. In this sense, the contradictions that appear as being veiled from the

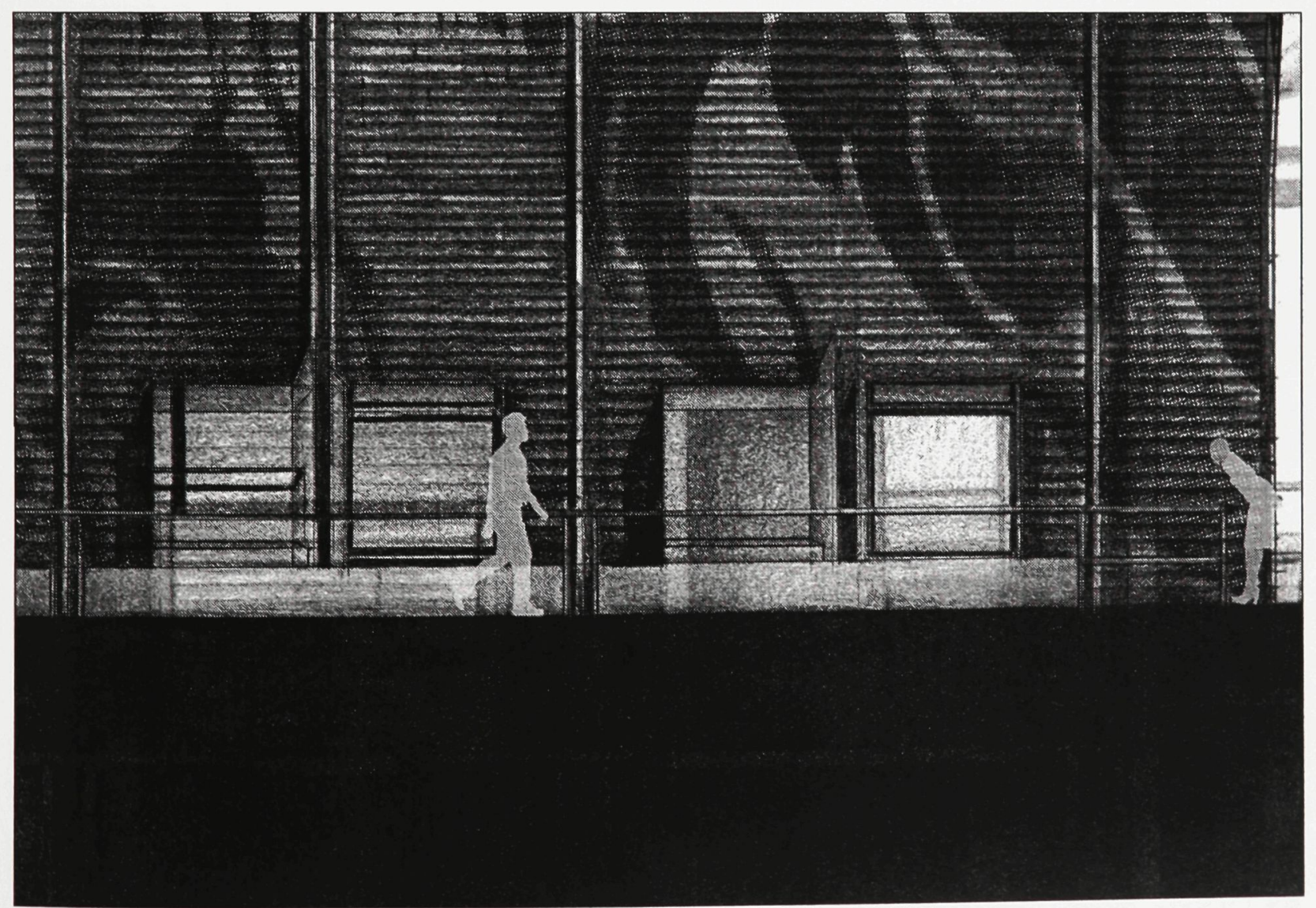

145: Vignette Showing Elevation of Tattoo Studios From Exterior. 
street become apparent when they are condensed into such a space. The only permanently designed aspect to this space exists as seating along the lightwell gaps between the groundplane and the building, and two sheltered spaces that exist above the lightwells as steel grates (one as a payphone shelter on Clarence, and the other as a taxi stand shelter along York Street).

\section{Referencing the Theoretical Process Through Architecture}

The representations of this project, consisting of both the drawings and models that are illustrated in the next section, exist as depictions of the design as an architecture of articulated idea, space and material. These, along with the text above, attempt to depict the experiential quality to the space, relating to the discomforting experience of the demark that exists in public spaces as I have defined previously through the anamorphic lens, while also addressing the specific site and programmatic issues through the lens itself. As such

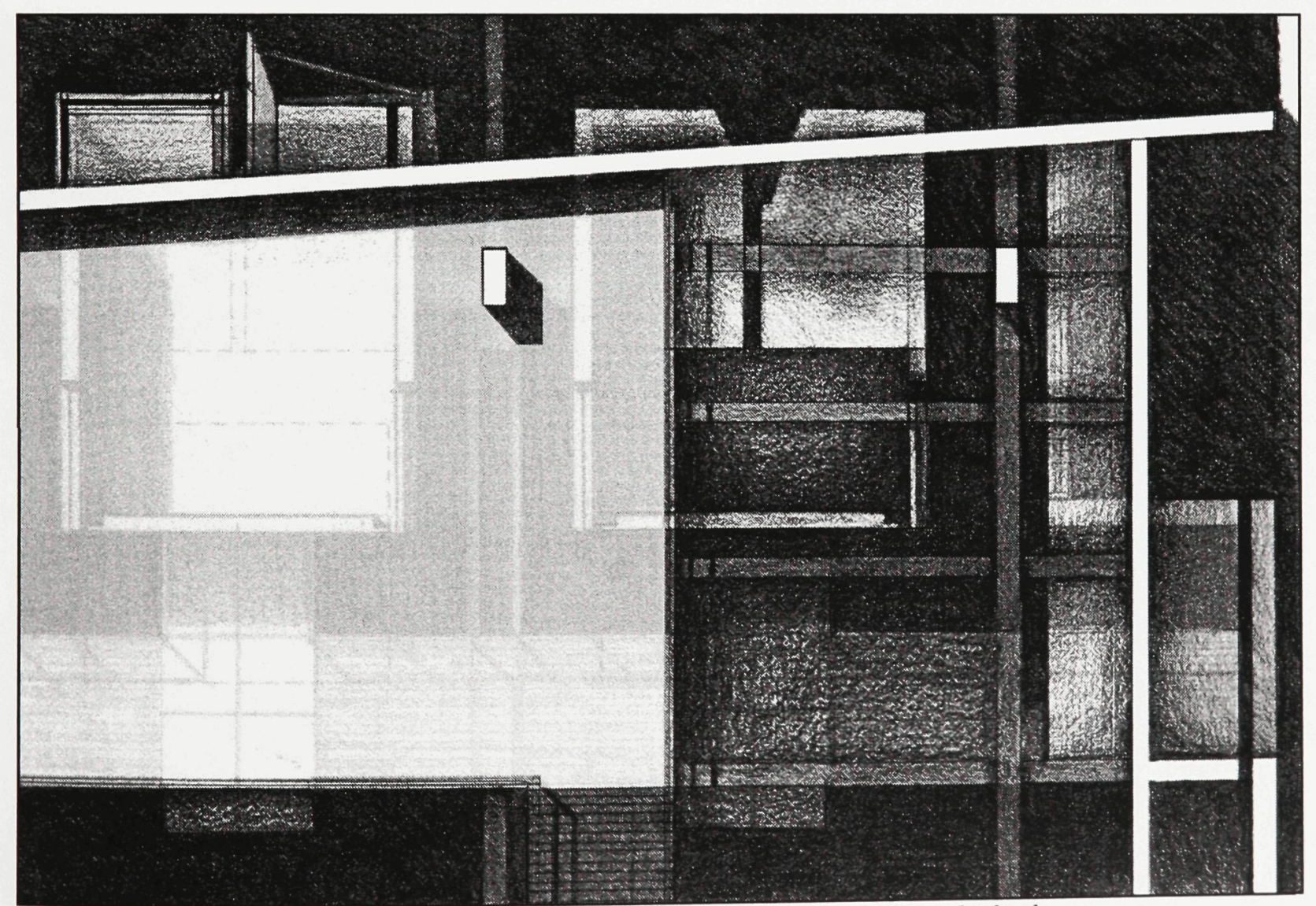

146: Vignette Showing Detail Plan of North Gallery and its Relationship to the body modification studio and tattoo parlour below. 
the architectural artifact exists as one that is stained (demarked), as both architect and reader no longer reside in a neutral position. Any previous understandings of space and its creation in the city are altered through the context created by the lens.

This architecture, as a manifestation of the theory, continually refers back to the theoretical and speculative process itself in its design both consciously and unconsciously due to the nature of the theoretical lens. Hence the theoretical investigations and the analogies used have the potential to come back into play in the making of the architecture, imposing themselves and their meanings upon the project through the lens. This has been further represented by the vignettes, which present a more detailed attempt at describing the experience of the space in relation to the demark. This is also where I have consciously ended the development of the project, and therefore many of the vignettes themselves suggest further explorations in the development of the architecture whereby the process itself comes back into play in the detail and material of the building.
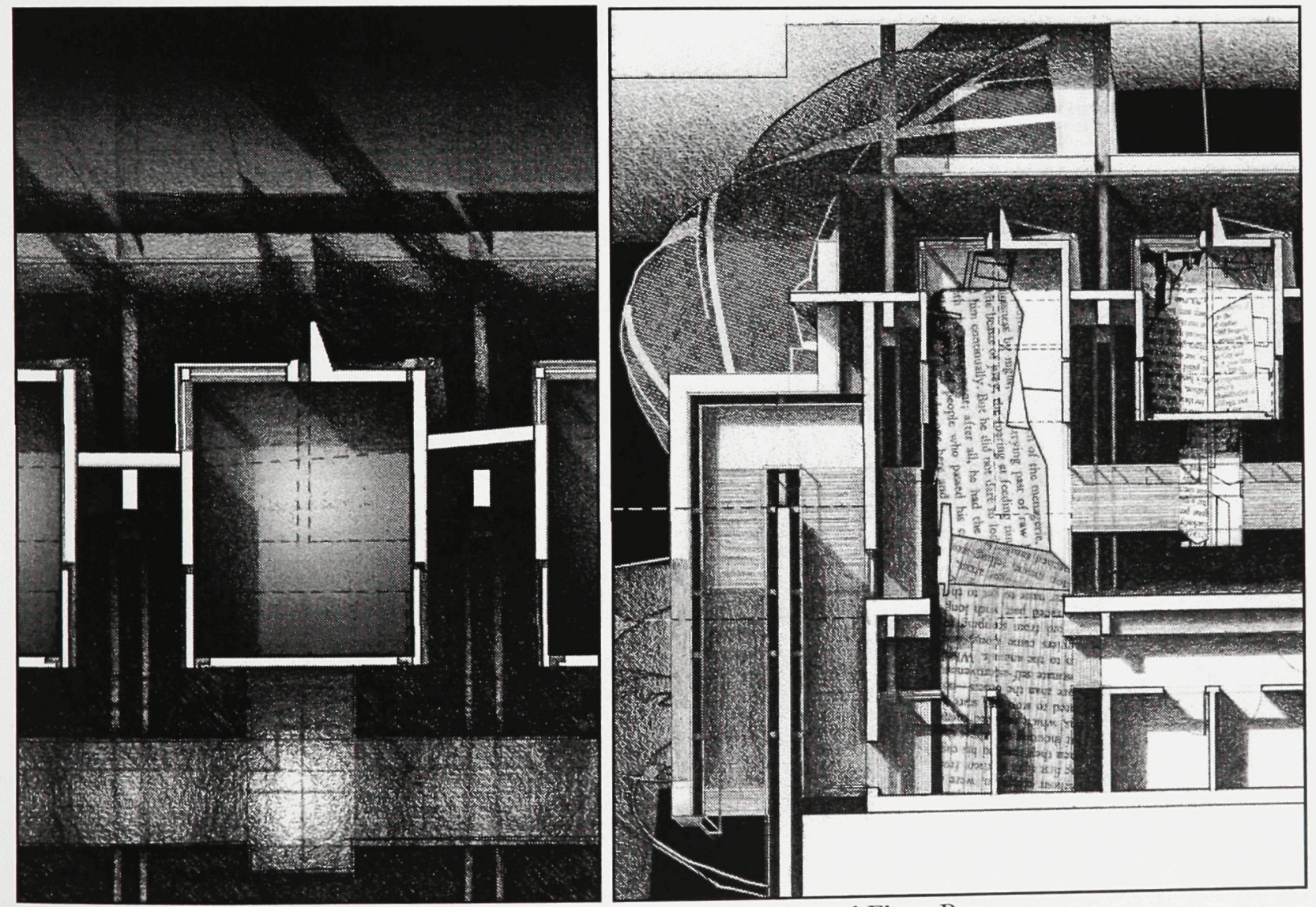

147: Vignettes Showing Nighttime Plan Detail of Tattoo Studio and Floor Pattern

Detail in Tattoo Studio and Exterior Court. 
From this point in the architectural and theoretical process I developed a video, Architecture as Stained Artifact, that illustrates the connections that exist between what has come before the lens and what exists after in the architecture itself as an artifact specific to the topos. This video, unlike the first video The Architecture of Hysteria - which attempted to develop a spatial, material, and experiential quality to the theory itself - presents to the viewer an experience of space within the proposed building that references the previous explorations by relating the architectural artifact and its experience directly to them.

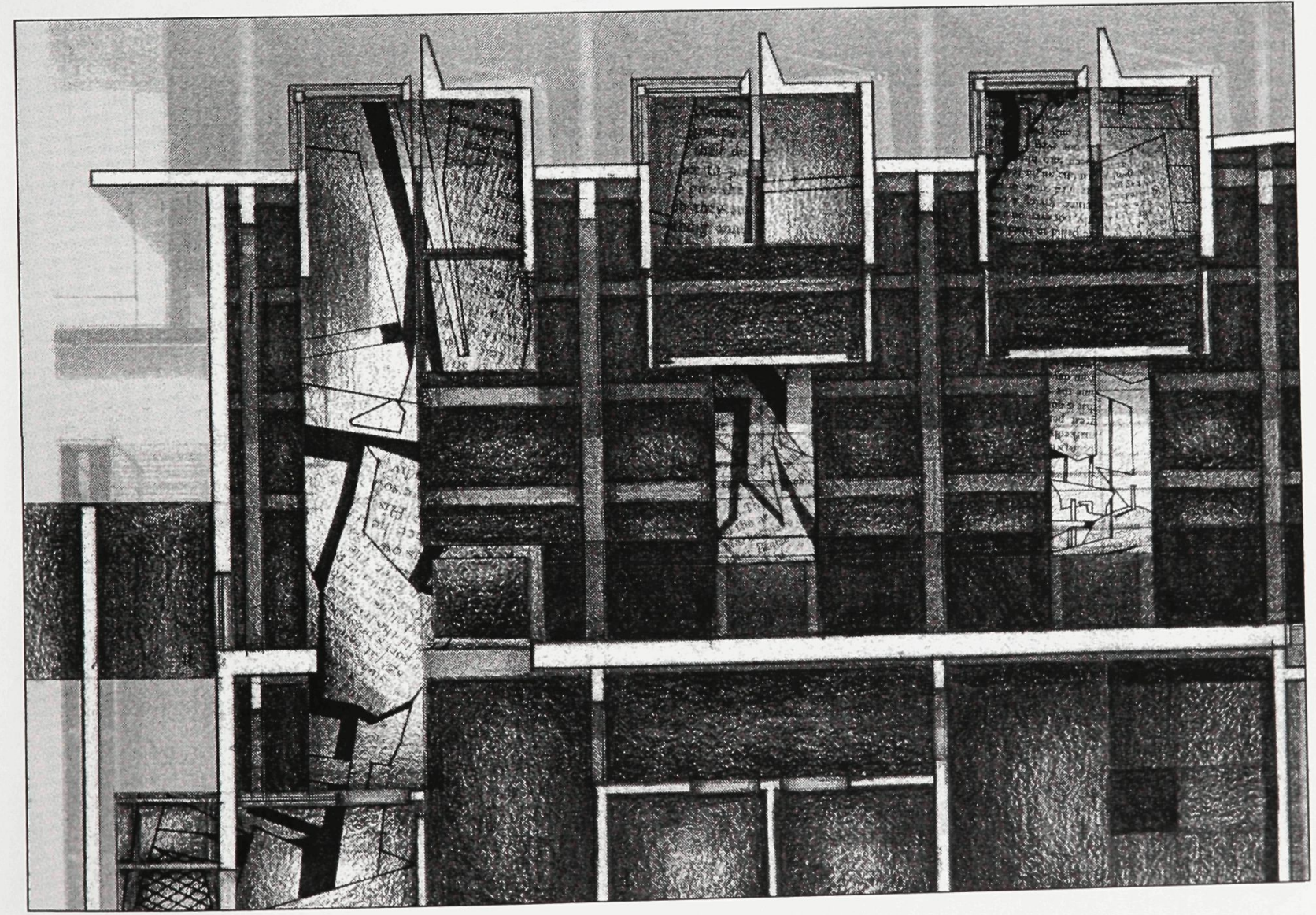

148: Vignette Showing Reflected Ceiling Plan in Tattoo Studio. 


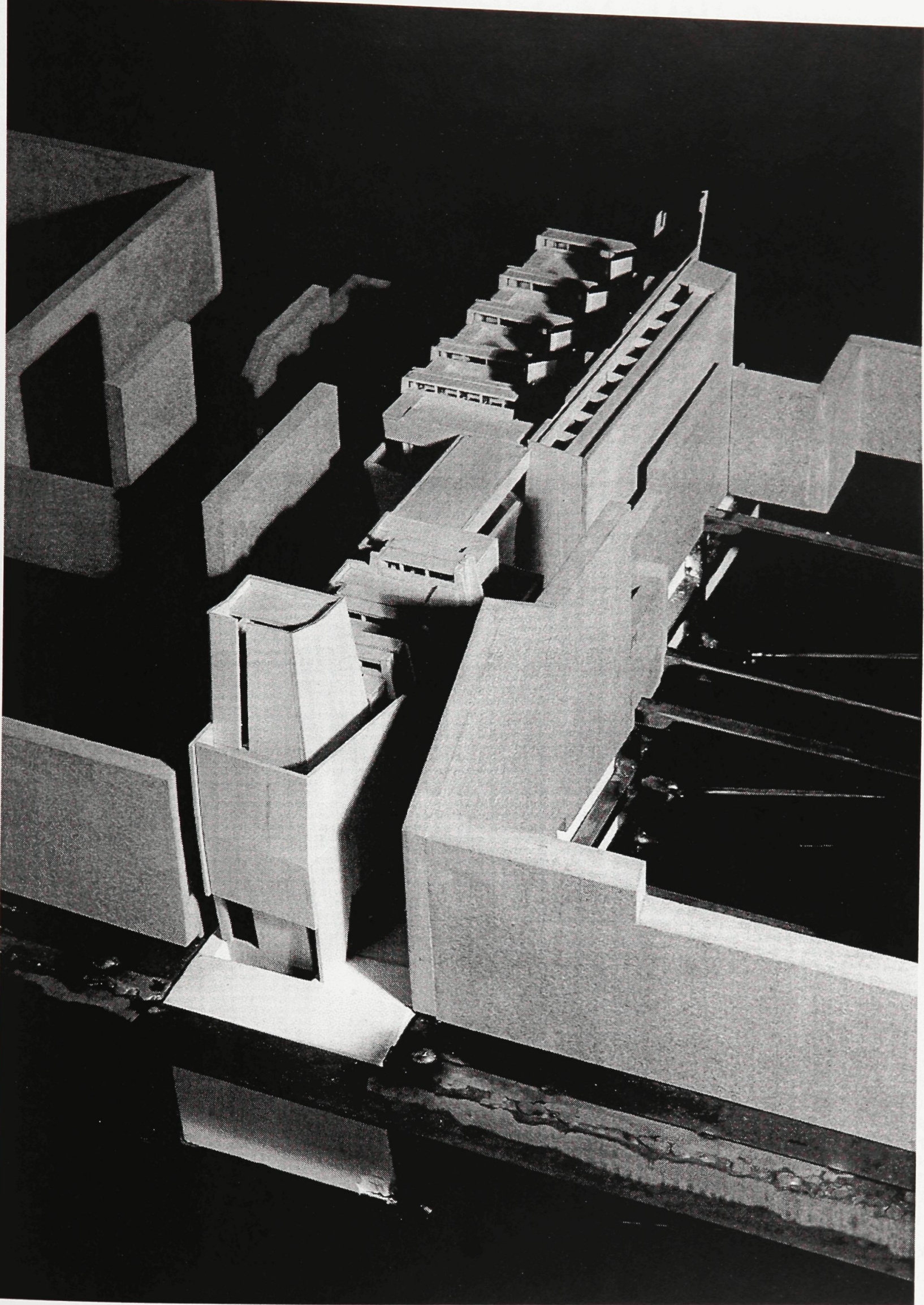

Plate 1: Photograph of Model from Southeast. Basswood and Plaster. 


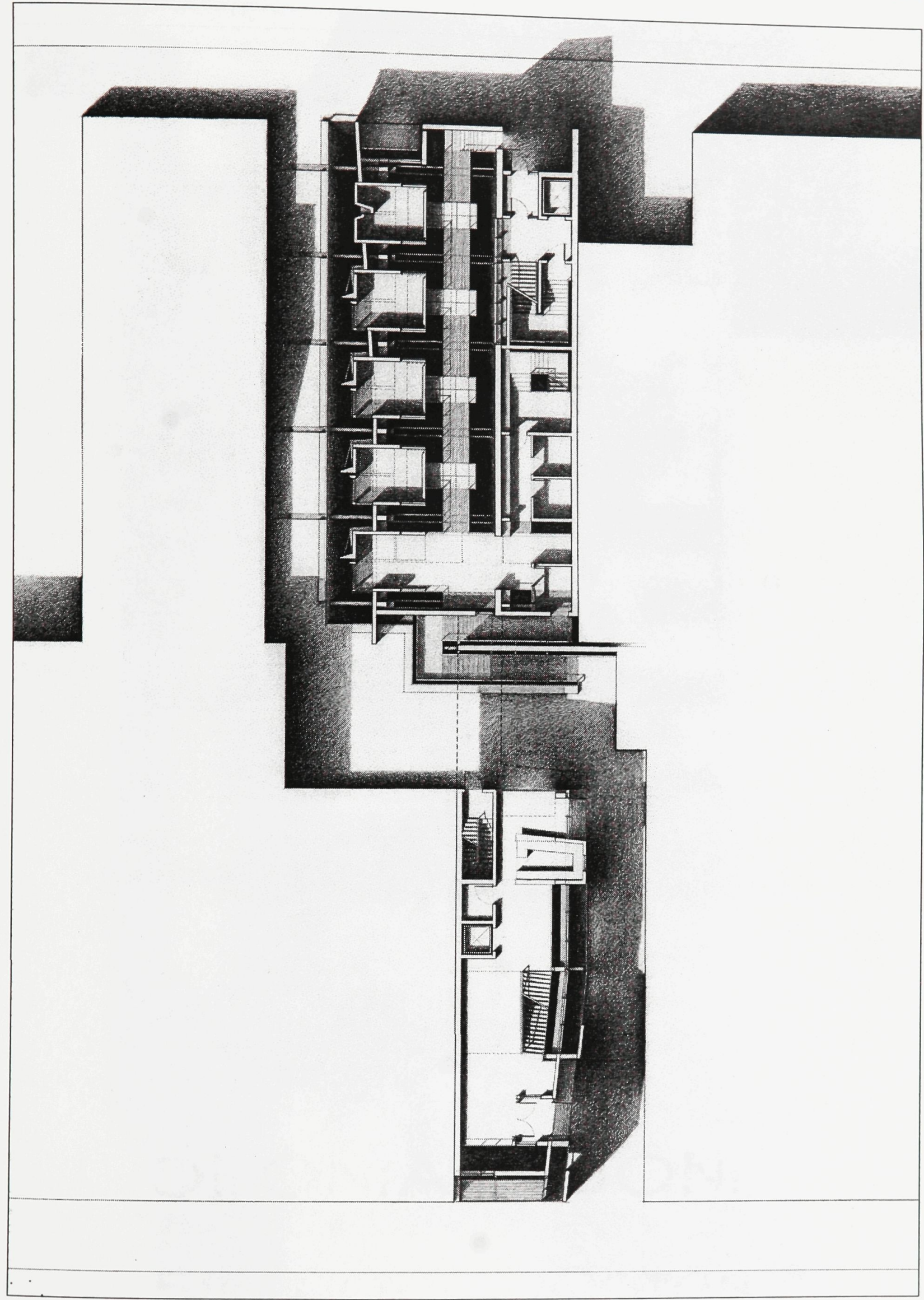

Plate 2: Grade Level Plan. Graphite on Strathmore, 61 x 91.4cm. 1:100. 


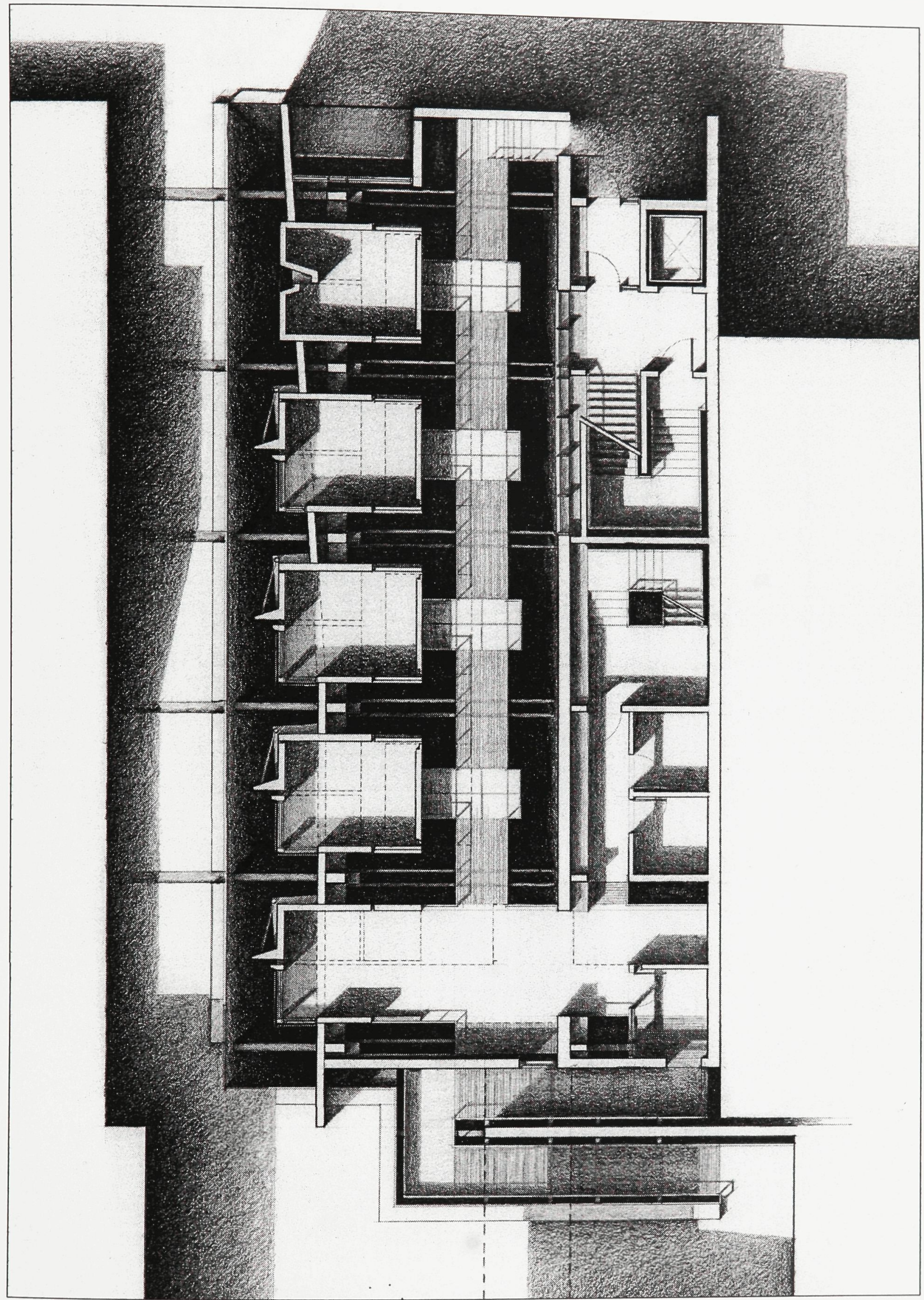

Plate 3: Detail of Grade Level Plan. 


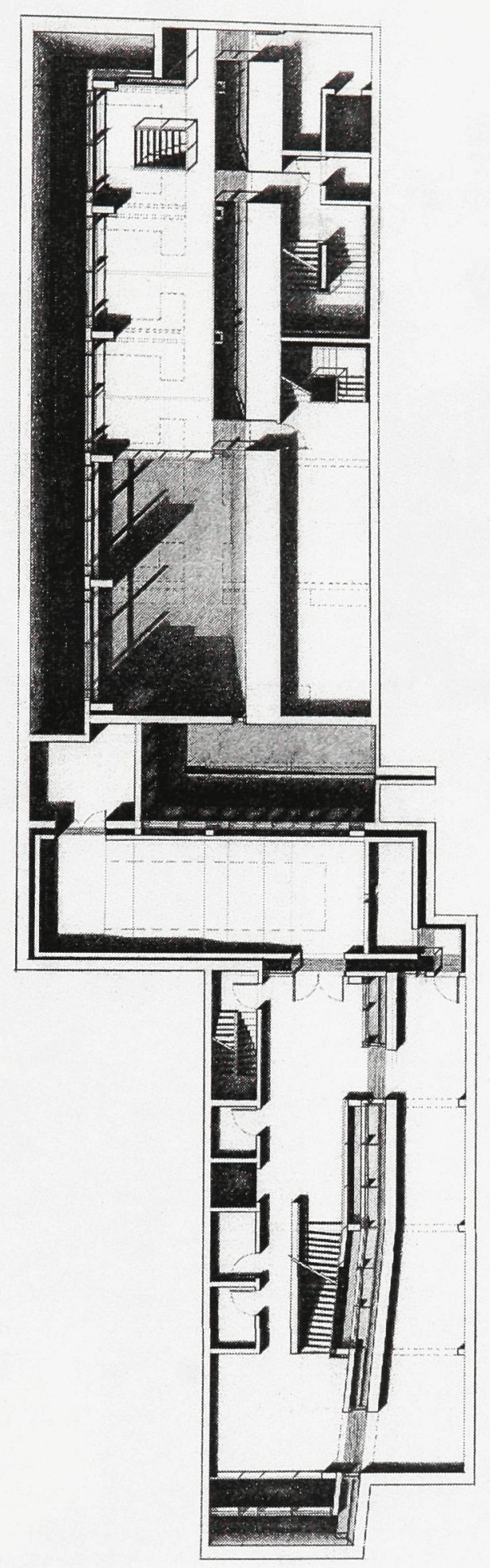

Plate 4: Below Grade Plan. Graphite on Strathmore, 61 x 91.4cm. 1:100. 


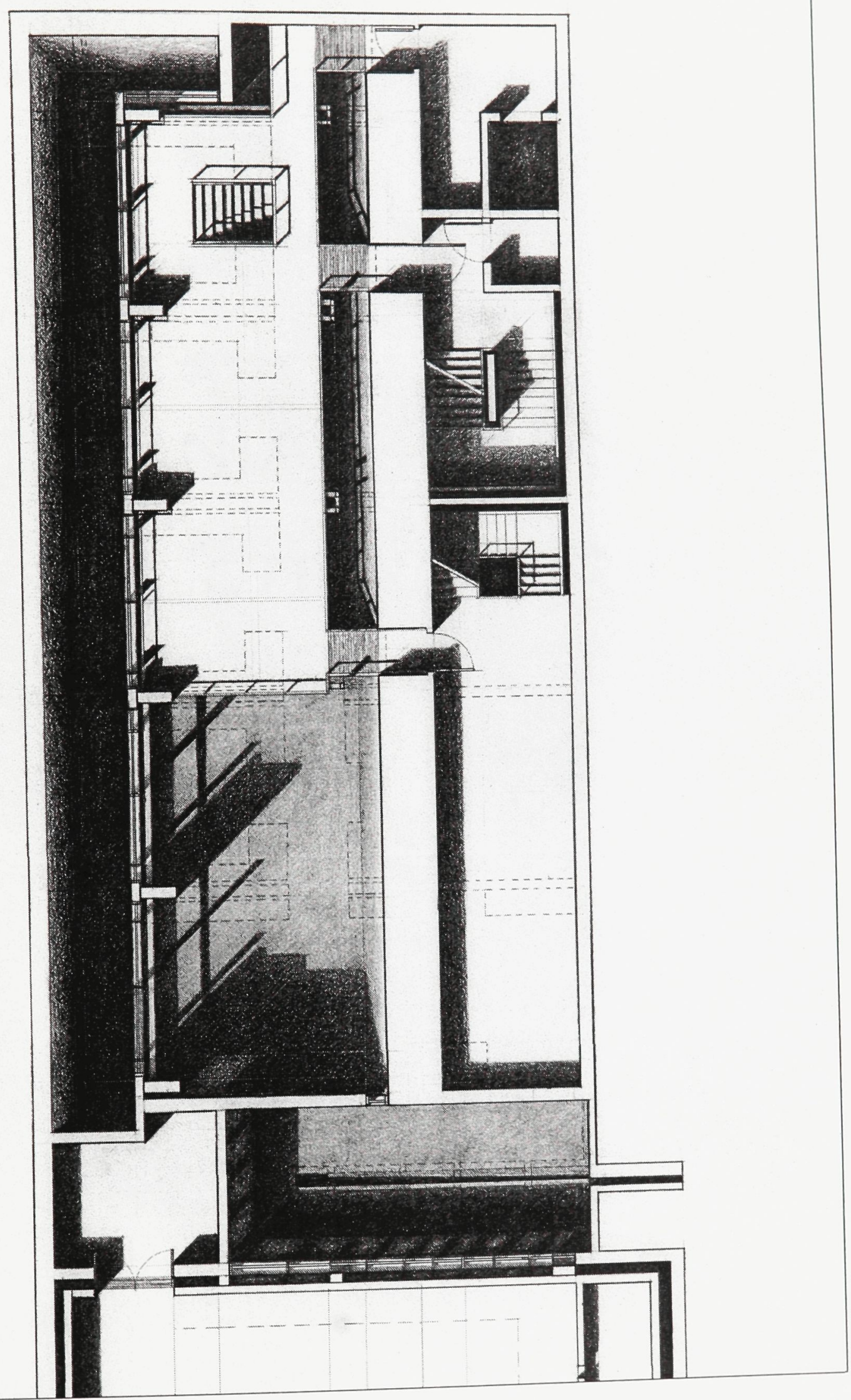

Plate 5: Detail of Below Grade Plan. 


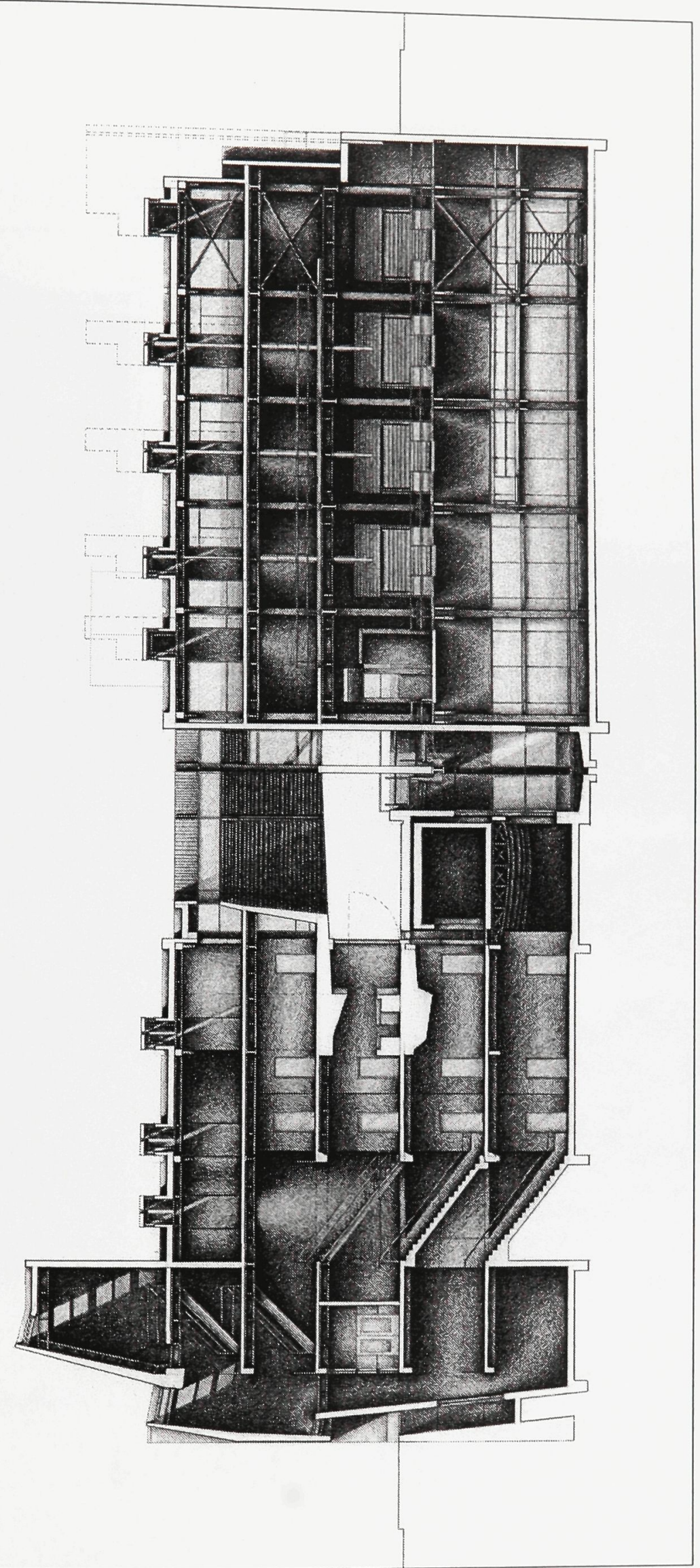

Plate 6: Longitudinal Section. Graphite on Strathmore, 61 x 91.4cm. 1:100. 


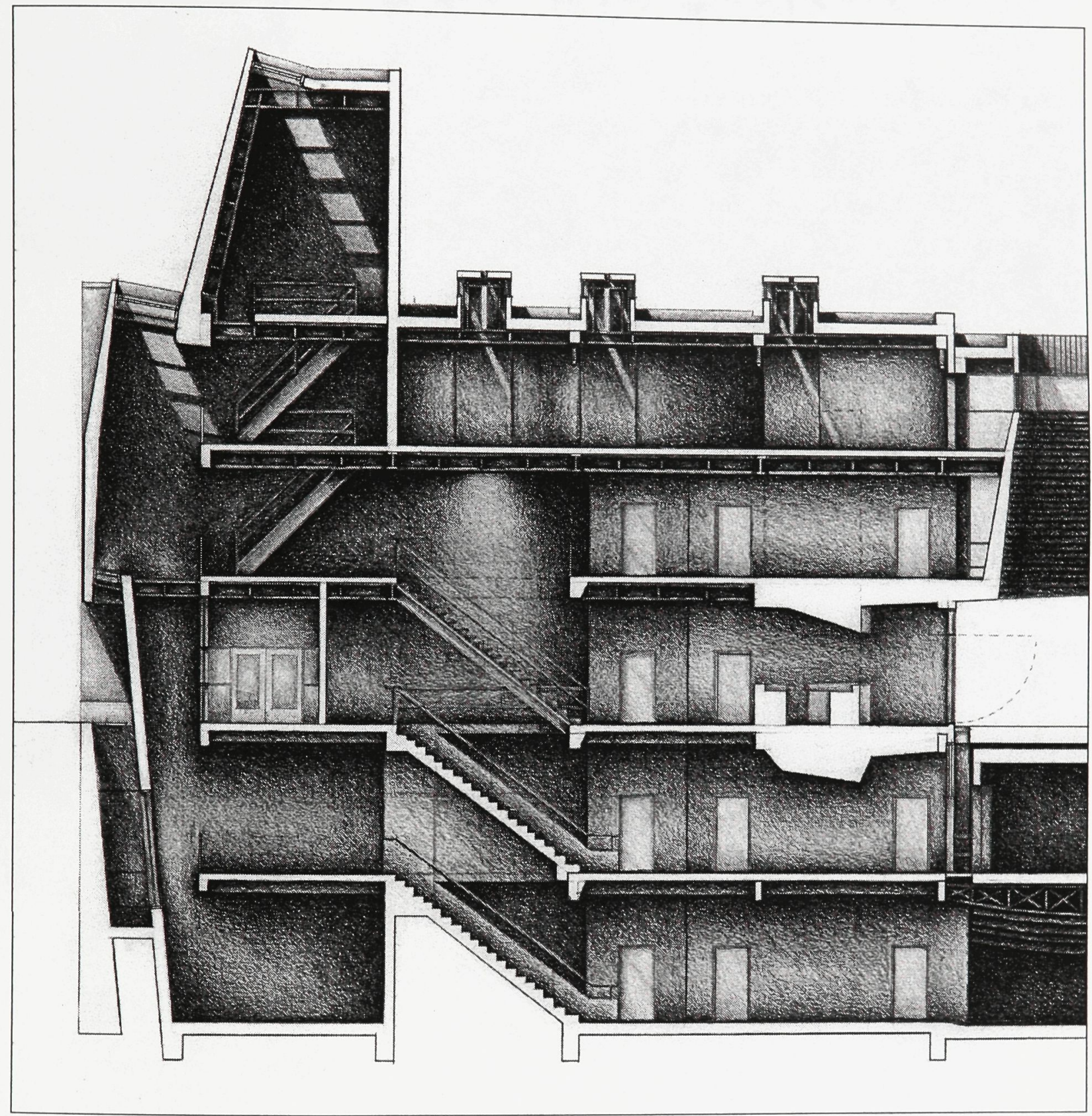

Plate 7: Detail of Longitudinal Section (South Building Form) 


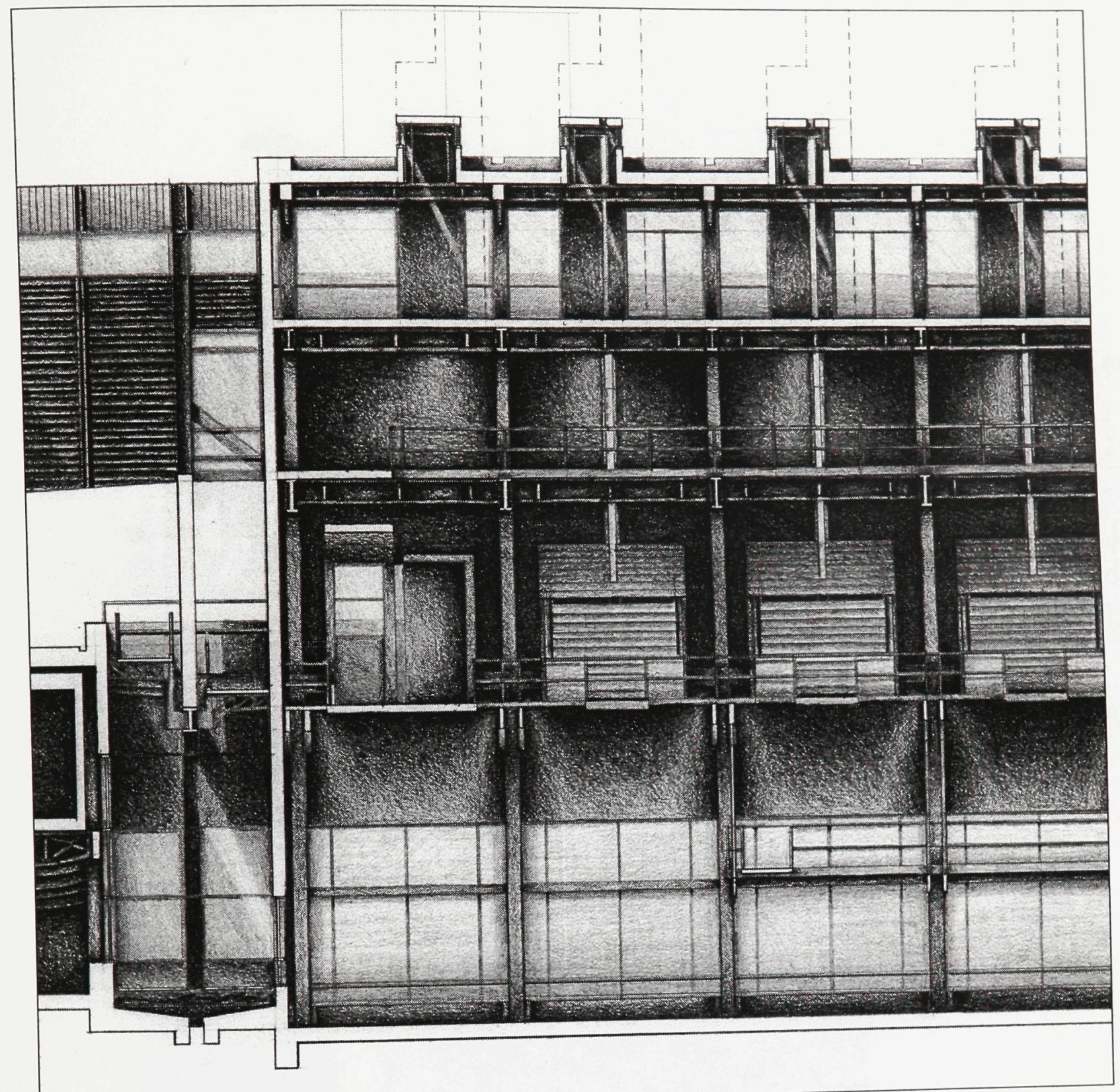

Plate 8: Detail of Longitudinal Section (North

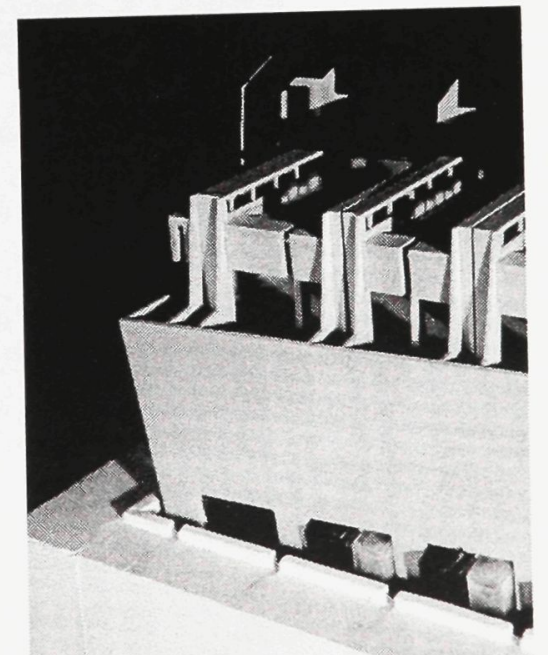
Building Form) and Photograph of Model. 


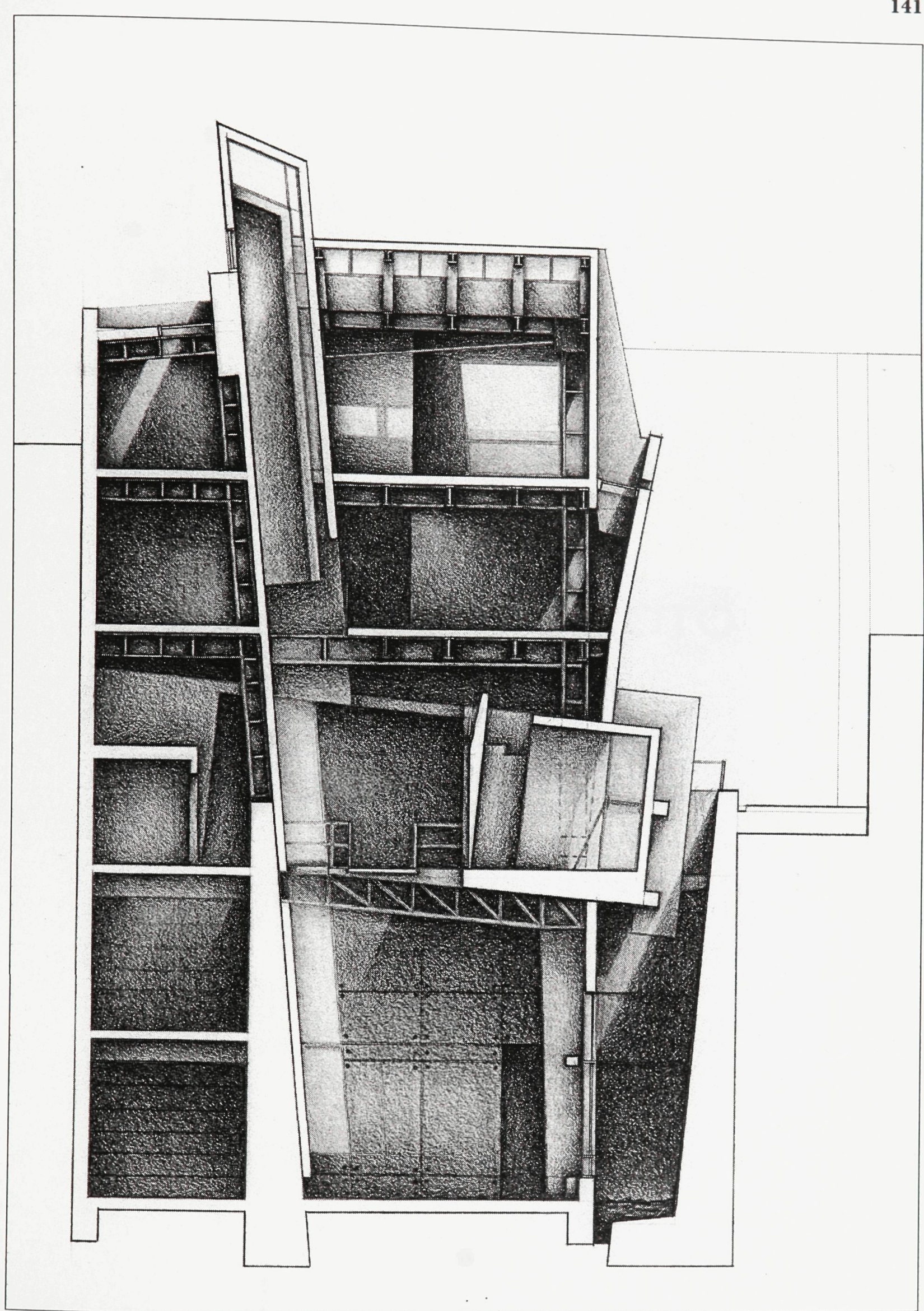

Plate 9: Detail of Cross Section. Graphite on Strathmore, 61 x $45.7 \mathrm{~cm} .1: 100$. 


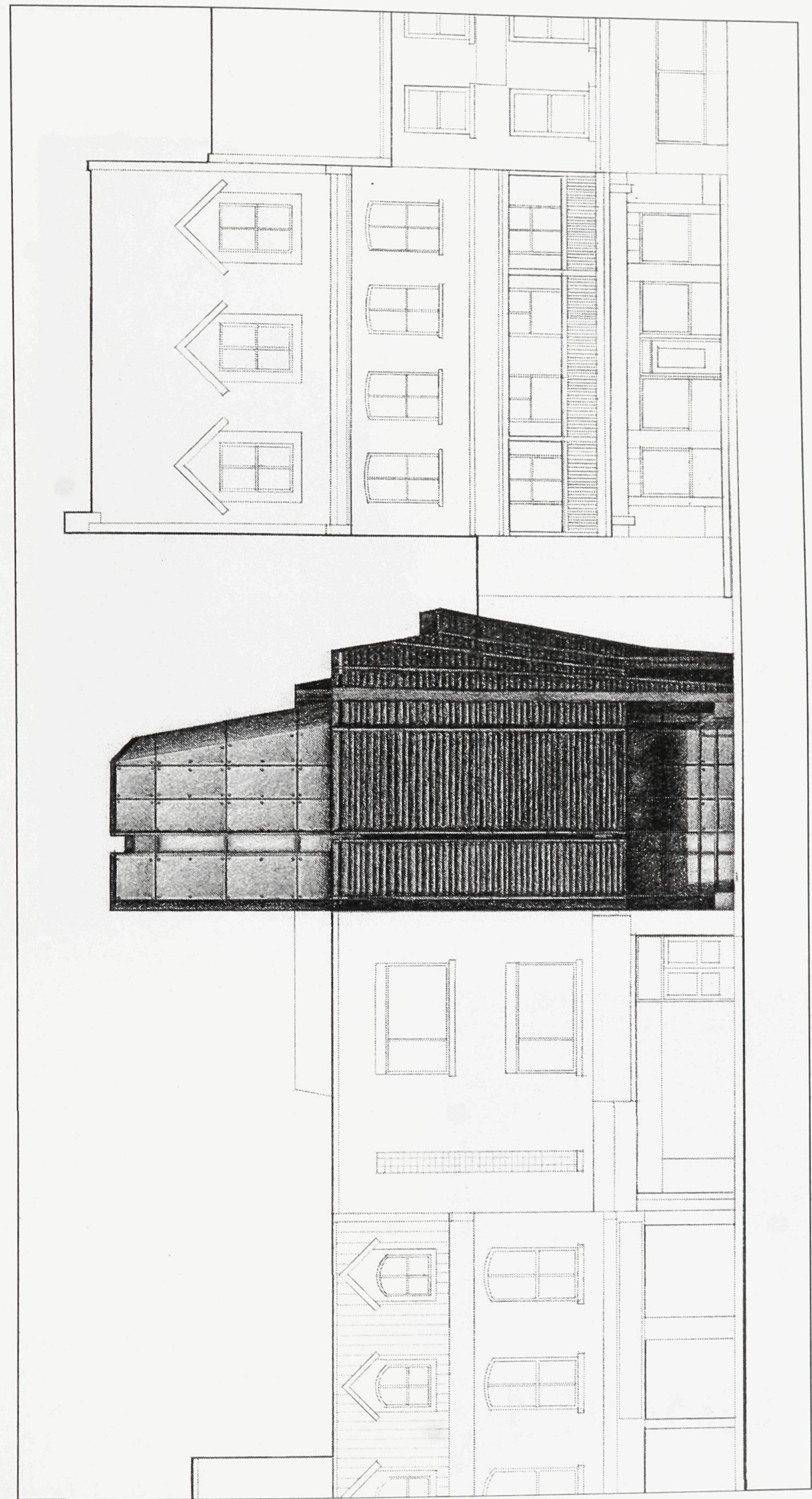

Plate 10: South Elevation. Graphite on Strathmore, 61 x 45.7cm. 1:100. 

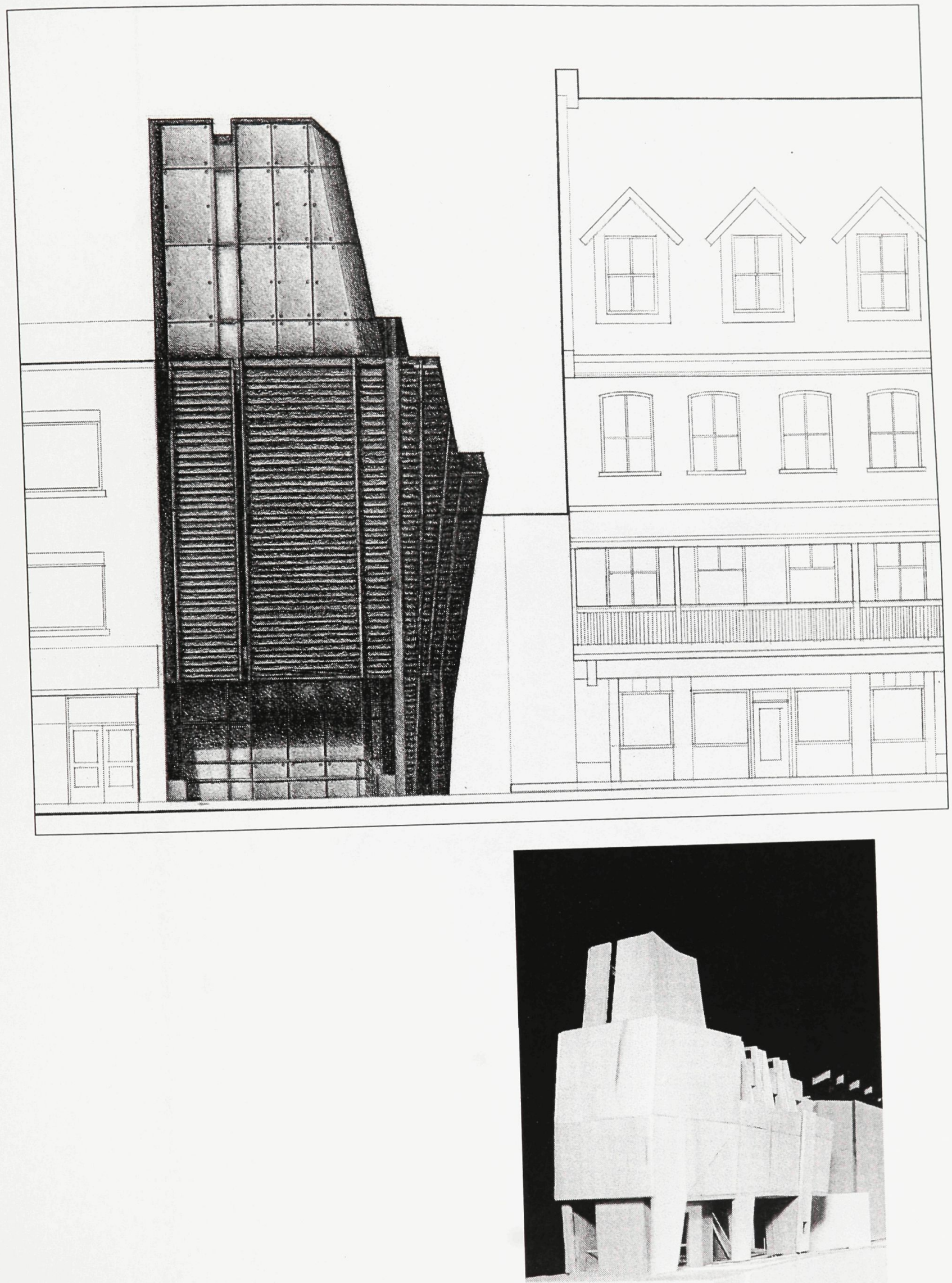

Plate 11: Detail of South Elevation and

Photograph of Model from South-East. 


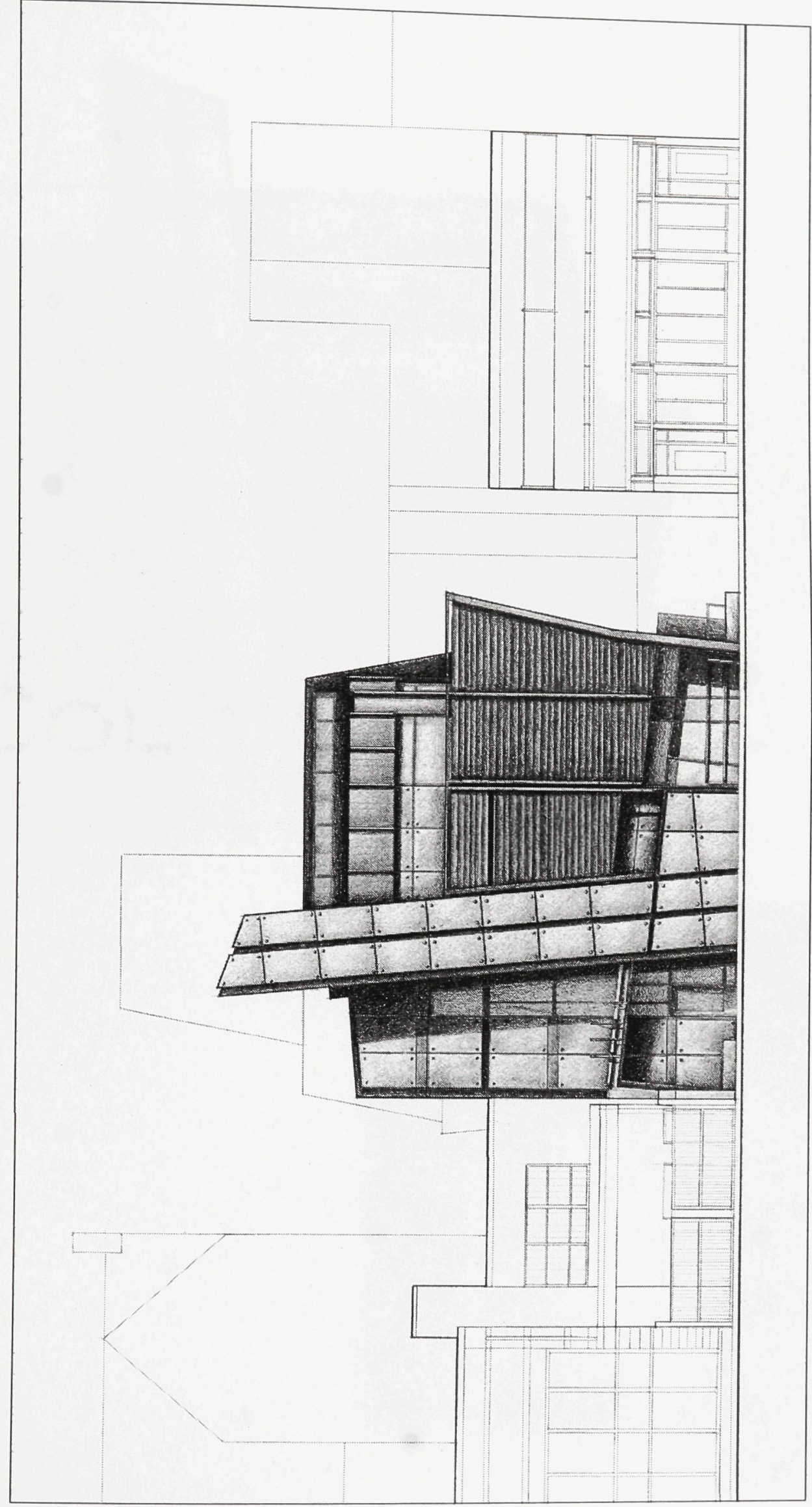

Plate 12: North Elevation. Graphite on Strathmore, 61 x 45.7cm. 1:100. 

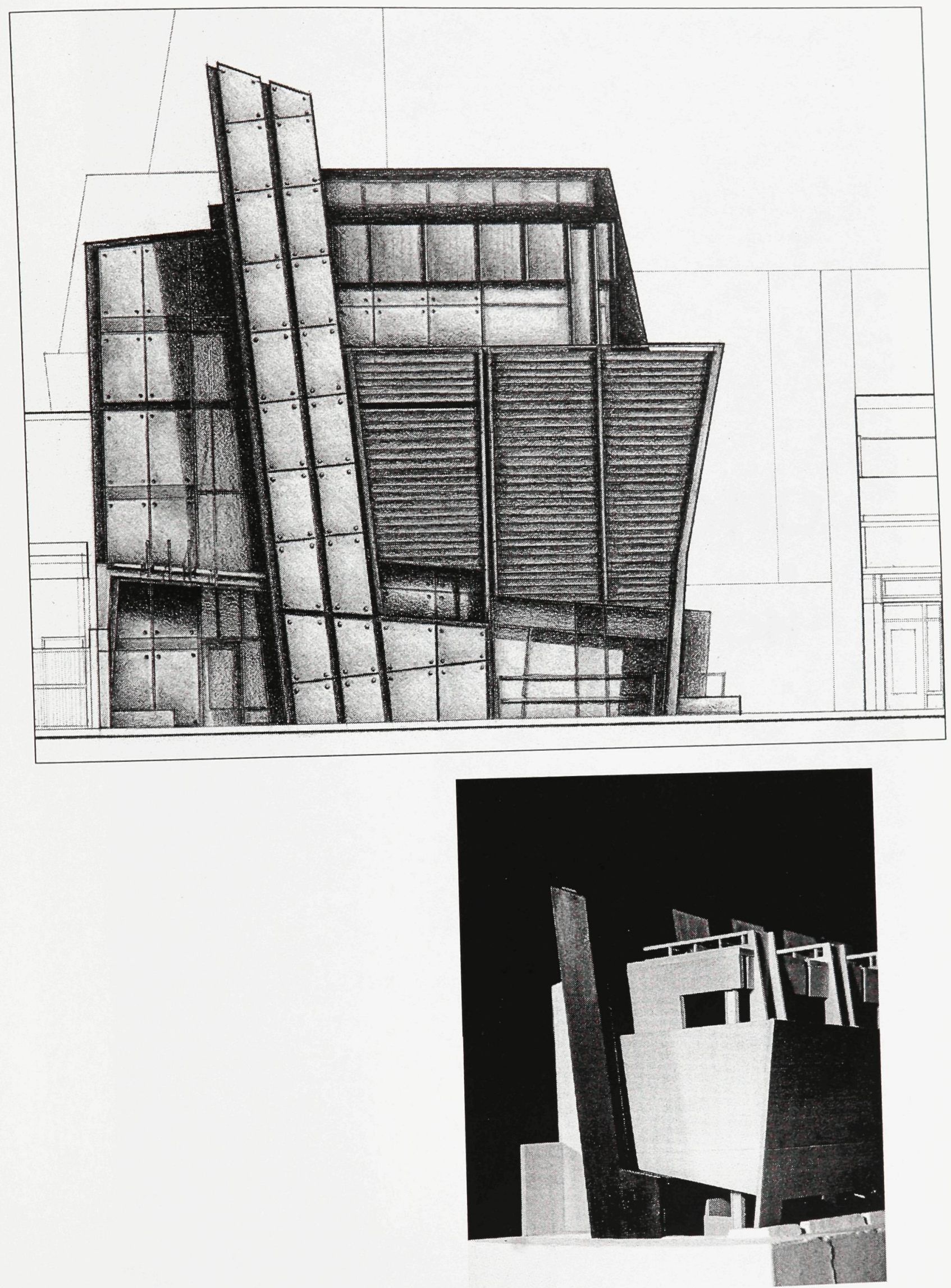

Plate 13: Detail of North Elevation and

Photograph of Model from North-West. 


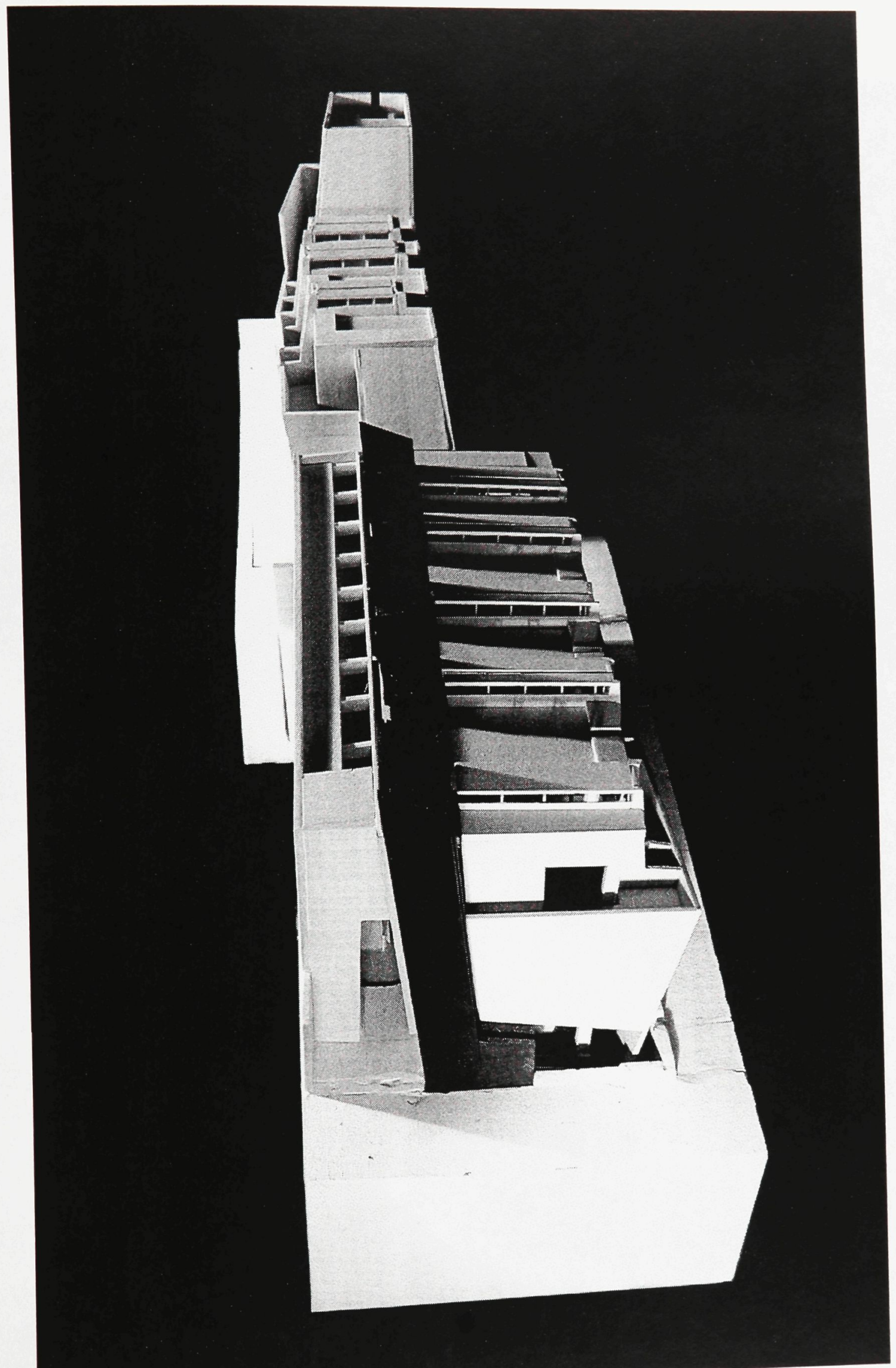

Plate 14: Photograph of Model from North. Basswood and Plaster. 


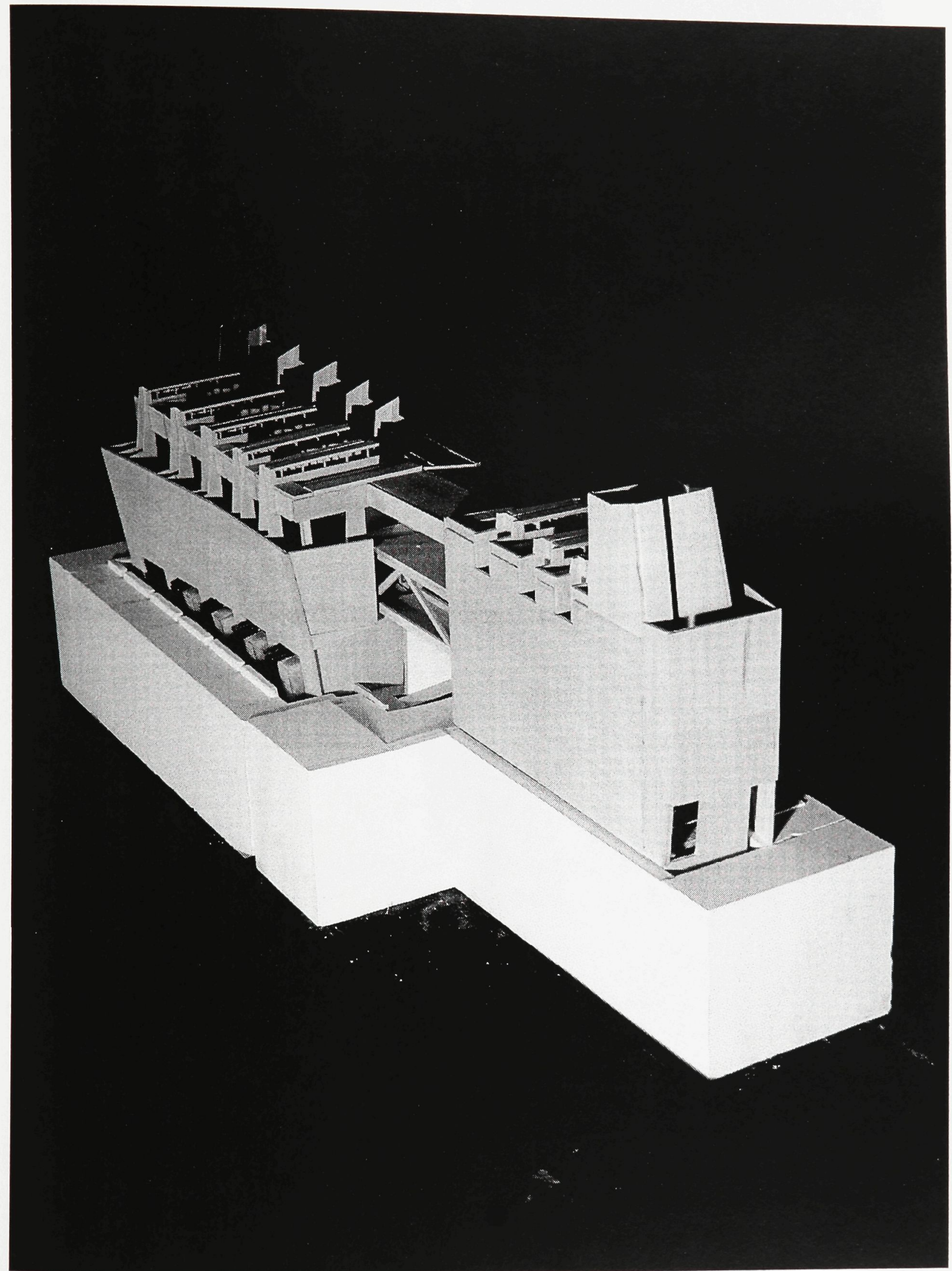

Plate 15: Photograph of Model from Southwest. Basswood and Plaster. 

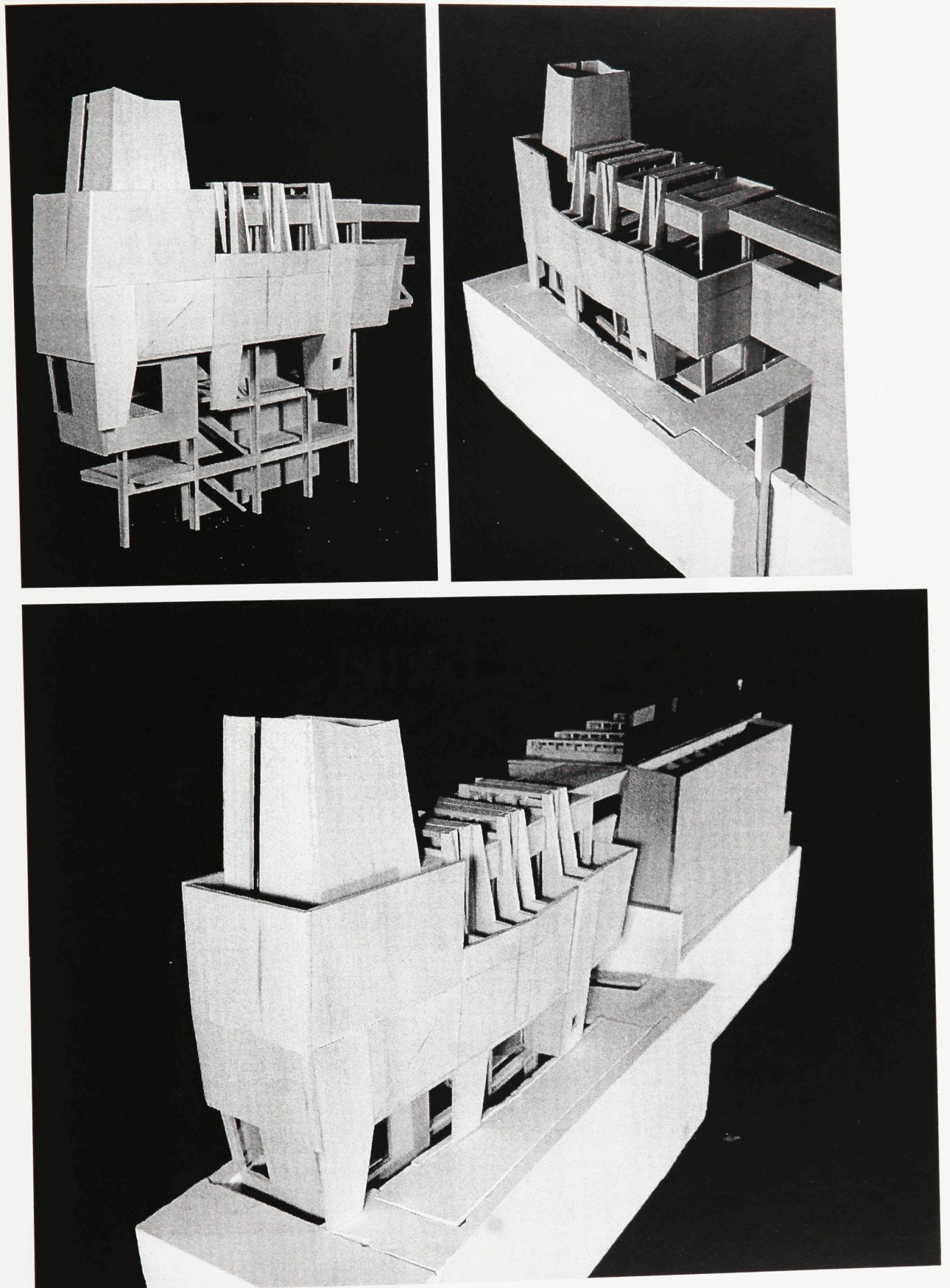

Plate 16: Photographs of South Building Form in Model. 

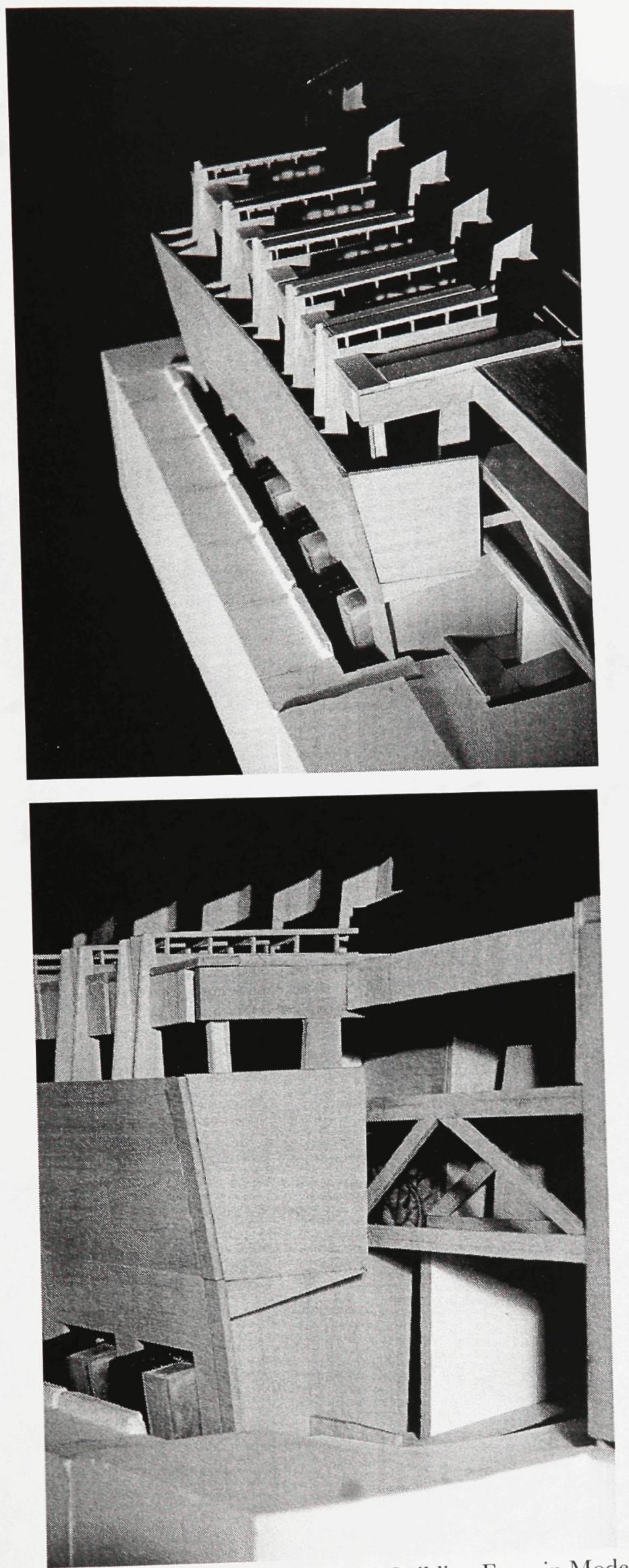

Plate 17: Photographs of North Building Form in Model. 


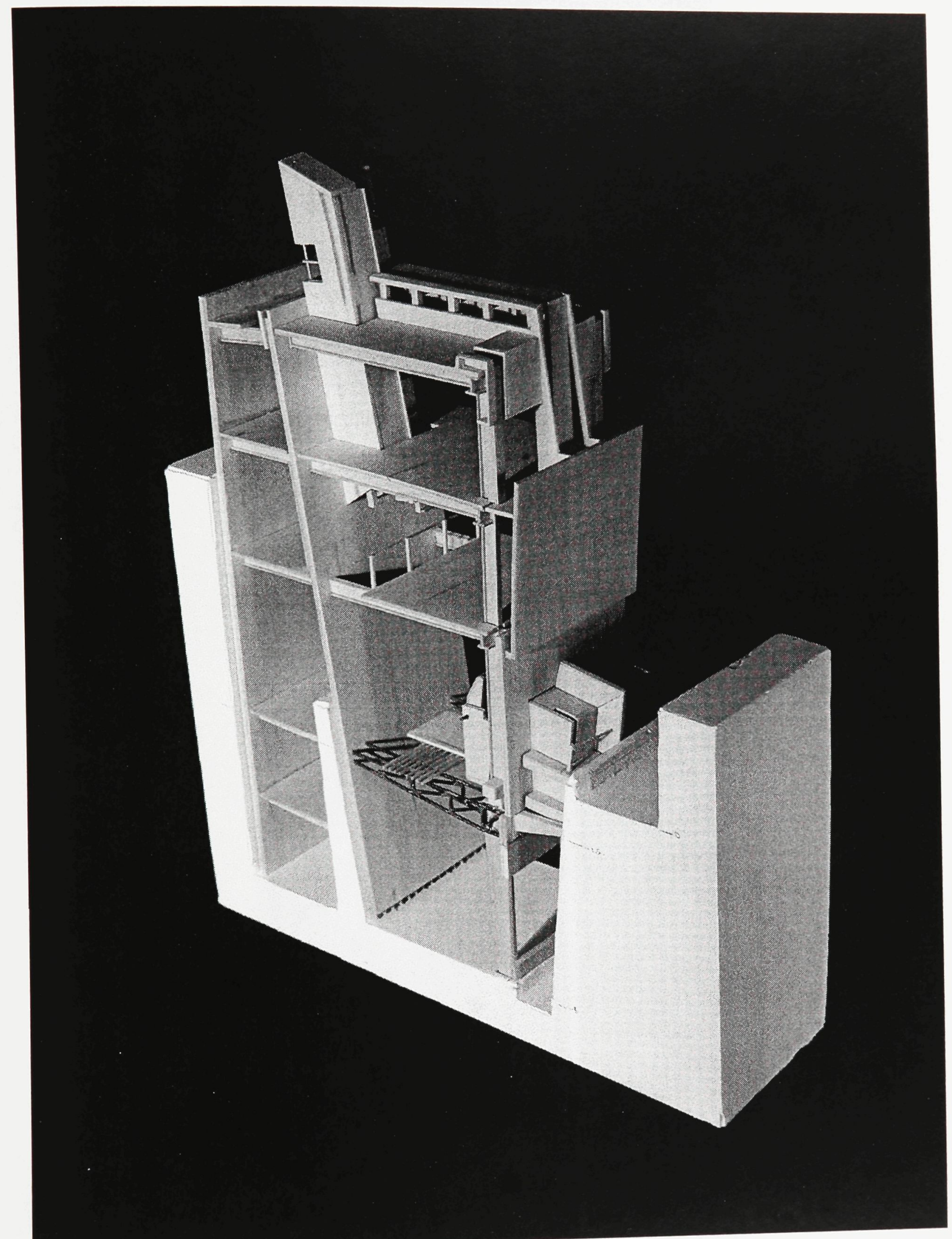

Plate 18: Photograph of Section Model. Basswood and Plaster. 


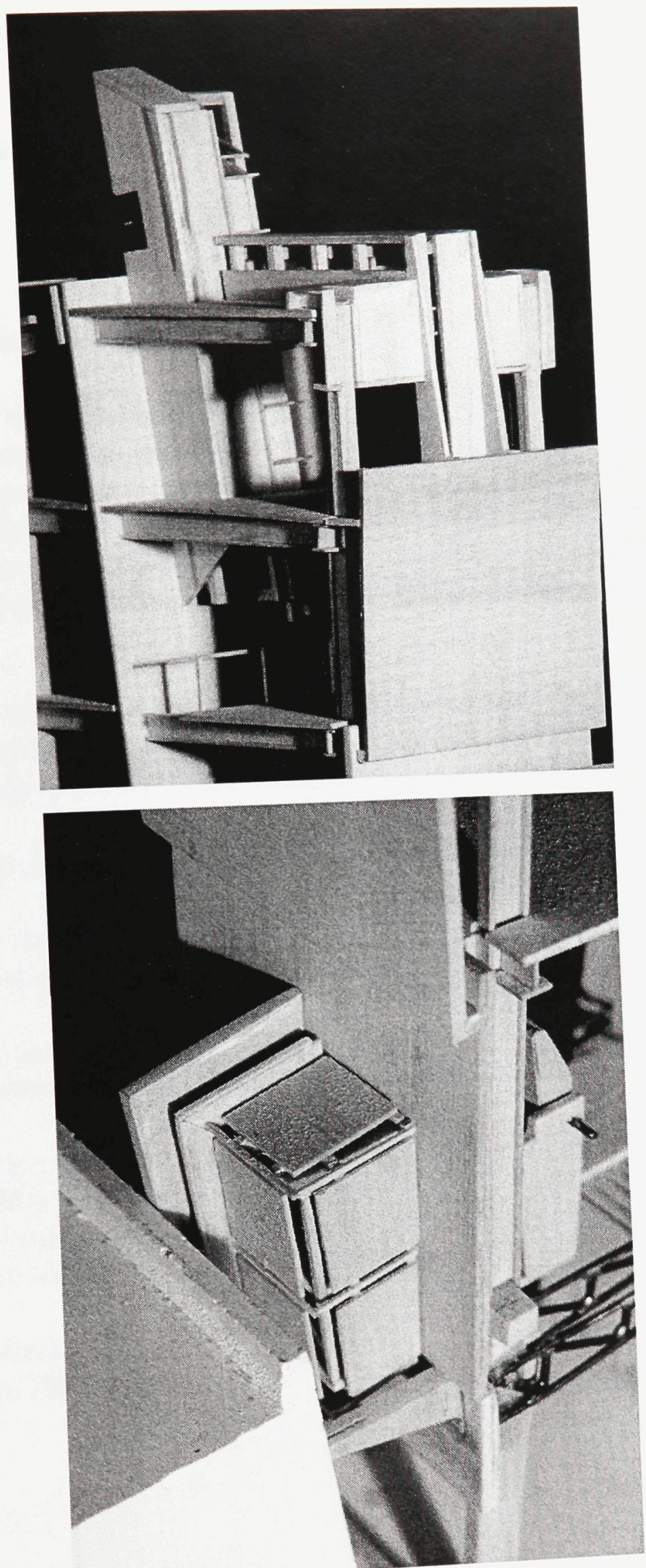

Plate 19: Detail Photographs of Section Model. 


\section{Addressing the Gut Notes:}

1 "History," byward-market.com (2005. The ByWard Market, 20 August 2005, $<$ http://www.byward-market.com/history.php $>$. This process did not occur smoothly, as the political situation that was created by disallowing the Lowertown residence to vote, escalated through violence between both the workers and the Englishmen who maintained the administration until its culmination in Stoney Monday, a near riot over the relocation of the capital, that was centered in the ByWard Market building. All history is sourced from this.

2 “Ottawa Downtown Urban Design Strategy," ottawa.ca, (2005, The City of Ottawa, 20 August 2005, <http://ottawa.ca/city_services/planningzoning/design_guide/ urbandesign/identify/precinct/index_en.shtml>"

${ }^{3}$ Refer to process in Chapter 3 for a full description of these categories.

${ }^{4}$ A tattoo 'flash' is a folder of tattoo-artwork by various tattoo artists ranging in styles from traditional and vernacular to the sacred and innovative.

${ }^{5}$ See Henk Schiffmacher, Ed. 1000 Tattoos (Köln, Germany: Taschen, 2005) 6-23, for a brief description on the history and practice of tattooing.

${ }^{6}$ This is an extremely derogatory term for a tattoo artist. Usually associated to a lack of artistic ability and/or a lack of cleanliness. It was typically associated to ex-carnival artists who would ensure repeat business by both misinforming clients about its aftercare, and by placing the ink closer to the surface of the skin.

${ }^{7}$ Slavoj Zizek, The Ticklish Subject: The Absent Centre of Political Ontology (New York: Verso, 1999) 372. 


\section{Conclusion}

This thesis began as an investigation into the making of architecture as a form of artistry, and thereby as a means of resolving an issue through a crafted, yet speculative approach. As a form of making through weaving the architectural threads of thinking and making, this investigation addressed the meanings and creation of public space and its role in the experience of the city. In doing so it traced a thread in the theoretical topos through various topics that relate to the issue at hand, and in doing so displaced the original issues inherent in the topic of concern as a means to create a lens that allows an anamorphic gaze towards the issue that preceded it, as well as followed it.

I have identified that this differs greatly from an applied use of theory in architecture and philosophy, in that displacement of an issue exists as "looking awry" at a topic. This enables the architect to discern what would normally escape a 'straightforward academic view' by being able to displace the original issue through the criss-crossing of various topics in both the text and made artifact through relationships and analogies that allow for an anamorphic view of the original topic, thereby allowing one to also 'make awry.' This use of theory as speculation within the architectural process itself allows for innovation, as the threads that are woven are never fixed.

In this thesis this has allowed us to discern a divergent conception of public space, 
where a great deal of depth to the issue has been shown through the use of these methods. The relationships that I have made between the experience of public space as a political and inter-subjective experience in the city and the experience of hysteria, and/or the demark as a spatial experience, has allowed for new architectural possibilities to arise in the creation of an architecture that is influenced by the lens created through the theoretical topos. Subsequently, this can be distinguished in the architectural artifact - as a manifestation of these theories - where its relation to an idea of public space is not one that is defined in 'typical' terms as a category, but rather has been expanded to include the experiential quality of space itself, specifically in the conflictual or demarked event as it framed by the architecture itself.

This lens through which the architecture is both understood and manifested is a woven relationship of issues that remains 'loose' and indefinite, thereby allowing it to change, alter or adapt to the creation of architecture as building. In this form it is a crafted understanding of an issue, allowing a specific point of reference through which we can understand the making of architecture. Consequently, while providing this unique viewpoint towards a given issue, it also leaves its stain upon the architecture itself due to the previous analogical associations made in both the text and graphic processes. These are manifested within the architectural artifact through our means of representations; in the drawings, models, and video, which all exist in a continuous/discontinuous relationship to the work that came before.

The method of looking awry in the making of an architecture that includes both the theory and architectural artifact is itself a crafted thing in that both work from each other in the speculative investigation of an issue in order to redefine and address it within the discipline of architecture. This thesis as a document then cannot be perceived as two separate topos of investigation, but both are forever marked by each other. As architect and reader the woven threads of the anamorphic lens stain us both, disallowing a neutral 


\section{Bibliography}

\section{Books}

Artaud, Antonin. The Theatre and Its Double. Trans. Mary Caroline Richards. New York: Grove P, 1958.

Badiou, Alain. Ethics: An Essay on the Understanding of Evil. Trans. Peter Hallward. New York: Verso, 2002.

Berman, Marshall. All That Is Solid Melts Into Air: The Experience of Modernity. New York: Simon and Schuster, 1982.

---. "Take It to the Streets: Conflict and Community in Public Space." Dissent: Fall 1986: 47685.

Bronfen, Elisabeth. The Knotted Subject: Hysteria and Its Discontents. Princeton, New Jersey: Princeton UP, 1998.

Deleuze, Gilles. Cinema 1: The Movement-Image. Trans. Hugh Tomlinson and Barbara Habberjam. Minneapolis, Minnesota: U of Minnesota P, 1986.

Derrida, Jacques. "Point de Folie - Maintenant L'Architecture." Rethinking Architecture: A Reader in Gultural Theory. Ed. Neil Leach. New York: Routledge, 1997.

Didi-Huberman, Georges. Invention of Hysteria: Charcot and the Photographic Iconography of the Salpêtriere. Trans. Alisa Hartz. Cambridge, Massachusetts: MIT P, 2003.

Ferrell, Jeff. Tearing Down the Streets: Adventures in Urban Anarchy. New York: Palgrave, 2001. 
Foucault, Michel. Madness and Civilization: A History of Insanity in the Age of Reason. Trans. Richard Howard. New York: Random House, 1965.

Freud, Sigmund. The Standard Edition of the Complete Psychological Works of Sigmund Freud. Vol. 1. Trans. James Strachey. London: The Hogarth Press and the Institute of PsychoAnalysis, 1966.

---. Studies on Hysteria. Trans. James and Alix Strachey. New York: Penguin, 1974.

Hays, K. Michael. Ed. Hejduk’s Chronotope. New York: Princeton Architectural P, 1996.

Hejduk, John. Mask of Medusa: Works 1947-1983. Ed. Kim Shkapich. New York: Rizzoli, 1985.

Hollier, Denis. Against Architecture: The Writings of Georges Bataille. Trans. Betsy Wing. Cambridge, Massachusetts: MIT P, 1992.

Kafka, Franz. "A Hunger Artist." Trans. Willa and Edwin Muir. The Complete Stories. Ed. Nahum N. Glatzer. New Yorl: Schocken, 1971. 268-77.

Krauss, Rosalind E. and Yve-Alain Bois. Formless: A User's Guide. 1997. New York: Zone, 1999.

Kristeva, Julia. Powers of Horror: An Essay on Abjection. New York: Columbia UP, 1982.

Kunze, Donald. "The Anxious Landscape: The Role of Hysteria in Perception and Portrayal of the Landscape." art3idea.psu.edu. 2005. The art3idea. 27 May 2005. <http://art3idea. psu.edu/texts/hysterical_landscape.pdf>

---. "Marks of the Abject Artifact." Working paper, n.d. 27 May 2005.

--- "The (Architectural) Section." art3idea.psu.edu. 2005. The art3idea. 27 May 2005. < http:// art3idea.psu.edu/boundaries/bolagrams/section.html>

Lefebvre, Henri. The Production of Space. Trans. Donald Nicholson-Smith. Cambridge, Massachusetts: Blackwell, 1991.

Emmanuel Lévinas. Totality and Infinity: an Essay on Exteriority. Pittsburgh: Duquesne U P, 1969.

Lomas, David. The Haunted Self: Surrealism, Psychoanalysis, Subjectivity. New Haven and London: Yale UP, 2000. 
Lukacher, Ned. "The Epistemology of Disgust." Forward. Hysteria from Freud to Lacan: Body and Language in Psychoanalysis. By Monique David-Ménard. Trans. Catherine Porter. Ithaca: Cornell UP, 1989. X - X.

Marx, Karl. Capital. Vol. 1. Moscow: Progress, 1967.

---. Economic and Philosophic Manuscripts of 1844. Moscow: Progress, 1977.

---. The Eighteenth Brumaire of Louis Bonaparte. Moscow: Foreign Languages Publishing House, 1950-59.

Merrifield, Andy. Dialectical Urbanism: Social Struggles in the Capitalist City. New York: Monthly Review P, 2002.

Micale, Mark S. Approaching Hysteria: Disease and Its Interpretations. Princeton, New Jersey: Princeton UP, 1994.

Mitchell, Don. The Right to the Gity: Social Justice and the Fight for Public Space. New York: The Guilford P, 2003.

Myers, Tony. Slavoj Zizek. New York: Routledge, 2003.

Pérez-Gómez, Alberto and Louise Pelletier, "Introduction." Anamorphosis: An Annotated Bibliography. Montreal: McGill University Libraries, 1995.

Richardson, Niall. "The Queer Activity of Extreme Male Bodybuilding: Gender Dissidence, Auto-Eroticism and Hysteria." Social Semiotics: 14-1 (April 2004): X-X.

Rykwert, Joseph. The Idea of a Town: The Anthropology of Urban Form in Rome, Italy and the Ancient World. Cambridge, Massachusetts: The MIT P, 1988.

Saco, Diana. Gybering Democracy: Public Space and the Internet. Minneapolis, MN: U of Minnesota P, 2002.

Sanders, Clinton R. "Drill and Frill: Client Choice, Glient Typologies, and Interactional Control in Commercial Tattooing Settings." Marks of Civilization: Artistic Transformations of the Human Body. Ed. Arnold Rubin. Los Angeles: Museum of Cultural History, 1988.

Schiffmacher, Henk, ed. 1000 Tattoos. Köln, Germany: Taschen, 2005.

Showalter, Elaine. Hystories: Hysterical Epidemics and Modern Gulture. New York: Columbia UP, 1997. 
Sontag, Susan, ed. "Introduction." Antonin Artaud, Selected Writings. Trans. Helen Weaver. Berkeley, California: U of California P, 1988.

Sorkin, Michael, ed. Variations on a Theme Park: The North American City and the End of Public Space. New York: Hill \& Wang, 1992.

Tschumi, Bernard. Event-Cities 2. Cambridge, Massachusetts: MIT P, 2000.

Vidler, Anthony. The Architectural Uncanny: Essays in the Modern Unhomely. Cambridge, Massachusetts: MIT P, 1992.

---. Warped Space: Art, Architecture, and Anxiety in Modern Culture. Cambridge, Massachusetts: MIT P, 2002.

Werner, Frank. Covering + Exposing: The Architecture of Coop Himmelb(l)au. Boston: Birkhäuser, 2000.

Zizek, Slavoj. For They Know Not What They Do: Enjoyment as a Political Factor. New York: Verso, 1991.

---. Looking Awry: An Introduction to Jacques Lacan through Popular Gulture. Cambridge, Massachusetts: MIT P, 1992.

---. Organs Without Bodies: On Deleuze and Gonsequences. New York: Routledge, 2004.

---. The Metastases of Enjoyment: Six Essays on Women and Causality. New York: Verso, 1994.

---. The Ticklish Subject: The Absent Centre of Political Ontology. New York: Verso, 1999.

\section{Websites}

"History." byward-market.com. 2005. The Byward Market. 20 August $2005<$ http://www. byward-market.com/history.php>.

"Ottawa Downtown Urban Design Strategy." ottawa.ca. 2005. The City of Ottawa. 20 August $2005<\mathrm{http}$ ///ottawa.ca/city_services/planningzoning/design_guide/urbandesign/ identify/precinct/index_en.shtml>.

\section{Films}

Foreign Correspondent. Dir. Alfred Hitchcock. Perf. Joel McCrea, Herbert Marshall, George Sanders, Albert Basserman, and Robert Benchley. 1940. DVD. Warner Brothers, 2004. 


\section{Appendix A: 40 Sites in the Market and 4 Models}

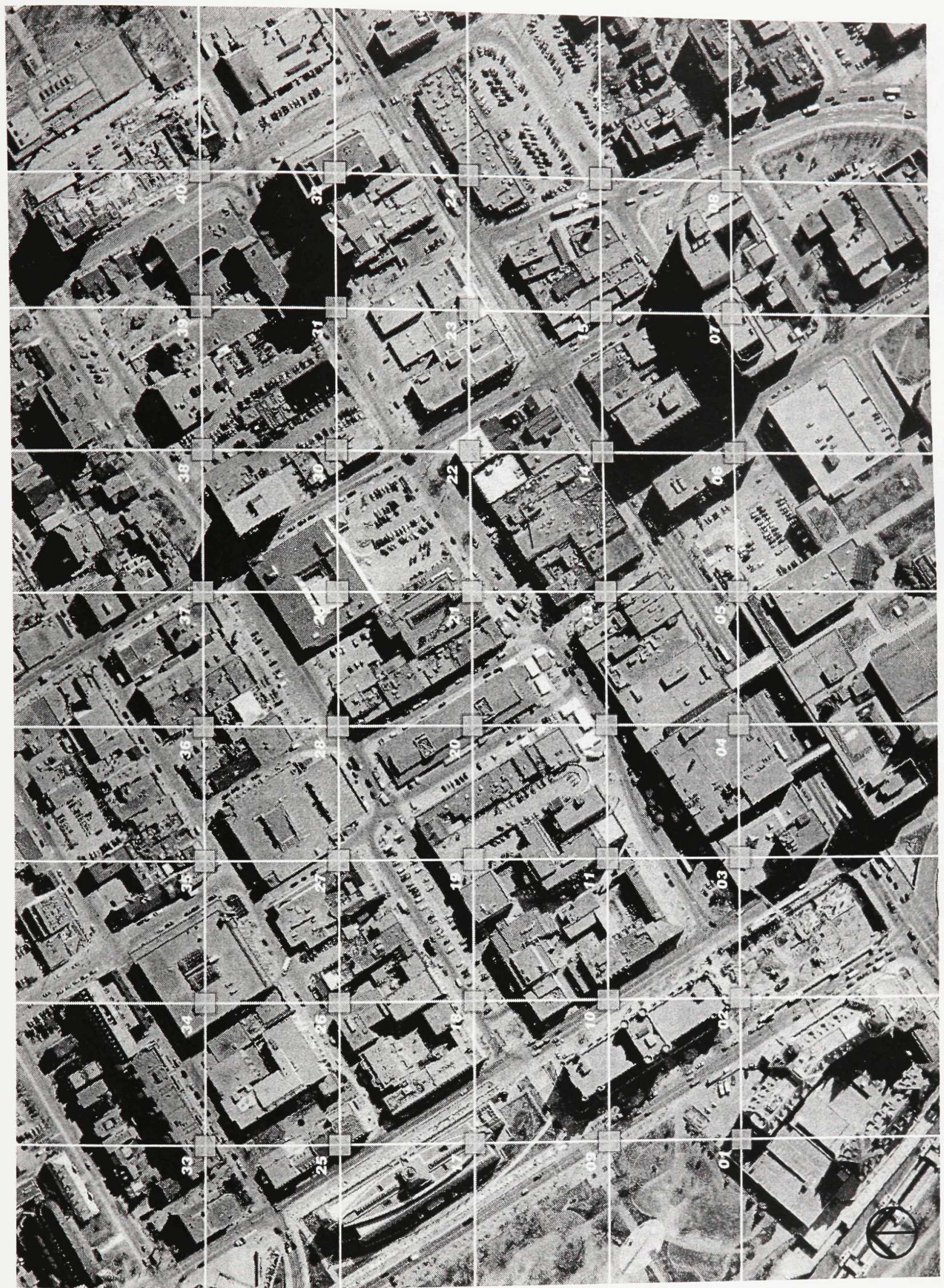

40 Sites of Proposed Installations of the Hunger Artist in the ByWard Market 


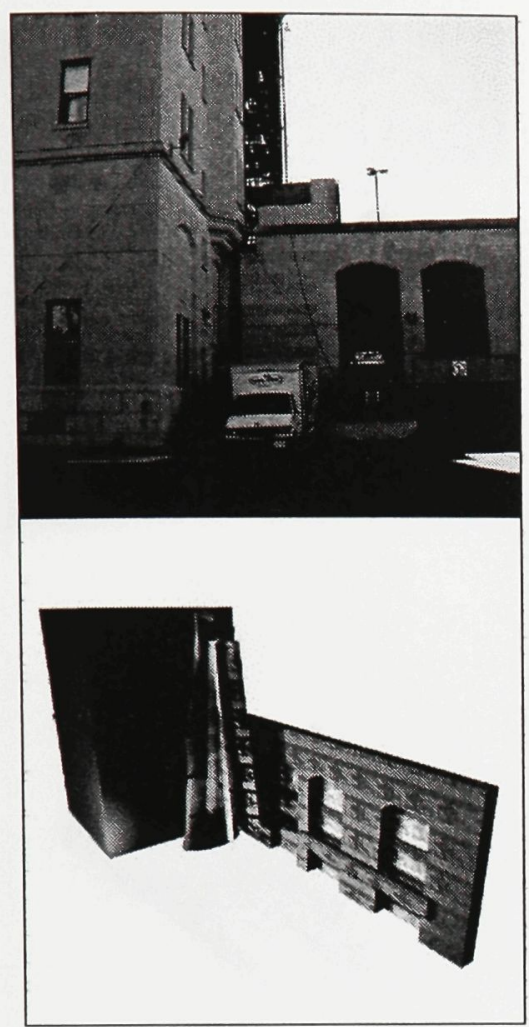

Site 1: Chateau Laurier Parking Garage Entrance

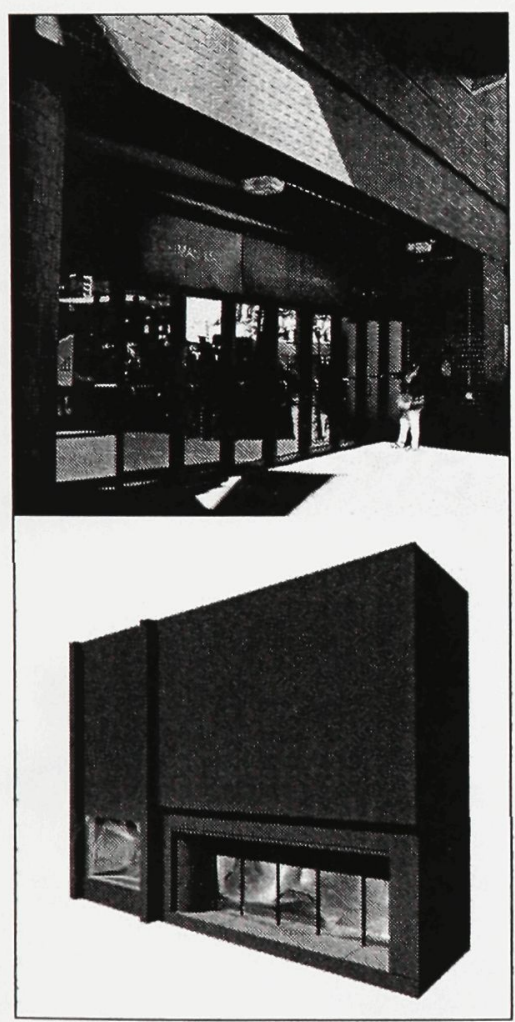

Site 4: Freiman Mall - Rideau Street Entrance
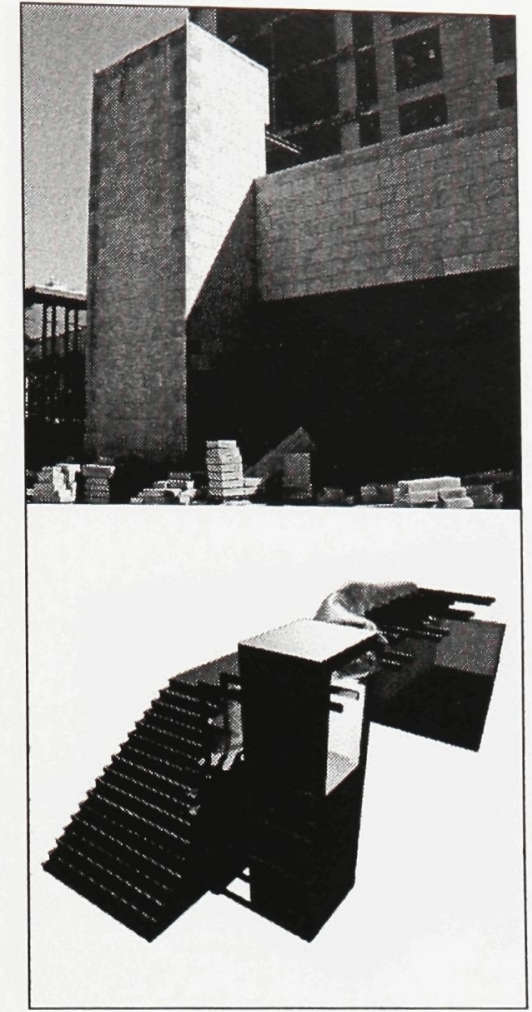

Site 2: 700 Sussex Service Entrance

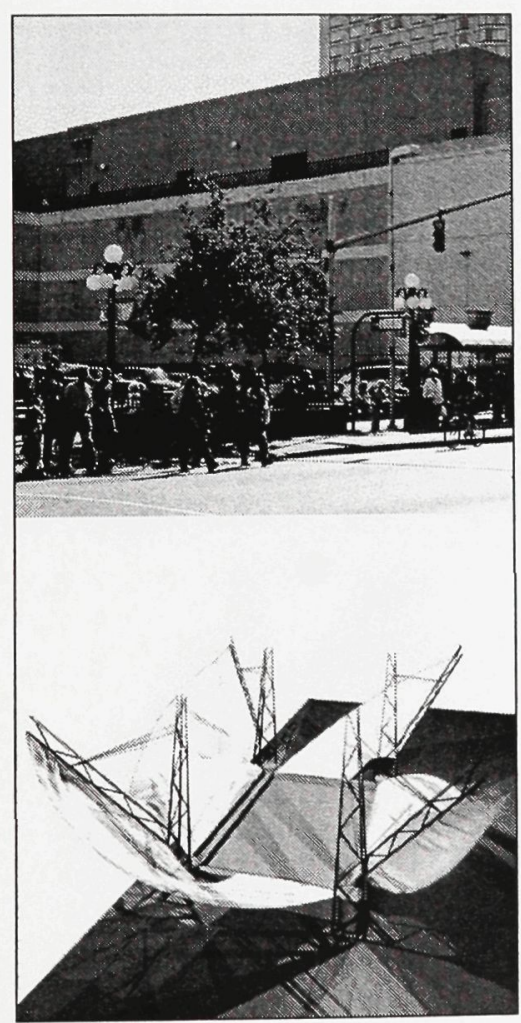

Site 5: Rideau Bus Stop at Rideau Centre

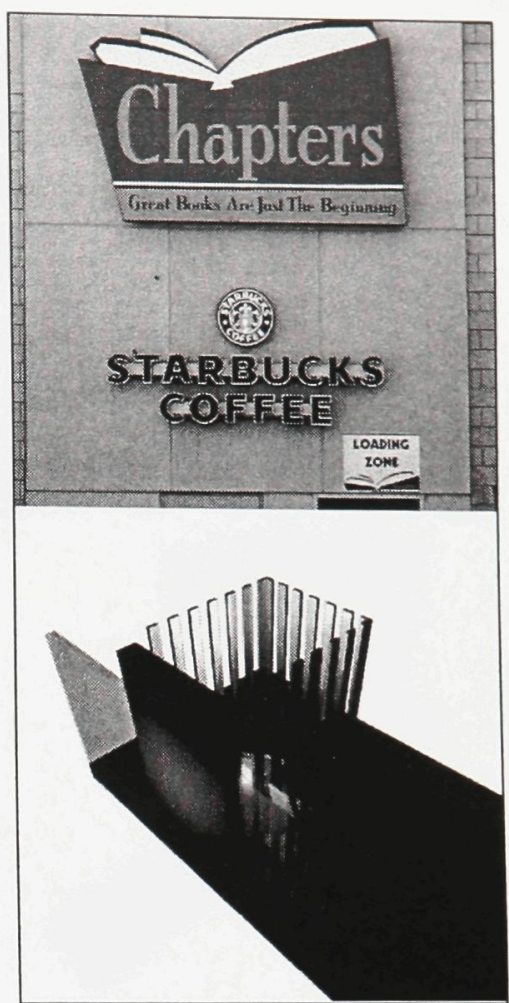

Site 3: Chapters Service Entrance

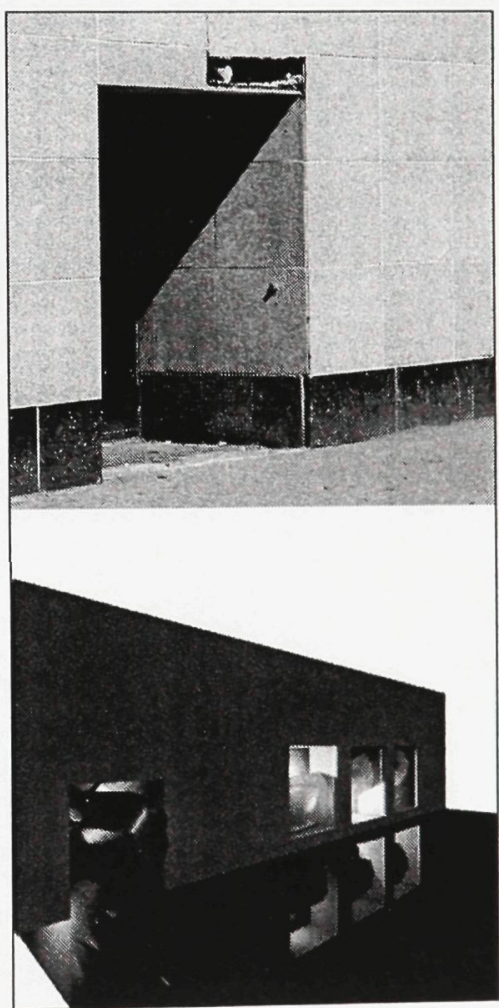

Site 6: Old Stitches Building on Besserer Street

Site Photos and Digital Models (Objective View) - Sites 1 to 6 


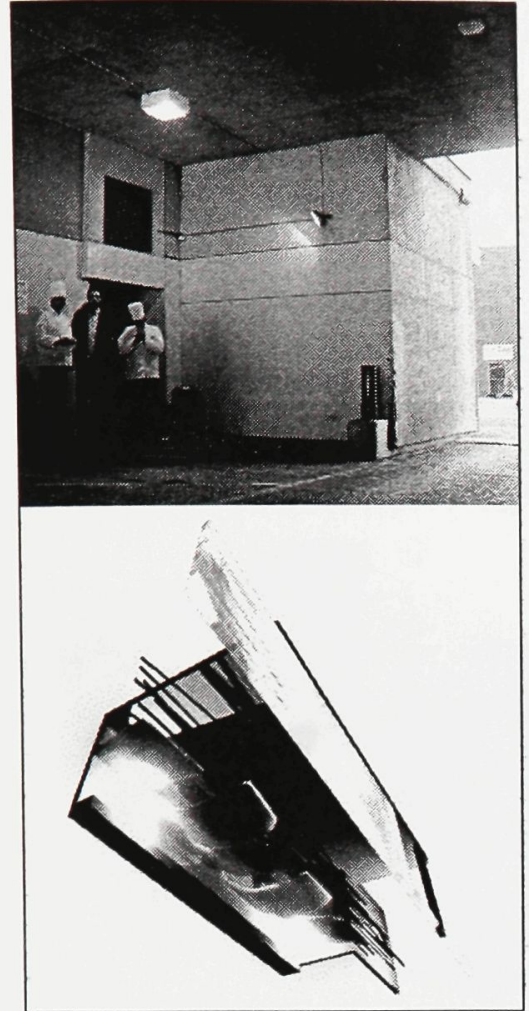

Site 7: Les Suites Hotel Service Entrance

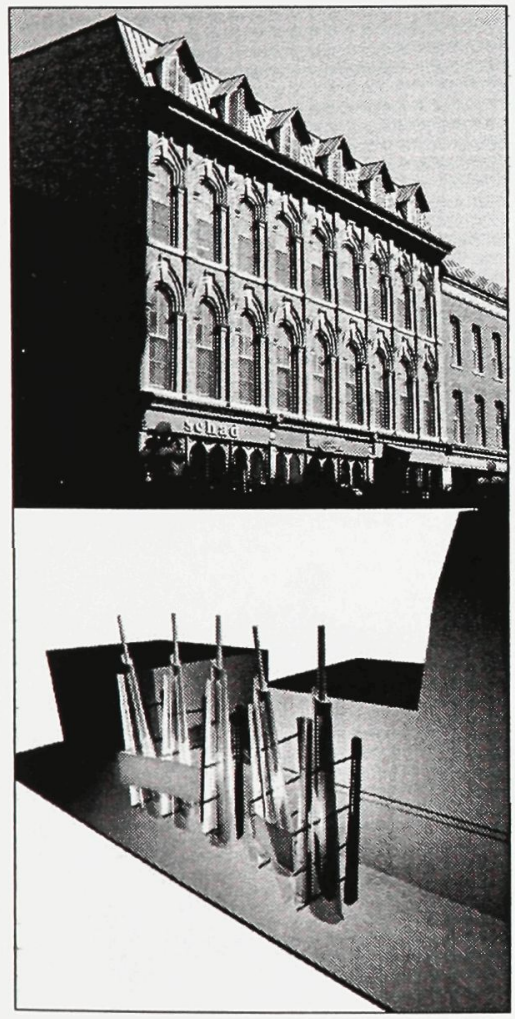

Site 10: Sussex Drive between George and York Street
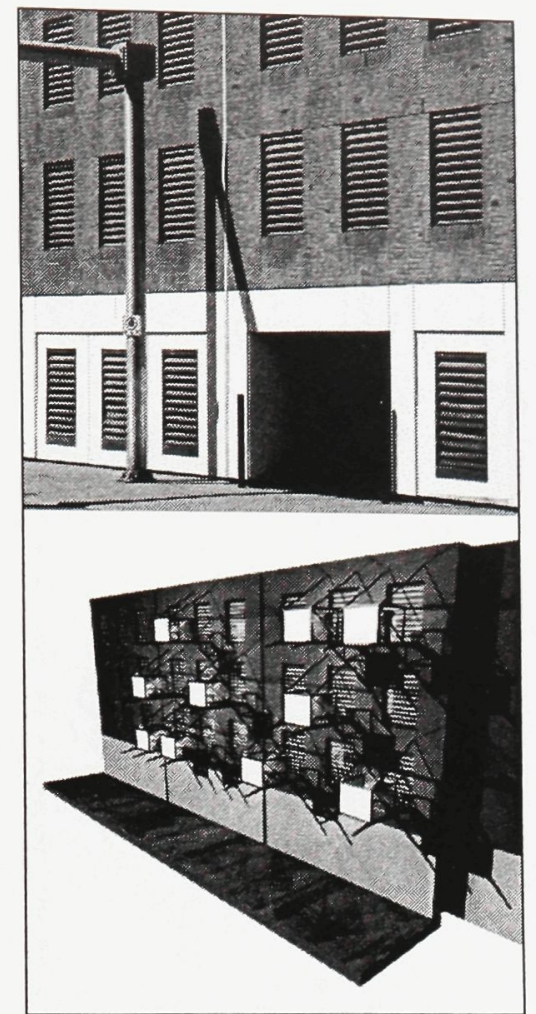

Site 8: Les Suites Hotel along Daly Street
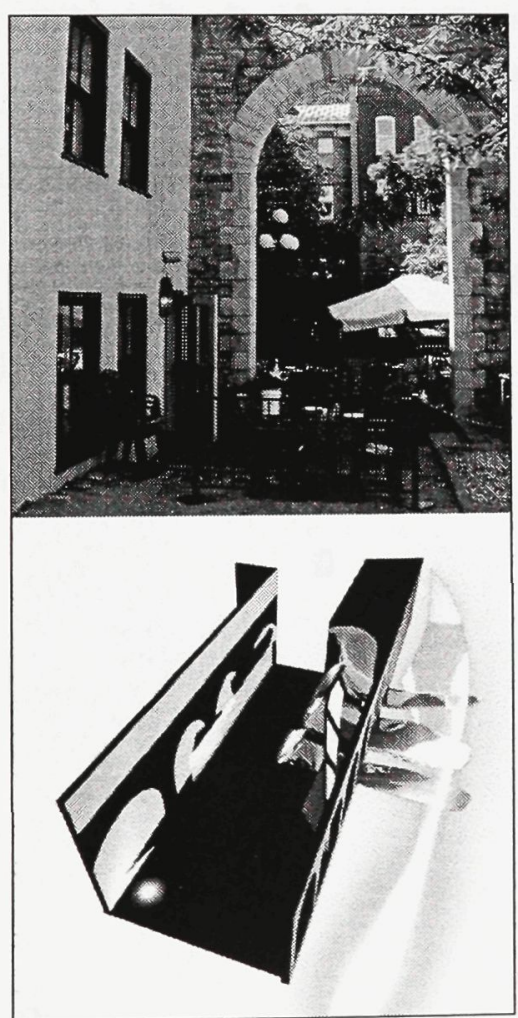

Site 11: York Street Courtyard Arcades
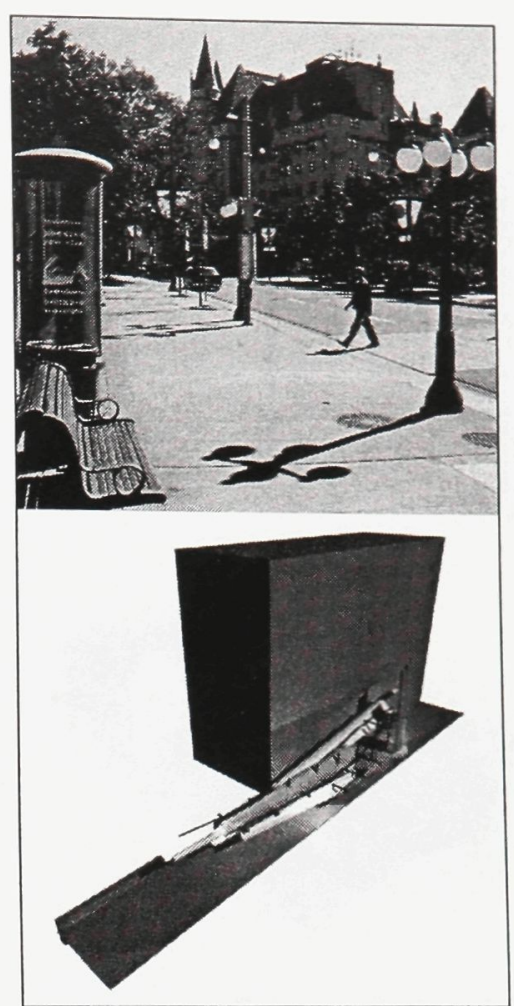

Site 9: MacKenzie Drve at Majors Hill Park

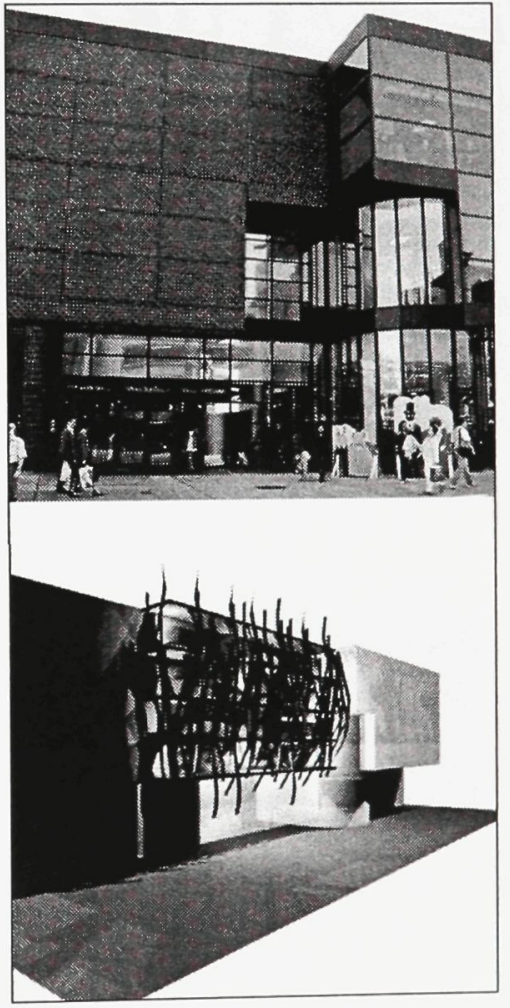

Site 12: Freidman Mall Entrance on George Street

Site Photos and Digital Models (Objective View) - Sites 7 to 12 


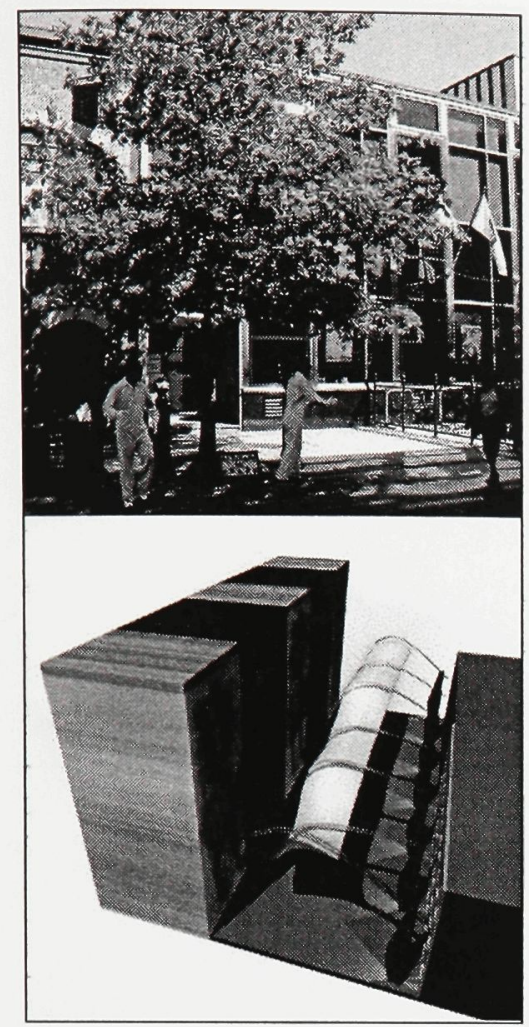

Site 13: Williams Street

Pedestrian Mall

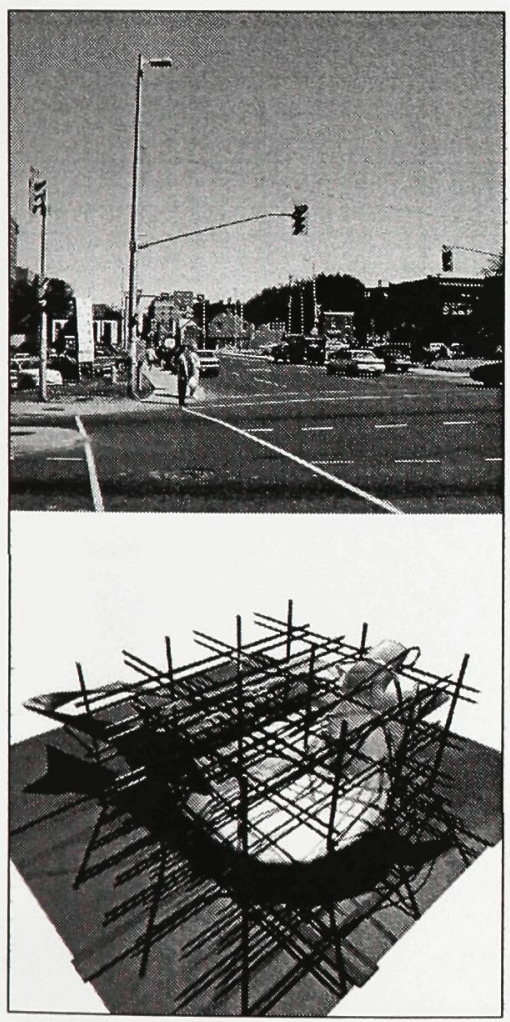

Site 16: Intersection of Besserer and Waller Streets
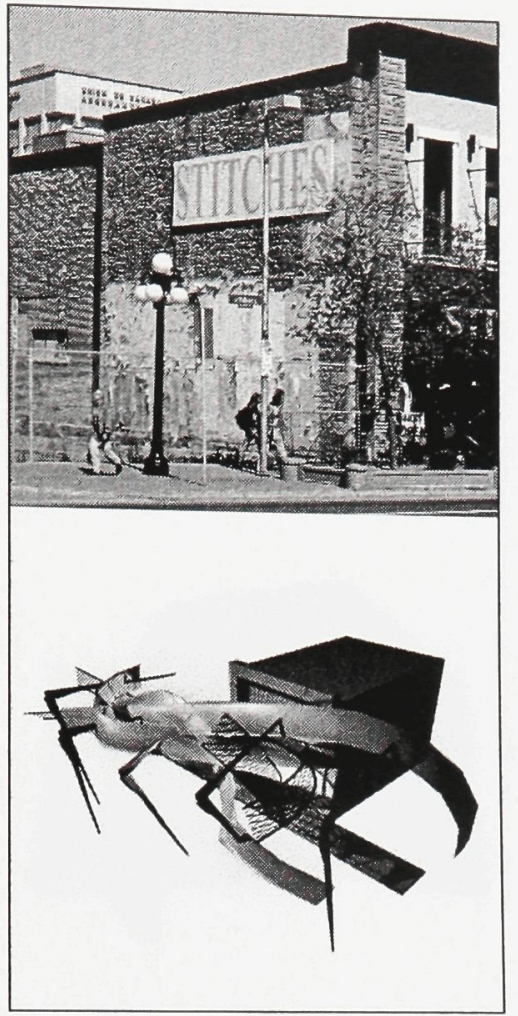

Site 14: Stitches on Rideau

Street

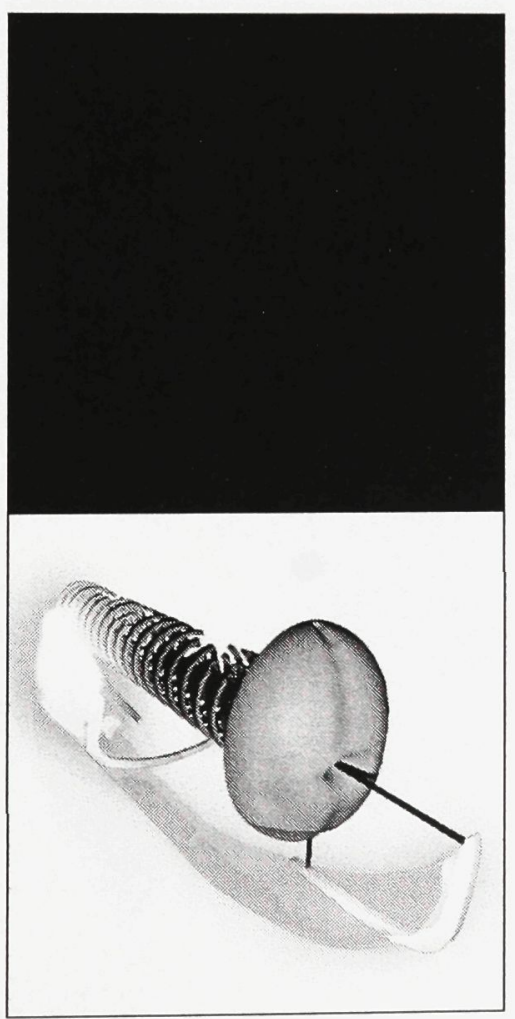

Site 17: Embassy of the United States of America
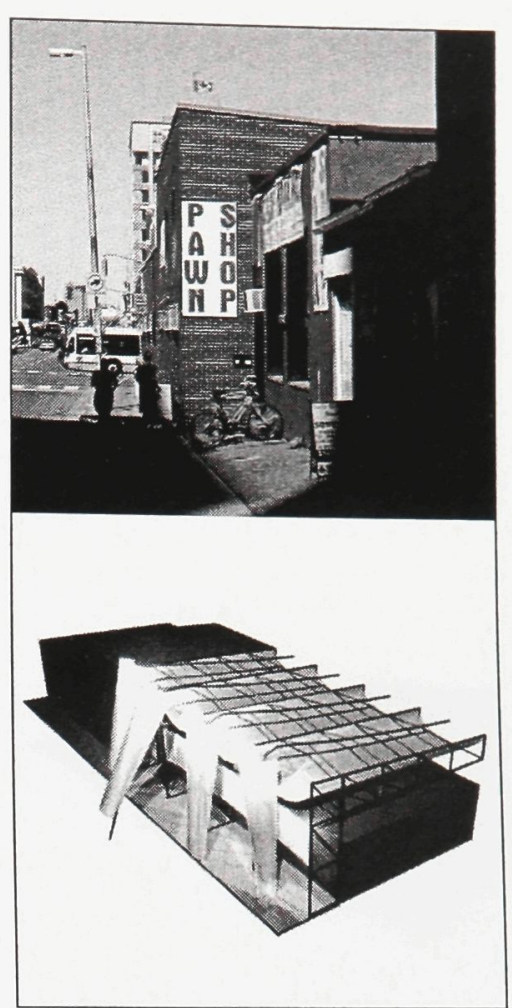

Site 15: Pawn Shop on

Dalhousie Street
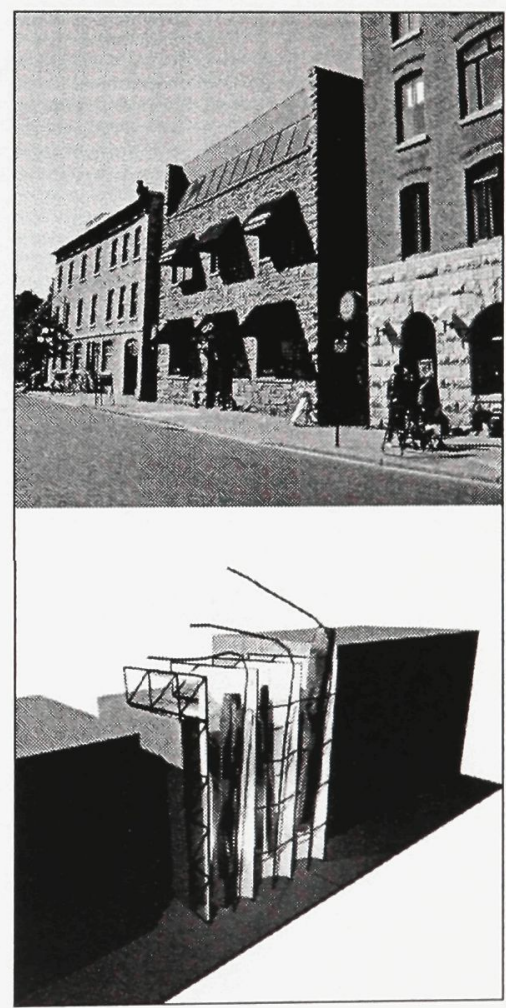

Site 18: Sidewalk Along York Street

Site Photos and Digital Models (Objective View) - Sites 13 to 18 

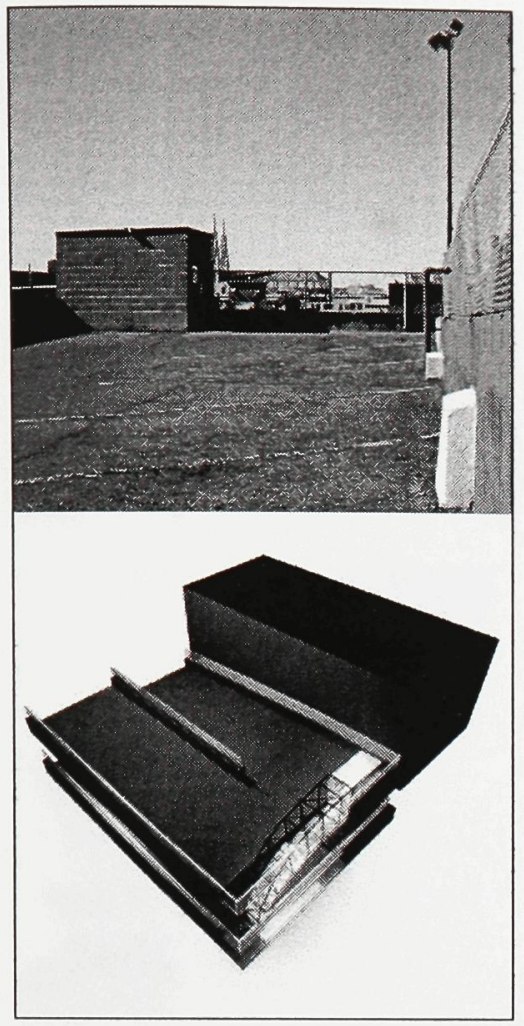

Site 19: Parking Garage
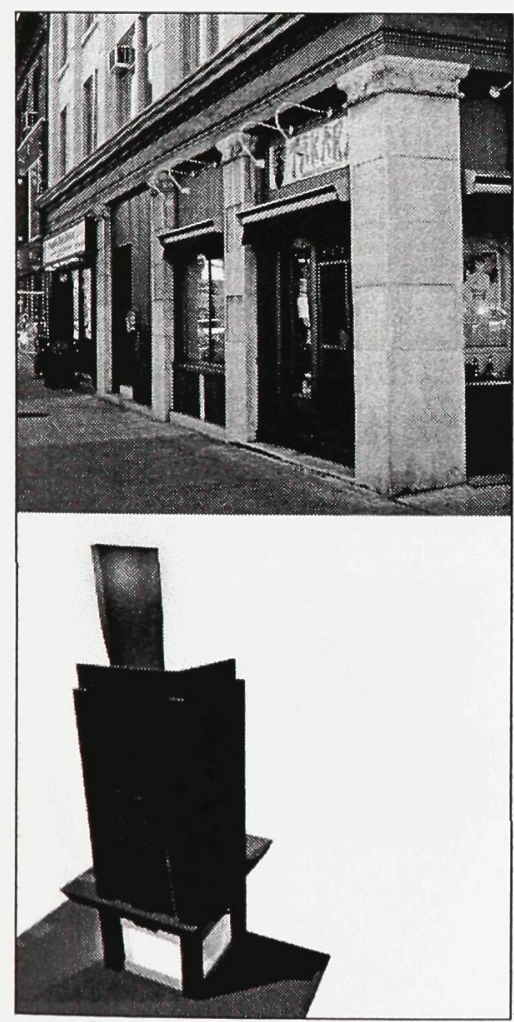

Site 22: Takura Japanese

Restaurant
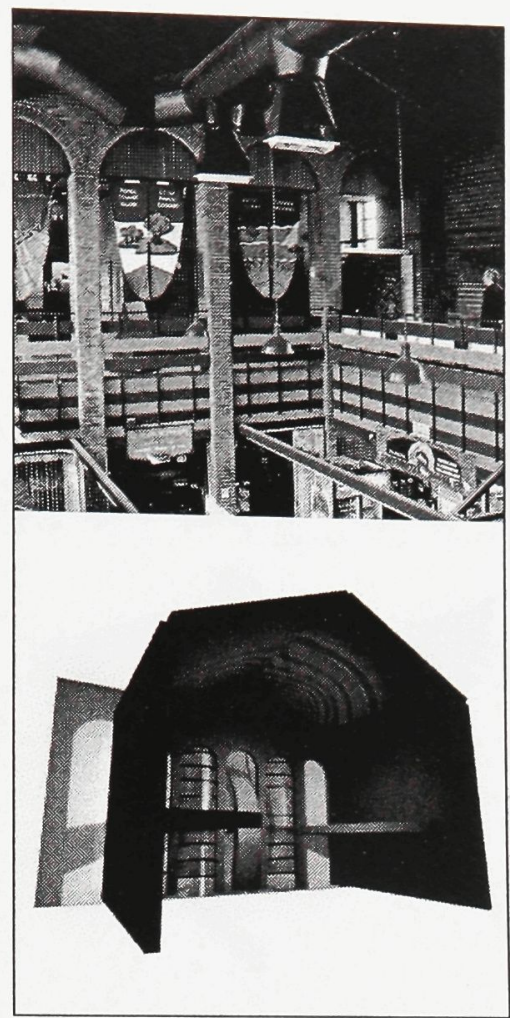

Site 20: The ByWard Market Building

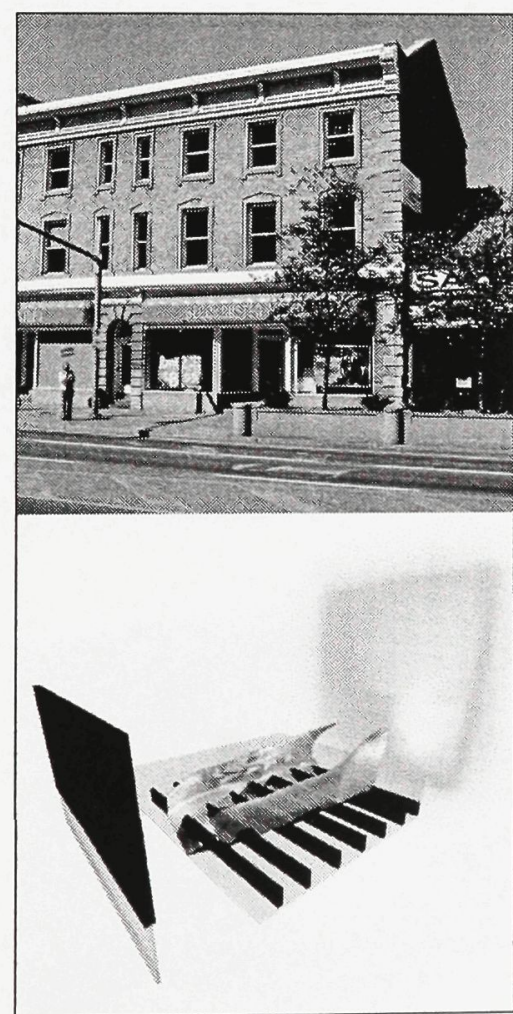

Site 23: Blockbuster Video on Rideau Street
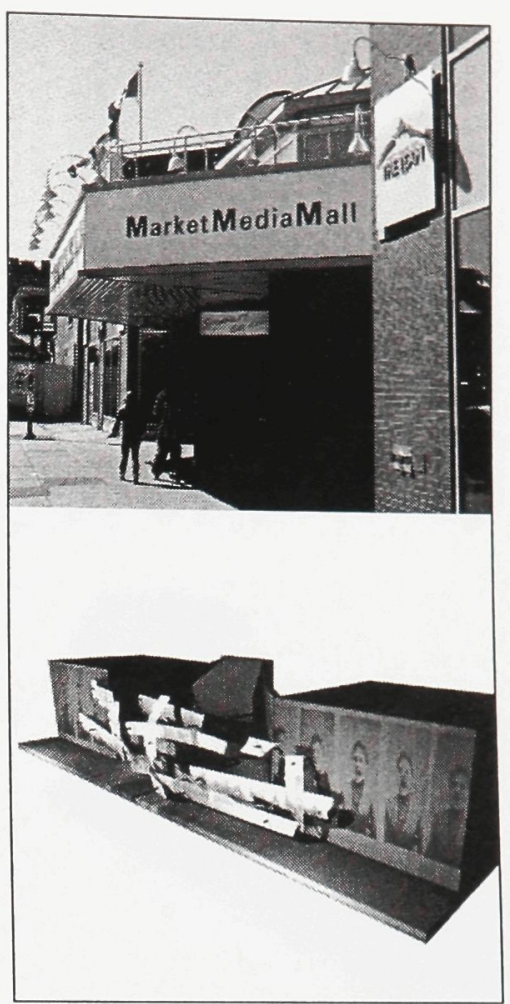

Site 21: Market Media Mall
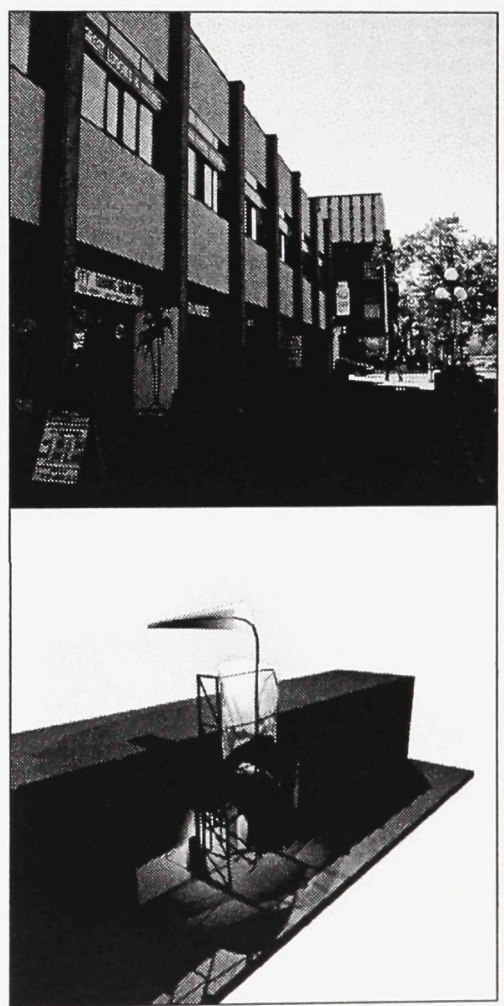

Site 24: Record Runner on Rideau Street

Site Photos and Digital Models (Objective View) - Sites 19 to 24 

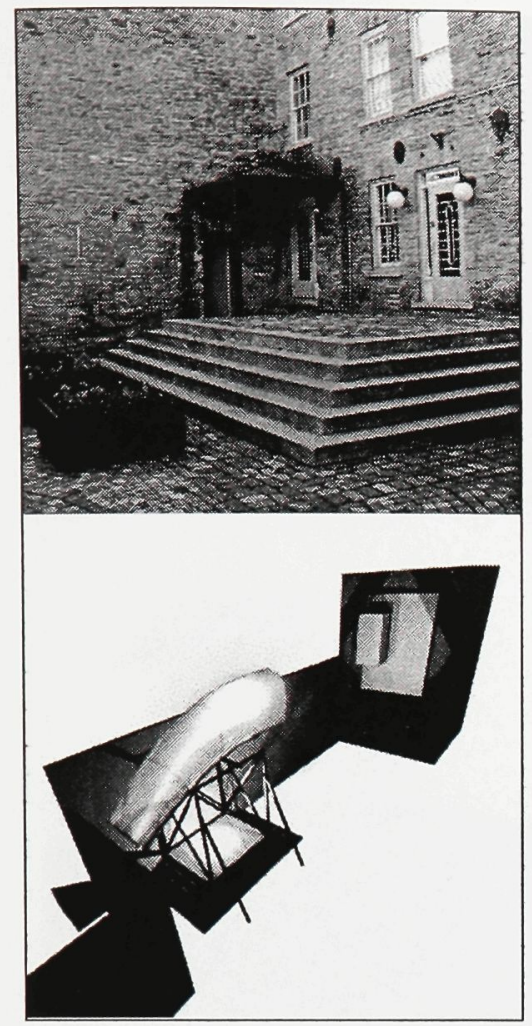

Site 25: The Tin Court

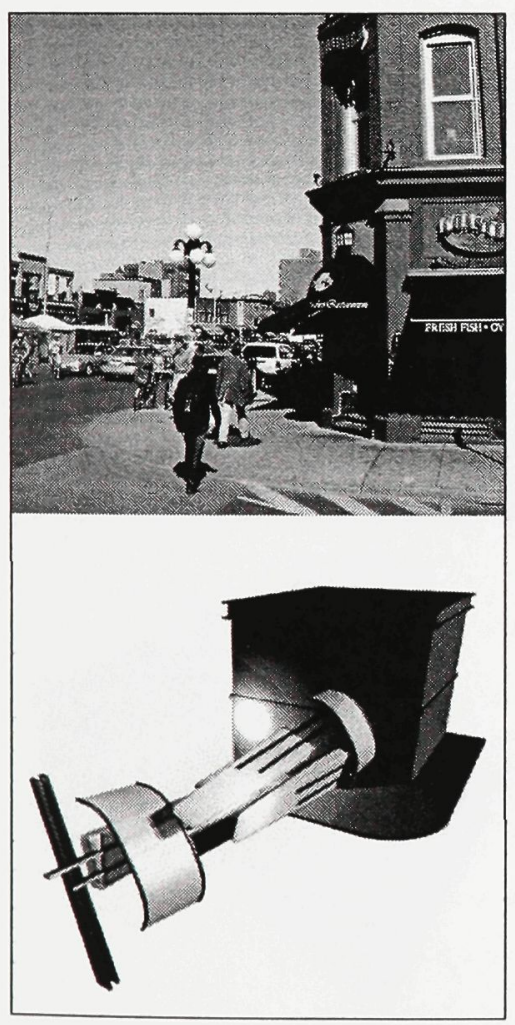

Site 28: The Fish Market

Restaurant on York Street
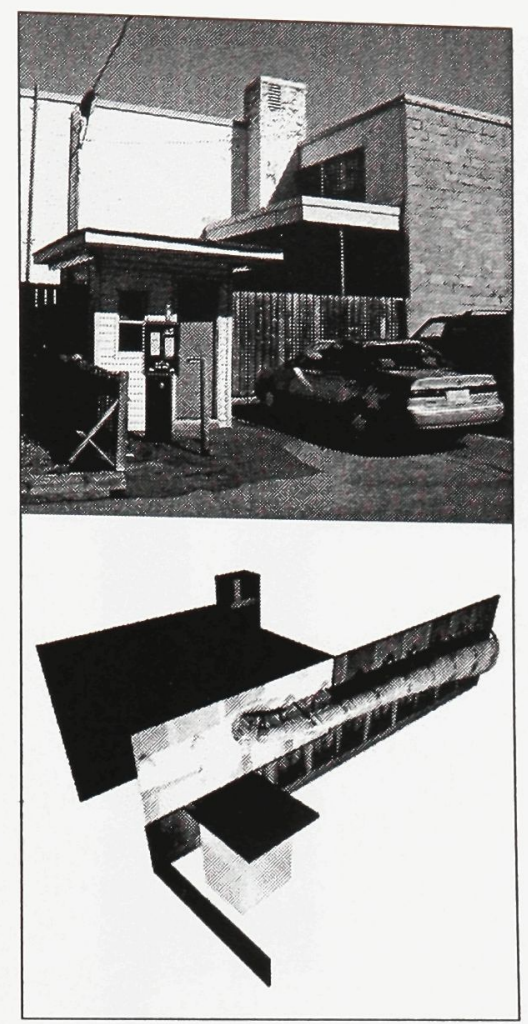

Site 26: Parking Lot Along Clarence Street
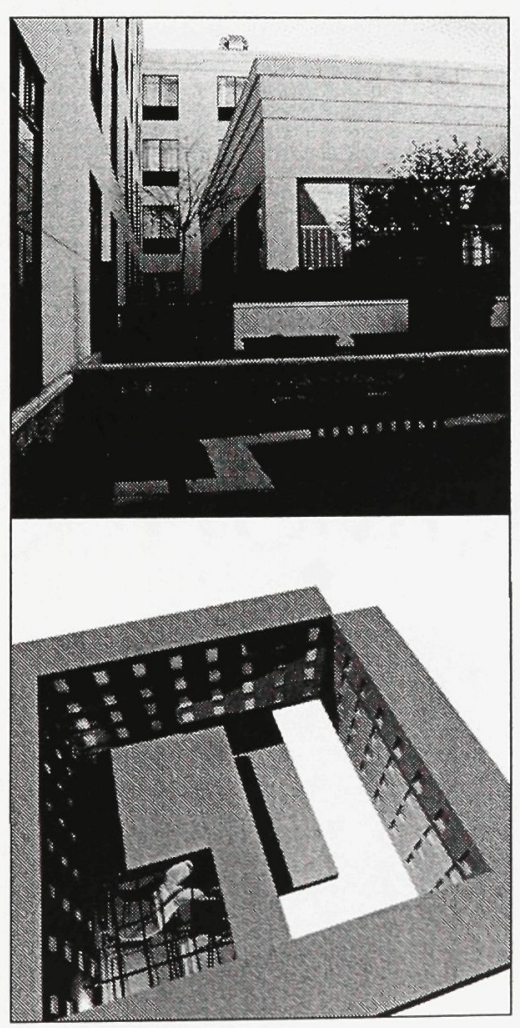

Site 29: Mariot Hotel Courtyard

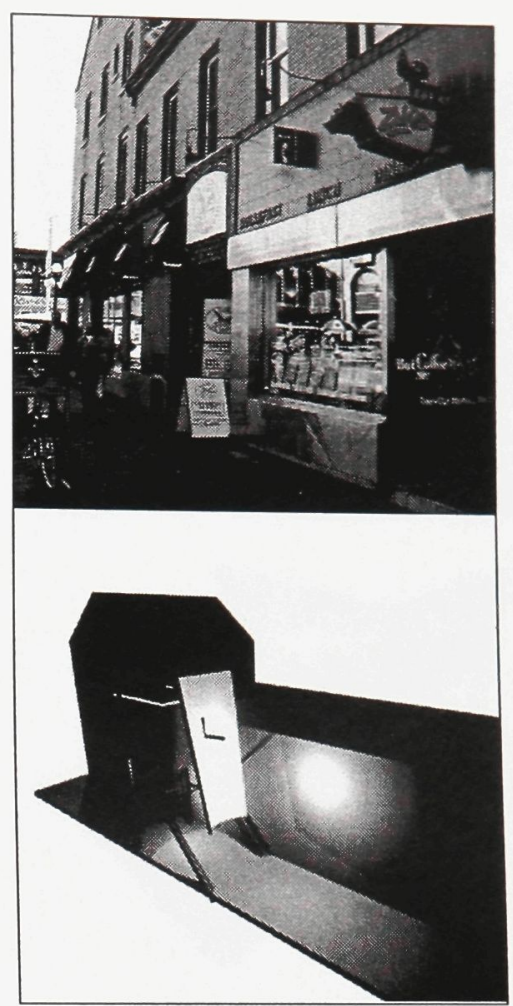

Site 27: ByWard Market Street at Zak's Diner

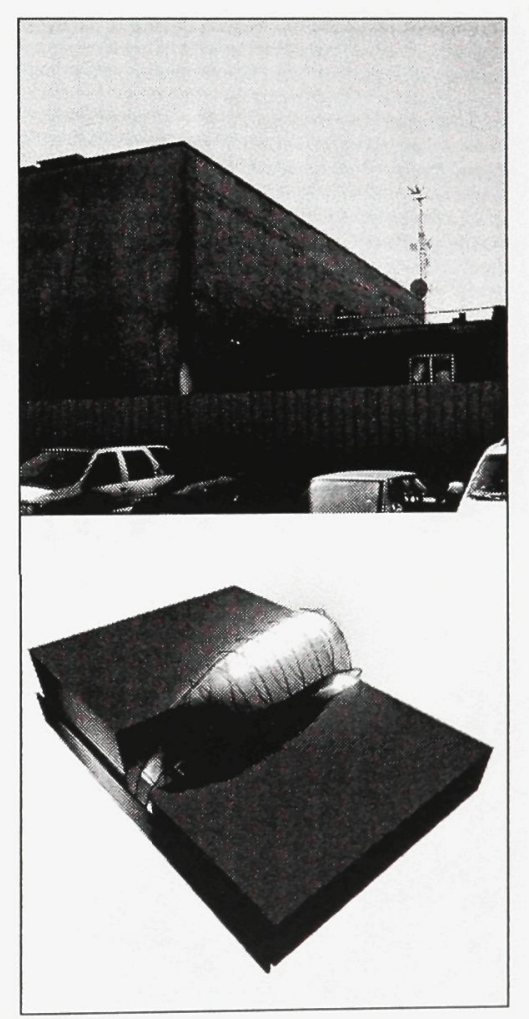

Site 30: Rose's Cafe on

Dalhousie Street

Site Photos and Digital Models (Objective View) - Sites 25 to 30 


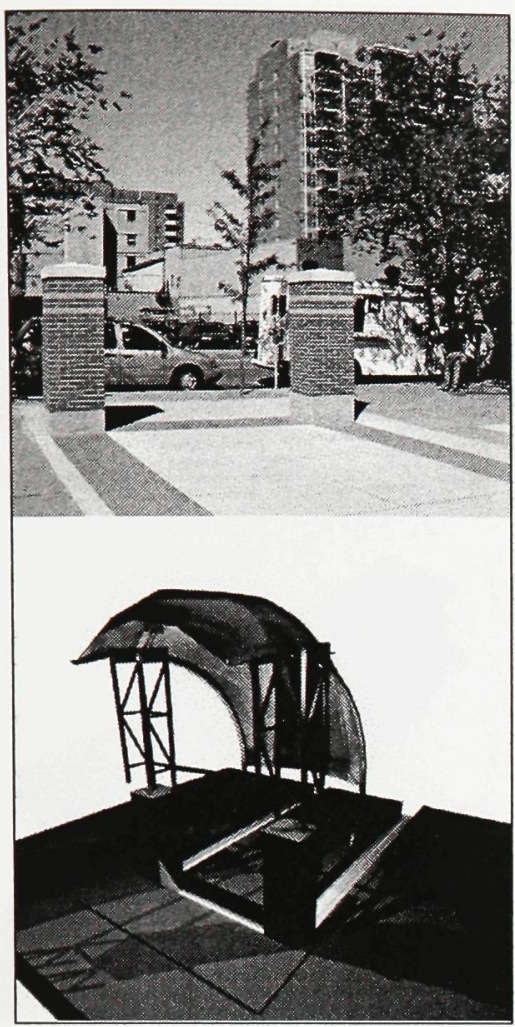

Site 31: Chip Stand on George Street
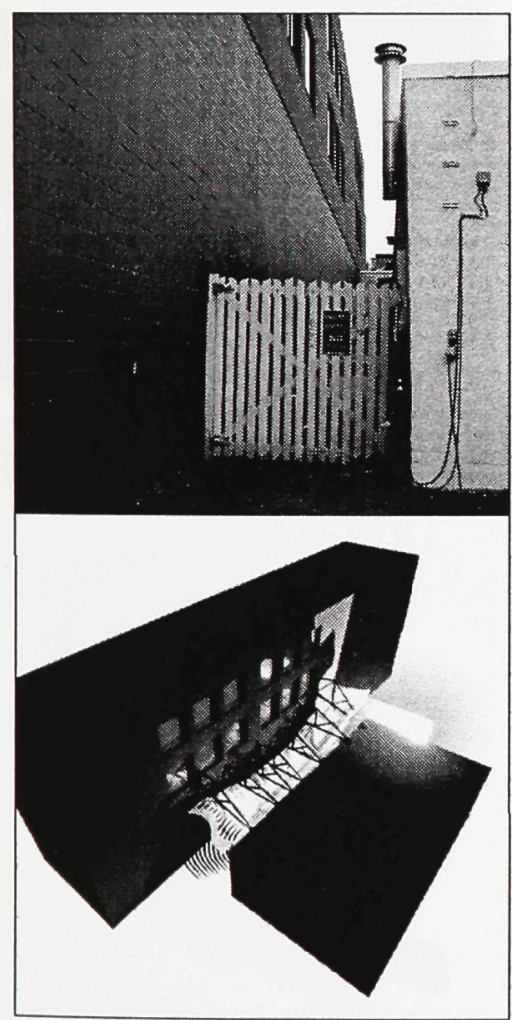

Site 34: Alleyway Beside Florist on Murray Street
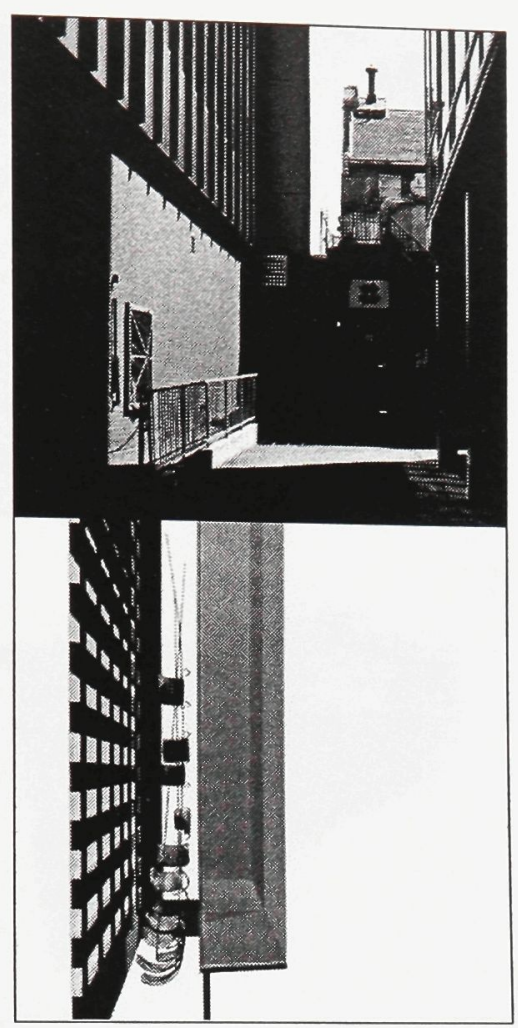

Site 32: Alleyway off George Street
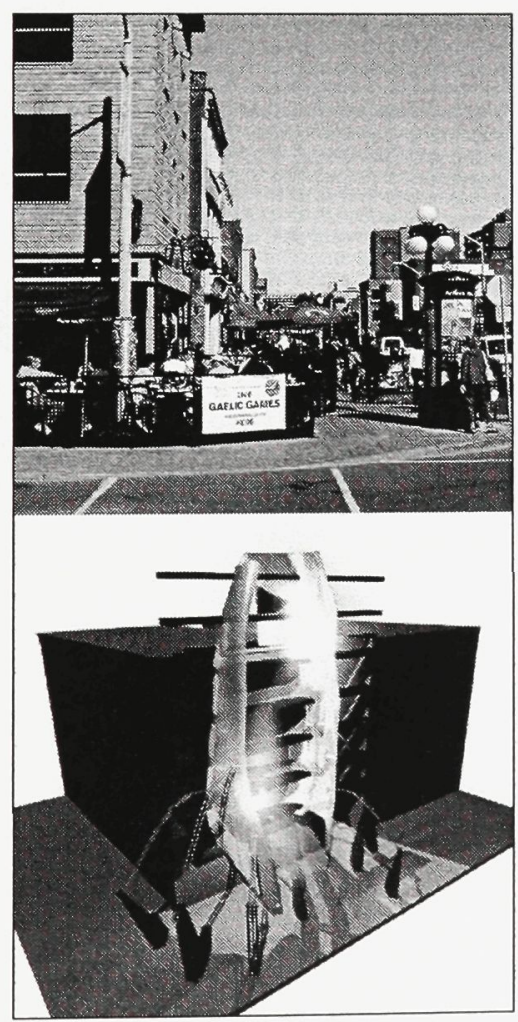

Site 35: The Heart \& Crown Pub Patio on Clarence Street
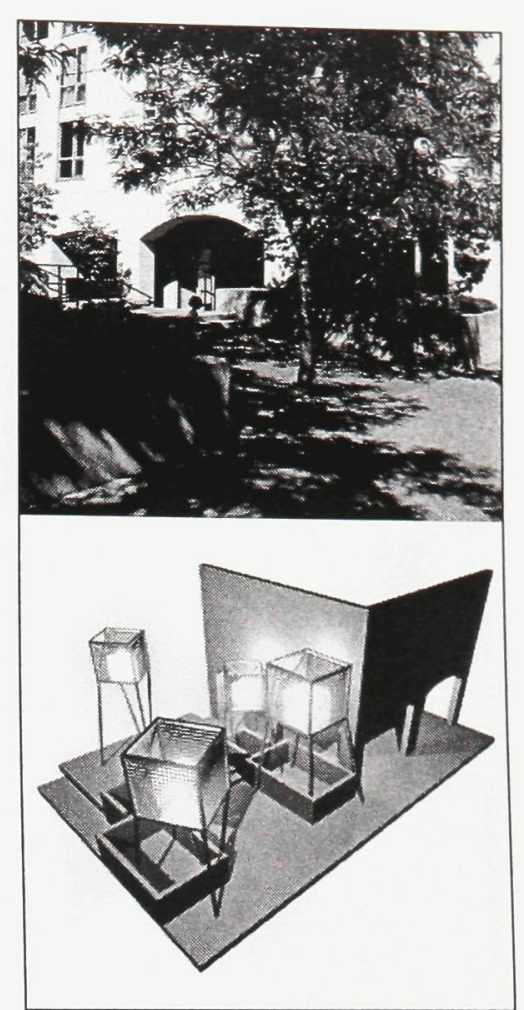

Site 33: Beaux Arts Court
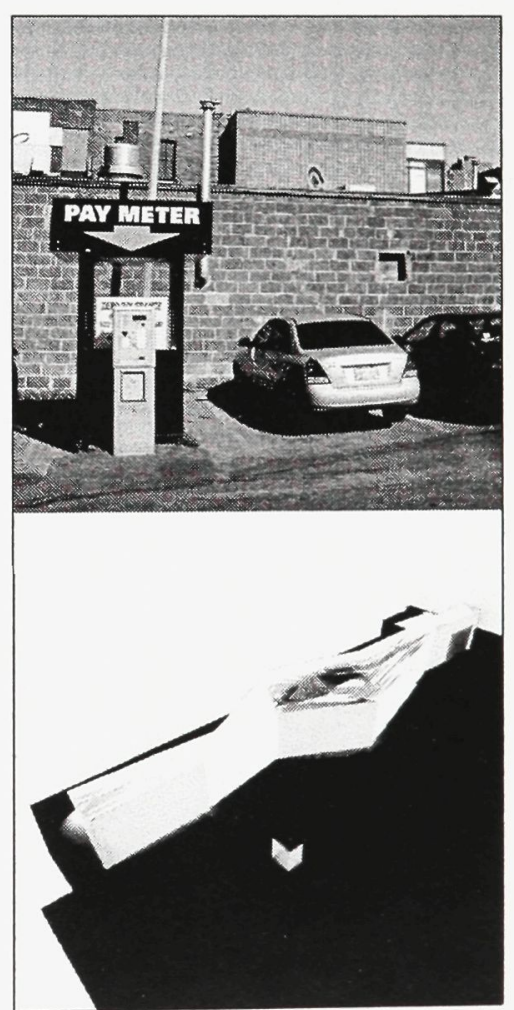

Site 36: Parking Lot on Clarence Street

Site Photos and Digital Models (Objective View) - Sites 31 to 36 


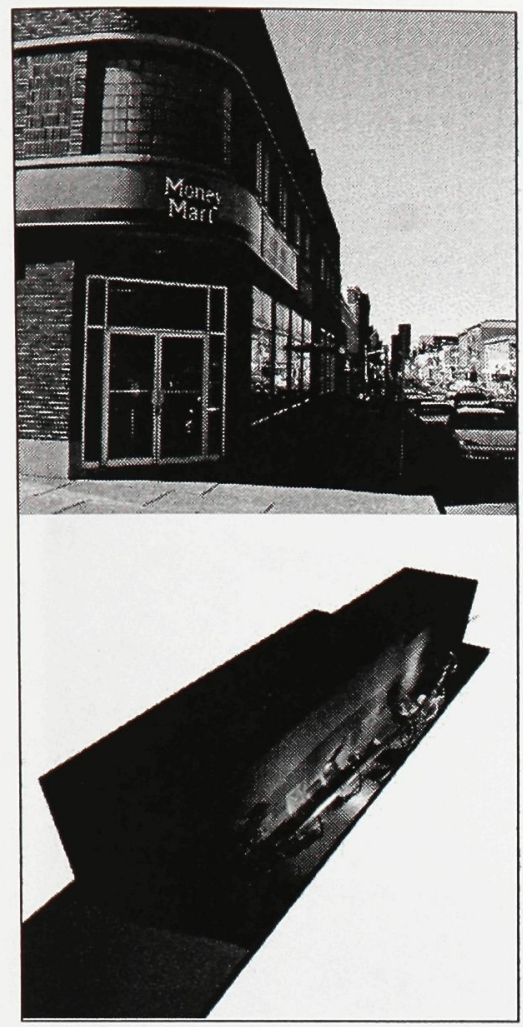

Site 37: Dalhousie at York Street
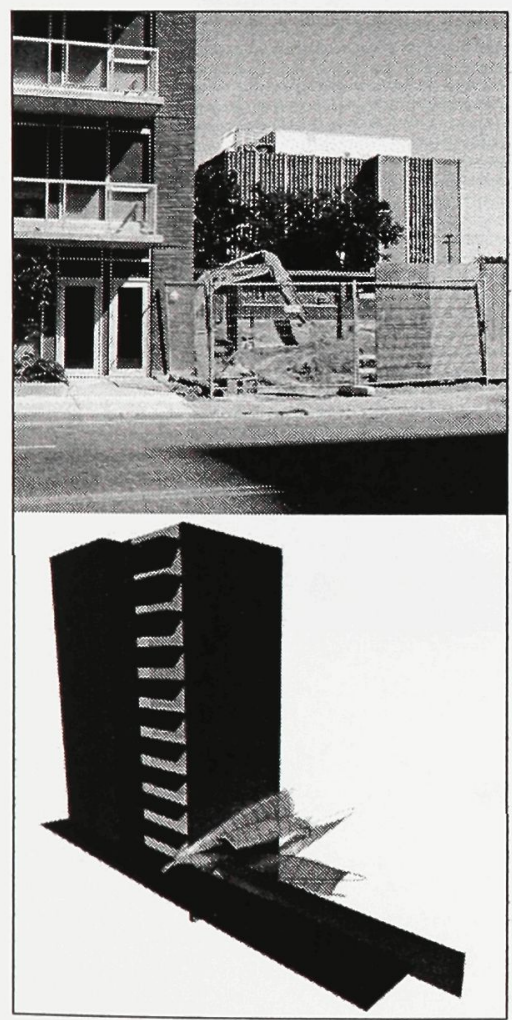

Site 40: Construction Site Along Cumberland Street

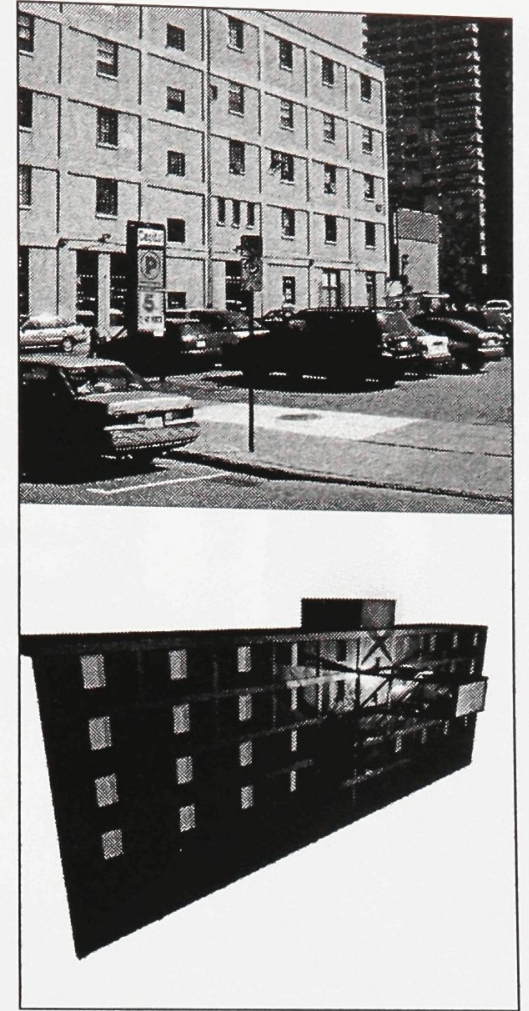

Site 38: Parking Lot along York Street

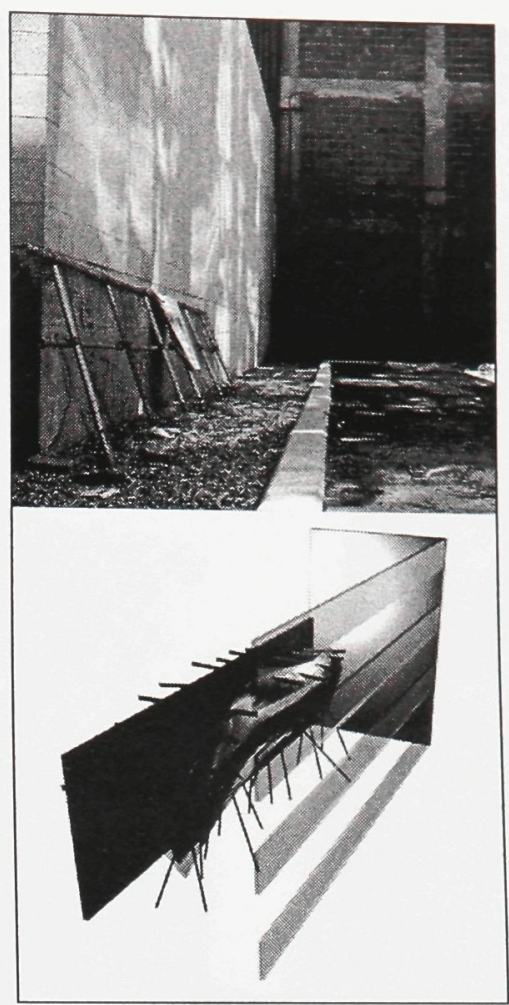

Site 39: Alley off Cumberland Street

Site Photos and Digital Models (Objective View) - Sites 37 to 40 

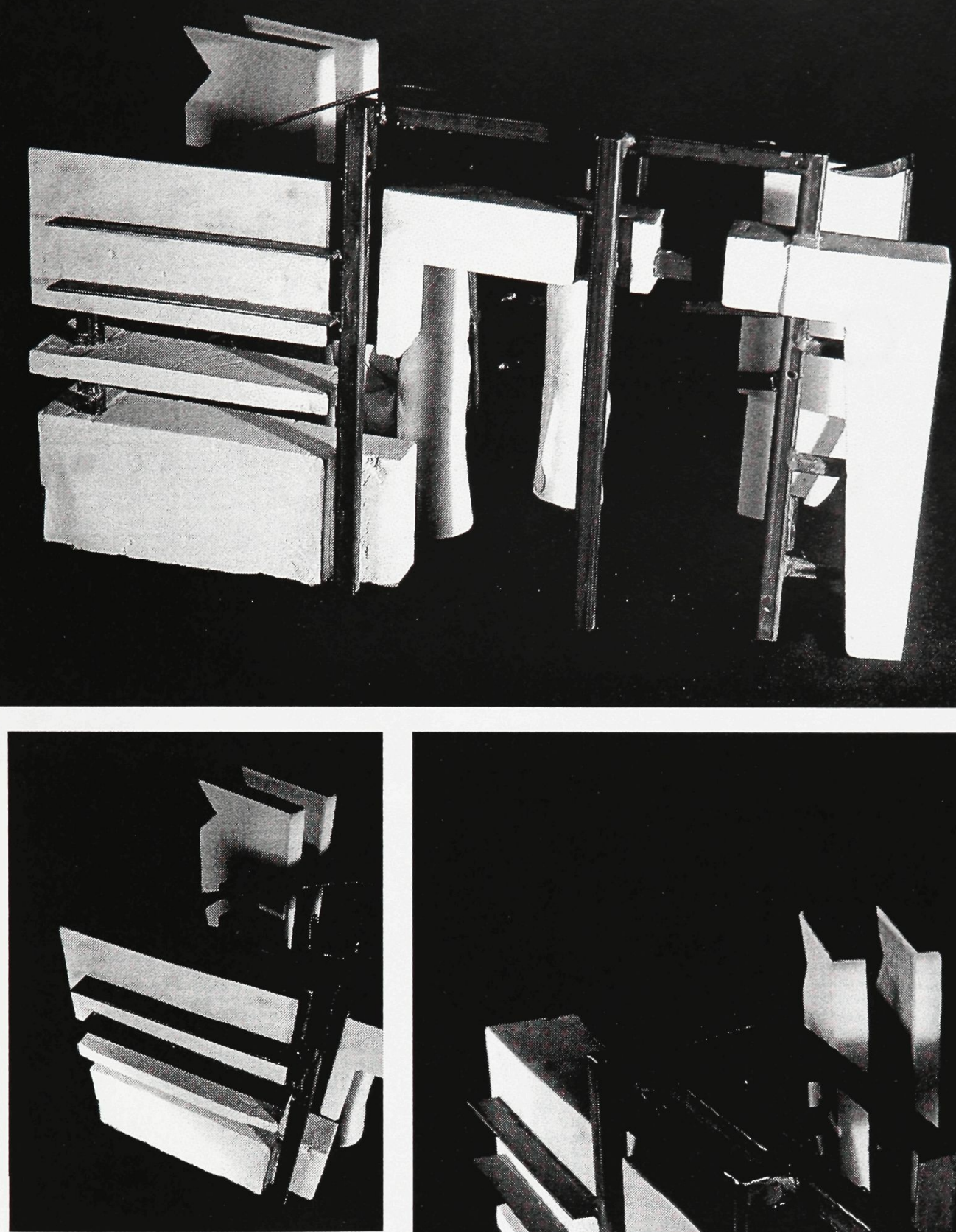

Impresario Model. Plaster, steel, and plastic.

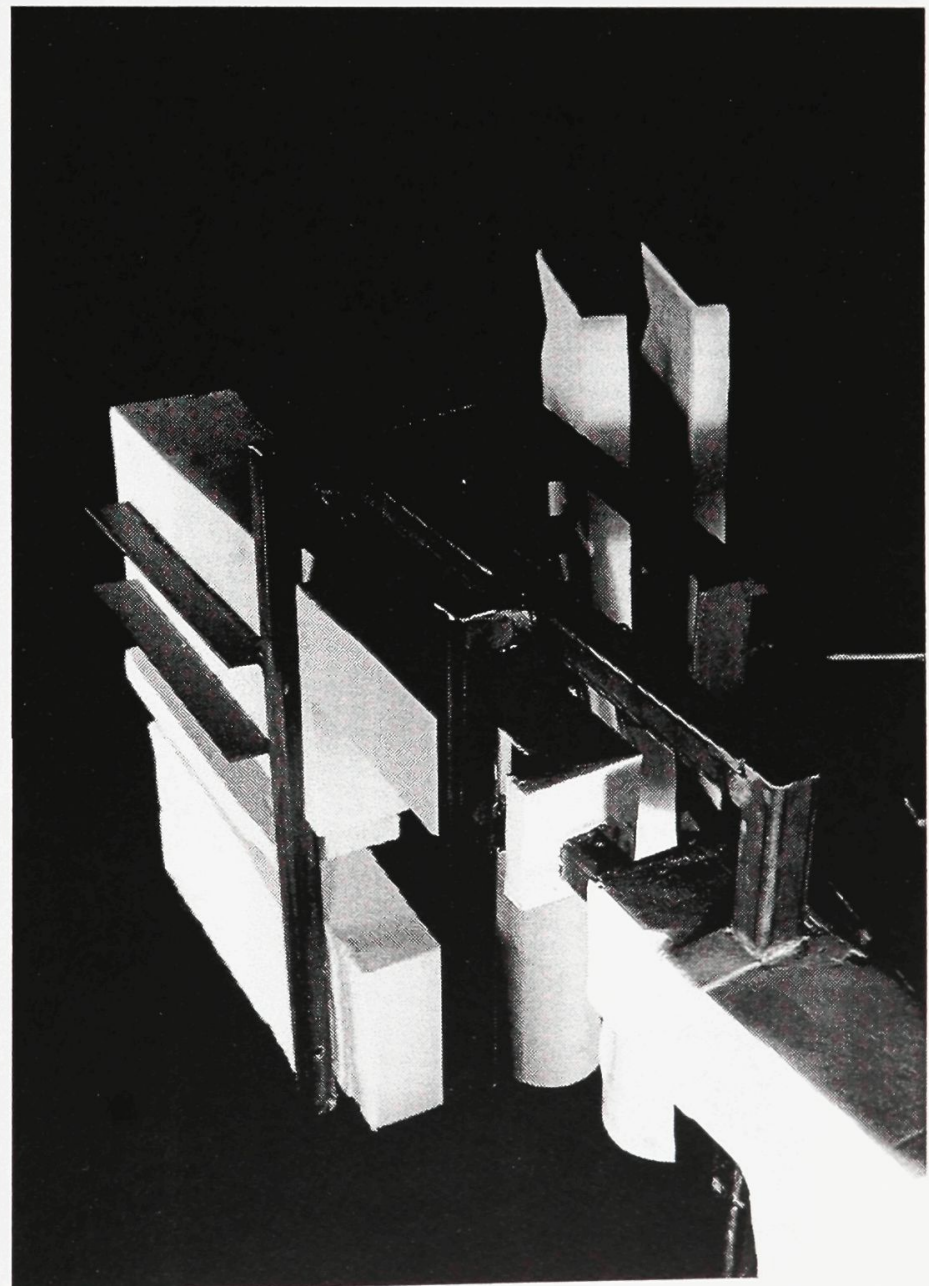



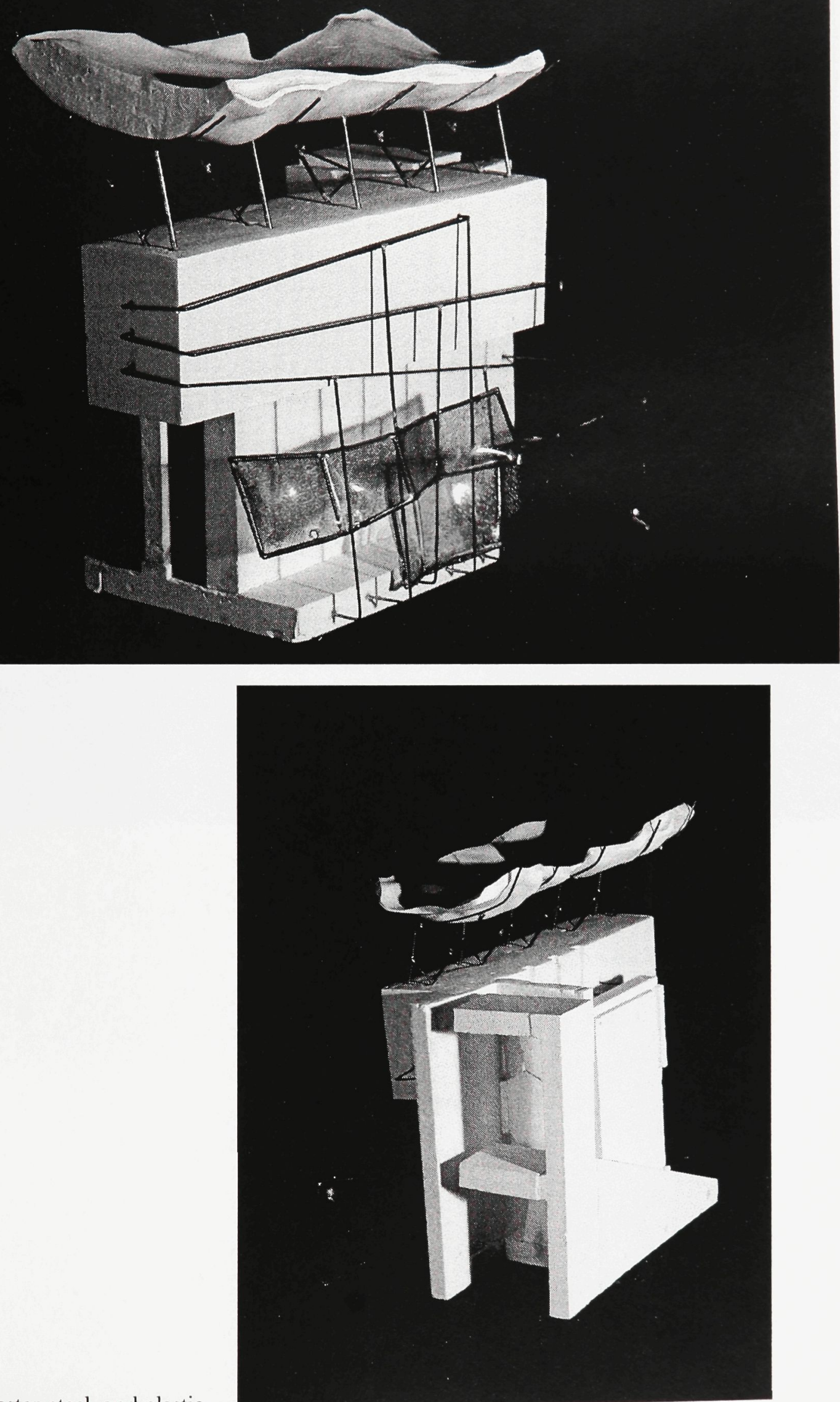

Frame Model. Plaster, steel, and plastic. 

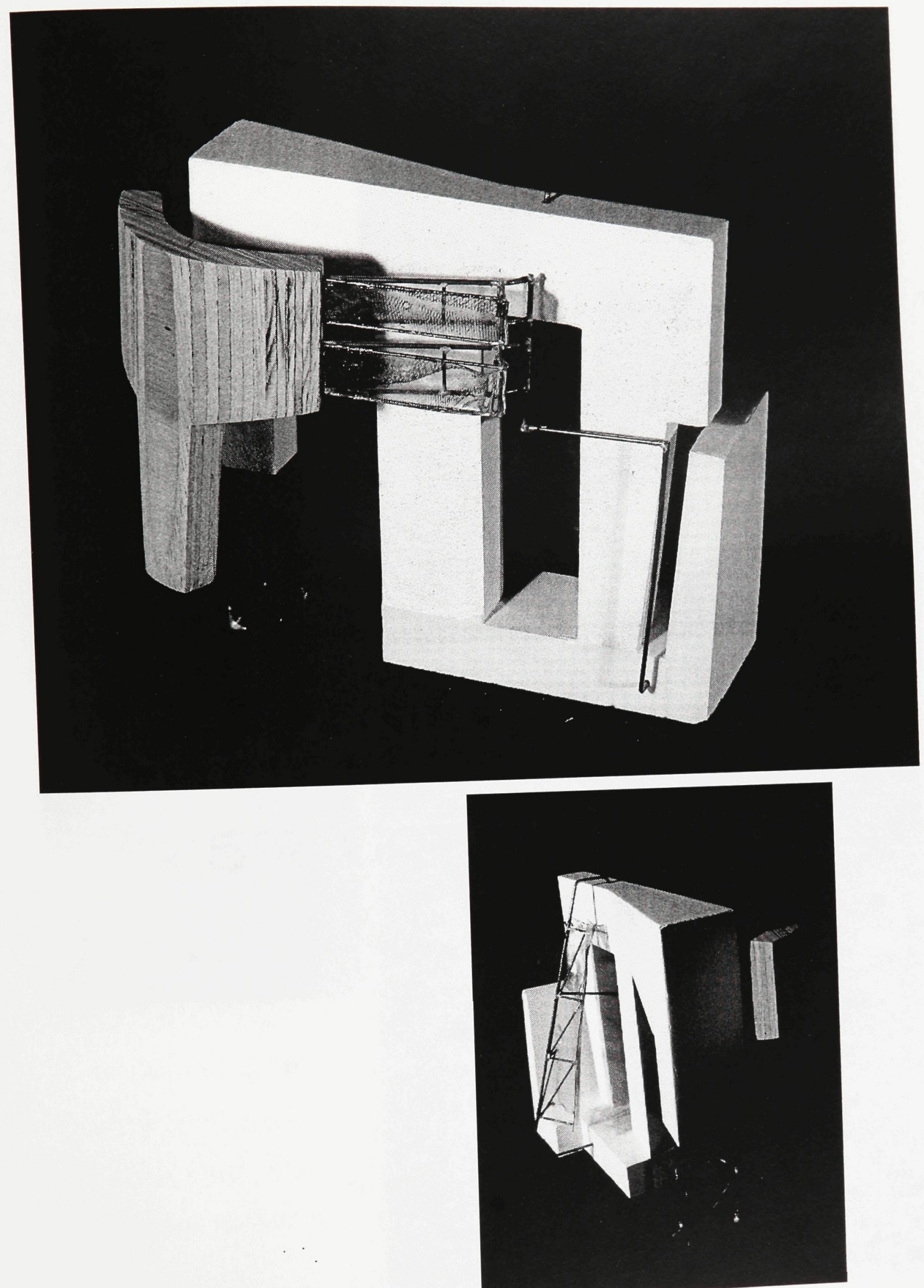

Discourse Model. Plaster, wood, steel, and plastic. 

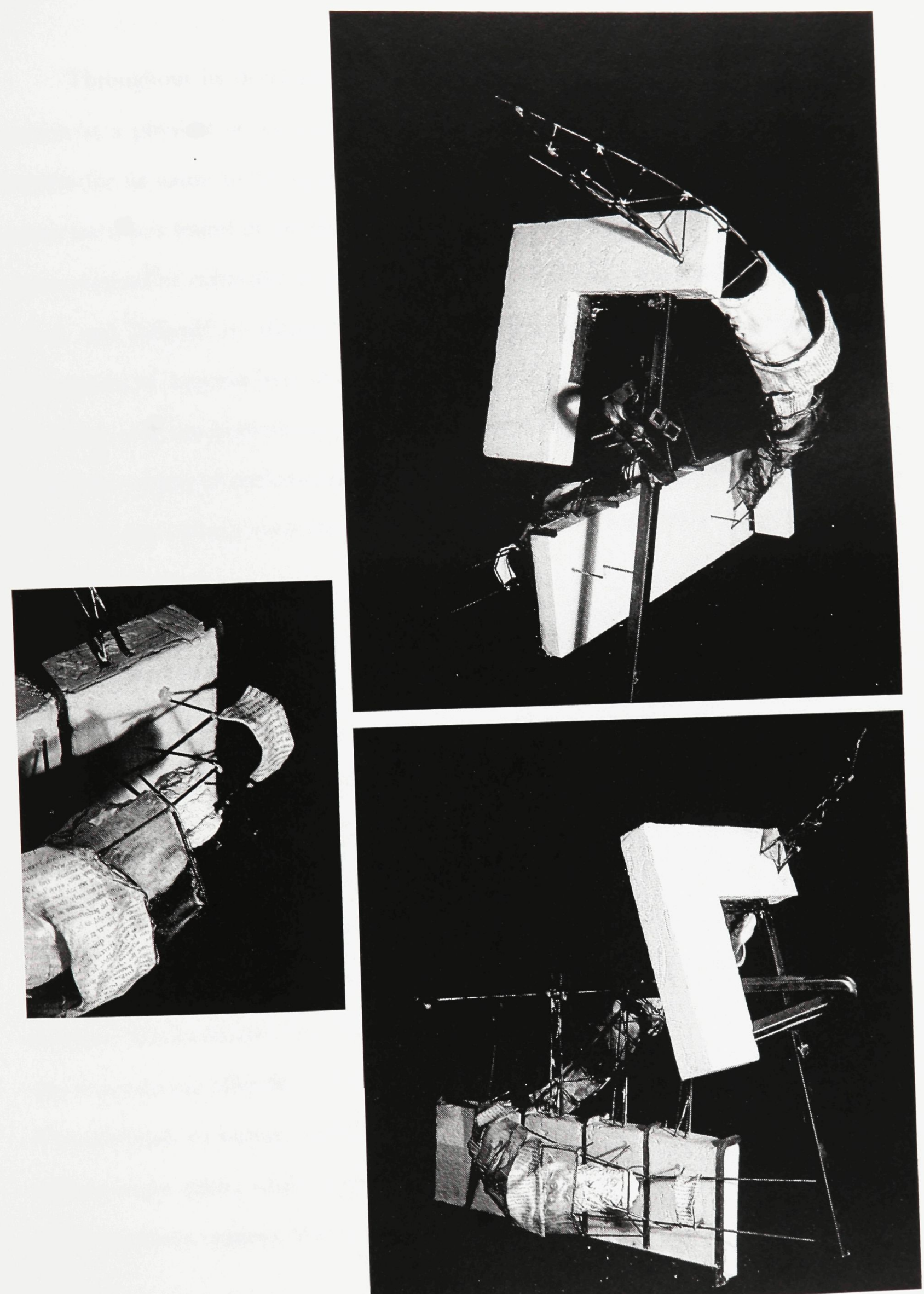

Flesh Model. Plaster, steel, and plastic. 


\section{Appendix B: A Brief History (on the Understandings) of Hysteria}

Throughout its development over two millennia, the figure of the hysteric and hysteria as a physical or mental affliction has remained a cultural anomaly, due to the inability for its cause to be successfully explained within scientific reasoning. The main reason for this is found in the deceifful nature of its mimetic symptoms, in that they are representations of culturally accepted forms of physical illness, thus making its afflictions varied and difficult to diagnose, having no apparent organic cause. Although the explanations of hysteria have changed throughout history, it has maintained its negative association with the irrationality and excessiveness of the female in society. This appendix outlines the variety of understandings through which hysteria has been viewed within both the clinical and cultural contexts in order to give the reader a general understanding of its place within culture.

\section{'The Female Malady'}

The term hysteria, which has come to be defined both as a form of psychoneurosis as well as the display of overwhelming or excessive behaviour, is derived from the Greek word for womb, hystera. Its association to the womb is based upon the ancient Egyptians understanding that the movement of the womb upwards from its normal position in the pelvis caused the irrational and excessive abnormalities that were typical in the hysterical female. This belief was rooted in an idea of the uterus as an independent organism within the body. ${ }^{1}$ Plato extended this perception by viewing the womb as an animal with the sole aim of producing offspring. If left barren for too great a period of time following puberty it would begin to wander throughout the body, impeding respiration and bringing the sufferer severe agony, while provoking the exhibited forms of disease including dizziness, motor paralyses, sensory losses, respiratory distress and excessive emotional behaviour. ${ }^{2}$ 
The movement associated with the animalistic nature of the womb gave the 'disease' a spatialized ordering in that its movement within the body, and specifically towards the head as the location of the logical mind, gave rise to a certainty in hysteria's subversive nature towards the body itself, overcoming the body's natural hierarchy. The ancient cures associated with this belief, attempted either to lure the womb back into place through the use of aromatic or vile substances, or by fastening it in place through the use of bandages.

With the arrival of Christian thought, hysteria would begin to take on different meanings due to new religious associations with what was considered to be evil. Mark S. Micale notes in Approaching Hysteria that, "in the writings of St. Augustine, all human suffering, including organic and mental illnesses, [were] perceived as a manifestation of innate evil, consequent upon original sin."3 Hysteria, with its excessive and violently represented symptoms, was believed to be caused by possession of the devil, or that its convulsive symptoms were marks of the devil, stigmata diaboli. Later in the Middle Ages these supernatural understandings of the 'disease' were transformed into epidemics of 'psychical contagion', and became the root of demonic possession and witchcraft. ${ }^{4}$ Although the religious understandings of the 'disease' displaced the previous physical causes of hysteria into supernatural ones, the connection of the uterus in medical knowledge lingered in common practice until the end of the eighteenth century. It would remain the means upon which theorists would define their thoughts until the twentieth century. ${ }^{5}$

\section{Hysteria as Madness}

The animalistic characteristics of the womb as the cause of the irrationality of the female hysteric would be transformed during the enlightenment from a disease of the body to a disease of the nerves and to the mind. ${ }^{6}$ During this period of time, where rationality took utmost precedence, anything corresponding to the animal nature, or low form of the human mind would become associated with madness. It was in this sensibility, with 
the goal of understanding, that the previous beliefs would be viewed as inaccurate. With the change from a physical cause to a mental one, the hysteric was no longer viewed to be worthy of clinical observation, but rather of ridicule, as the symptoms were understood as mental simulations and exaggerations. ${ }^{7}$ Once based upon 'natural' causes these symptoms would now move beyond possession to madness through deception and mimesis.

The previous symbolism and spiritual meanings that had existed in the Middle Ages came undone with the advent of rational thought, and thus the symbolic nature that had played a great part in the understanding of madness as a disease would no longer exist, but would become madness as unreason. Even still, opposing views on madness existed in such philosophers as Hegel, who saw insanity as one of the three stages through which the soul passed in search of the consciousness of self. His belief was that madness was greater knowledge pointing to the absurdity (or abstract nature) of knowledge itself. ${ }^{8}$ Its symbolism, which still existed in the early Renaissance as the ship of fools, a symbolic cargo of madmen searching for reason, would vanish when irrationality was given an almost criminal nature.

Though hysteria was not categorized as a form of madness, but rather a "spasmodic affection of the natural functions," 9 a form of convulsion, its qualities of bodily sensation were distinguished from logic. This caused its passionate forms of display to be viewed within the domain of unreason, and thereby directly associated to the female. Unreason in this way is categorized by error and dream; a blindness to reason caused by the very excess of sensibility, or that which provides sensibility to ones self.

With the negative view of unreason came the confinement of the madmen as a means of protecting the men of reason from those without. The asylum, which would replace the confinement of madmen with criminals, was intended to provide the essential functions of a hospital, while containing the 'evil' that had a potential to spread. In this 
ideal form, the asylum would provide a place "where unreason would be entirely contained and offered as spectacle" ${ }^{10}$ to visitors while being restored to its truest form as a cage. The association with unreason that the asylum maintained would cause its place to be one that would incite disgust, horror, disdain, and suffering, as it was viewed to contain "the most monstrous and vile things to be found in society." 11 Such places as the historic Salpêtrière in Paris created in the rational man an extreme sense of fear, both because of what was contained as well as the possibility that they too would be enclosed within its walls. Thus the asylum acted as an instrument of moral and religious segregation with the goal of reducing differences as a means to denounce that which was not believed to be 'essential virtues' in society. ${ }^{12}$

\section{Charcot: The Paternal Figure of Hysteria}

With the creation of the asylum came the placement of the physician as an authority figure, or paternal figure in his relationship to the hysteric or madman. From 1878 to 1893, the French clinical neurologist Jean-Martin Charcot's research on the hysterics of the Salpêtrière made him the most significant medical figure in the nineteenthcentury history of hysteria. His strong belief that the symptoms of hysteria were caused by an inherited disease of the central nervous system triggered by trauma, similar to that of epilepsy and other neurological diseases, would cause him to attempt to refute its religious interpretations of diabolical possession or saintly ecstasy. ${ }^{13}$

His greatest contribution to the study of the 'disease' was in his observations of hysterical attacks. By using hypnosis and other techniques including compression of 'hysterogenic zones,' as a means of triggering the attacks, he was able to categorize the generalized hysterical convulsions of the 'grande hystérie' into four stages: "a period of epileptiform agitation, a period of grands mouvements (including the famous arched back position), a period of 'passional attitudes,' and a period of delirious withdrawal"14. 
Although Charcot provided a great deal of documentation of the hysteric's exhibited symptoms, which still influence how we perceive the image of the hysterical body, he did not attempt to cure the symptoms. Rather he focused upon achieving an understanding of the disease through its observation.

The photographs of the hysterics that grace the pages of his Iconographie Photographique de la Salpêtrière (1875-80), and especially those of his greatest star, Augustine, give evidence to his belief that hysteria was implicit in the female personality in that they are "preoccupied with their appearance, deceitful and self-dramatising." 15 But in the case of Charcot, this deceit goes both ways, as the poses that he presents in the Iconographie had an exposure time of up to twenty minutes. ${ }^{16}$ In these photographs, the presentation of Augustine's symptoms appear to us as acts in that they occur in a temporal progression, bringing a theatrical nature to the whole spectacle.

The re-presentation of the hysterical symptoms took on more of a theatrical nature in that Charcot would direct the hysterics through 'suggestion' to exhibit their symptoms either in front of the camera or in front of an audience in his medical theatre almost like a puppet-master or director. The documentation that Charcot provided allowed for the movements and fits of the hysteric to influence both theatre and dance, which is in part due to the method in which Charcot used the spectacular nature of the symptoms to enchant the audience through visual and aural imitations, thus turning the hospital into an "environment for the manufacture and marketing of hysterics"

\section{Freud: Repressed Sexual Trauma}

Charcot's observations of the hysterical body and his belief that its cause was traumatic in nature would stimulate his student Sigmund Freud's views upon hysteria, which would later be described as the birth of psychoanalysis. Working with the minor form of hysteria, la 'petite-hystérie', whose symptoms included coughs, limps, headaches 
and the loss of voice, Freud would focus his studies upon the psychological formation of hysterical symptoms. Beginning from Charcot's formulations, Freud would invert the belief that trauma caused the onset of a hereditary neurological disease into a belief that as a neurosis it was caused by the repression of a traumatic event. This usually included conflicted sexuality and fantasy (especially the 'Oedipal fantasy' ${ }^{18}$ that was so overpowering that it was not possible to be integrated into the patient's mental framework. ${ }^{19}$

The varied symptoms that the hysterics suffer from are then reminiscences of the traumatic event brought into view through the conversion of the unconscious into physical symptoms, mimicking culturally accepted forms of disease. They are therefore complex symbolizations of the repressed experience, and "mark the agonizing real of a hysterical attack." ${ }^{20}$ As Freud notes in a paper entitled Hysteria, "hysterical manifestations have, by preference, the characteristic of being excessive: a hysterical pain is described by patients as extremely painful, an anaesthesia and a paralysis may easily become absolute, a hysterical contracture brings about the greatest retraction of a muscle of which it is capable." ${ }^{21}$ Thus for Freud, the cure would be in identifying what these excessive symptoms symbolized and through the analytic process these traumatic memories would "need to be integrated into existing mental schemes, and be transformed into narrative language,"22 in order for them to be relived and relieved. As opposed to a mere observation of hysteria, Freud restored the dialogue with unreason in order to provoke or construct a consistent and coherent narrative of the trauma that was the cause of the exhibited symptoms and the fragmentary and discontinuous nature of the hysteric's speech. Freud understood that the symptoms of the hysteric used the representation of images and attitudes because hysteria behaves like an image, an image of memory. ${ }^{23}$

\section{The Male Hysteric: Hypochondria and Shellshock}

Although the female hysteric has been the focus of our discussion on the history of 
hysteria thus far, it does not mean that there were not male hysterics, as there are records that both Freud and Charcot treated or studied them. The absence of the male figure in the history of hysteria is certainly not inadvertent, but is rather a result of its evasion, repression, and disguise. ${ }^{24}$ What has stigmatized the male hysteric is the fact that 'real' men were believed to be rational beings, immune to the effects of emotion. By labelling a male patient a hysteric, one was effectively labelling them unmanly, effeminate, or homosexual. This caused it to be very difficult for medicine to diagnose, and even more impossible for the male patients to accept hysteria as a correct diagnosis. As Foucault notes in Madness and Civilization, hypochondria, which is defined as extreme depression centred on imaginary physical symptoms, was another form of the symptoms associated with hysteria, and it was therefore able to be associated with men.

In the male form of hysteria, we find that it has been caused by excess, rather than a lack. When the 'disease' occurred in male physicians, blame would be placed upon their higher education and professional ambition. This excessive cause was also extended to include fear, shock, and terror, explaining why "those who succumbed to shellshock" during the First World War, "exhibited many of the strange mental and physical symptoms previously seen almost exclusively in female hysteria" ${ }^{25}$ Although the cause may not be consistent with that of the female hysteric, what is common between them is how the male hysteric has been viewed as 'other' within society as well as being just as 'other' from the self as the female hysteric.

\section{The Appropriation of Hysteria}

The varied and fascinating history of hysteria, as well as its nature as an image of disease allowed for its appropriation as a metaphor or subject of interest within the creative fields of art and writing. During the mid-nineteenth century, writers such as Baudelaire, Flaubert, and Mallarmé used the term as a metaphor for writing, as well as for the asexual 
nature of the process of creativity, which had been seen as a female characteristic due to its act of creation. The mental creations of the hysteric were easily linked to a similar malfunction of the organs of male artistic creativity, and were described by Max Nordau as the central motive in avant-garde $\operatorname{art}^{26}$

During the 1920s, using Freud's ideas on the unconscious in the creation of art, the French Surrealists would appropriate hysteria as a model for their symbolic language of dreams. The groups leaders, Louis Aragon and André Breton world describe hysteria as "the greatest poetic discovery of the nineteenth century," in their 1928 manifesto, entitled 'Le cinquantenaire de l'hysteria." ${ }^{27}$ They believed that there was a subversive potential to hysteria, as it subverts the harmony of a subject within the "moral world under whose authority they believe to be," ${ }^{28}$ but also in the fact that a gap appears in the scene of seduction of the female hysteric, through "the apparent reality of sex and the "staged performance of gendered subjectivity." 29 These views on its subversive nature have been associated to Breton's own wartime experience, where as a medical orderly he would have experienced the mute protest of the shellshock victims against the authority of the military. This subversion was one of a simulation of physical distress. Thus, the hysteric would become a means of expression upon which the surrealists would base their intended goal.

\section{The Discourse of the Hysteric and Feminism}

In the middle of the twentieth-century, another major figure would bring back the playfulness, wildness and ambiguity that had made hysteria such an exciting issue within the field of psychoanalysis and medicine. Jacques Lacan, a French psychoanalyst, approached this condition in a theoretical, rather than clinical manner, which made his seminars extremely popular in many fields outside of psychoanalysis itself. Basing his theoretical premises upon what Freud had conceived earlier in the century, Lacan rewrote the theoretical premises of psychoanalysis. He believed that hysteria was essentially 
symbolic of a woman struggling for her sexual identity in a society based upon patriarchal authority, and thus that hysteria, women, femininity, and gender were bound together. ${ }^{30}$ As one of the four discourses that he identified, the discourse of the hysteric dealt with the dialogue between the analyst and the patient, and attempted to situate the hysterics symptoms within what he referred to as the Symbolic Order, or the law of the father and/ or language in general. By attempting to name the represented symptoms put forth by the hysteric, it was able to be placed within the symbolized, although the hysteric would be inclined to reject this naming, thus maintaining its place outside of the Symbolic. It is this discourse that Lacan believed to be the discourse of women in society, which would also be understood as the genuine subject.

Because of this association with the female in general, feminism, a movement which would occur at approximately the same time as Lacan, would take hold of this view of the hysteric in order to describe it as a "product of nineteenth-century conflicts over sex roles and female sexuality." 31 For the feminists the hysteric became the semiotic language of the female who was powerless against the patriarchal Symbolic Order, and whose symptoms would act as "passive antipatriarchal protests in the symbolically encoded language of the physical symptom." ${ }^{32}$ With the advent of feminism in society, there was a belief that hysteria had no reason to exist, as the repression that had occurred in Victorian society no longer existed.

Since this time hysteria has become to be seen as too broad a 'disease', and is no longer used within the field of neurology, although it remains a term within Freudian and Lacanian based psychoanalysis. As I have shown in my short depiction of the variety of understandings that have occurred throughout its more than two-millennia years of existence, the affliction is not one merely of medical value, but has also achieved a cultural value, whether positive or negative. 


\section{A Brief History of Hysteria Notes:}

${ }^{1}$ Mark S. Micale, Approaching Hysteria: Disease and Its Interprestations (Princeton, New Jersey: Princeton UP, 1994) 19. In this book, Micale provides a more concise and in-depth history of hysteria as both a cultural and medical phenomenon.

${ }^{2}$ Micale, 19. Based upon a quote from Plato in the Timaeus, describing hysteria as a disease.

${ }^{3}$ Micale, 20.

${ }^{4}$ Sigmund Freud, The Standard Edition of the Complete Psychological Works of Sigmund Freud, Vol. 1 (The Hogarth Press and the Institute of Psycho-Analysis, 1966) 41. Although Freud does refer briefly to the historical precedents of views on hysteria, his greatest attention, from which he derived his knowledge of hysteria was from his mentor, Charcot.

${ }^{5}$ Michel Foucault, Madness and Civilization: A History of Insanity in the Age of Reason (New York: Random House, 1965) 144.

${ }^{6}$ Foucault, 139.

${ }^{7}$ Freud, Complete. 41.

${ }^{8}$ David Lomas, The Haunted Self: Surrealism, Psychoanalysis, Subjectivity (New Haven and London: Yale UP, 2000) 58.

${ }^{9}$ Foucault, 136.

${ }^{10}$ Foucault, 207.

${ }^{11}$ Foucault, 203.

${ }^{12}$ Foucault, 258. Michel Foucault recognizes these non-essential virtues to be noncelibacy, debauchery and laziness.

${ }^{13}$ Elaine Showalter, Hystories: Hysterical Epidemics and Modern Culture (New York: Columbia UP, 1997) 32.

${ }^{14}$ Micale, 25.

${ }^{15}$ Showalter, 34. 
${ }^{16}$ Micale, 96.

${ }^{17}$ Showalter, 32.

${ }^{18}$ The Oedipal Fantasy includes the wish to have sexual relations with the mother and commit patricide.

${ }^{19}$ Showalter, 144.

${ }^{20}$ Georges Didi-Huberman, Invention of Hysteria: Charcot and the Photographic Iconography of the Salpêtriere (Cambridge, Massachusetts: MIT P, 2003) 159.

${ }^{21}$ Freud, Complete. 48.

${ }^{22}$ Showalter, 144.

${ }^{23}$ Freud, Studies on Hysteria (New York: Penguin, 1974) 296-98.

${ }^{24}$ Showalter, 64. This book contains an entire chapter discussing the male hysteric, as well as a later chapter that deals with the Gulf War Syndrome.

${ }^{25}$ Lomas, 72.

${ }^{26}$ Showalter, 95.

${ }^{27}$ Showalter, 46.

${ }^{28}$ Lomas, 53.

${ }^{29}$ Lomas, 56.

${ }^{30}$ Showalter, 47.

${ }^{31}$ Showalter, 55.

${ }^{32}$ Micale, 76. 


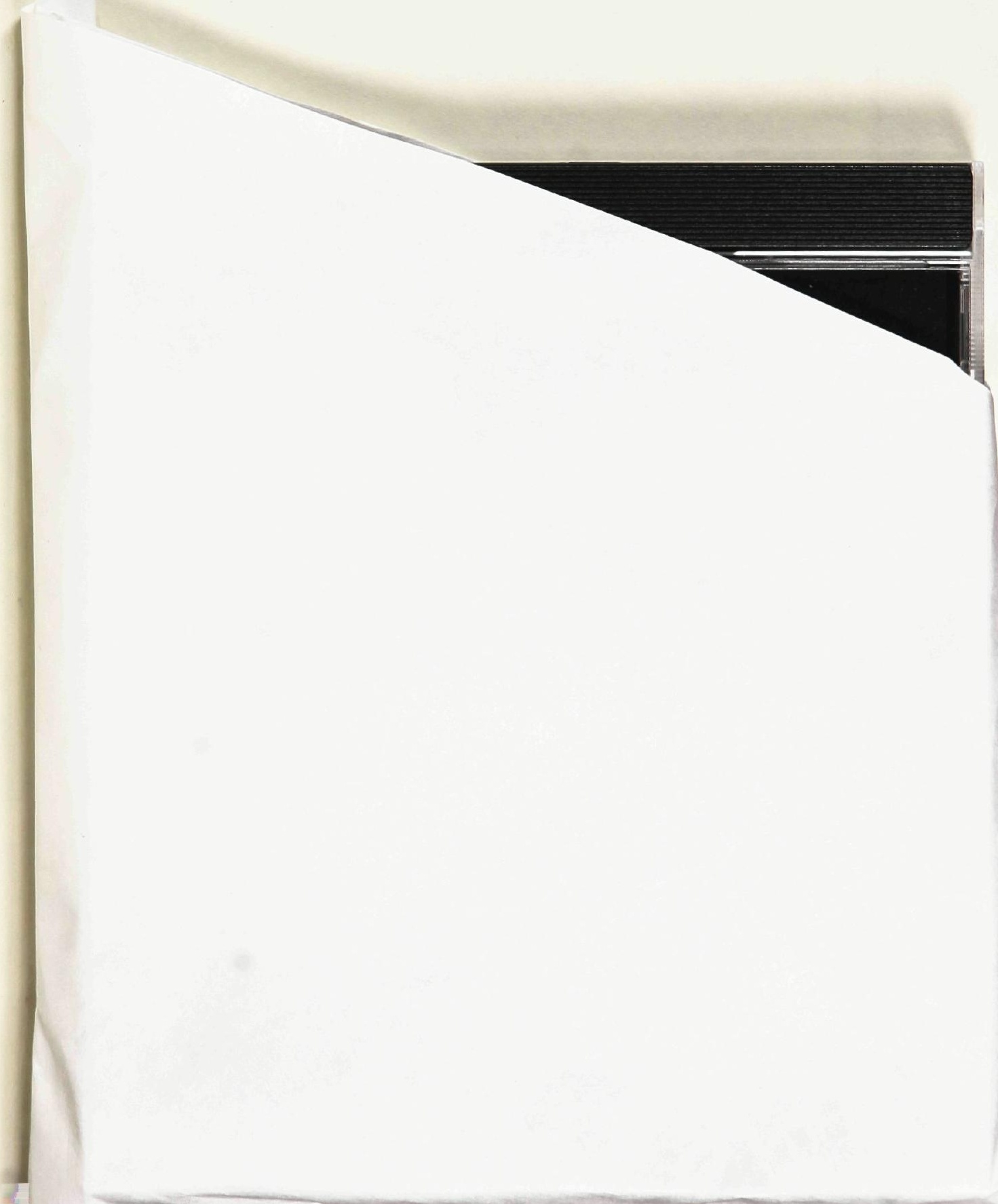

